FACULTAD DE CIENCIAS AGRARIAS Y FORESTALES

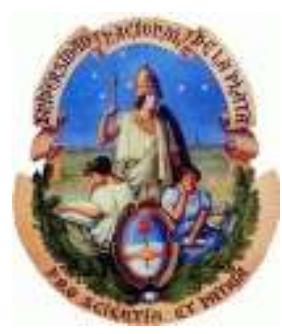

Trabajo de Tesis Doctoral

\title{
FACTORES DE PRE Y POSCOSECHA QUE AFECTAN EL CONTENIDO DE COMPUESTOS ANTIOXIDANTES EN
}

\section{HORTALIZAS}

\author{
Ing. Agr. Magalí Darré
}

Directora: Dra. Analía Concellón

Co-directora: Dra. Ma. Laura Lemoine

Lugar de trabajo:

Centro de Investigación y Desarrollo en Criotecnología de Alimentos (CIDCA). Fac. Cs. Exactas, UNLP. CONICET. CIC. Calle 47 y 116 (CP 1900) La Plata, Buenos Aires, Argentina. 


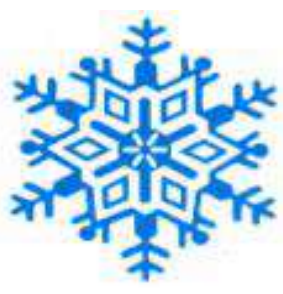

CIDCA

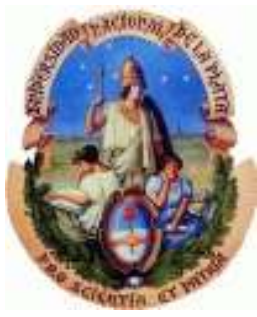

U. N. L. P.

El presente trabajo de Tesis para acceder al título de Doctora de la Facultad de Ciencias Agrarias y Forestales de la Universidad Nacional de La Plata, fue realizado por la Ing. Agr. Magalí Darré en el Centro de Investigación y Desarrollo en Criotecnología de Alimentos (CIDCA-UNLP-CONICET-CICPBA, La Plata, Argentina), bajo la dirección de la Dra. Analía Concellón y co-dirección de la Dra. María Laura Lemoine.

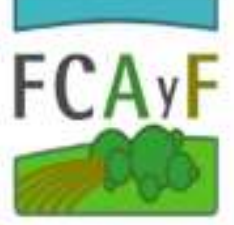




\section{AGRADECIMIENTOS}

Quiero agradecer en primer lugar a mis Directoras, Dra. Analía Concellón y Dra. María Laura Lemoine por su ayuda y compromiso para la realización de este trabajo por haberme compartido todos sus conocimientos y haber transitado este camino conmigo. Al Dr. Ariel Vicente por apoyarme, ayudarme y acompañarme con su inmensa humildad y generosidad todos estos años en mi formación profesional como docente y científica.

A la Facultad de Ciencias Agrarias y Forestales de la Universidad Nacional de La Plata, institución en la que realicé mis estudios de Postgrado.

A los directivos del Centro de Investigación y Desarrollo en Criotecnología de Alimentos (CIDCA) donde desarrollé mi trabajo de tesis y a los compañeros becarios, investigadores, personal de apoyo, secretarias.

Al Consejo Nacional de Investigaciones Científicas y Técnicas (CONICET) y a la Agencia Nacional de Promoción Científica y Tecnológica (ANPCyT), por otorgarme las distintas becas con las cuales puede llevar adelante mi trabajo.

A Elisa Miceli, Jorge Lara, Gabriela Bello, Laura Terminello, Cristian Ortiz y Eduardo Artiñano docentes y compañeros del curso de Agroindustrias por todas sus enseñazas y palabras de aliento durante estos años.

Un agradecimiento especial a los integrantes del grupo "Vegetales": A Carolina Ortiz Lucia Valerga y Majo por ser tan buenas amigas y compañeras, por los momentos compartidos de risas y de llantos y por estar siempre alentándome y colaborando con mi trabajo. A Lucía G F., Natalia Q., Federico P., Joaquín, Facu, Luis por su compañerismo y colaboración en el laboratorio.

A todos los integrantes del CIDCA con quienes compartí lugar de trabajo, charlas de pasillo y especialmente lindos momentos.

Por último agradezco a mis amigos y a mi familia, que me ayudaron apoyaron y alentaron a seguir con mi formación profesional por todo su cariño y por ser incondiconales. Especialmente mis padres, Ethel y Horacio y mi hermano Matías. 


\section{INDICE GENERAL}

1.1. Importancia del consumo de vegetales en la dieta y la salud humana.......................... 22

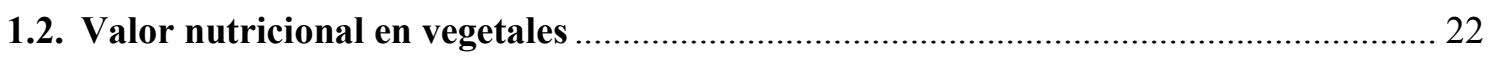

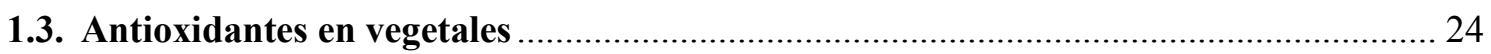

1.3.1. Especies reactivas del oxígeno (EROs) y mecanismo antioxidante.................................... 24

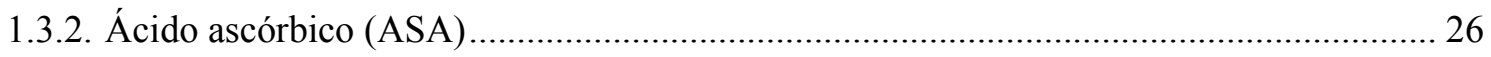

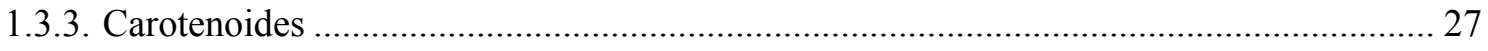

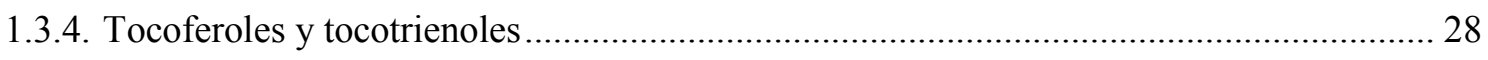

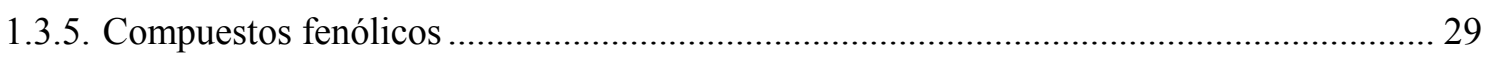

1.4. Factores que afectan la acumulación y estabilidad de antioxidantes en hortalizas..... 33

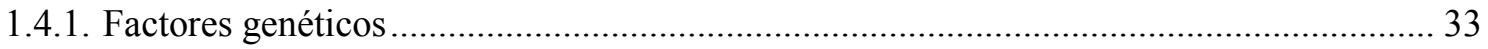

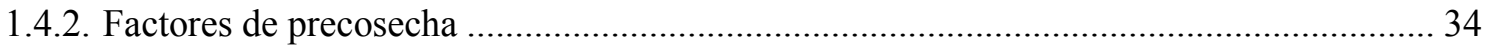

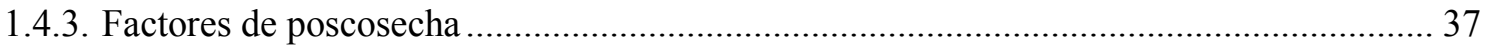

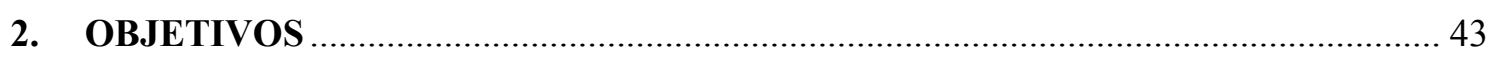

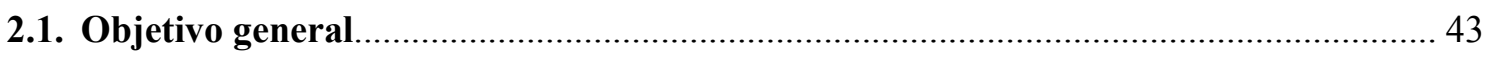

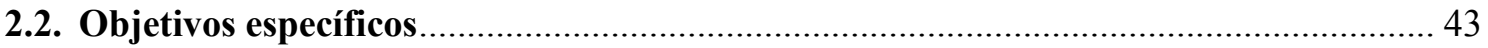

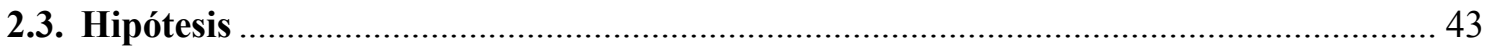

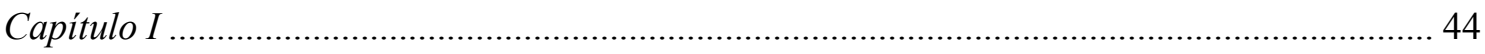

Efecto del empleo de portainjertos sobre el crecimiento, morfología, calidad y contenido de

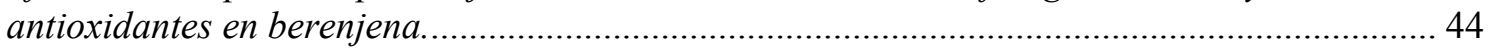

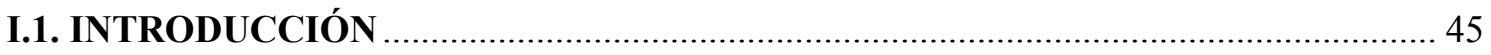

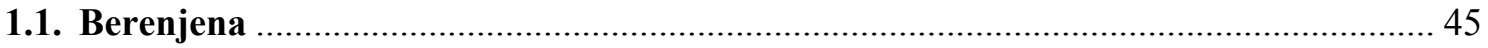

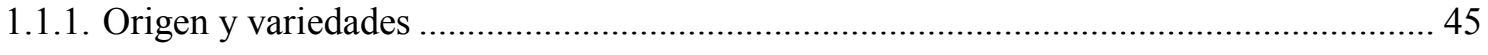

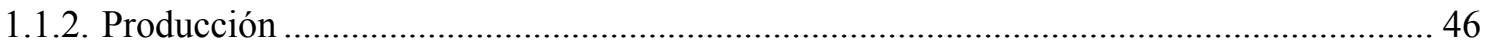

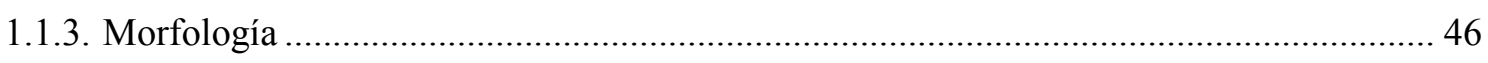

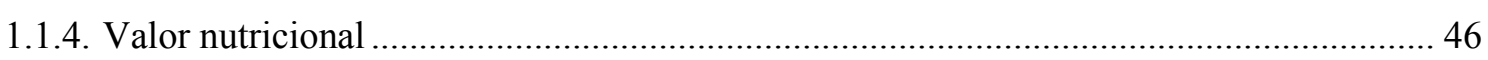

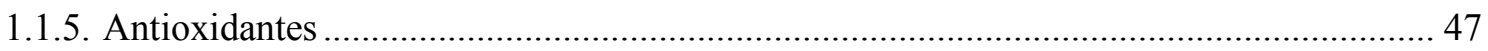

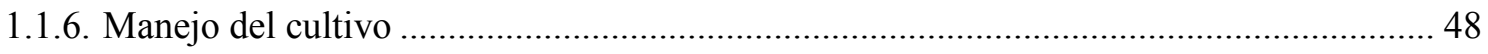

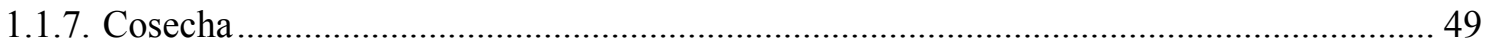

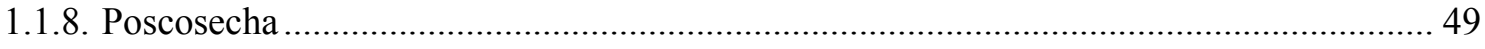

1.2. Empleo de la técnica de injertación en el Cinturón Hortícola de La Plata: Situación

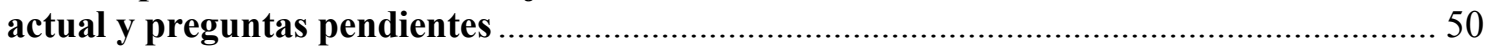

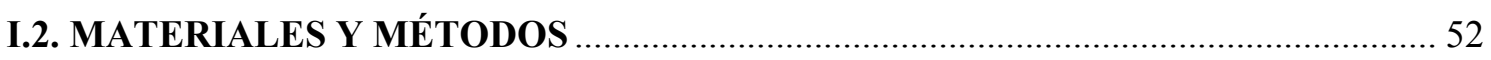

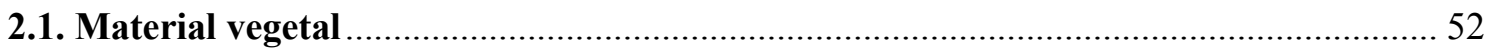

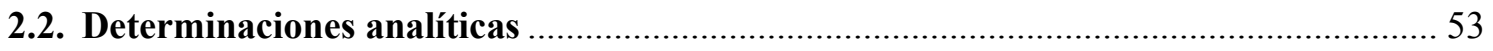

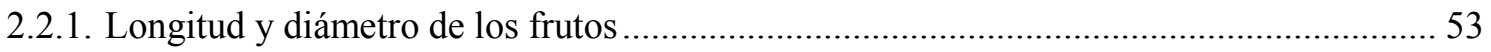




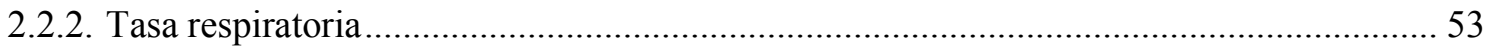

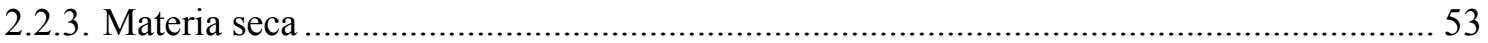

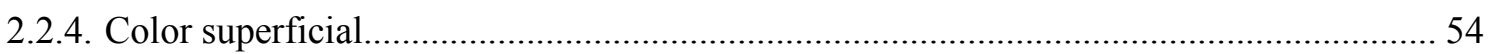

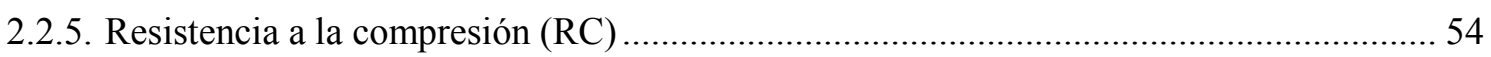

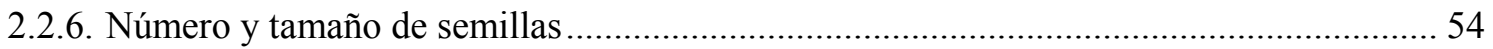

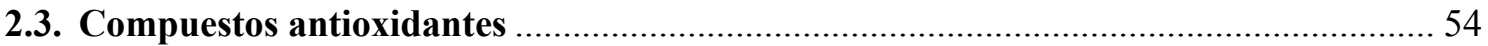

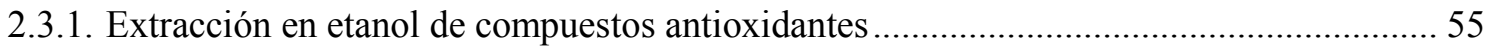

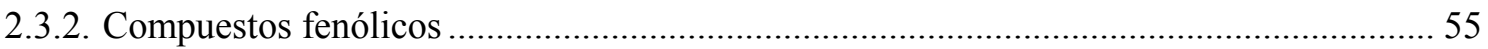

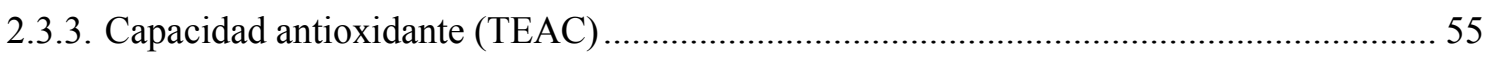

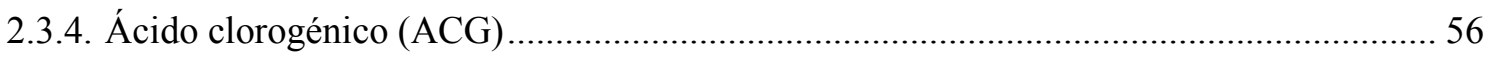

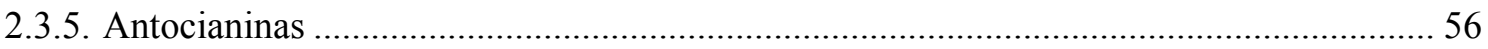

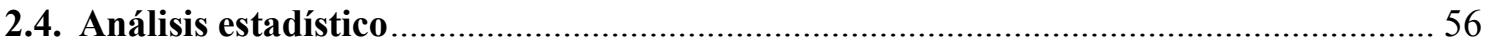

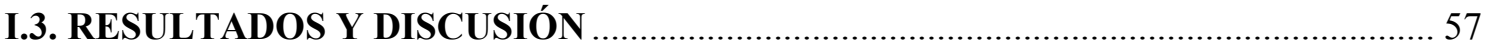

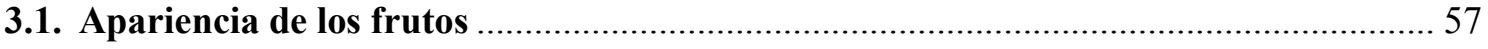

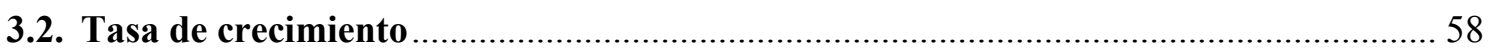

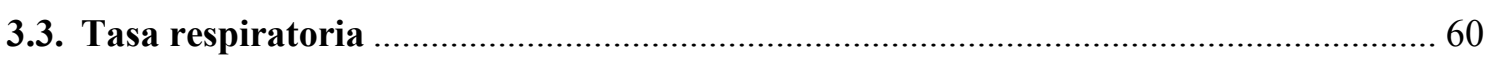

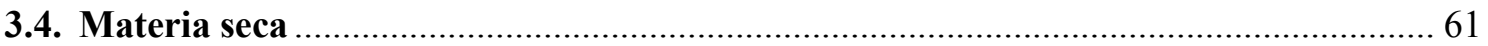

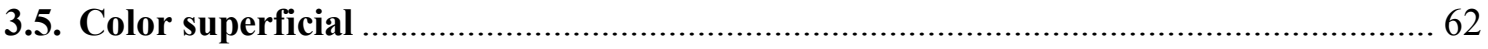

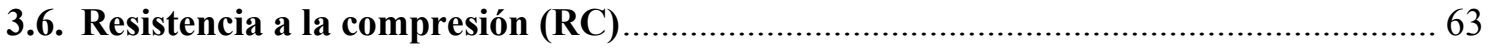

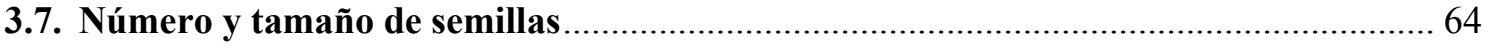

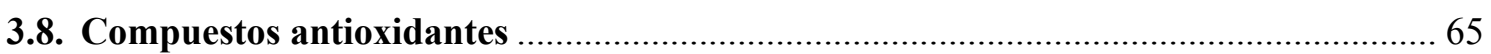

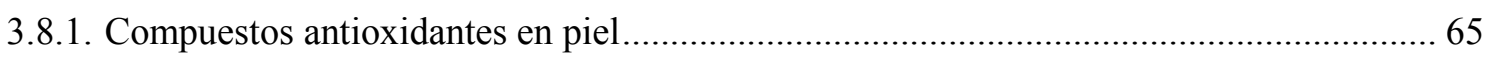

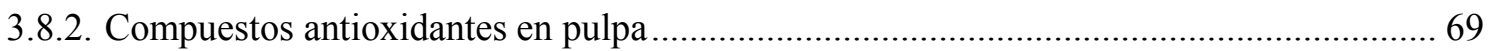

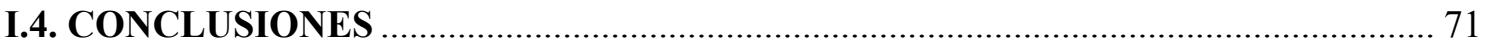

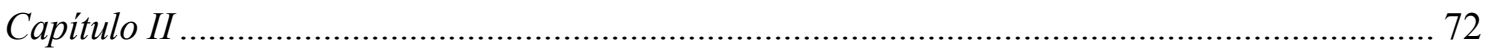

Influencia del empleo de portainjerto sobre la calidad, comportamiento poscosecha y susceptibilidad al daño por frío en frutos de berenjena ........................................................... 72

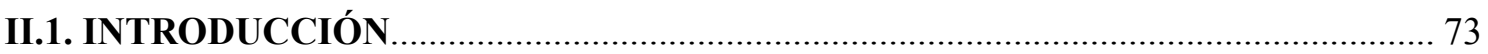

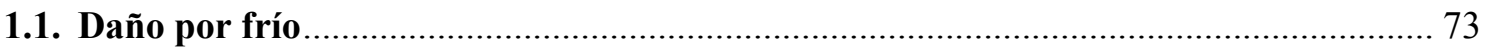

1.2. Uso de portainjertos: Efectos sobre la fisiología de la planta entera, características fenotípicas de la copa y de los productos cosechados ......................................................... 75

1.3. ¿El empleo de portainjertos posee influencia sobre la poscosecha? ............................ 77

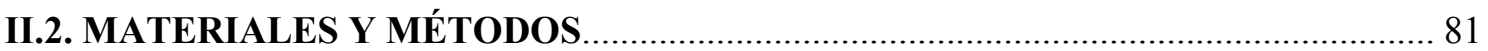

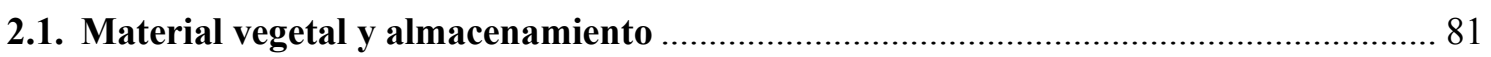

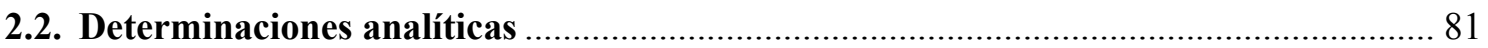

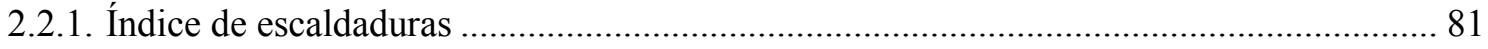

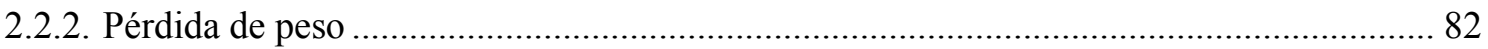




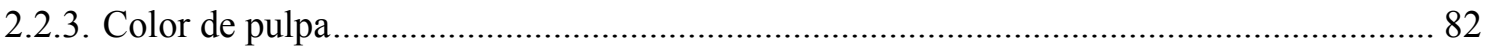

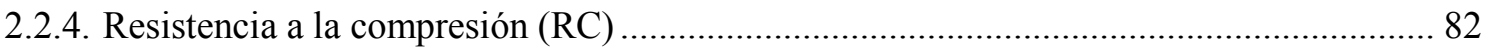

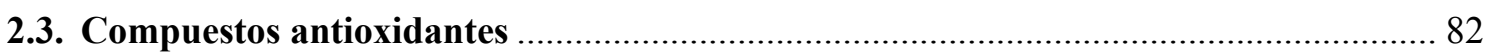

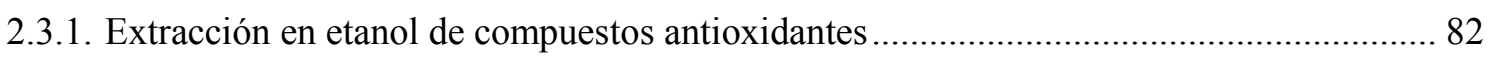

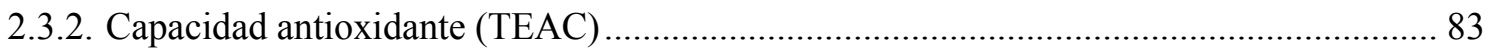

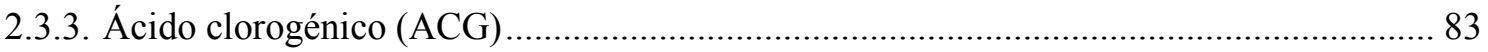

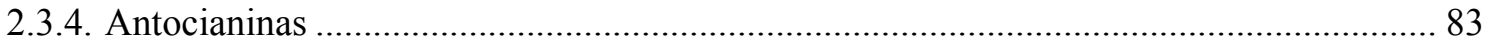

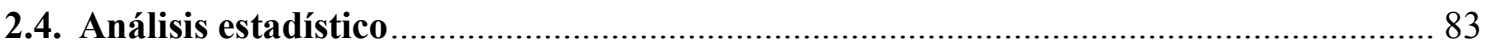

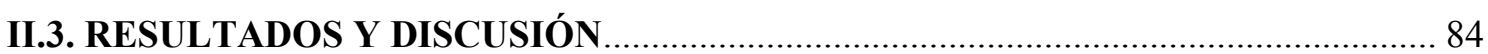

3.1. Efecto del portainjerto sobre el comportamiento poscosecha en almacenamiento a $\mathbf{1 0}$ ${ }^{\circ} \mathrm{C} 84$

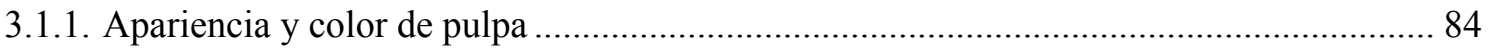

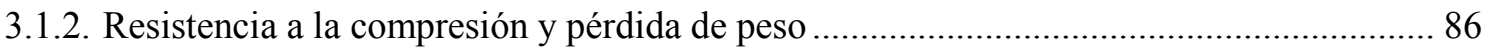

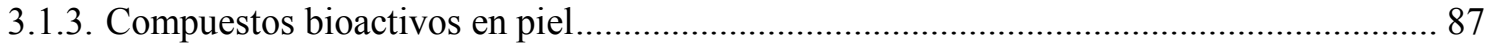

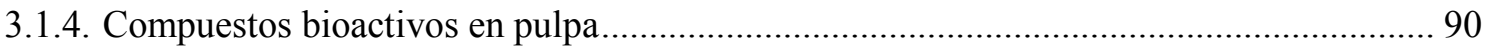

3.2. Efecto del portainjerto sobre el comportamiento poscosecha en almacenamiento a $0{ }^{\circ} \mathrm{C}$

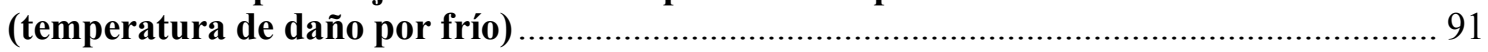

3.2.1. Apariencia, síntoma de daño y pardeamiento de pulpa..................................................... 91

3.2.2. Resistencia a la compresión y pérdida de peso ..................................................................... 94

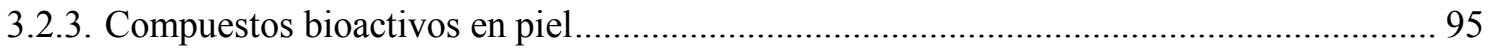

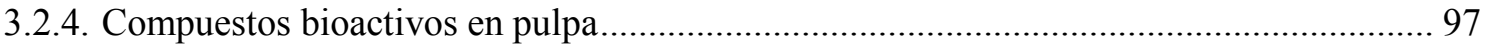

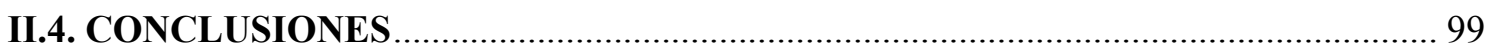

Capitulo III. 100

Efecto de tratamientos de acondicionamiento a baja temperatura (LTC) sobre el daño por frio y contenido de antioxidantes en genotipos de berenjena (violeta y rayada) y en dos estados de

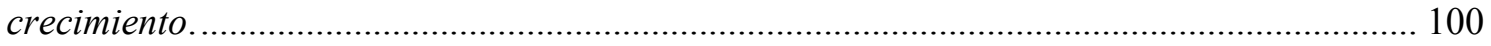

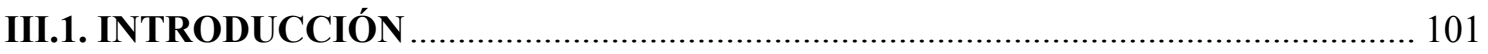

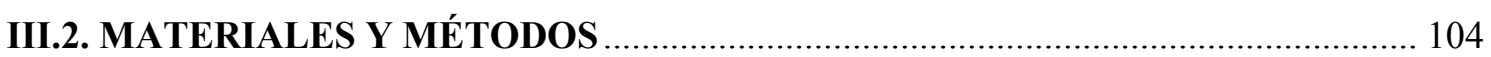

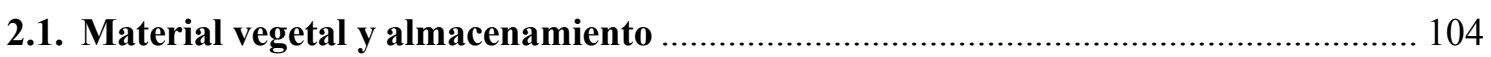

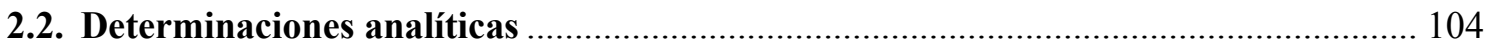

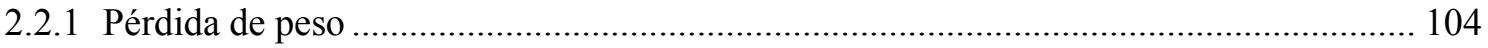

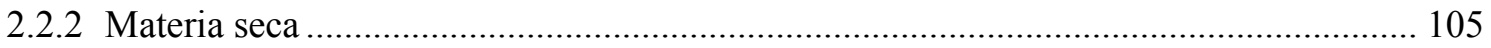

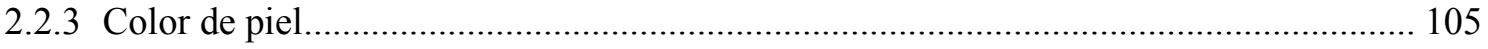

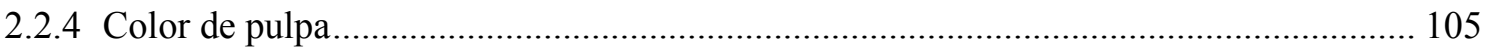

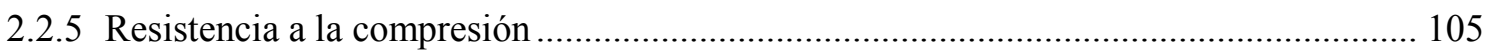

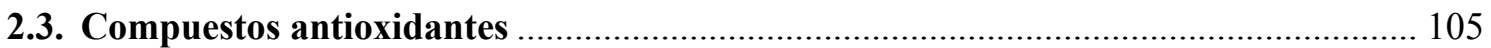

2.3.1. Extracción en etanol de compuestos antioxidantes......................................................... 105

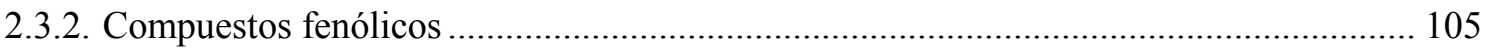




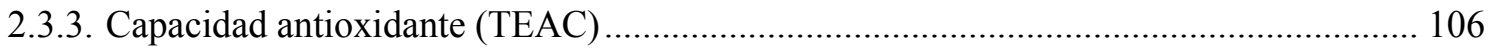

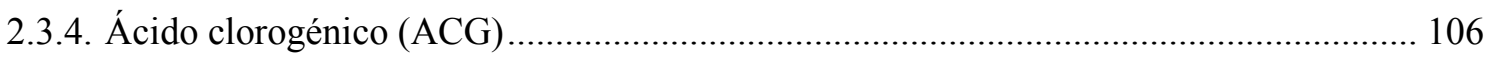

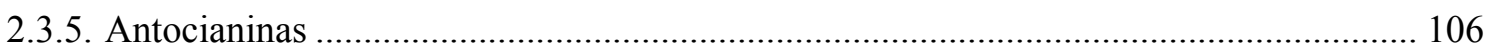

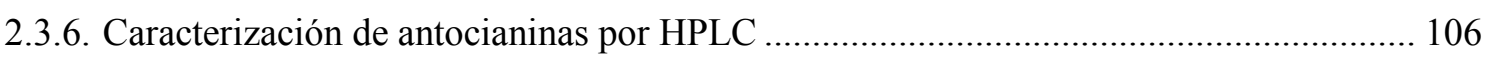

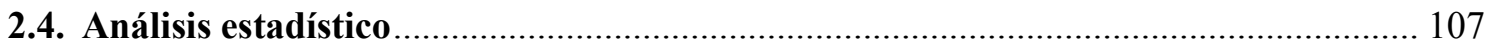

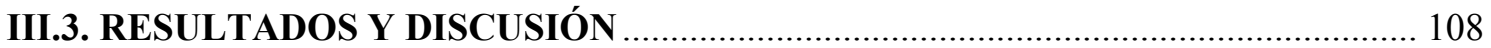

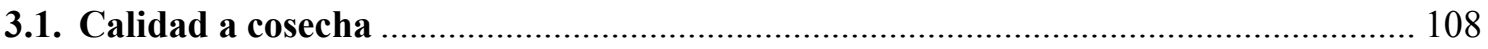

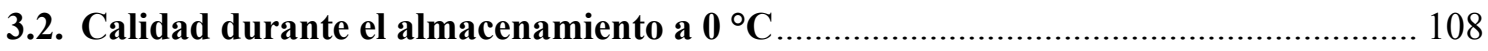

3.2.1. Apariencia externa e interna, color de piel y de pulpa..................................................... 108

3.2.2. Pérdida de peso, materia seca y resistencia a la compresión ........................................... 113

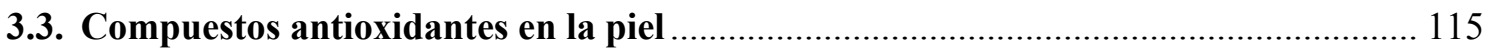

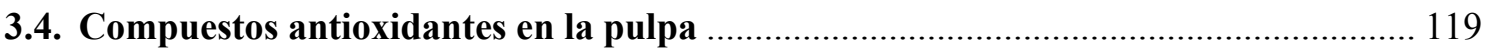

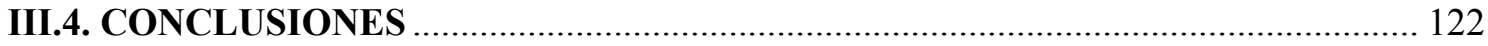

Capitulo IV

Efecto de la dosis e intensidad de radiación UV-B sobre la calidad y el contenido de compuestos bioactivos en brócoli mínimamente procesado......................................................................... 123

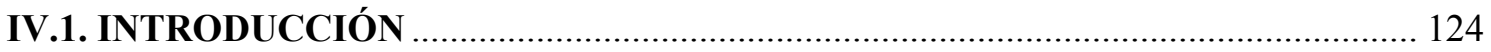

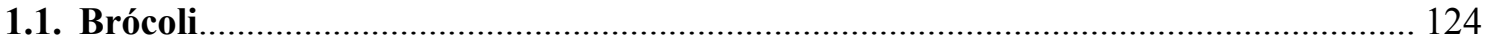

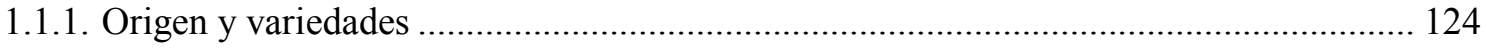

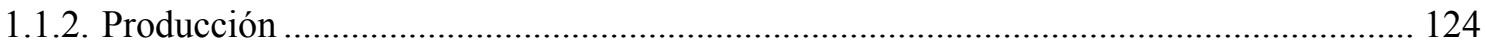

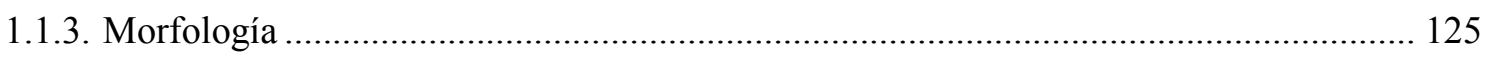

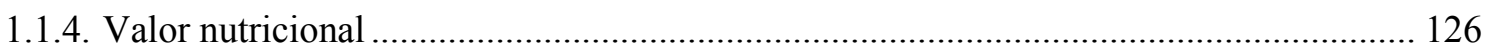

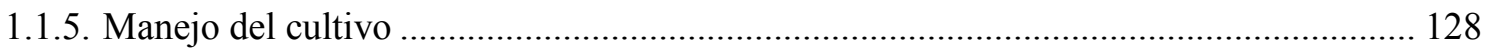

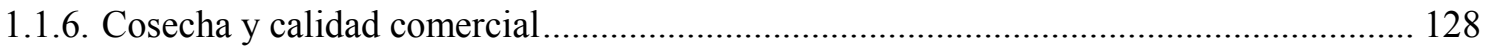

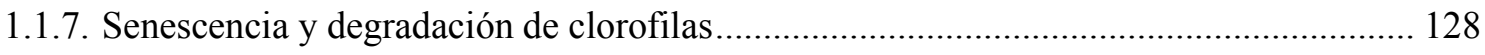

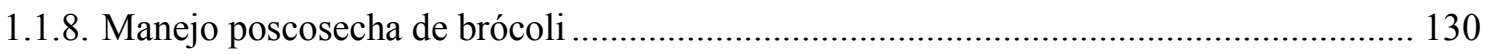

1.2. Niveles de compuestos antioxidantes en brócoli: ¿Es posible promover su acumulación

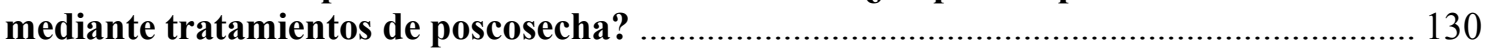

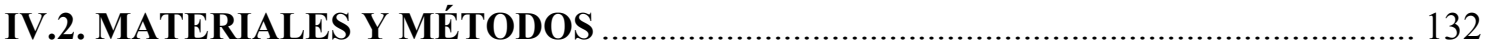

2.1. Efecto de la intensidad y dosis de radiación UV-B sobre la calidad de brócoli

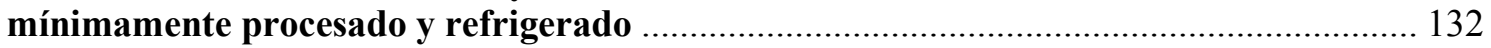

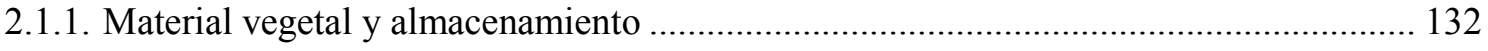

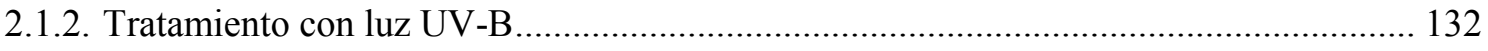

2.2. Efecto de la intensidad y dosis de radiación UV-B sobre la estimulación de compuestos antioxidantes a tiempos cortos y estabilidad luego del almacenamiento congelado........... 134

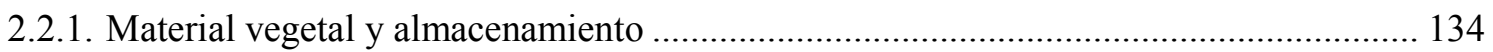

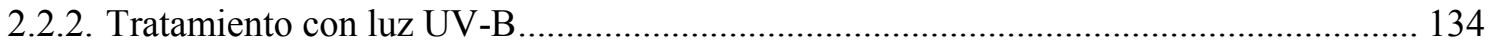

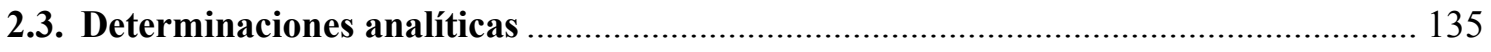




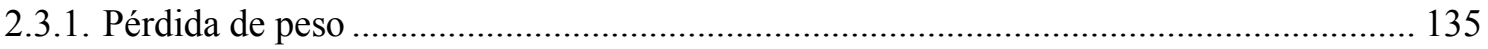

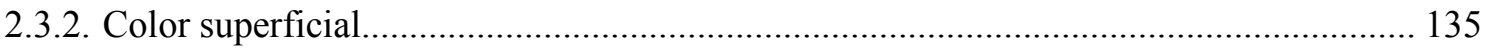

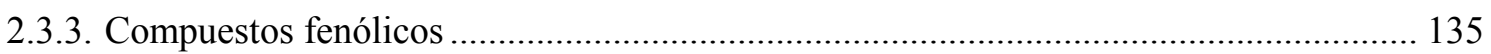

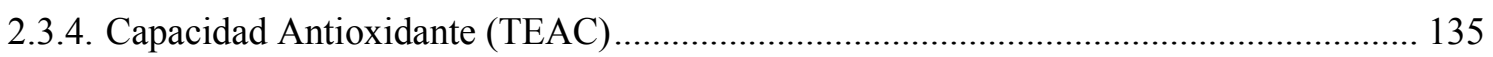

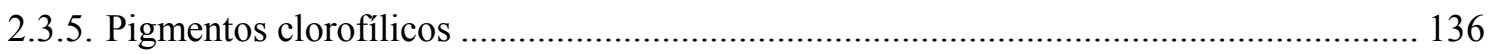

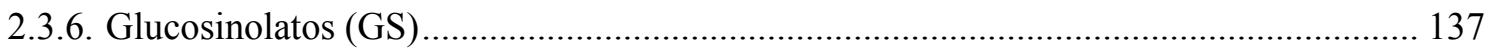

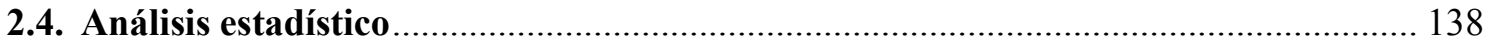

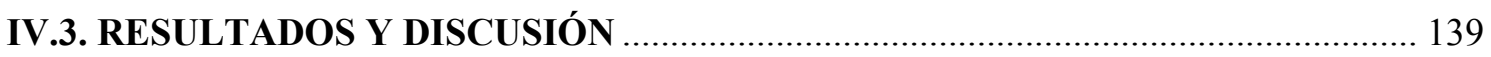

3.1. Efecto de la intensidad y dosis de radiación UV-B sobre la calidad de brócoli mínimamente procesado y almacenado en refrigeración .................................................... 139

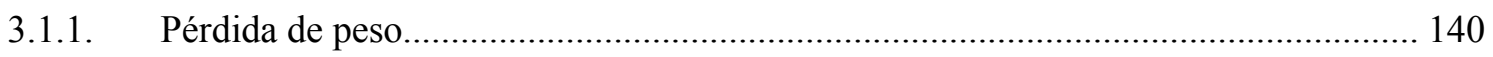

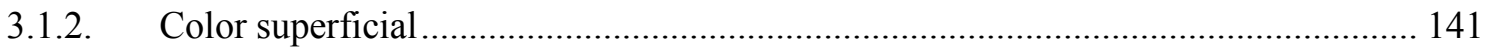

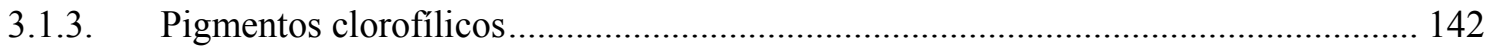

3.1.4. Capacidad antioxidante y compuestos fenólicos.................................................... 144

3.2. Efecto de la intensidad y dosis de radiación UV-B sobre la estimulación de compuestos a tiempos cortos y estabilidad luego de un almacenamiento a $-18^{\circ} \mathrm{C}$ de brócoli mínimamente

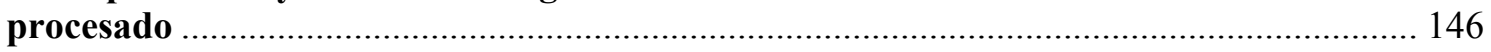

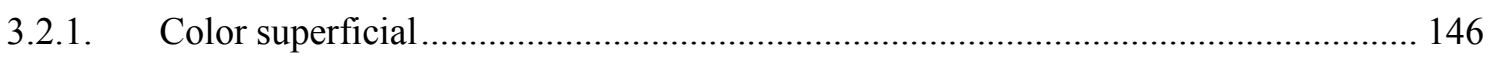

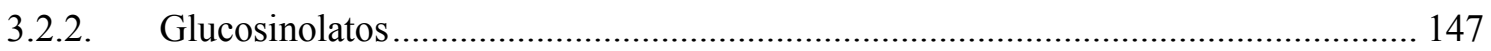

3.2.3. Capacidad antioxidante y compuestos fenólicos..................................................... 151

3.2.4. Capacidad antioxidante en almacenamiento congelado durante 30 días................... 152

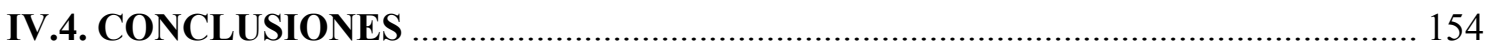

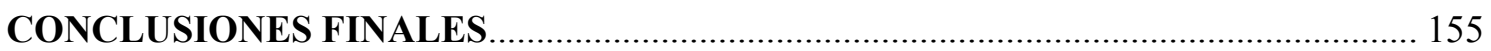

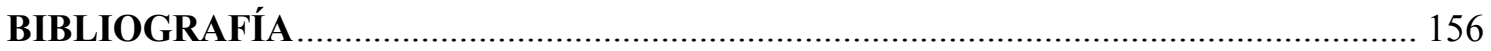




\section{INDICE DE FIGURAS}

Figura 1. Estructura química del complejo de vitaminas B.........................................................24

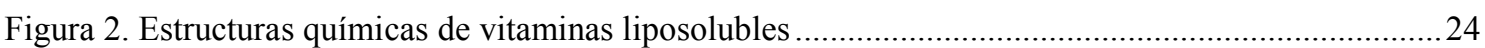

Figura 3. Formación de especies reactivas de oxígeno (EROs) en las plantas. Adaptado Meyer, (2008). . 25

Figura 4. Factores de estrés biótico y abiótico que incrementan la formación de especies reactivas de oxígeno (EROs) en las plantas. Adaptado de Meyer, (2008)..........................................................26

Figura 5. Estructura química de la vitamina $\mathrm{C}$ o ácido ascórbico (ASA) . .............................................227

Figura 6. Ácido ascórbico y sus productos de oxidación. Adaptado de Potters y col. (2002)..................27

Figura 7. Estructura química de los principales compuestos carotenoides presentes en frutas y hortalizas.

.

Figura 8. Estructura del $\alpha$-tocoferol.

29

Figura 9. Estructura de compuestos fenólicos derivados del ácido hidroxibenzoico e hidroxicinámico.

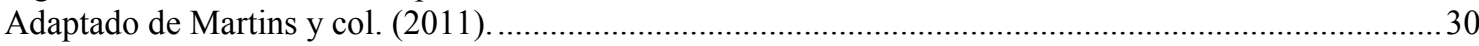

Figura 10. Estructura básica y estructura de las diferentes sub-clases de flavonoides. Adaptado de Ignat y

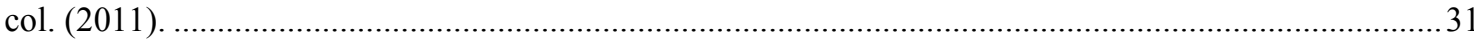

Figura 11. Estructura de las principales antocianinas presente en vegetales. ..........................................32

Figura 12. A) Plantines injertados mostrando: el pie (patrón o portainjerto) y la púa (injerto, variedad o

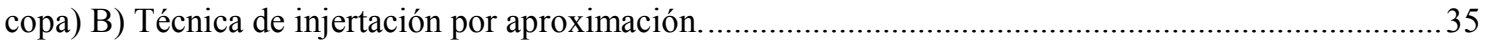

Figura 13. Tipos de injerto: A) de yema, B) de púa, C) de aproximación o "a bisel" que se utiliza

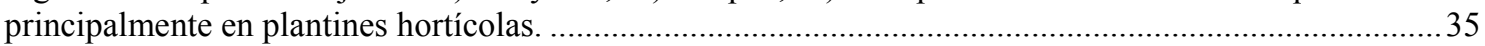

Figura I.1. Clasificación de berenjena por tipos comerciales A) blanca, B) rayada, C) violeta, D) japonesa,

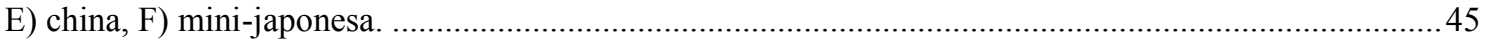

Figura I.2. Secuencia del procesamiento de imágenes de frutos de berenjena (I), en sistema binario (II), en imagen filtrada (III) y en escala de grises (IV) para realizar un análisis morfológico digital.....................54

Figura I.3. Frutos de berenjena violeta provenientes de plantas control (C) e injertadas (I) sobre A) pie Maxifort, B) pie Java en tres estados de crecimiento: estado 1 (E1): 9 cm ("baby"), estado 2 (E2): $17 \mathrm{~cm}$ (comercial), estado 3 (E3): $19 \mathrm{~cm}$ (sobremaduro).

Figura I.4. Curvas de crecimiento de frutos de berenjena provenientes de plantas control (C) e injertadas (I) sobre pie Maxifort y Java, en tres estados de crecimiento: E1 $(9 \mathrm{~cm})$, E2 $(17 \mathrm{~cm})$ y E3 $(19 \mathrm{~cm})$

Figura I.5. Tasa respiratoria de frutos de berenjena violeta provenientes de plantas control (C) e injertadas (I) sobre pie Maxifort y pie Java, en tres estados de crecimiento: estado 1 (E1): 9 cm ("baby"), estado 2 (E2): $17 \mathrm{~cm}$ (comercial), estado 3 (E3): $19 \mathrm{~cm}$ (sobremaduro). Letras distintas, para un mismo portainjerto, indican diferencias significativas según el test LSD de Fisher con un nivel de significancia de $\mathrm{P}<0,05.60$

Figura I.6. Contenido de materia seca de frutos de berenjena provenientes de plantas control (C) e injertadas (I) sobre pie Maxifort y pie Java, en tres estados de crecimiento E1 $(9 \mathrm{~cm})$, E2 $(17 \mathrm{~cm})$ y E3 $(19 \mathrm{~cm})$. Letras distintas, para un mismo portainjerto, indican diferencias significativas según el test LSD de Fisher con un nivel de significancia de $\mathrm{P}<0,05$.

Figura I.7. Parámetros de color de piel: A) Luminosidad (L*), B) a* C) b* de frutos de berenjena provenientes de plantas control (C) e injertadas (I) sobre pie Maxifort y pie Java, en tres estados de crecimiento E1 $(9 \mathrm{~cm})$, E2 $(17 \mathrm{~cm})$ y E3 $(19 \mathrm{~cm})$. Letras distintas, para un mismo portainjerto, indican diferencias significativas según el test LSD de Fisher con un nivel de significancia de $\mathrm{P}<0,05$.

Figura I.8. Resistencia a la compresión (RC) de frutos de berenjena provenientes de plantas control (C) e injertadas (I) sobre pie Maxifort y pie Java, cosechadas en tres estados de crecimiento E1 (9 cm), E2 (17 $\mathrm{cm})$ y E3 $(19 \mathrm{~cm})$. Letras distintas, para un mismo portainjerto, indican diferencia significativa según el test LSD de Fisher con un nivel de significancia de $\mathrm{P}<0,05$. . .64

Figura I.9. A) Capacidad antioxidante (TEAC) y B) Fenoles totales en piel de frutos de berenjena provenientes de plantas control (C) e injertadas (I) cosechadas en tres estados de crecimiento diferente E1 
$(9 \mathrm{~cm})$, E2 $(17 \mathrm{~cm})$ y E3 $(19 \mathrm{~cm})$. Letras distintas indican diferencias significativas según el test LSD de Fisher con un nivel de significancia de $\mathrm{P}<0,05$.

Figura I.10. A) Antocianinas y B) ácido clorogénico (ACG) en piel la de frutos de berenjena provenientes de plantas control (C) e injertadas (I) cosechadas en tres estados de crecimiento E1 $(9 \mathrm{~cm})$, E2 $(17 \mathrm{~cm}) \mathrm{y}$ E3 $(19 \mathrm{~cm})$. Letras distintas indican diferencias significativas según el test LSD de Fisher con un nivel de significancia de $\mathrm{P}<0,05$.

Figura I.11. A) Capacidad antioxidante (TEAC), B) Fenoles totales y C) ácido clorogénico (ACG) en pulpa de frutos de berenjena provenientes de plantas control (C) e injertadas (I) cosechadas en tres estados de crecimiento E1 $(9 \mathrm{~cm})$, E2 $(17 \mathrm{~cm})$ y E3 $(19 \mathrm{~cm})$. Letras distintas indican diferencias significativas según el test LSD de Fisher con un nivel de significancia de $\mathrm{P}<0,05$.

Figura II.1. Cambios en la integridad y funcionalidad de las membranas celulares asociados a lesiones por bajas temperaturas (Chilling stress). Adaptado de Aghdam y Bodbodak, (2013). . .74

Figura II.2. A) Expresión de genes vinculados con el metabolismo de citoquininas visualizado mediante la proteína verde fluorescente (GFP) 8 días luego de la injertación. B) Sección de la zona de unión de un injerto de tomate revelando la formación de callo y nuevo tejido vascular xilemático entre el portainjerto y la variedad. Adaptado de Melnyk y Meyerowitz, (2015).

Figura II.3. Apariencia de frutos de berenjenas provenientes de plantas control e injertadas almacenadas a $10{ }^{\circ} \mathrm{C}$ por 0,21 y $28 \mathrm{~d}$.

Figura II.4. Luminosidad ( $\left.\mathrm{L}^{*}\right)$ de frutos de berenjena provenientes de plantas control (C) e injertadas (I) almacenadas a $10{ }^{\circ} \mathrm{C}$ durante $0,7,14,21$ y 28 días. Letras distintas indican diferencia significativa según el test LSD de Fisher con un nivel de significancia de $\mathrm{P}<0,05$.

Figura II. 5. A) Resistencia a la compresión y B) pérdida de peso de frutos de berenjena provenientes de plantas control (C) e injertadas (I) almacenadas a $10^{\circ} \mathrm{C}$ durante $0,7,14,21$ y 28 días. Letras distintas indican diferencia significativa según el test LSD de Fisher para: A) el factor tiempo de almacenamiento, B) la interacción tiempo*tipo de fruto, con un nivel de significancia de $\mathrm{P}<0,05$. . .87

Figura II.6. A) Capacidad antioxidante equivalente a trolox (TEAC), B) Antocianinas y C) Ácido clorogénico (ACG) en piel de frutos de berenjenas provenientes de plantas control (C) e injertadas (I) almacenadas a $10^{\circ} \mathrm{C}$ durante $0,7,14,21$ y 28 días. Letras distintas indican diferencia significativa según el test LSD de Fisher con un nivel de significancia de $\mathrm{P}<0,05$. . .89

Figura II.7. A) Capacidad antioxidante equivalente a trolox (TEAC), B) Ácido clorogénico (ACG) en pulpa de frutos de berenjenas provenientes de plantas control (C) e injertadas (I) almacenadas a $10{ }^{\circ} \mathrm{C}$ durante 0 , 7, 14, 21 y 28 días. Letras distintas indican diferencia significativa según el test LSD de Fisher con un nivel de significancia de $\mathrm{P}<0,05$. .90

Figura II.8. Apariencia externa e interna de frutos de berenjena provenientes de plantas control e injertadas almacenadas a $0{ }^{\circ} \mathrm{C}$ por $0,7,14,21$ y $28 \mathrm{~d}$.

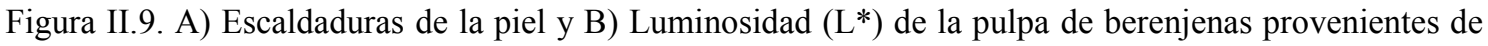
plantas control (C) e injertadas (I) almacenadas a $0{ }^{\circ} \mathrm{C}$ durante $0,7,14,21$ y 28 días. Letras distintas indican diferencia significativa según el test LSD de Fisher para: A) el factor tiempo de almacenamiento, B) la interacción tiempo*tipo de fruto, con un nivel de significancia de $\mathrm{P}<0,05$.

Figura II.10. A) Resistencia a la compresión y B) pérdida de peso de frutos de berenjena provenientes de plantas control (C) e injertadas (I) almacenadas a $0{ }^{\circ} \mathrm{C}$ durante $0,7,14,21$ y 28 días. Letras distintas indican diferencia significativa según el test LSD de Fisher con un nivel de significancia de $\mathrm{P}<0,05$.

Figura II.11. A) Capacidad antioxidante equivalente a trolox (TEAC), B) Antocianinas y C) Ácido clorogénico (ACG) en piel de frutos de berenjenas provenientes de plantas control (C) e injertadas (I) almacenadas a $0^{\circ} \mathrm{C}$ durante $0,7,14,21$ y 28 días. Letras distintas indican diferencia significativa según el test LSD de Fisher con un nivel de significancia de $\mathrm{P}<0,05$.

Figura II.12. A) Capacidad antioxidante equivalente a trolox (TEAC), B) ácido clorogénico (ACG) en pulpa de frutos de berenjenas provenientes de plantas control (C) e injertadas (I) almacenadas a $0{ }^{\circ} \mathrm{C}$ durante 0 , 7, 14, 21 y 28 días. Letras distintas indican diferencia significativa según el test LSD de Fisher con un nivel de significancia de $\mathrm{P}<0,05$. . .98

Figura III.1. Apariencia externa de frutos de berenjena rayada y violeta control o acondicionados a $10{ }^{\circ} \mathrm{C}$ por $48 \mathrm{~h}$ rayada y violeta (LTC), en estado 1 (E1) y estado 2 (E2) y posteriormente almacenados a $5{ }^{\circ} \mathrm{C}$ por 0, 14 y 17 días. 
Figura III.2. Color de piel A) Luminosidad ( $\left.\mathrm{L}^{*}\right)$ y B) $\mathrm{b}^{*}$ de frutos de berenjena rayada y violeta control (R $\mathrm{C}$ y V C) o acondicionados a $10{ }^{\circ} \mathrm{C}$ por $48 \mathrm{~h}$ (R LTC y V LTC), en estado 1 (E1) y estado 2 (E2) y posteriormente almacenados a $5{ }^{\circ} \mathrm{C}$ por 0,14 y 17 días. Letras distintas indican diferencias significativas para cada estado de crecimiento según el test LSD de Fisher con un nivel de significancia de $\mathrm{P}<0,05.111$

Figura III.3. Apariencia interna de frutos de berenjena rayada y violeta control o acondicionados a $10{ }^{\circ} \mathrm{C}$ por $48 \mathrm{~h}$ rayada y violeta (LTC), en estado 1 (E1) y estado 2 (E2) y posteriormente almacenados a $5{ }^{\circ} \mathrm{C}$ por 0,14 y 17 días. 112

Figura III.4. Luminosidad de pulpa de frutos de berenjena rayada y violeta control ( $\mathrm{R} \mathrm{C} \mathrm{y} \mathrm{V} \mathrm{C)} \mathrm{o}$ acondicionados a $10^{\circ} \mathrm{C}$ por $48 \mathrm{~h}$ (R LTC y V LTC), en estado 1 (E1) y estado 2 (E2) y posteriormente almacenados a $5{ }^{\circ} \mathrm{C}$ por 0,14 y 17 días. Letras distintas indican diferencias significativas para cada estado de crecimiento según el test LSD de Fisher con un nivel de significancia de $\mathrm{P}<0,05$. 112

Figura III.5. Pérdida de peso de frutos de berenjena rayada y violeta control ( $\mathrm{R} \mathrm{C} \mathrm{y} \mathrm{V} \mathrm{C)} \mathrm{o} \mathrm{acondicionados}$ a $10{ }^{\circ} \mathrm{C}$ por $48 \mathrm{~h}$ (R LTC y V LTC), en estado 1 (E1) y estado 2 (E2) y posteriormente almacenados a $5^{\circ} \mathrm{C}$ por 0,14 y 17 días. Letras distintas indican diferencias significativas para cada estado de crecimiento según el test LSD de Fisher con un nivel de significancia de $\mathrm{P}<0,05$. 114

Figura III.6. Materia seca de frutos de berenjena rayada y violeta control ( $\mathrm{R} \mathrm{C} \mathrm{y} \mathrm{V} \mathrm{C)} \mathrm{o} \mathrm{acondicionados} \mathrm{a}$ $10{ }^{\circ} \mathrm{C}$ por $48 \mathrm{~h}$ (R LTC y V LTC), en estado 1 (E1) y estado 2 (E2) y posteriormente almacenados a $5{ }^{\circ} \mathrm{C}$ por 0,14 y 17 días. Letras distintas indican diferencias significativas para cada estado de crecimiento según el test LSD de Fisher con un nivel de significancia de $\mathrm{P}<0,05$. 114

Figura III.7. Resistencia a la compresión de frutos de berenjena rayada y violeta control (R C y V C) o acondicionados a $10^{\circ} \mathrm{C}$ por $48 \mathrm{~h}$ (R LTC y V LTC), en estado 1 (E1) y estado 2 (E2) y posteriormente almacenados a $5{ }^{\circ} \mathrm{C}$ por 0,14 y 17 días. Letras distintas indican diferencias significativas para cada estado de crecimiento según el test LSD de Fisher con un nivel de significancia de $\mathrm{P}<0,05$. 115

Figura III.8. A) Capacidad antioxidante equivalente a trolox (TEAC) y B) Fenoles totales en piel de frutos de berenjena rayada y violeta control (R C y V C) o acondicionados a $10{ }^{\circ} \mathrm{C}$ por $48 \mathrm{~h}$ ( $\mathrm{R} \mathrm{LTC} \mathrm{y} \mathrm{V} \mathrm{LTC),}$ en estado 1 (E1) y estado 2 (E2) y posteriormente almacenados a $5{ }^{\circ} \mathrm{C}$ por 0,14 y 17 días. Letras distintas indican diferencias significativas para cada estado de crecimiento según el test LSD de Fisher con un nivel de significancia de $\mathrm{P}<0,05$.

116

Figura III.9. Perfil representativo de HPLC de las antocianinas presentes en la piel de berenjenas rayada y violeta. Pico 1: delfinidina 3-rutinósido-5-galactósido, Pico 2: delfinidina 3-rutinósido-5-glucósido, Pico 3: delfinidina 3-glucósido y Pico 4: delfinidina 3-rutinósido.

Figura III.10. A) Antocianinas y B) Ácido clorogénico (ACG) en piel de frutos de berenjena rayada y violeta control (R C y V C) o acondicionados a $10{ }^{\circ} \mathrm{C}$ por $48 \mathrm{~h}$ (R LTC y V LTC), en estado 1 (E1) y estado 2 (E2) y posteriormente almacenados a $5{ }^{\circ} \mathrm{C}$ por 0,14 y 17 días. Letras distintas indican diferencias significativas para cada estado de crecimiento según el test LSD de Fisher con un nivel de significancia de $\mathrm{P}<0,05$. 118

Figura III.11. A) Capacidad antioxidante equivalente a trolox (TEAC) y B) Fenoles totales en pulpa de frutos de berenjena rayada y violeta control ( $\mathrm{R} \mathrm{C} \mathrm{y} \mathrm{V} \mathrm{C)} \mathrm{o} \mathrm{acondicionados} \mathrm{a} 10{ }^{\circ} \mathrm{C}$ por $48 \mathrm{~h}(\mathrm{R} \mathrm{LTC} \mathrm{y} \mathrm{V}$ LTC), en estado 1 (E1) y estado 2 (E2) y posteriormente almacenados a $5{ }^{\circ} \mathrm{C}$ por 0,14 y 17 días. Letras distintas indican diferencias significativas para cada estado de crecimiento según el test LSD de Fisher con un nivel de significancia de $\mathrm{P}<0,05$ 120

Figura III.12. ACG en pulpa de frutos de berenjena rayada y violeta control (R C y V C) o acondicionados a $10{ }^{\circ} \mathrm{C}$ por $48 \mathrm{~h}$ (R LTC y V LTC), en estado 1 (E1) y estado 2 (E2) y posteriormente almacenados a $5^{\circ} \mathrm{C}$ por 0,14 y 17 días. Letras distintas indican diferencias significativas para cada estado de crecimiento según

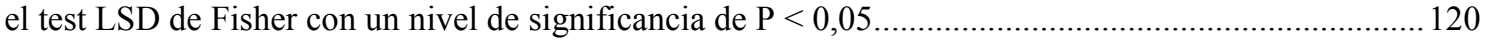

Figura IV.1. Principales especies de Brasicáceas de interés comercial A) Brassica oleracea L. var. Itálica L, B) Brassica oleracea var. Botrytis, C) Brassica oleracea var. Capitata L., D) Brassica oleracea var. Gemmifera L., E) Brassica oleracea var. Sabellica. 124

Figura IV.2. A) Estructura de clorofila $a$ y $b$, B) Espectro de absorción las clorofilas $a$ y $b$. Se muestra el espectro de luz solar visible. Adaptado de Buchanan y col. (2000).

Figura IV.3. Ruta de degradación de la clorofila. Adaptado de Aiamla y col. (2012) y Smolikova y col. (2017). 130 
Figura IV.4. A) Equipo de tratamiento UV-B, B) radiómetro y C) disposición del producto y sonda del radiómetro dentro del equipo.

Figura IV.5. Esquema de realización de extractos para la determinación de pigmentos clorofílicos y derivados. 136

Figura IV.6. Apariencia de brócoli mínimamente procesado control y tratado con intensidades de irradiación UV-B (Baja: 3,2 W/m², Media 4,0 W/m² y Alta: 5,0 W/m²) y dosis $\left(2,4,8,12 \mathrm{~kJ} / \mathrm{m}^{2}\right.$ ) y almacenados a $4{ }^{\circ} \mathrm{C}$ durante 17 días.

Figura IV.7. Pérdida de peso en brócoli mínimamente procesado control y tratado con intensidades de irradiación UV-B (Baja: 3,2 W/m², Media 4,0 W/m² y Alta: 5,0 W/m²) y dosis $\left(2,4,8,12 \mathrm{~kJ} / \mathrm{m}^{2}\right.$ ) y almacenados a $4{ }^{\circ} \mathrm{C}$ durante $17 \mathrm{~d}$. Las barras de error representan la desviación estándar de la media. Se muestra el valor de LSD. 140

Figura IV.8. Parámetros de color A) Hue y B) luminosidad (L*) de brócoli mínimamente procesado control y tratado con intensidades de irradiación UV-B (Baja: 3,2 W/m², Media 4,0 W/m² y Alta: 5,0 W/m²) y dosis $\left(2,4,8,12 \mathrm{~kJ} / \mathrm{m}^{2}\right)$ y almacenados a $4{ }^{\circ} \mathrm{C}$ durante $17 \mathrm{~d}$. Las barras de error representan la desviación estándar de la media. Se muestra el valor de LSD. 141

Figura IV.9. Pigmentos clorofílicos: A) Clorofila $a$, B) clorofilido $a$, C) feofítina $a$ y D) feofórbido $a$ en brócoli mínimamente procesado control y tratado con intensidades de irradiación UV-B (Baja: $3,2 \mathrm{~W} / \mathrm{m}^{2} \mathrm{y}$ Alta: $\left.5,0 \mathrm{~W} / \mathrm{m}^{2}\right)$ y dosis $\left(2,4,8,12 \mathrm{~kJ} / \mathrm{m}^{2}\right)$ y almacenados a $4{ }^{\circ} \mathrm{C}$ durante $17 \mathrm{~d}$. Las barras de error representan la desviación estándar de la media. Se muestra el valor de LSD. 143

Figura IV.10. A) Capacidad antioxidante equivalente a trolox (TEAC) y B) compuestos fenólicos totales en brócoli mínimamente procesado control y tratado con intensidades de irradiación UV-B (Baja: 3,2 W/ $/ \mathrm{m}^{2}$, Media 4,0 W/m $/ \mathrm{m}^{2}$ y Alta: $\left.5,0 \mathrm{~W} / \mathrm{m}^{2}\right)$ y dosis $\left(2,4,8,12 \mathrm{~kJ} / \mathrm{m}^{2}\right)$ y almacenados a $4{ }^{\circ} \mathrm{C}$ durante $17 \mathrm{~d}$. Las barras de error representan la desviación estándar de la media. Se muestra el valor de LSD. 145

Figura IV.11. Color A) Hue y B) luminosidad ( $\left.\mathrm{L}^{*}\right)$ en brócoli mínimamente procesado control (C) y tratado con intensidades de irradiación UV-B (Baja: 3,2 W/m², Alta: 5,0 W/m²) y dosis (2 o $\left.12 \mathrm{~kJ} / \mathrm{m}^{2}\right) \mathrm{B} 2, \mathrm{~B} 12$, A2 y A12 y analizados a tiempos cortos pos-tratamiento $\left(0,2,6\right.$ y 18 h) a $20{ }^{\circ} \mathrm{C}$. Las barras de error representan la desviación estándar de la media. Se muestra el valor de LSD.

Figura IV.12. Cromatograma HPLC-DAD obtenido a $229 \mathrm{~nm}$ de extractos de muestras de brócoli A) control B) Alta intensidad: $5,0 \mathrm{~W} / \mathrm{m}^{2}$ y dosis $2 \mathrm{~kJ} / \mathrm{m}^{2}$ (A2) y C) Baja intesidad: $3,2 \mathrm{~W} / \mathrm{m}^{2}$ y dosis $12 \mathrm{~kJ} / \mathrm{m}^{2}$ (B12). El pico $\mathrm{N}^{0} 5$ corresponde a la sinigrina empleada como como estándar interno. 148

Figura IV.13. A) Glucosinolatos totales, B) alifáticos y C) indólicos de brócoli mínimamente procesado control y tratado con intensidades de irradiación UV-B (Baja: 3,2 W/m², Alta: 5,0 W/m²) y dosis (2 y 12 $\left.\mathrm{kJ} / \mathrm{m}^{2}\right)$ denominados B2, B12, A2 y A12 y analizados a tiempos cortos pos-tratamiento (0, 2, 6 y $\left.18 \mathrm{~h}\right)$ a 20 ${ }^{\circ} \mathrm{C}$.

Figura IV.14. A) Capacidad antioxidante equivalente a trolox (TEAC) y B) compuestos fenólicos totales en brócoli mínimamente procesado control y tratado con intensidades de irradiación UV-B (Baja: 3,2 W/m², Alta: $\left.5,0 \mathrm{~W} / \mathrm{m}^{2}\right)$ y dosis $\left(2\right.$ y $\left.12 \mathrm{~kJ} / \mathrm{m}^{2}\right)$ denominados B2, B12, A2 y A12 y analizados a tiempos cortos postratamiento $(0,2,6$ y $18 \mathrm{~h})$ a $20^{\circ} \mathrm{C}$. Las barras de error representan la desviación estándar de la media. Se muestra el valor de LSD.

Figura IV.15. Capacidad antioxidante equivalente a trolox (TEAC) de brócoli mínimamente procesado control (C) y tratado con dosis de 2 y $12 \mathrm{~kJ} / \mathrm{m}^{2}$ a las intensidades baja (B) y alta (A) de luz UV-B luego de $6 \mathrm{~h}$ pos tratamiento almacenado a $-18^{\circ} \mathrm{C}$ por 30 días. Las barras de error representan la desviación estándar de la media. Se muestra el valor de LSD dentro de la figura. .153 


\section{ÍNDICE DE TABLAS}

Tabla I.1.Composición de berenjena Solunum melongena L. cada $100 \mathrm{~g}$ de producto (USDA, 2018)......55

Tabla I.2 Longitud, diámetro y peso de frutos de berenjena violeta provenientes de plantas control (C) e injertadas (I) con pie Maxifort, y pie Java en tres estados de crecimiento: estado 1 (E1): 9 cm ("baby"), estado 2 (E2): $17 \mathrm{~cm}$ (comercial), estado 3 (E3): $19 \mathrm{~cm}$ (sobremaduro). Letras distintas, para un mismo portainjerto, indican diferencias significativas según el test LSD de Fisher con un nivel de significancia de $\mathrm{P}<0,05$. . .66

Tabla I.3 Numero y tamaño de semillas de frutos de berenjena provenientes de plantas control (C) e injertadas (I) sobre pie Maxifort y pie Java, en tres estados de crecimiento diferente E1 $(9 \mathrm{~cm}), \mathrm{E} 2(17 \mathrm{~cm})$ y E3 $(19 \mathrm{~cm})$. Letras distintas, para un mismo portainjerto, indican diferencias significativas según el test LSD de Fisher con un nivel de significancia de $\mathrm{P}<0,05$

Tabla II.1 Algunos efectos resultantes del empleo de portainjertos sobre parámetros de calidad de frutas y hortalizas durante el almacenamiento poscosecha descritos en la literatura. 78

Tabla III.1 Tratamientos de acondicionamiento (LTC) utilizados en algunos productos frutihorticolas en poscosecha.

Tabla IV.1 Composición nutricional de brócoli cada $100 \mathrm{~g}$ de producto (USDA, 2018). 126

Tabla IV.2 Estructura básica, clasificación y nombre de los glucosinolatos presentes en brócoli (Adaptado de Tian y col., 2005).

Tabla IV.3 Tiempos de exposición a luz UV-B de brócoli mínimamente procesado sin tratar (control) y tratado a las intensidades Baja $(B=3,2 \mathrm{~W} / \mathrm{m} 2)$, Media $(\mathrm{M}=4,0 \mathrm{~W} / \mathrm{m} 2)$ y Alta $(\mathrm{A}=5,0 \mathrm{~W} / \mathrm{m} 2)$ y con dosis de $2,4,8$ y $12 \mathrm{~kJ} / \mathrm{m} 2$ de luz UV-B.

Tabla IV.4 Ecuaciones para la determinación de contenido de pigmentos clorofílicos.

Tabla IV.5 Glucosinolatos analizados por HPLC-DAD de brócoli control a cosecha. Los picos resaltados son los hallados en mayor porcentaje. 


\section{LISTADO DE ABREVIATURAS}

\begin{tabular}{|c|c|}
\hline 1-MCP & 1-metil-ciclopropeno \\
\hline $\mathrm{ABA}$ & Ácido absícico \\
\hline ABTS & Ácido 2,2'-azino-bis-(3-etillbenzotiazolin)-6-sulfónico \\
\hline $\mathrm{AC}$ & Atmosfera controlada \\
\hline $\mathrm{ACG}$ & Ácido clorogénico \\
\hline AMP & Atmósferas modificadas pasivas \\
\hline APX & Ascorbato peroxidasa \\
\hline ASA & ácido ascórbico \\
\hline $\mathrm{C}$ & control \\
\hline CAT & catalasa \\
\hline Chl & Clorofila \\
\hline Chlide & Clorofílido \\
\hline CHLP & Cinturón Hortícola de La Plata \\
\hline D3R & Delfinidin-3-rutinósido \\
\hline DAFS & Days after fruits set (Días luego de la fructificación) \\
\hline DHA & ácido dehidroascórbico \\
\hline DPF & daño por frío \\
\hline EROs & Especies reacivas del oxígeno \\
\hline FAO & Organización de las Naciones Unidas para la Alimentación \\
\hline GFP & proteína verde fluorescente \\
\hline GPX & Glutatión peroxidasa \\
\hline GS & Glucosinolatos \\
\hline HPLC-DAD & High Performance Liquid Chromatography-Diode Array Detector \\
\hline HPLC-MSD & $\begin{array}{l}\text { High Performance Liquid Chromatography-Mass Spectrometry } \\
\text { Detector }\end{array}$ \\
\hline I & Injertado \\
\hline LSD & Least significant difference (Test de mínima diferencia significativa) \\
\hline LTC & Low Temperature Conditioning \\
\hline DHA & Dehidro ascorbato \\
\hline MS & Materia seca \\
\hline Pheo & Feofórbido \\
\hline Phy & Feofitina \\
\hline PPO & Polifenoloxidasa \\
\hline $\mathrm{RC}$ & Resistencia a la compresión \\
\hline SOD & Superóxido dismutasa \\
\hline TEAC & Capacidad antioxidante equivalente a Trolox \\
\hline TR & Tasa respiratoria \\
\hline USDA & Departamento de Agricultura de los Estados Unidos \\
\hline UV-A & Ultravioleta A \\
\hline UV-B & Ultravioleta B \\
\hline UV-C & Ultravioleta $\mathrm{C}$ \\
\hline
\end{tabular}




\section{PUBLICACIONES}

Trabajos en revistas internacionales:

- Darré M, Valerga L, Ortiz L C, Lemoine M L, Demkura P, Vicente A, Concellón A. Role of UV-B irradiation dose and intensity on color retention and antioxidant elicitation in broccoli florets (Brassica oleracea var. Italica). 2017. Postharvest Biology and Technology 128 (2017): 76-82.

Trabajos completos en congresos:

- Darré M, Zaro M. J, Valerga L, Ortiz L C, Chaves A, Vicente A, Lemoine M. L, Concellón A. "Influencia del empleo de portainjertos sobre el desarrollo y la calidad de berenjena violeta". VIII Jornadas Argentinas de Biología y Tecnología de Poscosecha. 10-12 de noviembre de 2015 Balcarce, Buenos Aires, Argentina. Libro de actas Pág. 185189. ISBN 978-987-45726-2-2.

- Darré M, Ortiz L C, Valerga L, Chaves A, Vicente A, Lemoine M L, Concellón A. "Efecto de la aplicación de distintas dosis de UV-B a intensidades variables en brócoli mínimamente procesado y refrigerado". VIII Jornadas Argentinas de Biología y Tecnología de Poscosecha. 10-12 de noviembre de 2015 Balcarce, Buenos Aires, Argentina. Libro de actas Pág. 111-115. ISBN 978-987-45726-2-2.

- Darré M, Ortiz L.C, Valerga L, Chaves A, Vicente A, Lemoine M. L, Concellón A. Rápida respuesta de compuestos bioactivos de brócoli ante tratamientos de radiación UVB. VI Congreso Internacional de Ciencia y Tecnología de Alimentos (CICYTAC 2016). Córdoba, Prov. de Córdoba, Argentina.

- Darré M, Valerga L, Ortiz L C, Zaro M. J, Vicente A, Lemoine M L, Concellón A. Efecto de tecnologías precosecha sobre la calidad poscosecha de berenjena violeta. $X V I$ Congreso Argentino de Ciencia y Tecnología de Alimentos. 18-20 septiembre de 2017. Mar del Plata, Buenos Aires.

- Darré M, Valerga L, Ortiz Araque L, Zaro M. J, Vicente A. R, Lemoine M. L, Concellón A. Comportamiento poscosecha de frutos de berenjena violeta proveniente de plantas injertadas. I Congreso Argentino De Biología Y Tecnología Poscosecha. IX Jornadas Argentinas de Biología y Tecnología Poscosecha. 25-27 de Octubre de 2017. Concordia, Entre Ríos, Argentina.

Resúmenes en congresos:

- Darré M, Ortiz LC, Valerga L, Chaves A, Vicente A, Lemoine M L, Concellón A "Rápida respuesta de compuestos bioactivos de brócoli ante tratamientos de radiación UV-B”. VI Congreso Internacional Ciencia y Tecnología de los Alimentos 2016. 2-4 de noviembre de 2016. Córdoba. Argentina. Presentación en CD

- Darré M, Valerga L, Ortiz C, Vicente A, Lemoine ML, Concellón A. Efecto de tecnologías precosecha sobre la calidad poscosecha de berenjena violeta". $X V I$ CONGRESO CYTAL ${ }^{\circledR}$ Congreso Argentino de Ciencia y Tecnología de Alimentos 2017. 18-20/9/2017. Mar del Plata, Buenos Aires, Argentina. Publicado en CD.

- Darré M, Valerga L, Ortiz C, Zaro MJ, Vicente A, Lemoine ML, Concellón A. Comportamiento poscosecha de frutos de berenjena violeta proveniente de plantas injertadas. I Congreso Argentino de Biología y Tecnología Poscosecha, IX Jornadas Argentinas de Biología y Tecnología Poscosecha. 25-27/10/2017. Concordia, Entre Ríos, Argentina. Libro de Resúmenes. p67.

- Darré M, Valerga L, Ortiz Araque L, Zaro M. J, Vicente A. R, Lemoine M. L, Concellón A. Efecto del injerto sobre los antioxidantes y daño por frío en frutos de 
berenjena violeta. VIII Congreso Internacional Ciencia y Tecnología de los Alimentos 2018. 1-3 de Octubre de 2018. Córdoba. Argentina.

- Darré M. Pérez, J., Valerga L., Zaro M. J., Vicente A. R., Lemoine M. L., Concellón A.; Efecto del pre-acondicionamiento sobre la calidad comercial y el control del daño por frío en dos genotipos de berenjena. VIII Congreso Internacional Ciencia y Tecnología de los Alimentos 2018. 1-3 de Octubre de 2018. Córdoba. Argentina.

Artículos de divulgación:

- Darré M, Ortiz L.C, Valerga L, Chaves A, Vicente A, Lemoine M. L, Concellón A. Aplicación de Tecnología limpia para exaltar compuestos bioactivos en brócoli. ¿Porque debemos consumir frutas y hortalizas? ¿Qué hay de nuevo? Jornada Fanus. Octubre 2016. CABA, Buenos Aires.

- Darré, Magali, Valerga, Lucia, Ortiz, L C, Zaro, M. José, Vicente, Ariel, Lemoine, M. Laura, Concellón, Analía. Tecnologías de precosecha y compuestos fenólicos de la piel y pulpa de berenjenas violetas en distinto estados de crecimiento. Seminario de polifenoles en frutas y hortalizas. 22 de septiembre 2017. Foro de la alimentación, la nutrición y la salud. FANUS. CABA, Buenos Aires.

Trabajos enviados a revistas internacionales:

- Darré M, Valerga L, Ortiz L C, Zaro M J, Vicente A, Concellón A, Lemoine M L, Influence of grafting on purple eggplant antioxidants during development and postharvest storage. Postharvest Biology and Technology. 2018. Enviado.

Trabajos en redacción:

- Efficacy of low temperature conditioning to ammeliorate chilling injury in stripped and purple eggplant as affected by fruit maturity stage. 


\section{RESUMEN}

Los beneficios para la salud asociados al consumo de frutas y hortalizas frescas se vinculan con la presencia de compuestos antioxidantes, capaces de prevenir algunas enfermedades crónicas y degenerativas. Las clases y contenidos de estos componentes están definidos por la especie y cultivar que se considere. De todos modos, para una variedad dada, sus niveles de antioxidantes son marcadamente dependientes de las condiciones de pre y poscosecha. Varios de estos factores ya se han estudiado con detenimiento, otros aún no han recibido atención en la literatura. Una tecnología de cultivo empleada tradicionalmente en fruticultura, pero mucho más reciente en la producción hortícola, es el empleo de portainjertos, que si bien, se utiliza comúnmente para mejorar la respuesta a condiciones de estrés abiótico y biótico, podría modificar la composición y comportamiento de los vegetales en la poscosecha La información disponible al respecto en el caso de especies hortícolas es muy limitada. En tal sentido, en la primera parte del presente trabajo se estudió la influencia del empleo de portainjertos en la calidad comercial y nivel de compuestos antioxidantes en frutos de berenjena (capítulo I). Asimismo, se analizó si el empleo de dicha tecnología de cultivo modulaba además el comportamiento de los frutos en el almacenamiento tanto a temperaturas recomendadas $\left(10{ }^{\circ} \mathrm{C}\right)$ como en condiciones predisponentes al daño por frío $\left(0{ }^{\circ} \mathrm{C}\right)$ (capítulo II). El empleo de portainjertos Java y Maxifort en berenjena violeta cv. Monarca aumentó la velocidad de crecimiento de los frutos. Los frutos de plantas injertadas fueron más delgados y más rojizos que los controles. Asimismo, presentaron menor contenido de materia seca y antioxidantes tanto en la piel como en la pulpa al final de su crecimiento. El empleo del portainjerto Java no mostró marcadas diferencias en su deterioro poscosecha ni en la estabilidad de antioxidantes durante el almacenamiento a $10{ }^{\circ} \mathrm{C}$. Contrariamente, las berenjenas de plantas injertadas presentaron una menor susceptibilidad al daño por frío cuando se almacenaron a $0{ }^{\circ} \mathrm{C}$, evidenciado por una menor deshidratación y pardeamiento de la pulpa, por mayores niveles de resistencia a la compresión y por una mejor retención de compuestos antioxidantes de piel y pulpa que los frutos control. Esto sugiere que el empleo de portainjertos puede ser de utilidad para la mejora a la respuesta al daño por frío, uno de los principales problemas que limita el aprovechamiento al máximo de los beneficios de la refrigeración en algunas especies.

Durante la poscosecha, también se han evaluado algunas técnicas para reducir los desórdenes por frío. Uno de los tratamientos que se destaca por su relativa simplicidad es el acondicionamiento a bajas temperaturas (LTC) que consiste en un descenso gradual de temperatura de modo que los frutos mejoren su respuesta al estrés cuando se los coloca a temperaturas aún más bajas. Existe un reporte que encontró una mejora en berenjena violeta utilizando esta estrategia, pero no se conoce su eficacia en diferentes genotipos, ni estados de crecimiento de berenjena, ni el impacto sobre los compuestos antioxidantes. En una tercera etapa del presente trabajo, se estudió la influencia del LTC en la susceptibilidad al frío y estabilidad de antioxidantes en dos genotipos de berenjena (rayada y violeta) para dos estados de crecimiento ("baby" y comercial convencional) (capítulo III). A diferencia de lo que ocurre en otros frutos la susceptibilidad al frío en berenjena fue mayor en estados más avanzados de crecimiento para el genotipo violeta. El empleo de LTC ( 2 días a $10{ }^{\circ} \mathrm{C}$ previo al almacenamiento a $5^{\circ} \mathrm{C}$ ) logró un retraso del daño por frío y mantuvo así una mejor calidad comercial poscosecha, reteniendo en mayor medida los compuestos antioxidantes en la piel y pulpa de ambos genotipos y estados de crecimiento estudiados, sugiriendo que puede ser una tecnología valiosa capaz de combinarse y mejorar el comportamiento de las berenjenas en el almacenamiento refrigerado. 
Finalmente, una tecnología de poscosecha que se ha explorado recientemente para inducir la acumulación de antioxidantes es la irradiación UV. Su empleo en algunas especies no es posible debido a que induce algunos cambios indeseables. En el caso de berenjena en nuestros estudios preliminares se observó que estos tratamientos favorecían el bronceado del cáliz. Contrariamente, en hortalizas de inflorescencia se ha informado que puden inducir la acumulación de antioxidantes. De todos modos, la influencia que poseen otros factores del proceso de irradiación diferentes de las dosis, tales como la intensidad de radiación para una misma dosis total, se desconocen. En una última etapa del presente trabajo se analizó el efecto de tratamientos UV-B de distinta intensidad en la calidad y contenido de compuestos antioxidantes en brócoli (capítulo IV). Los resultados permitieron establecer de qué manera las condiciones de tratamiento influencian los efectos en el vegetal. Así, los tratamientos con baja dosis $\left(2\right.$ y $\left.4 \mathrm{~kJ} / \mathrm{m}^{2}\right)$ y baja intensidad de radiación $\left(3,2 \mathrm{~W} / \mathrm{m}^{2}\right)$ fueron eficaces para retrasar la senescencia manteniendo niveles más elevados de clorofila y mejor color en el producto por lo que podrían ser valiosos para complementar a la refrigeración. Estos tratamientos no fueron eficaces para inducir una acumulación significativa de compuestos antioxidantes en inflorescencias almacenadas a baja temperatura. Por su parte, los tratamientos UV-B a intensidades altas $\left(5 \mathrm{~W} / \mathrm{m}^{2}\right)$ resultaron más eficaces para inducir la acumulación de antioxidantes. Este aumento se debió principalmente a una inducción en la biosíntesis de compuestos fenólicos luego de 6 horas de finalizado el tratamiento de irradiación. La inducción de antioxidantes observada fue transiente y a tiempos cortos luego del almacenamiento. Esto indica que el uso de la irradiación UV-B como método de priming para inducir la acumulación de antioxidantes sería de utilidad en el caso de vegetales que sean sometidos con posterioridad a tratamientos de estabilización metabólica intensos, como la congelación. Esto se comprobó al verificar una gran estabilidad de la capacidad antioxidante del brócoli, luego de 30 días de almacenamiento congelado. De este modo, podría incrementarse la capacidad antioxidante del brócoli hasta un $30 \%$.

En síntesis, los resultados del presente trabajo permitieron establecer la influencia de metodologías de cultivo (empleo de portainjertos), tratamientos de poscosecha emergentes (acondicionamiento e irradiación UV-B) sobre la calidad, comportamiento poscosecha y contenido de antioxidantes en hortalizas. 


\begin{abstract}
Health benefits that are associated to fresh fruits and vegetables are linked to the presence of antioxidants compounds, which are capable of preventing chronological and degenerative diseases. Different types and contents of these components are determined by a particular species and variety. However, for some species, its antioxidant levels are highly dependent of the pre- and postharvest conditions. Many of these factors have been carefully studied, while others have not gathered any attention in literature yet. A farming technology which is usually used on fruit growing, but brand new on vegetable production, is graft. Even though it is commonly used for tolerance improvement on abiotic and biotic stress, it could alter the composition of vegetables on postharvest. The information available about it and related to vegetable species is very limited. On the first part of the current work, it has been studied the influence of using grafting on a commercial level, and the amount of antioxidant compounds on eggplants (chapter I). In addition to this, it has been analyzed if this technology affects the fruit behavior in storage at recomended temperatures $\left(10^{\circ} \mathrm{C}\right)$ as well as in chilling injury conditions $\left(0^{\circ} \mathrm{C}\right)$ (chapter II). The use of rootstock Java and Maxifort on dark-purple eggplants cv. Monarca sped up the fruit growth. The products of grafted plants were thinner and had a brighter red color than controls. Also, they had less content of dry matter and antioxidants during storage at $10^{\circ} \mathrm{C}$. However, grafted eggplants developed a stronger resistance to chilling injury when stored at $0{ }^{\circ} \mathrm{C}$. This is because of a smaller dehydration and browning of the pulp, also because of a higher resistance to crushing and a better retention of skin and pulp antioxidant compounds than control fruit. This suggests that the use of rootstock can be really helpful for chilling injury resistant, one of the main issues that forbids the benefits of refrigeration for some species.
\end{abstract}

During postharvest, there are some techniques that have been tested to reduce disorders caused by cold storage. One of the treatments that stand out from the rest, because of its simplicity, is the Low Temperature Conditioning (LTC), consisting on a gradual temperature decrease so fruits can improve their reaction to stress when transferred at even lower temperatures. There is a report which shows an improvement using this technique in dark-purple eggplant, but at the same time, it is unknown neither its efficiency within different types or growing states in eggplants nor the impact that it has on antioxidant compounds. On the third part of the current work, it has been studied the influence of LTC on the susceptibility to chilling injury, and stability of antioxidants in two genotypes of eggplant (striped and dark-purple) for two growing states (baby and commercial conventional) (chapter III). Unlike other fruits, the susceptibility to chilling injury on eggplant was greater in more advanced growing states for the dark-purple genotype. The use of LTC ( 2 days at $10^{\circ} \mathrm{C}$ prior to storage at $5{ }^{\circ} \mathrm{C}$ ) achieved a delay of chilling injury symptoms and maintained a better postharvest commercial quality, retaining at a higher scale antioxidant compounds on skin and pulp of both genotypes and growing states studied. These suggest that LTC can be a technology of great worth capable of combining and improving behavior of eggplant on refrigerated storage.

Finally, a postharvest technology that has been tested recently to induce the accumulation of antioxidants is UV irradiation. It is not possible to use it on some species because it makes changes which affects them in a bad way. When it was applied to eggplant, it has been found that these treatments favored the bronzed of the calyx. However, in inflorescence vegetables, it has been informed that this technology can induce the accumulation of antioxidants. The influence that other irradiation factors such as radiation intensity, are unknown. On a last part of the current work, it has been analyzed the effect of UV-B treatments with different intensity on quality and content of antioxidant compounds in broccoli (chapter IV). The results allowed to establish how the treatment 
conditions affects vegetables. So, low doses $\left(2\right.$ and $\left.4 \mathrm{~kJ} / \mathrm{m}^{2}\right)$ and low intensity of radiation $\left(3,2 \mathrm{~W} / \mathrm{m}^{2}\right)$ treatments were able to delay the senescence by keeping high levels of chlorophyll and a better color of the product, reason why they could be valuable to complement refrigeration. However, these treatments were not capable of inducing a significant amount of antioxidant compounds in inflorescence stored at a low temperature. UV-B treatments at high intensity $\left(5 \mathrm{~W} / \mathrm{m}^{2}\right)$ were more efficient to induce antioxidants accumulation. This increase was mainly because of an induction on the biosynthesis of phenolic compounds after 6 hours after irradiation treatment. The antioxidant induction was transient and shortly after storage. As a result, the use of UV$\mathrm{B}$ irradiation as a priming method to induce the antioxidant accumulation would be useful in cases of vegetables that are subjected to intense metabolic stabilization treatments, such as freezing. Therefore, the antioxidant capacity of broccoli could increase up to $40 \%$.

To conclude, the results of the current work allowed to establish the influence of cultivation methodologies (graft), emergent postharvest treatments (conditioning and $U V-B$ irradiation) on quality, postharvest behavior and antioxidant content on vegetables. 


\section{Introducción general}




\section{INTRODUCCIÓN GENERAL}

\subsection{Importancia del consumo de vegetales en la dieta y la salud humana}

En años recientes se observan cambios importantes en la dieta, acompañada por una variación en los ritmos de vida y en cambios socio-culturales. Dentro de estos cambios se destaca un incremento en el consumo de alimentos ricos en almidón, grasas saturadas, azúcares añadidos altamente energéticos en detrimento de la ingesta de frutas y hortalizas frescas. Actualmente en los Estados Unidos se consumen menos del 50-60 \% de las frutas y vegetales recomendados por el Departamento de Agricultura del mismo país. Esta situación no difiere de la que se ha informado en nuestro país. La ingesta de frutas y hortalizas en la Argentina se ubica en 240 g por habitante y por día, sin incluir la papa, lo que dista de los $400 \mathrm{~g}$ recomendados por la FAO. Existe evidencia que sugiere que estos cambios de dieta han sido responsables del incremento en la incidencia de ciertas enfermedades como problemas cardiovasculares, hipertensión, colesterol, diabetes, obesidad y algunos tipos de cáncer (Martin y col., 2013).

En la actualidad, comienza a observarse que cada vez más consumidores se concientizan acerca de los beneficios de una alimentación saludable. Esto redunda en una mayor demanda de alimentos saludables con menos aditivos y azúcares agregados, con mayor contenido de fibra y bajos en grasas saturadas. Estas modificaciones comienzan a traccionar la demanda sobre las propiedades funcionales de los alimentos y sobre el aporte de componentes bioactivos capaces de realizar aportes en la salud más allá de su valor nutricional (Bisbis y col., 2018; Kyriacou y col., 2017; Gürbüz y col., 2018). Las frutas y hortalizas, dado su importante aporte a las dietas saludables, parecen comenzar a tener nuevamente un valor central en la alimentación como ocurrió en tiempos Paleolíticos.

\subsection{Valor nutricional en vegetales}

De acuerdo a su composición, la mayor parte de las frutas y hortalizas se presentan como alimentos ricos en vitaminas y minerales, con muy pocas calorías y con una gran proporción de agua 80-95 \%. La misma varía en función del tipo de producto, del estado de crecimiento, época y condición de cultivo, entre otros. Los hidratos de carbono constituyen entre el 50-80\% del peso seco total, es decir que son los segundos componentes en abundancia, luego del agua, y su principal función es de reserva de energía. Los azúcares principales son la glucosa, fructosa y sacarosa. Las tres forman los azúcares totales solubles en agua que le dan el sabor dulce a las frutas y hortalizas. Las 
proporciones de los carbohidratos al igual que el agua, pueden variar en función del producto, del estado de crecimiento, etc. Los azúcares simples de las frutas son de fácil digestión y de rápida absorción en las personas. El almidón es otro hidrato de carbono de importancia en los vegetales como la papa, el plátano, etc.

El aporte de fibra es del 1-3\% del peso seco en los vegetales, y está formada principalmente por los componentes de pared celular, celulosa, hemicelulosa, pectinas, lignina y carbohidratos no digeribles. Las nueces, legumbres y frutas secas poseen alto contenido de fibra. La fibra contribuye a la intensificación de los movimientos peristálticos intestinales y la salud intestinal en las personas, induciendo cambios beneficiosos en el microbioma colónico, creando un ambiente menos propicio a la proliferación de células cancerosas, promoviendo funcionalidades prebióticas (Martin y col., 2013). A modo de ejemplo, las almendras poseen $12 \%$ y las nueces $7 \%$ de fibra dietaria mientras que el pimiento, la espinaca, frutilla y naranja sólo poseen el $2 \%$ de fibra.

El contenido de proteínas es menor al $1 \%$, la mayor cantidad de estos compuestos es aportada por las semillas de leguminosas y los frutos secos que aportan entre 15-30\% de proteínas de alta calidad.

Los lípidos, en este grupo de alimentos, también se encuentran en muy bajas proporciones, inferiores al $1 \%$. Por ejemplo, en manzanas, plátanos y uvas se encuentran en $0,2 \%$ aunque aquí también hay algunas excepciones como la palta y la aceituna que poseen entre $30-70 \%$. Los ácidos grasos que predominan en los vegetales son el oleico y linoleico con uno y dos enlaces dobles, respectivamente, que ayudan a reducir el colesterol LDL ("malo") y protegen el colesterol HDL ("bueno"). También pueden regular la presión arterial, niveles de lípidos en sangre, etc.

Los vegetales son ricos en un gran número de vitaminas y tienen diversas funciones en nuestro organismo ya que no podemos sintetizarlas en cantidad suficiente y debemos incorporarlas en la dieta. Se las puede clasificar según su solubilidad en vitaminas liposolubles: A, E, K e hidrosolubles: complejo B y C. Algunas de ellas tienen propiedades antioxidantes y se las describirá con más detalle en la sección 1.3.

Dentro del complejo de vitaminas B se encuentran B1: tiamina, B2: riboflavina, B3: niacina, B5: ácido pantoténico, B6: piridoxina, B9: ácido fólico, B12: cianobalamina (Figura 1). Las legumbres, pimiento, remolacha, espinaca y las almendras son ricas en este grupo de vitaminas. Porotos, espinaca y repollos contienen cantidades importantes de vitamina B6. Nueces, brócoli y champiñones son ricos en ácido pantoténico. Son 
importantes para los seres humanos en el metabolismo de los carbohidratos, como precursores de $\mathrm{NADH}$, en el caso de la niacina o ácido nicotínico, el ácido fólico es esencial para la reproducción y crecimiento.

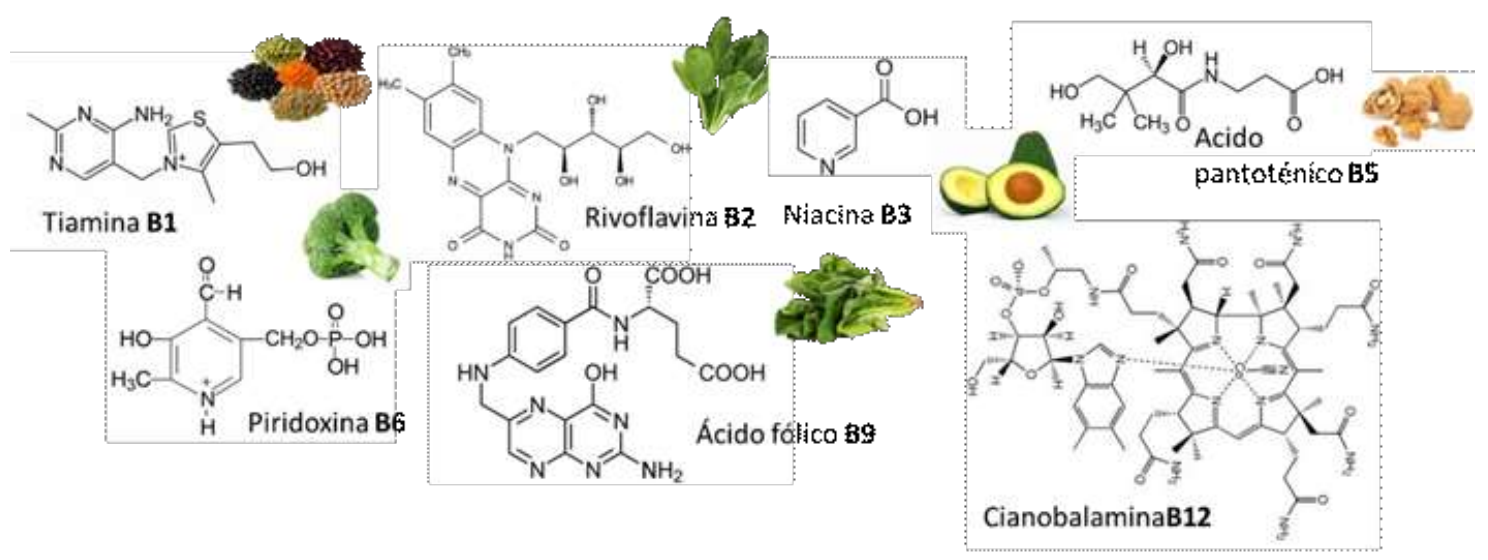

Figura 1. Estructura química del complejo de vitaminas B.

Las vitaminas liposolubles D y K (Figura 2), se encuentran en pequeñísimas cantidades en frutas y hortalizas. La lechuga, espinaca, coliflor y coles son la mayor fuente de estas vitaminas. Asi, por ejemplo, la vitamina $\mathrm{K}$ es esencial para la coagulación de la sangre. La vitamina $\mathrm{D}$ es esencial para el metabolismo del calcio y la mineralización de los huesos.

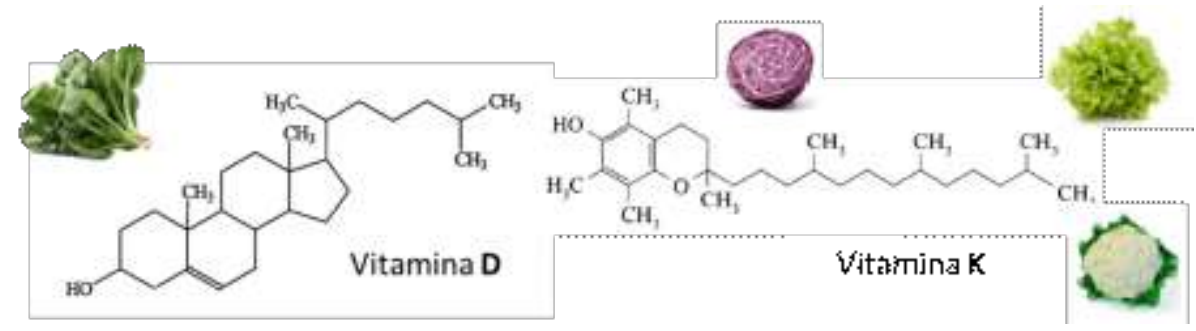

Figura 2. Estructuras químicas de vitaminas liposolubles

\subsection{Antioxidantes en vegetales}

\subsubsection{Especies reactivas del oxígeno (EROs) y mecanismo antioxidante}

Las especies reactivas del oxígeno (EROs) son especies químicas altamente reactivas capaces de promover la oxidación celular. Muchas de ellas poseen electrones desapareados en sus orbitales externos que le dan alta reactividad e inestabilidad estructural, transformándolos en radicales libres capaces de captar electrones de moléculas biológicas, para lograr estabilizarse. 
Algunas de estas moléculas son el oxígeno parcialmente reducido, como el oxígeno singulete, peróxido de hidrógeno, anión superóxido, radical oxhidrilo (Asada, 1999). Estas especies parcialmente reducidas y altamente reactivas se generan en la cadena respiratoria a partir del oxígeno. Son el resultado de la excitación del $\mathrm{O}_{2}$ a la forma de oxígeno singulete $\left({ }^{1} \mathrm{O}_{2}\right.$ ) (Figura 3), o de la transferencia de uno, dos o tres electrones, para formar el radical superóxido $\left(\mathrm{O}_{2}^{-}\right)$, peróxido de hidrógeno $\left(\mathrm{H}_{2} \mathrm{O}_{2}\right)$ o el radical hidroxilo ( $\left.\mathrm{HO}^{*}\right)$, respectivamente. En condiciones de estrés, las EROs se producen en cantidades exacerbadas (Halliwell, 1999).

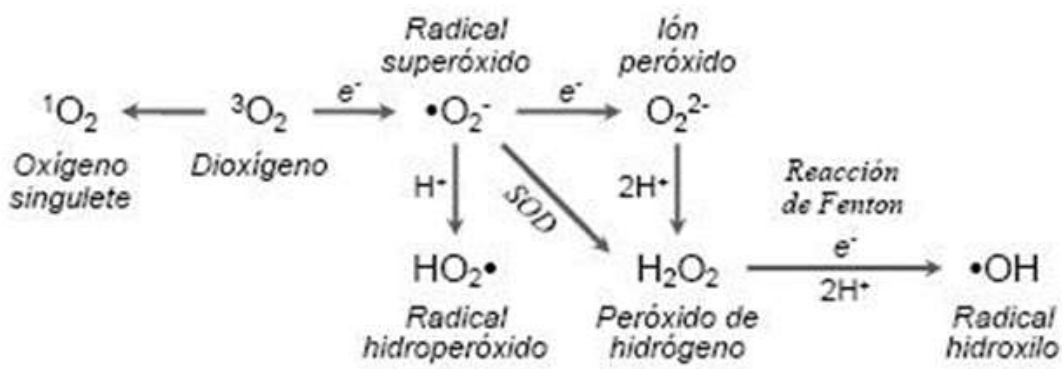

Figura 3. Formación de especies reactivas de oxígeno (EROs) en las plantas. Adaptado Meyer, (2008).

El metabolismo celular normal resulta en la producción de EROs en los diferentes compartimentos celulares. De todos modos, los niveles de estas especies suelen incrementarse en condiciones de estrés biótico y abiótico (Figura 4).

Las EROs, si no se las mantiene bajo control, pueden resultar en daños irreversibles (Zimmermann y Zentgraf, 2005). Para ello los organismos vivos cuentan con un variado "pool” de antioxidantes, moléculas capaces de oponerse a la oxidación celular (Haliwell, 1999; Vicente y col., 2009; Laguerre y col., 2010). 


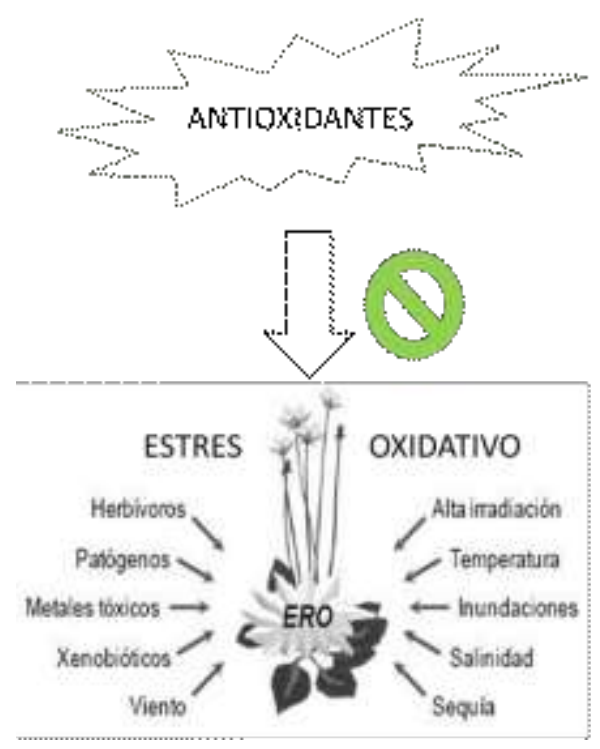

Figura 4. Factores de estrés biótico y abiótico que incrementan la formación de especies reactivas de oxígeno (EROs) en las plantas. Adaptado de Meyer, (2008).

Los antioxidantes pueden dividirse en dos grandes grupos: enzimáticos y no enzimáticos. Dentro de los primeros, se puede mencionar a enzimas como la superóxido dismutasa (SOD), glutatión peroxidasa (GPX), ascorbato peroxidasa (APX) y catalasa (CAT) (Zaro, 2014; Castenmiller, 2000). Por su parte, entre los antioxidantes no enzimáticos encontramos al ácido ascórbico, los tocoferoles y tocotrienoles, los carotenoides, los compuestos fenólicos, el glutatión y algunas proteínas (Castenmiller, 2000; Zimmermann y Zentgraf, 2005).

A continuación, se desriben las características de los principales antioxidantes presentes en frutas y hortalizas:

\subsection{2. Ácido ascórbico ( $\boldsymbol{A S A}$ )}

Su principal función es neutralizar las especies reactivas al oxígeno, donando electrones, interviniendo de esta manera en la disminución del daño oxidativo. Su concentración depende del producto considerado, pero puede variar entre $1-150 \mathrm{mg} / 100 \mathrm{~g}$ de peso fresco. El $90 \%$ de la vitamina C o ASA que consumimos proviene de los vegetales. El ASA (Figura 5) se encuentra en gran cantidad en vegetales como frutilla, kiwi, cítricos, pimiento, espinaca y brócoli (Vicente y col., 2009) La naranja aporta $50 \mathrm{mg} / 100 \mathrm{~g}$ aproximadamente, el kiwi $63 \mathrm{mg} / 100 \mathrm{~g}$, pero las hortalizas como pimiento rojo y verde, perejil, espinaca aportan entre 100-200 mg/100 g y las crucíferas entre 80-90 mg/100 g. 


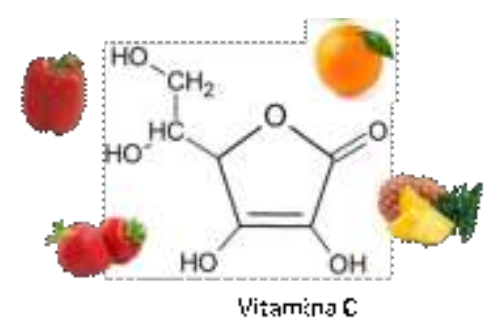

Figura 5. Estructura química de la vitamina $\mathrm{C}$ o ácido ascórbico (ASA).

El ascorbato es una molécula multifuncional en las células de las plantas debido a sus propiedades redox. Como antioxidante, el ascorbato participa en el ciclo del ascorbatoglutatión. Además, en las plantas participa en eventos de señalización redox tales como la capacidad de respuesta a patógenos, determinación del tiempo de floración, influye en la expresión de genes relacionados con respuestas de defensa, crecimiento de plantas y señalización de hormonas vegetales. Hay evidencia genética convincente que la biosíntesis de ascorbato procede a través de la vía $\mathrm{D}$-manosa/L-galactosa (Ishikawa y col., 2018). Su actividad antioxidante deriva de la oxidación al ácido dehidroascórbico (DHA) (Figura 6), que puede ser reciclado en el ciclo de Halliwell-Asada. (Thompson y col., 2010).

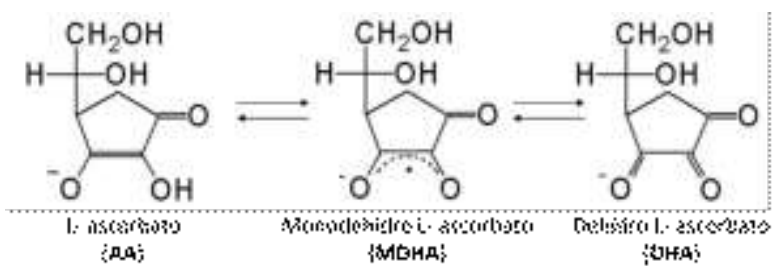

Figura 6. Ácido ascórbico y sus productos de oxidación. Adaptado de Potters y col. (2002).

\subsubsection{Carotenoides}

Los carotenoides son tetraterpenos constituidos por unidades múltiples de isopreno. Se pueden dividir en dos grupos (Figura 7): los carotenos que no contienen oxígeno en sus anillos terminales, sólo contienen átomos de carbono e hidrógeno ( $\alpha$-caroteno, $\beta$ caroteno, licopeno, etc.) y las xantófilas que llevan al menos un átomo de oxígeno en su molécula (luteína, zeaxantina, etc.) (Giordano y Quadro, 2018). 


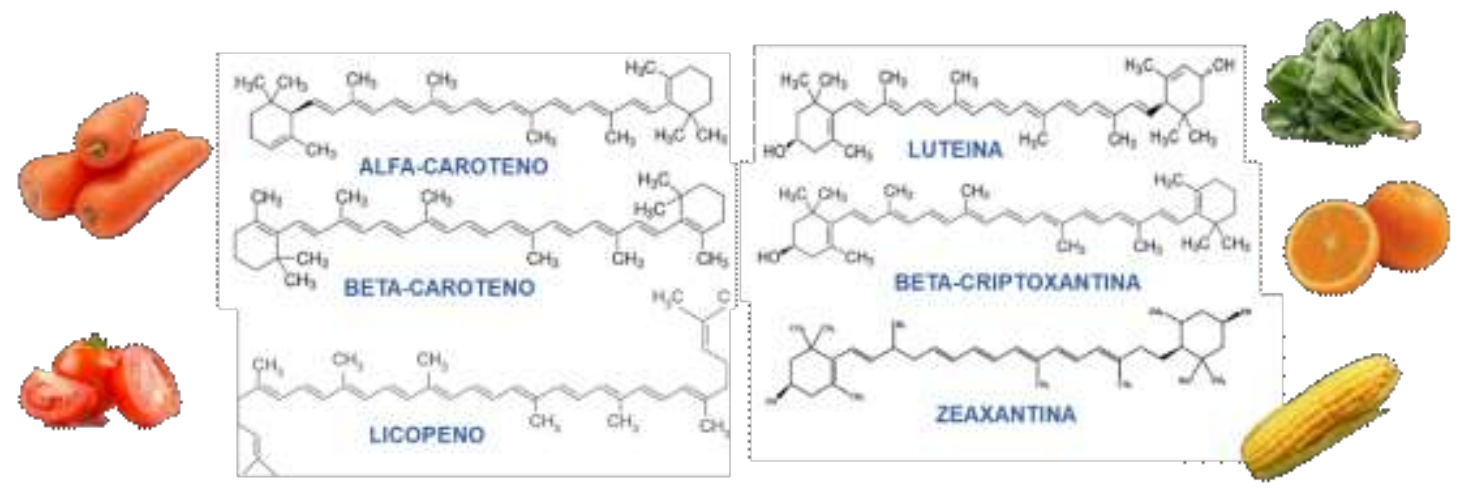

Figura 7. Estructura química de los principales compuestos carotenoides presentes en frutas y hortalizas.

Los carotenos poseen importantes propiedades antioxidantes por lo que pueden prevenir algunas enfermedades debido a la presencia de extensas cadenas de dobles enlaces en sus moléculas. Se encuentran en las membranas celulares o formando parte de lipoproteínas, o bien en plástidos específicos en el caso de frutos maduros. Poseen extensas cadenas de dobles enlaces conjugados que les permiten absorber luz en la región visible otorgando coloraciones amarillas, naranjas o rojas características de los vegetales (CarrancoJauregui y col., 2011). Algunas frutas y hortalizas ricas en este tipo de compuestos son el tomate, la zanahoria, la calabaza, el maíz, y la naranja. En general en las hortalizas predominan la luteína y $\beta$-caroteno, mientras que en las frutas predominan las xantófilas.

\subsubsection{Tocoferoles y tocotrienoles}

Comprenden 4 tocoferoles ( $\alpha$-tocoferol, $\beta$-tocoferol, $\gamma$-tocoferol y $\delta$-tocoferol) y 4 tocotrienoles ( $\alpha$-tocotrienol, $\beta$-tocotrienol, $\gamma$-tocotrienol y $\delta$-tocotrienol), poseen un anillo cromano (un anillo heterocíclico y un anillo fenólico) y una cadena extensa lateral (Figura 8). Su capacidad antioxidante radica en el poder redox del anillo cromano, que presenta un oxhidrilo capaz de donar un átomo de hidrógeno y reducir así, los radicales libres. Actúan en forma sinérgica con los carotenoides para proporcionar mayor actividad antioxidante (Zhang y col., 2014). Por ser de naturaleza lipofílica protegen a los ácidos grasos polinsaturados de las membranas fosfolipídicas del ataque de EROs. La forma más activa y abundante en los seres vivos es $\alpha$ - tocoferol. Se encuentran en mayor proporción en granos oleaginosos (soja, maíz, girasol) y cereales (trigo, avena y arroz) y aceites vegetales (Febles Fernández y col., 2002). 


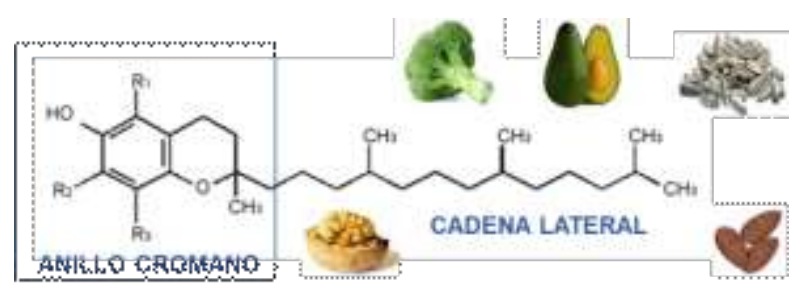

Figura 8. Estructura de $\alpha$-tocoferol.

\subsubsection{Compuestos fenólicos}

Los compuestos fenólicos son los metabolitos secundarios más abundantes en los vegetales. Se sintetizan en las plantas superiores por dos vías básicas: la vía del ácido shikímico y la vía del ácido malónico. Su presencia en el reino animal se debe a la ingesta de los mismos. Son el grupo más diverso y abundante en las plantas y se caracterizan por presentar al menos un anillo aromático con distinto grado de hidroxilación.

Por su gran complejidad y variabilidad estructural cumplen en las plantas múltiples funciones, por ejemplo, como antimicrobianos, como fitoalexinas para defenderse de depredadores, protección contra radiación ultravioleta, aportan coloración y pigmentación a frutas y hortalizas (color azul, violeta, rojo), pueden aportar astringencia y sabor amargo (Taiz y Zeiger, 2006; Dai y Mumper, 2010). En los últimos años, se ha incrementado en forma marcada el interés en el estudio de los compuestos fenólicos, debido a su capacidad de prevenir enfermedades crónicas, que se asocian con la facilidad de estos compuestos para ceder átomos de hidrógeno de un grupo hidroxilo aromático, a la posibilidad de deslocalización de cargas en el sistema de dobles enlaces del anillo aromático (Duthie y col., 2003; Carocho y Ferreira, 2013), y en algunos casos a la capacidad de captar iones metálicos (principalmente hierro y cobre) y por tanto para inhibir la formación de radicales libres a través de la reacción de Fenton (Rice-Evans y col., 1997). Están presentes en muchísimos alimentos frutas, vegetales, té, café, cerveza, vino, cacao, aceite de oliva virgen. En función de su estructura los compuestos fenólicos pueden dividirse en varias clases; ácidos fenólicos, flavonoides y taninos, estilbenos y lignanos (Dai y Mumper, 2010).

\section{a. Ácidos fenólicos}

Entre estos ácidos se encuentran los derivados del ácido benzoico (ácidos $p$ hidroxibenzoico, vainíllico, siríngico y gálico) y los derivados del cinámico (ácidos $p$ cumárico, cafeíco, ferúlico y sinápico), dependiendo del grado de hidroxilación o metoxilación del anillo aromático (Figura 9). El ácido cafeíco es el más abundante en 
frutas $(75-100 \%$ del total de los ácidos hidroxicinámicos), mientras que en cereales, el ácido ferúlico ocupa el $90 \%$ de los ácidos fenólicos totales. Estos compuestos, normalmente, forman ésteres con los ácidos quínico, shikímico o tartárico. Así, el ácido clorogénico (ACG), éster de los ácidos cafeíco y quínico es el más abundante en la naturaleza. Este ácido es el ácido 5-cafeoilquínico, se encuentra en berenjena, papa, ciruela, alcaucil (Vermerris y Nicholson., 2006).

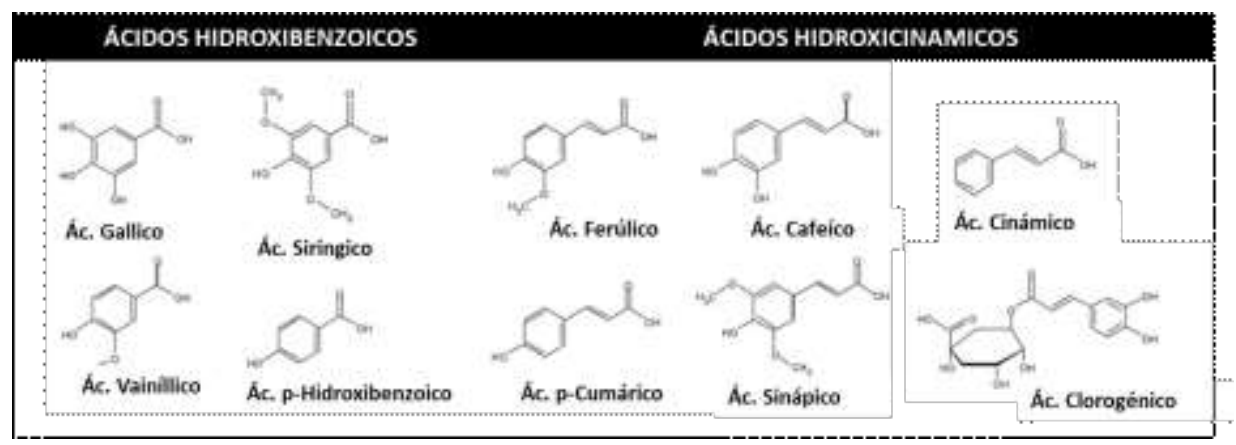

Figura 9. Estructura de compuestos fenólicos derivados del ácido hidroxibenzoico e hidroxicinámico. Adaptado de Martins y col. (2011).

El ACG se presenta en un gran número de especies vegetales con un rol central en la defensa de la planta y como antioxidante (Plazas y col., 2013). Es el principal compuesto fenólico soluble en Solanáceas populares como la berenjena, papa o tomate, y en miembros de la familia Rubiáceas cultivados en todo el mundo, como el café. Resulta de esta forma uno de los antioxidantes fenólicos más abundantes en la dieta humana (Niggeweg y col., 2004). En este sentido, su importancia radica en sus actividades biológicas con efectos beneficiosos para la salud humana, que incluyen: capacidad para captar radicales libres, regulación de la actividad enzimática y modulación de los mecanismos de señalización celular (Sato y col., 2011). A su vez, el ACG en particular presenta propiedades antioxidantes, anticarcinogénicas, antinflamatorias, analgésicas, antimicrobianas, neuro-cardioprotectoras (Plazas y col., 2013).

\section{b. Flavonoides}

Su estructura está formada por dos anillos aromáticos unidos entre sí, por tres átomos de carbono, formando un heterociclo oxidado (Figura 10). Este grupo se subdivide en seis clases por la estructura del heterociclo: flavonoles, flavonas, flavanonas, flavanoles, antocianidinas e isoflavonas. Se han identificado más de 5.000 flavonoides diferentes. Aunque los hábitos alimenticios son muy diversos en el mundo, el valor medio de ingesta 
de flavonoides se estima como $23 \mathrm{mg}$ /día, siendo la quercetina el predominante con un valor medio de $16 \mathrm{mg}$ /día (Martinez-Flores y col., 2002). Desempeñan un papel importante en la biología vegetal; así, responden a la luz y controlan los niveles de las auxinas reguladoras del crecimiento y diferenciación de las plantas. Otras funciones incluyen un papel antifúngico y bactericida, confieren coloración, lo que puede contribuir a los fenómenos de polinización.

Los flavonoides en general existen como glucósidos en la naturaleza y las diferencias entre grupos dependen del número y disposición de los grupos hidroxilo y del grado de alquilación y/o glicosilación. Existe una relación directa entre la estructura de los flavonoides y la capacidad de secuestrar radicales libres y quelar metales como el hierro y el cobre que le confieren su capacidad antioxidante. Se encuentran en vegetales, semillas, frutas y en bebidas como vino, cerveza, té verde y té negro.

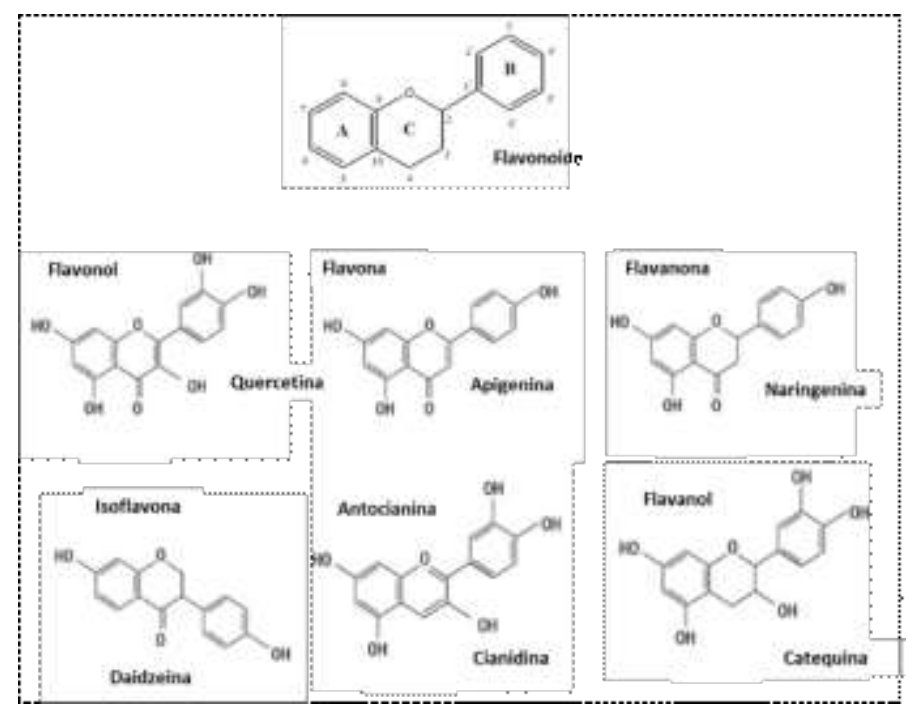

Figura 10. Estructura básica y estructura de las diferentes sub-clases de flavonoides. Adaptado de Ignat y col. (2011).

Uno de los principales flavonoides en vegetales son las antocianidinas, son pigmentos hidrosolubles que le dan las coloraciones azul, violeta, rojo y naranja a las flores y frutos, se hallan glicosiladas en los tejidos de las plantas para formar las antocianinas, con una o dos unidades de glucosa, galactosa o rutinósido. Por lo general, llevan el nombre de la planta donde se encontraron y difieren entre sí por el número de hidroxilos que se unen al heterociclo oxidado. Es así, que se conocen 5 antocianidinas (Figura 11), las cuales podrían ser agrupadas por el color mayoritario en: pelargonidina (naranja), cianidina y peonidina (naranja-rojo) delfinidina, petunidina y malvidina (color azul-rojo) (Durst y Wrolstad, 2001). Las antocianinas son buenas captadoras de radicales libres y quelantes 
de metales, aunque esto va a depender del grado de hidroxilación y metoxilación del anillo oxidado (Del Valle Leguizamón y col., 2005; Aguilera-Otíz y col., 2011).

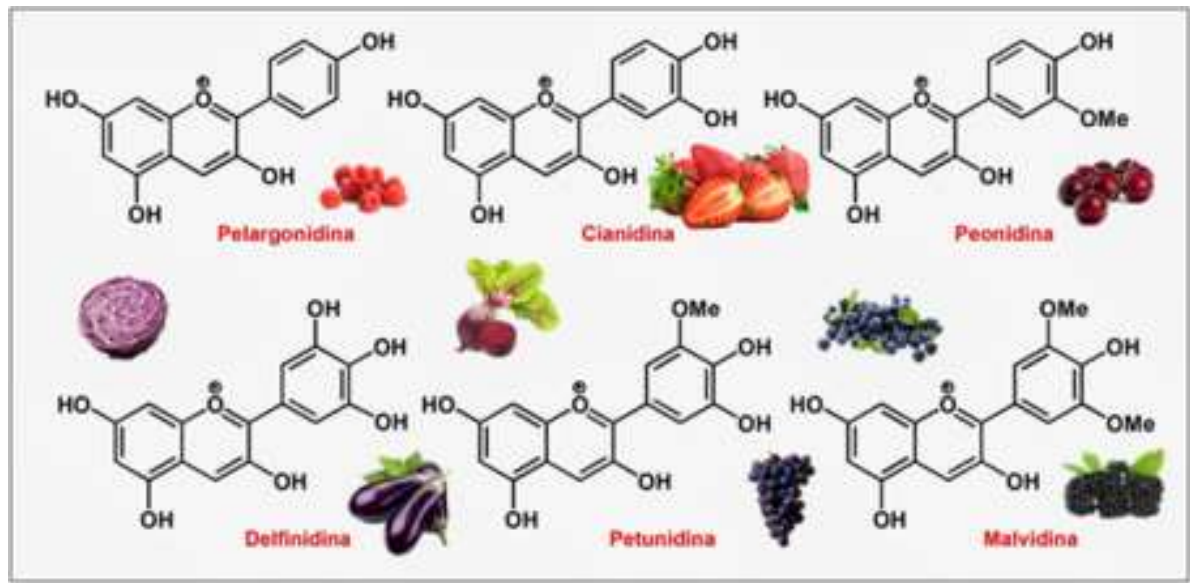

Figura 11. Estructura de las principales antocianinas presente en vegetales.

Los flavonoles son los más abundantes en las plantas, la quercetina y el kampferol son los más comunes y se encuentran en importantes cantidades en cebollas, en la cáscara de arándanos, apio, brócoli, manzana, uvas y cerezas.

Los flavanoles se encuentran en las uvas que son ricas en catequina y epicatequina. Las manzanas, almendras y arándanos, también el té verde y negro son buena fuente de estos compuestos.

Dentro de las flavanonas se destaca la narinjenina que da el sabor amargo a frutas como la naranja, limón y toronja.

Las isoflavonas son fitoestrógenos difenólicos que están principalmente en leguminosas; en productos derivados de la soja como tofu, tempeh, son una buena fuente de estos flavonoides. Ejercen una función similar a la hormona estrógeno y metabolizados en el intestino pueden tener efectos beneficiosos para la salud (Liu, 2003).

\section{c. Otros}

Los taninos son compuestos fenólicos de alto peso molecular que pueden dividirse en dos grupos: según su estructura química, en taninos condensados o proantocianidinas (polímeros de flavonoides vinculados a través de un enlace de carbono) y taninos hidrolizables (que contienen un núcleo central de glucosa esterificado con ácido gálico o con ácido elágico) (Ricco y col., 2003). Están presentes principalmente en bebidas como vino, té, café y en plantas como castaño de indias, clavo de olor, canela, eucalipto, entre otras. En vegetales y frutas se halla en espinaca, frutilla, uva, nueces, arándano, 
frambuesa, cereza y granada. La astringencia en algunas bebidas como el vino, té o café es causada por taninos. Por su parte, los estilbenos son compuestos fenólicos de bajo peso molecular, que se generan en las plantas como respuesta a una infección o lesión, se conocen como fitoalexinas. El más importante de este grupo es el resveratrol que se encuentra en uva y vino tinto y ha cobrado interés por su asociación con la prevención de ciertos tipos de cáncer (Ramprasath y Jones, 2010).

Los lignanos son estructuras difenólicas sintetizadas por la vía del ácido shikínico, también fitoestrógenos, desempeñan funciones fisiológicas principalmente de defensa de las plantas. Se encuentran principalmente en semillas de lino, sésamo, cereales, centeno, calabaza, soja y legumbres (Samuel, 2004). Estos compuestos importantes en semillas oleaginosas contribuyen a prevenir la oxidación de los lípidos.

\subsection{Factores que afectan la acumulación y estabilidad de antioxidantes en}

\section{hortalizas}

El contenido de antioxidantes en vegetales puede verse afectada por factores genéticos (especie, variedad), de precosecha (clima y manejo del cultivo, estado de crecimiento, etc.) $y / o$ de poscosecha (almacenamiento, tratamiento, acondicionamiento $y$ procesamiento). Según Kalt (2005), los compuestos fenólicos suelen ser más sensibles, respecto de otros grupos de antioxidantes, a las modificaciones en su contenido en respuesta a factores ambientales de precosecha, contribuyendo a la amplia variabilidad en el nivel de antioxidantes que en general presentan los productos con altos niveles de fenoles.

A continuación se detallan los factores que afectan el contenido de antioxidantes en los vegetales:

\subsubsection{Factores genéticos}

El genotipo ejerce sin duda el mayor efecto en el contenido de estos metabolitos secundarios (Li y col., 2012). Cada género o grupo de vegetales posee distinto tipo de compuestos antioxidantes y dentro de la misma especie las distintas variedades pueden tener también diferente contenido de estos compuestos. Numerosos autores estudiaron genotipos de distintas especies para caracterizar y cuantificar los principales grupos de antioxidantes presentes (Al-Saikhan y col., 1995; Simonne y col., 1997; Kurilich y col., 2002; George y col., 2004; Kaur y col., 2007; Deepa y col., 2007; Bogusz y col., 2018; Tripodi y col., 2018; Petropoulos y col., 2018; Pal y col., 2018). 


\subsubsection{Factores de precosecha}

El contenido de antioxidantes en vegetales puede variar entonces como ya se mencionó por factores de precosecha como pueden ser: las condiciones ambientales en que se desarrollan los cultivos, la temperatura, humedad, irradiación, agua, nutrientes del suelo, fertilización, manejo de cultivo y el estado de crecimiento considerado (Li y col., 2012). Muchas de las condiciones ambientales van a ser influidas por la elección de realizar cultivos a campo o bajo invernadero y esa decisión va a terminar modificando el valor nutricional de los productos cultivados (Kuti y Konuru, 2005; Stommel y col., 2015; Ku y col., 2018). Los materiales de polietileno con los que son construidos los invernaderos también pueden afectar el contenido de antioxidantes dado que la luz es necesaria para promover la acumulación de ciertos pigmentos como el licopeno y $\beta$ caroteno en tomates (Giuntini y col., 2005; Ahmadi y col., 2018). Las fechas de siembra o épocas de cosecha y especialmente los estados de cosecha pueden modificar el nivel de antioxidantes y compuestos beneficiosos para la salud (Howard y col., 2003; Ferreyra y col., 2007; Ghasemnezhad y col., 2011; SB y col., 2013; Ariza y col., 2015; Winardiantika y col., 2015).

Las situaciones de estrés tanto biótico, como abiótico con frecuencia pueden variar los antioxidantes, es así que, tanto los regímenes de riego como el ataque de patógenos pueden generar situaciones de estrés y por tanto modificar el rendimiento, la composición, la calidad nutricional y contenido de compuestos biológicamente activos de los cultivos (Jiang y Zhang, 2002; Hernández y Almansa, 2002; Martinez y col., 2018; Di Stasio y col., 2018; Ferreira y col., 2019). Una tecnología aplicada en cultivo que permite reducir los problemas causados por diferentes condiciones ambientales y de manejo es el uso de injertos (Sen y col., 2018). Numerosos trabajos dan idea de los beneficios de implementar la tecnología de injertación que permitió mejorar características agronómicas como rendimiento, producción y vigor de planta (Scalzo y col., 2005; Khah y col., 2006; Khah, 2012; Sabatino y col., 2018) y la tolerancia a distintos tipos de estrés biótico y abióticos tales como ataque de patógenos como Verticillum sp, Fusarium sp, Meloidogyne sp., estrés hídrico, salino, entre otros (Rivero y col., 2003; FernandezGarcía y col., 2004; Colla y col., 2010; Lee y col., 2010; Sánchez-Rodríguez y col., 2012; Penella y col., 2016). A continuación, se describen los aspectos más salientes de esta técnica. 


\subsubsection{Injerto}

La injertación consiste en la unión de una porción de tejido de distintas partes de las plantas (púa, injerto, variedad o copa) sobre otra ya asentada que aporta el sistema radical (portainjerto, patrón o pie), de manera tal que ambas crezcan como un solo individuo (Figura 12).

Si bien dónde y cuándo se originó no es completamente claro, existe evidencia de que comenzó a utilizarse en China en el año 1000 a.C. (Hartmann y col., 2002). La técnica se difundió durante la época romana donde ya se realizaba injertos en frutales a escala comercial (Hartmann y col., 2002).

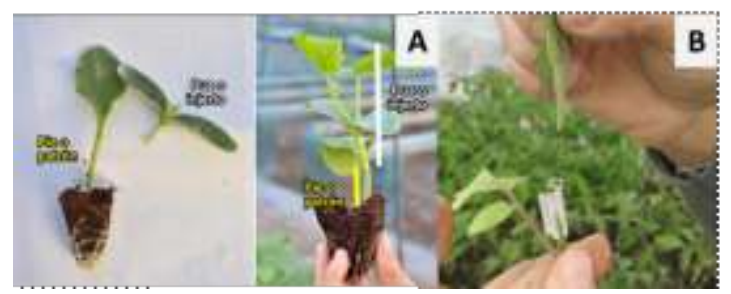

Figura 12. A) Plantines injertados mostrando: el pie (patrón o portainjerto) y la púa (injerto, variedad o copa) B) Técnica de injertación por aproximación.

Los injertos se pueden efectuar de distinta manera, pudiendo clasificarse en:

- $\quad$ De yema: la parte a injertar es una yema acompañada de un trozo de corteza.

- $\quad$ De púa: se injerta una pequeña rama o púa con 3 o más yemas.

- De aproximación: al momento de injertar tanto el patrón como el injerto están sobre sus propias raíces, luego se corta la copa del patrón y las raíces del injerto y se unen por aproximación. En el caso de las Solanáceas, el injerto de aproximación consiste en cortar el portainjerto y el vástago en ángulo de 45 grados llamada "a bisel”, alinearlos cuidadosamente y mantener ambas partes en su lugar usando un clip de injerto de silicona (Figura 13).

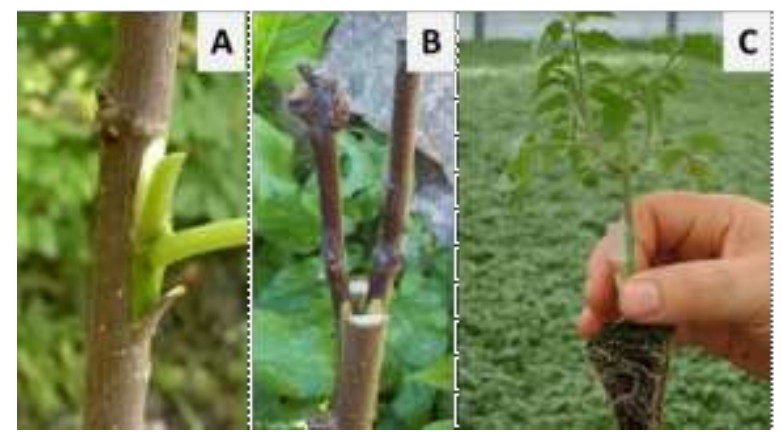

Figura 13. Tipos de injerto: A) de yema, B) de púa, C) de aproximación o "a bisel" que se utiliza principalmente en plantines hortícolas. 
Un factor fundamental para que la realización de la injertación sea posible es la compatibilidad entre injerto y portainjerto. Esto no resulta simple, ya que se requieren complejas interacciones anatómicas, fisiológicas y bioquímicas (Trinchera y col., 2013; Vršič y col., 2015). Por lo general, cuanto mayor es la afinidad botánica y morfológica entre las especies a injertar, mayor es la probabilidad de éxito. En caso de existir incompatibilidad, los síntomas se manifiestan con crecimiento anormal, amarillamiento de las hojas, entre otros (Chen y col., 2016).

Los injertos se han utilizado con diversos objetivos: a) propagar vegetativamente las especies; b) evitar la juvenilidad, cuando se quiere acortar los tiempos de floración y fructificación de una planta nueva; c) cambio de cultivares y aprovechar el sistema radicular de un árbol maduro; d) creación de formas de crecimiento inusuales; e) control del tamaño de los individuos con portainjertos enanizantes; f) resistencia al estrés biótico y abiótico; y g) estudios fisiológicos.

En el caso de especies hortícolas la injertación comenzó a utilizarse en Japón y Corea recién en la década de 1920. El primer injerto interespecífico se registra en sandías injertadas con calabaza (Lee, 1994). Desde 1960-1970, el injerto se aplicó comercialmente en la producción de sandía, pepino y melón (Oda, 1995; 1999). A pesar de ello su uso ha sido y es mucho más restringido que en el caso de especies frutícolas leñosas. Esto obedece probablemente en buena parte a que la duración de las plantas en los cultivos hortícolas es mucho menor (lo que determina un menor tiempo de amortización del costo de producción) y a la existencia de algunos problemas técnicos con la realización de injertos en especies herbáceas. A pesar de ello, en los últimos años ha tomado gran interés. De hecho, hasta finales de la década del ' 80 la técnica de injertado era bastante ineficiente. La introducción de metodologías de injerto por aproximación conocidas en Japón y en Europa permitió realizar injertos en forma mucho más barata y eficiente. Como resultado de ello el uso de portainjertos se ha convertido en una práctica mucho más común en algunas zonas hortícolas.

Al inicio los objetivos se centraron en mejorar la resistencia contra enfermedades de suelo. En Europa, los injertos de hortalizas comenzaron a utilizarse comercialmente a principios de la década de 1990, inicialmente en respuesta a la necesidad de cultivar productos sin residuos y al aumento de la demanda de sistemas orgánicos, pero más recientemente, debido a las restricciones impuestas a la fumigación del suelo empleando bromuro de metilo, un esterilizante químico de suelo con efectos tóxicos para seres humanos y para el medio ambiente cuyo uso se ha prohibido (Bletsos y Olympios, 2008). 
Más recientemente, los injertos en tomate y otras hortalizas se han utilizado para inducir resistencia contra estrés abiótico con mayor rapidez respecto de los cultivos convencionales. Así, se ha logrado mejorar la tolerancia a temperaturas altas y bajas (Rivero y col., 2003; Venema y col., 2005), mejorar la absorción de nutrientes (Ruiz y col., 1997) y optimizar el uso del agua (Cohen y Naor, 2002).

Actualmente y dependiendo de la especie se ofrecen portainjertos que atienden a muchos de los aspectos mencionados con anterioridad más allá del control contra agentes bióticos, como la resistencia al estrés por temperaturas extremas y déficit hídrico se promueve sugiriendo que puede mejorar el anclaje, desarrollo radicular y establecimiento de las plantas y en ciertos casos incrementar la rusticidad crecimiento, vigor y otras (Schwarz y col., 2010; Gisbert y col., 2012).

Como se mencionó, la utilización de portainjertos es común en fruticultura, aunque se hallan algunos trabajos que estudiaron la influencia de la aplicación de distintos portainjertos sobre características agronómicas de especies hortícolas, muy pocos trabajos han profundizado en el efecto de esta tecnología sobre la calidad nutricional y compuestos bioactivos a cosecha. Se ha determinado que la elección del portainjerto es la clave en la determinación de la cantidad de producción a cosecha (Scalzo y col., 2005). Sin embargo, no está claro, cómo los portainjertos ejercen su influencia en la calidad de los frutos. A su vez, aún no se hallan reportes relacionados a la velocidad de variación de distintos parámetros de calidad durante el crecimiento e incluso durante el almacenamiento poscosecha que garantizara la extensión de la vida útil de los frutos.

\subsubsection{Factores de poscosecha}

En términos generales, la refrigeración es la tecnología poscosecha más difundida para retrasar maduración y senescencia, retrasar síntomas de deterioro, lentificar procesos metabólicos tales como la respiración, el ablandamiento, la degradación de pectinas y oligosacáridos asociados a pared celular y pérdida de color verde (Vicente y col., 2007). Se ha observado que diferentes temperaturas y tiempos de almacenamiento pueden variar el contenido de antioxidantes de algunos productos (Sheng y col., 2016; Vargas-Arcila y col., 2017). Numerosas tecnologías poscosecha pueden influir en el contenido de antioxidantes de los vegetales que se pueden combinar o complementar y se mencionan a continuación: 


\subsubsection{Tratamientos químicos}

La principal función de los tratamientos químicos es desinfectar, sanitizar y reducir la carga microbiana, aunque algunos trabajos muestran que también pueden afectar la calidad poscosecha de los vegetales. El agua clorada es el método más usado, económico y difundido en nuestro país, aunque en algunos casos puede formar derivados con la materia orgánica (cloraminas) por lo que en algunos países no está permitido su uso. Este tipo de manejo puede afectar el contenido de antioxidantes (Collado y col., 2017).

El ozono es otro tratamiento utilizado para sanitizar agua, y es efectivo para un amplio rango de microorganismos. Tiene como principal limitante que debe ser generado in situ por su carácter explosivo, además puede ser tóxico en concentraciones superiores a 5 $\mathrm{mg} / \mathrm{L}$. Los tratamientos con ozono pueden inducir la acumulación de compuestos fenólicos (Rodoni y col., 2009; Onopiuk y col., 2017).

\subsubsection{Tratamientos hormonales}

El etileno es una de las principales hormonas vegetales, producido por los órganos y tejidos de las plantas que puede aplicarse por vía exógena con fines comerciales para regular la maduración de frutos (Vendrell y McGlasson, 1971). Sin embargo, en los productos hortícolas, puede acelerar la senescencia o la madurez dependiendo del tipo de vegetal, disminuyendo la vida útil del producto, por lo tanto la estrategia poscosecha más común es evitar la exposición al etileno o minimizar la producción y la acción del mismo durante la cosecha, el almacenamiento y el transporte mediante el control de la temperatura y la atmósfera (Watkins, 2006). El etileno fue un tratamiento efectivo posterior a la cosecha para acelerar el cambio de color en pimientos, permitiendo una cosecha más temprana y aumentando al doble los antioxidantes (Fox y col., 2005). Para espinaca y kiwi, el etileno aceleró la maduración y senescencia disminuyendo el contenido de antioxidantes (Hodges y Forney, 2000; Park y col., 2008). Existen otras hormonas de menor uso en poscosecha como las citoquininas, el ácido jasmónico y el ácido abscísico, que también poseen influencia en el contenido de compuestos bioactivos (Kumar y col., 2008; Reinbothe y col., 2009; Li y col., 2010).

\subsubsection{Tratamientos físicos}

Los tratamientos físicos han ganado gran interés en los últimos años para controlar, reducir o retrasar el desarrollo de patógenos poscosecha debido a la ausencia total de residuos en el producto tratado y al mínimo impacto ambiental. Estos incluyen 
tratamientos con agua caliente y aire caliente, atmósferas controladas y modificadas, microondas, radiación ultravioleta (Usall y col., 2016), que se desarrollan a continuación.

\section{a. Tratamientos térmicos}

Se puede utilizar para realizar estos tratamientos:

- Agua caliente: para control de insectos.

- Vapor caliente: para control de insectos y patógenos.

- Aire caliente: para control de insectos y patógenos y además retrasar alteraciones fisiológicas y de maduración.

Se utilizan temperaturas de entre $45-70{ }^{\circ} \mathrm{C}$ por períodos de entre pocos segundos hasta minutos dependiendo fundamentalmente del medio de calentamiento.

Se han empleado como estrategia para retrasar la maduración y senescencia de vegetales, reducir el desarrollo microbiano, alargar la vida útil de productos y en algunos casos también reducir daño por frío.

Casi todos estos tipos de tratamientos han demostrado mejorar la actividad del sistema antioxidante (Tian y col., 1997; Lurie, 1998; Funamoto y col., 2002; Vicente y col., 2002; Rodoni, y col., 2016; Zhao y col., 2019).

En frutillas se demostró que logra mantener la capacidad antioxidante, informando elevados niveles de ácido ascórbico y compuestos fenólicos (Vicente y col., 2002). En peras y lechugas logra disminuir el pardeamiento enzimático, en tomates almacenados a baja temperatura puede disminuir el daño por frío. El tratamiento combinado de aire caliente con levaduras podría controlar las enfermedades fúngicas, además de retrasar la disminución de la calidad y los parámetros antioxidantes en frutos de durazno (Zhao y col., 2019). En brócoli, tratamientos térmicos con agua caliente (Tian y col., 1997) permiten retrasar el amarillamiento y desarrollo de enfermedades. Tratamientos en aire a $50{ }^{\circ} \mathrm{C}$ durante $2 \mathrm{~h}$ retrasan la degradación de clorofilas (Funamoto y col., 2002). Tratamientos térmicos suaves por inmersión en agua para pimientos verdes y rojos evitaron la marchitez, la pérdida de peso, no alteraron el contenido de azúcar, la acidez o la capacidad antioxidante de la fruta durante el almacenamiento (Rodoni y col., 2016).

\section{b. Atmósferas controladas y modificadas}

En general, una reducción de la concentración de oxígeno y una elevación del dióxido de carbono que rodea al producto, fundamentan esta tecnología. Las atmósferas permiten extender la vida útil y mantener compuestos bioactivos en mayor medida que un 
almacenamiento convencional. Como consecuencia se produce una reducción de la tasa respiratoria, de la producción de etileno, del ataque microbiano, de la pérdida de peso y la oxidación de los productos. En berenjena, se ha reportado en la literatura que luego del almacenamiento en bolsas de polietileno, atmósferas activas y pasivas, presentaron mayor contenido de vitamina C y retraso en el daño por frío (Fallik., 1995; Concellón 2003; Arvanitoyannis y col., 2005). En brócoli mínimamente procesado envasado en bolsas de polipropileno (atmósferas modificadas pasivas, AMP) y almacenados a $4{ }^{\circ} \mathrm{C}$, preservaron la calidad sensorial, el contenido total de glucosinolatos y la capacidad antioxidante (Paulsen y col., 2018). En espinaca "baby" bajo atmósfera controlada (AC) se mantuvo la actividad antioxidante total y los flavonoides (Mudau y col., 2018). En mango, tratamientos combinados de 1-MCP y AC redujeron la incidencia de antracnosis, pérdida de peso y firmeza, y mantuvo el ácido ascórbico, los carotenoides, el contenido total de fenólicos y flavonoides, y la actividad antioxidante (Sivakumar y col., 2012). Manzanas, peras y frutillas también tienen buena respuesta a las atmósferas (Watkins y col., 2000; Bai y col., 2005; Thompson, 2010; Stanger y col., 2018; Flaherty y col., 2018; Ramírez-Acosta y col., 2018).

\section{c. Irradiación $U V$}

El espectro electromagnético de la radiación que corresponde al UV puede dividirse según Maverakis y col, (2010) en: UV-A 320-400 nm; UV-B 280-320 nm; UV-C 200$280 \mathrm{~nm}$.

Este tipo de irradiación no se considera una radiación ionizante. Puede causar daño en la mayoría de las macromoléculas que componen las células vegetales. El ADN es la molécula más afectada por la radiación. Además, puede tener efecto en la fisiología de los cloroplastos, sobre el metabolismo de los flavonoides, sobre estructura de membranas, sobre la producción de etileno (Civello y col., 2007). Si bien la radiación puede causar daños y alteraciones en la organización de los tejidos, la formación de radicales libres puede actuar en las plantas accionando mecanismos de defensa que le permitan adaptarse a esta nueva situación como puede ser la estimulación de síntesis de sustancias antioxidantes. Es decir, que si la radiación es demasiado excesiva causará daños irreparables en los tejidos, pero si se utiliza en dosis e intensidad adecuada puede tener efectos beneficiosos. Esto se conoce como "hormesis"; estimulación de un efecto beneficioso en los vegetales en respuesta a un agente causante de estrés tanto físico como 
químico (Lukey, 1980). Es así, como surge la radiación como estrategia tecnológica en poscosecha.

La radiación UV-A penetra en un $95 \%$ en la superficie terrestre, es la de menor energía y posee actividad antimicrobiana, pero en mucha menor proporción que la radiación UV-

C. La radiación UV-B puede tener efectos sobre las proteínas ya que afecta los residuos de aminoácidos aromáticos. La radiación UV-C produce reacciones de fotoxidación en las plantas a través de la producción de radicales libres y generación de EROs. Los radicales libres y superóxidos pueden dañar las membranas celulares, ácidos nucleicos, paredes celulares, proteínas, dando lugar a la aceleración de la senescencia. Es letal para bacterias, virus, hongos, levaduras y protozoos (Civello y col., 2007). Numerosos trabajos estudiaron el efecto de la radiación ultravioleta con la extensión de la vida útil y el mantenimiento de la calidad poscosecha en frutillas, tomate, brócoli (Pan y col., 2004;

Costa y col., 2006a; Liu y col., 2009; Bravo y col., 2012).

\subsubsection{Acondicionamiento a baja temperatura (LTC)}

El acondicionamiento a baja temperatura (LTC= Low Temperature Conditioning, por sus siglas en inglés) es la exposición a temperaturas ligeramente por encima del rango de enfriamiento crítico por un corto período de tiempo que puede inducir tolerancia a subsecuentes temperaturas más bajas durante el almacenamiento (Chaudhary y col., 2014; Jin y col., 2015). Permite aumentar la tolerancia a las bajas temperaturas, reducir el daño por frío y aumentar la vida útil de los productos (Wang, 1993). Los efectos de este tipo de tratamientos sobre los niveles de antioxidantes no se han estudiado con detenimiento y si bien se ha sugerido que la mejor respuesta a las bajas temperaturas de frutos con LTC se asocia a mejoras en las defensas antioxidantes la evidencia de ello en el caso de especies hortícolas es escasa. 
En función de lo antedicho, los niveles de compuestos antioxidantes presentes en productos frutihortícolas son afectados por un sinnúmero de factores de cultivo y almacenamiento poscosecha. Para muchos de ellos ya se ha caracterizado en detalle la influencia que ejercen sobre los niveles de los distintos grupos de antioxidantes. Contrariamente, en el caso de otros factores, la información disponible en la literatura es acotada y sumamente fragmentada. Asimismo, en varios casos se observa para un mismo factor resultados opuestos en términos de su influencia en la capacidad antioxidante de los vegetales. Dentro de los factores de cultivo que no han recibido mayor atención a la fecha respecto de su efecto sobre la capacidad antioxidante se destaca una tecnología de uso relativamente reciente como es el empleo de portainjertos en hortalizas. En el área de poscosecha algunos tratamientos empleados para reducir la incidencia y severidad del daño por frío como el acondicionamiento a bajas temperaturas (LTC), tampoco se ha caracterizado con detenimiento la eficacia en distintas variedades de hortalizas y el impacto sobre el nivel de compuestos antioxidantes. Finalmente, en el caso de los tratamientos de irradiación $U V-B$, varios estudios realizados a la fecha han establecido los efectos de la dosis de radiación en el mantenimiento de la calidad y en el nivel de antioxidantes. De todos modos, estudios recientes muestran que más allá de la dosis, la intensidad de radiación es una variable determinante de los efectos metabólicos de este tipo de tratamiento en los vegetales. Esto no ha sido estudiado hasta la fecha en el caso de inflorescencias de brócoli. En el marco de la presente tesis se estudió la influencia que estos factores de cultivo y poscosecha poseen sobre el contenido de compuestos antioxidantes y calidad de berenjena y brócoli. 


\section{OBJETIVOS}

\subsection{Objetivo general}

Determinar la influencia de diferentes factores de pre y poscosecha sobre la calidad, vida poscosecha y contenido de compuestos antioxidantes en hortalizas (berenjena y brócoli).

\subsection{Objetivos específicos}

I- Evaluar la influencia del empleo de portainjertos sobre el crecimiento, morfología, calidad comercial, comportamiento poscosecha y contenido de antioxidantes en berenjena.

II- Determinar el efecto de tratamientos de acondicionamiento a baja temperatura (LTC) sobre la tolerancia al daño por frío y contenido de antioxidantes en berenjena rayada y violeta en dos estados de crecimiento.

III- Evaluar el efecto de la intensidad y dosis de radiación UV-B sobre la calidad visual y retención de compuestos bioactivos de importancia nutricional en brócoli mínimamente procesado.

\subsection{Hipótesis}

I- $\quad$ El uso de portainjertos puede modular el crecimiento, la morfología, calidad y contenido de antioxidantes de frutos de berenjena.

II- $\quad$ El uso de portainjertos afecta el comportamiento poscosecha y la estabilidad de compuestos antioxidantes en berenjena y mejora la tolerancia al daño por frío.

III- El acondicionamiento a baja temperatura (LTC) reduce la incidencia y severidad del daño por frío en berenjena y mejora la retención de compuestos antioxidantes, siendo la eficacia de los tratamientos dependiente del genotipo y estado de crecimiento considerados.

$I V$ - Las condiciones de irradiación UV-B (intensidad y dosis) afectan marcadamente la eficacia de este tipo de tratamientos para retrasar la senescencia e incrementar la capacidad antioxidante en brócoli mínimamente procesado. 


\section{Capítulo I}

Efecto del empleo de portainjertos sobre el crecimiento, morfología, calidad y contenido de antioxidantes en berenjena. 


\section{I.1. INTRODUCCIÓN}

\subsection{Berenjena}

\subsubsection{Origen y variedades}

La berenjena es originaria del sudoeste de Asia, principalmente India y China. Esta región se reconoce como el centro de diversidad primario de la especie Solanum melongena (Prohens y col., 2005; Frary y col., 2007). Pertenece a la familia de las Solanáceas, al igual que el tomate, papa y pimiento. Los frutos más difundidos comercialmente son los de variedades violetas de tamaño grande y piriforme. De todos modos, existe dentro de la especie una gran diversidad en cuanto a forma, tamaño, color (Prohens y col., 2005; Mohammed y Brecht, 2003; Knnap y col., 2013).

Cantwell y Suslow (2000) clasificaron a los tipos comerciales de berenjena (Figura I.1) en:

a) Blanca: frutos comúnmente de tamaño medio pequeños y de forma ovalada o globular, que presentan piel delgada y clara.

b) Rayada: frutos caracterizados por presentar forma ovalada y piel de color de fondo blanco cubierto por estrechas líneas violetas.

c) Violeta o Americana: frutos de forma ovalada o globosa, firmes, con piel de color violeta oscuro.

d) Japonesa: frutos largos y delgados, de color púrpura claro a oscuro y altamente perecederas.

e) China: variedad de frutos oblongos y delgados, de color púrpura claro.

f) Mini-Japonesa: pequeña, redonda y con vetas de diferentes tonalidades entre el púrpura y violeta.

g)

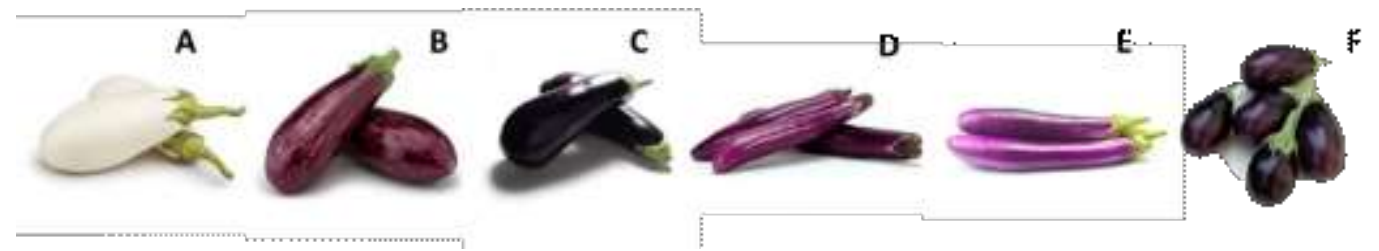

Figura I.1. Clasificación de berenjena por tipos comerciales A) blanca, B) rayada, C) violeta, D) japonesa, E) china, F) mini-japonesa. 


\subsubsection{Producción}

Se ubica en tercer lugar dentro de la familia de las Solanáceas luego de la papa y el tomate. La producción mundial supera los 50 millones de Tn producidos en una superficie de casi 2 millones de ha. China es el principal productor aportando el $60 \%$ de la producción mundial con casi 30 millones de Tn, seguida por India, Egipto y Turquía (FAOSTAT, 2014) que producen 13,5, 1,200 y 0,83 millones de Tn, respectivamente. En nuestro país, se cultiva a campo en una superficie de aproximadamente 1.254 ha y bajo invernadero 29 ha. Las principales provincias productoras son: Buenos Aires (23\%), Santa Fé (17 \%), Salta (17,5 \%), Córdoba (7,5 \%) y Jujuy, Mendoza y Formosa (10 \%) (Censo Nacional Agropecuario, 2002), y conforman los principales cinturones hortícolas del país y abastecen al mercado casi todo el año desde las distintas regiones.

\subsubsection{Morfología}

De acuerdo a su descripción botánica es una planta perenne que se cultiva como anual dado que decae bruscamente su rendimiento año a año, herbácea, de aspecto arbustivo con sistema radical muy desarrollado y varios tallos secundarios erectos pubescentes que pueden alcanzar una altura de hasta 2,5 $\mathrm{m}$ de crecimiento indeterminado. Posee hojas simples alternas ovadas, de borde entero con pubescencia grisácea en el envés. Flores violáceas muy vistosas con 6-9 pétalos (Zaro y col., 2015b). Tanto el pedúnculo como el cáliz pueden poseer espinas dependiendo de las variedades. La mayor parte de las variedades florecen en ramilletes de tres a cinco flores, una de las cuales es hermafrodita y de pedúnculo corto y continuo desde el tallo hasta el cáliz, y da lugar a un fruto comercial, mientras que el resto de las flores abortan o dan lugar a un fruto pequeño y de menor calidad. La planta es principalmente autógama (Daunay y col., 2001). Normalmente la primera flor aparece en el vértice de la primera bifurcación o tallo principal de la planta. El fruto es una baya alargada o globosa de color negro, morado, blanco, blanco jaspeado, morado o verde. Presenta pequeñas semillas de color amarillo muy pequeñas, en un gramo pueden contarse 250 semillas que poseen un poder germinativo de 4 a 6 años (Sekara y col., 2007). La parte comestible incluye toda la baya, es decir el tejido placentario y semillas de la pulpa, y la piel.

\subsubsection{Valor nutricional}

La berenjena es una hortaliza con un elevado contenido en agua y por lo tanto, un bajo contenido en calorías, proteínas y lípidos. Contiene cantidades apreciables de 
carbohidratos, fibras, vitamina A, ácido ascórbico, niacina, riboflavina y tiamina (Tabla I.1), además de algunos minerales como calcio, fósforo, hierro, sodio y potasio (Lorenz y Maynard, 1998). Además, presenta un elevado nivel de compuestos antioxidantes ubicandose dentro de las 10 hortalizas más ricas en estos compuestos.

Tabla I.1.Composición de berenjena Solunum melongena L. cada $100 \mathrm{~g}$ de producto (USDA, 2018).

\begin{tabular}{|c|c|c|c|c|c|c|c|}
\hline \multicolumn{2}{|c|}{ Macrocomponentes } & \multicolumn{2}{|c|}{ Minerales } & \multicolumn{2}{|l|}{ Vitaminas } & \multicolumn{2}{|l|}{ Lípidos } \\
\hline $\operatorname{Agua}(g)$ & 92,30 & Calcio (mg) & 9 & $\begin{array}{c}\text { Vitamina } C \\
(m g)\end{array}$ & 2.2 & Saturados (g) & 0,03 \\
\hline Energía (kcal) & 25 & Hierro (mg) & 0,2 & Tiamina (mg) & 0,04 & Monoinsat.) & 0,02 \\
\hline Proteína (g) & 0,98 & $\begin{array}{l}\text { Magnesio } \\
\quad(m g)\end{array}$ & 14 & $\begin{array}{l}\text { Riboflavina } \\
\text { (mg) }\end{array}$ & 0,04 & Poliinsat.(g) & 0,08 \\
\hline Lipidos totales (g) & 0,18 & Fosforo (mg) & 24 & Niacina $(m g)$ & 0,65 & $\begin{array}{c}\text { Grasas trans } \\
(\mathrm{g})\end{array}$ & 0 \\
\hline $\begin{array}{l}\text { Hidratos de } \\
\text { carbono (g) }\end{array}$ & 5,88 & Potasio (mg) & 229 & $\begin{array}{c}\text { Vitamina B6 } \\
(\mathrm{mg})\end{array}$ & 0,08 & $\begin{array}{l}\text { Colesterol } \\
\text { (mg) }\end{array}$ & 0 \\
\hline Fibra $(g)$ & 3,0 & Sodio (mg) & 2 & Folatos $(\mu g)$ & 22 & & \\
\hline \multirow[t]{3}{*}{ Azúcares totales (g) } & 3,5 & Zinc $(m g)$ & 0,16 & Vitamina $A(\mu g)$ & 1 & & \\
\hline & & & & Vitamina $E(\mu g)$ & 0,3 & & \\
\hline & & & & $\begin{array}{c}\text { Vitamina } K \\
(\mu g)\end{array}$ & 3,5 & & \\
\hline
\end{tabular}

\subsubsection{Antioxidantes}

Estos frutos no son particularmente ricos en ácido ascórbico (400-700 mg/kg peso seco) (Zaro y col., 2014) o carotenoides (40-100 mg/kg peso seco) (El-Qudah., 2009). Por el contrario, se considera que la berenjena es una excelente fuente de compuestos fenólicos (Gürbüz y col., 2018). Varios estudios han demostrado que la berenjena tiene un contenido fenólico diverso y una elevada variabilidad entre genotipos (Okmen y col., 2009; Mennella y col., 2012; Prohens y col., 2013; Kaur y col., 2014). De todos modos, comúnmente existen dos grupos de compuestos que se destacan, las antocianinas y los ésteres del ácido cafeico y quínico, principalmente el ácido clorogénico (Cao y col., 1996). El contenido de componentes fenólicos totales en variedades silvestres suele, en muchos casos, ser superior al de los cultivares comerciales (Prohens y col., 2007; Raigon y col., 2010; Prohens y col., 2013).

El ácido clorogénico (ACG) es alto en las primeras etapas de desarrollo (20 g/kg de peso seco) y disminuye en un $50 \%$ al tamaño de cosecha comercial ( $80 \%$ de tamaño completo) (Zaro y col., 2014b). 
Las tonalidades violetas de la piel de las variedades oscuras son impartidas principalmente por antocianinas de tipo delfinidina (Matsuzoe y col., 1999). Estudios previos demostraron que los cultivares violeta oscuro pueden diferir en la antocianina principal: en algunos casos predomina la delfinidina-3-( $p$-cumaril-rutinosido)-5glucósido (nasunina o NAS), mientras que en otras variedades está presente en concentraciones más altas la delfinidina-3-rutinósido (D3R o tulipanina) (Matsubara y col., 2005; Wu y Prior, 2005). Las antocianinas se ubican solamente en la piel en niveles de 0 a $850 \mathrm{mg} / \mathrm{kg}$, dependiendo entre otros de la variedad, intensidad de radiación, temperatura, condiciones de almacenamiento y procesamiento (Dranca y Oroian, 2016). A diferencia de otros frutos que acumulan antocianinas, en las que los pigmentos surgen al final del desarrollo (manzana, frutilla), en berenjena de etapas ontogénicas muy tempranas las antocianinas ya alcanzan un $70 \%$ de la concentración máxima (Zaro y col., 2014). Por ello frutos muy pequeños ya presentan su característica tonalidad violeta oscura y el color no puede emplearse como un indicador de madurez como en otras especies frutihortícolas.

\subsubsection{Manejo del cultivo}

La berenjena (Solanum melongena L.) es una de las Solanáceas que más se cultiva en el Cinturón Hortícola de La Plata (CHLP) luego del tomate y pimiento, se realiza en general bajo invernadero, con riego por goteo y fertilización en el mismo sistema. Es un cultivo de clima cálido y seco, por lo que se considera uno de los más exigentes en calor incluso más que el tomate y el pimiento, ya que puede soportar bien las temperaturas de hasta 40 ${ }^{\circ} \mathrm{C}$. La temperatura media para el cultivo es de $25^{\circ} \mathrm{C}$ (Sekara y col., 2007). La humedad adecuada ronda el $65 \%$, ya que humedades relativas muy elevadas favorecen el desarrollo de enfermedades aéreas como hongos del genero Botrytis sp. y dificultan la fecundación. Cuando la humedad y la temperatura son elevadas se produce una floración deficiente, caída de flores, frutos deformes y disminución del crecimiento. A su vez, la berenjena es muy sensible al clima frío, por lo que el cultivo expuesto a bajas temperaturas no será del todo eficiente en términos productivos. En las estaciones frías, la floración, fertilidad y fructificación se ven gravemente afectadas (Nothmann y Koller, 1975). Con temperaturas entre $10-12^{\circ} \mathrm{C}$, el crecimiento se detiene y la floración y fructificación están notablemente comprometidas (Zaro y col., 2015b), lo que acota el período de producción a la primavera, verano y otoño, al menos en zonas donde las temperaturas invernales son bajas como es el caso del CHLP. 
Es una planta muy exigente en luz, ya que requiere entre 10-12 h, por lo que en otoñoinvierno donde los días son cortos suelen ocurrir aborto de flores y mayor desarrollo vegetativo. En suelos es poco exigente debido a su potente sistema radicular, aunque los suelos francos y profundos son los más adecuados. Presenta dificultades de crecimiento en suelos ácidos y salinos (Nothmann, 1986).

\subsubsection{Cosecha}

Las berenjenas se cosechan fisiológicamente inmaduras y antes de que la semilla alcance su completo desarrollo (Gajewski y Arasimowicz, 2004; Anónimo, 2011). En general, se recolectan cuando alcanzan aproximadamente el $80 \%$ de su tamaño final (Mohammed y Brecht, 2003), aunque los índices de cosecha son principalmente el tamaño, la forma, la apariencia externa, la firmeza, el color y el brillo. También se considera deseable que la pulpa muestre color uniforme, claro y semillas pequeñas (Mangione y Sanchez, 1999; Siller-Cepeda, 2004) y que el cáliz y pedúnculo se encuentren presentes y muestren aspecto fresco y color verde. La cosecha se hace de forma manual y escalonada en la medida que los frutos alcanzan el tamaño deseado. El tiempo requerido desde la floración hasta que los frutos alcanzan el tamaño comercial es de alrededor 15-35 días, dependiendo de la variedad, la temperatura y la intensidad de luz solar (Uzun, 2007). Sin embargo, las berenjenas pueden recolectarse y consumirse en todos los estados de desarrollo, incluso los más tempranos de acuerdo a las exigencias del mercado (Chen y Li, 1996). En el CHLP el período de cosecha abarca desde noviembre a mayo. Es así que, dicho período se centra en la época de mayor calor en la región, mientras que en los meses extremos en esa ventana de cosecha (noviembre y mayo) predominan las bajas temperaturas que lentifican el crecimiento de los frutos. Sin embargo, son los períodos de mayor valor económico de los mismos debido a la menor oferta en el mercado.

\subsubsection{Poscosecha}

Las berenjenas muestran un comportamiento de tipo no climatérico, con una moderada tasa respiratoria, en el rango de $8-11 \mathrm{~mL} \mathrm{CO}_{2} / \mathrm{kg} \mathrm{h}$ y una baja producción de etileno $(0,1$ $0,7 \mu \mathrm{L} / \mathrm{kg} \mathrm{h}$ ) a $12,5^{\circ} \mathrm{C}$ (Cantwell y Suslow, 2000). A pesar de esto, las berenjenas son sensibles a la presencia de etileno y debe evitarse exponerlas con productos que sí lo generan en mayor cantidad y que pueden estar presentes durante el almacenamiento o transporte. En este sentido, se ha informado que el contacto con etileno disminuye el tiempo de conservación de 14 a 3-5 días (Mangione y Sánchez, 1999). A su vez, cuando 
las berenjenas son expuestas a más de 1 ppm de etileno, puede ocurrir la abscisión del cáliz y pardeamiento (Cantwell y Suslow, 2000; Kader, 2002). Por el contrario, el tratamiento con el inhibidor de la acción del etileno, 1-metil-ciclopropeno (1-MCP), redujo el deterioro de berenjenas almacenadas a $10{ }^{\circ} \mathrm{C}$ y luego transferidas a $20{ }^{\circ} \mathrm{C}$ (Massolo y col., 2011).

Si bien para el control de la actividad respiratoria y extender el período de vida poscosecha, se recomienda la implementación del almacenamiento a bajas temperaturas, (Toivonen, 2011), debe tenerse en cuenta que se trata de frutos susceptibles al daño por frío a temperaturas inferiores a $10^{\circ} \mathrm{C}$ (Concellón y col., 2007). Las berenjenas son incluso más sensibles que los tomates y pimientos (Mohammed y Brecht, 2003). Por esta razón, se recomienda su almacenamiento a temperaturas no inferiores a $10{ }^{\circ} \mathrm{C}$ y $90 \%$ de humedad relativa. En estas condiciones el potencial de almacenamiento de berenjena es de 14-21 días, ya que posteriormente la calidad visual y sensorial comienza a declinar (Cantwell y Suslow, 2000). El enfriamiento a esta temperatura, inmediatamente después de la cosecha, es beneficioso para retardar la decoloración, pérdida de peso, la deshidratación del cáliz y las pudriciones (Kader, 2002).

\subsection{Empleo de la técnica de injertación en el Cinturón Hortícola de La Plata:}

\section{Situación actual y preguntas pendientes}

En el Cinturón Hortícola de La Plata la técnica de injertación se ha incorporado en forma relativamente reciente. Se emplean mayormente en el cultivo de tomate donde crecientemente se observan plantas injertadas sobre pies Maxifort, Beaufort (Monsanto, Seminis), Emperador (Rijk Zwaan). El uso de estos pies ha cobrado interés por los resultados obtenidos en cultivos injertados para la resistencia a nematodos, lo que constituye un problema importante en los suelos del CHLP y por el beneficio de reemplazar el bromuro de metilo. El pimiento (Capsicum annuum) también pueden injertarse, aunque solo sobre pies de variedades o híbridos intraespecíficos de pimiento (Lee y col., 2010) como Capsifort (Monsanto, Seminis), Silver (Sakata), Ultron (H. M. Clause), Creonte (Monsanto, Seminis). Por su parte, la berenjena (Solanum melongena) al igual que el tomate pueden injertarse sobre otras especies e híbridos interespecíficos e incluso especies silvestres no tradicionales (Schwarz y col., 2010; Penella y col., 2013; López-Marín y col., 2013, 2017). Se están empleando portainjertos tales como: Maxifort (Monsanto, Seminis), Java (Takii), Emperador (Rijk Zwaan). En este cultivo se busca acortar el período de crecimiento para adelantar la cosecha y extender el ciclo del cultivo, 
ambos con el objetivo de obtener producción en periodos más fríos en los que el precio de los frutos suele ser más elevado. Si bien mucho menos que en tomate, en la literatura existen algunos trabajos que evalúan el empleo de portainjertos en berenjena. El portainjerto para cultivo de berenjena más reportado es el híbrido Solanum torvum, otros portainjertos potenciales incluyen especies silvestres/aliadas de berenjena, $S$. macrocarpon, S. aethiopicum, S. aethiopicum x S. paniculatum y S. indicum (Sabatino y col., 2018). Se han efectuado estudios de compatibilidad de pies en berenjena para determinar si se pueden usar variedades de tomate o incluso solanáceas silvestres como patrones (Leonardi y Giuffrida., 2006; Gisbert y col., 2011). También se ha buscado usar como portainjertos diferentes híbridos interespecíficos para incrementar el vigor y la precocidad (Gisbert y col., 2011). En berenjena injertada sobre portainjerto $S$. melongena cv. Nianmaoquie, resistente a altas temperaturas, se alcanzó un $10 \%$ de incremento en la producción (Wang y col., 2007). Por su parte, pocos estudios han evaluado portainjertos que permitan mejorar la tolerancia a las bajas temperaturas. En esta temática se ha observado que las plantas de berenjena injertada sobre portainjertos de tomate "Taibyo" o "Hiranasu" podían crecer a bajas temperaturas con buen vigor e incremento de la producción (Gao y col, 2006). Los portainjertos de Solanum torvum han mostrado buenos resultados en cuanto a vigor y producción tanto para el cultivo de tomate como de berenjena a baja temperatura (Okimura y col., 1986).

El aumento en el número de publicaciones referidas al empleo de plantas injertadas en especies hortícolas pone en evidencia el renovado interés en esta técnica. De todos modos, la mayor parte de los estudios han focalizado en aspectos de cultivo siendo muy escasa la información referida a los efectos que posee sobre el producto, su fisiología, morfología, calidad y comportamiento poscosecha. Estos aspectos deben ser aún estudiados ya que por el momento la limitada información disponible al respecto proviene mayoritariamente de las empresas proveedoras de plantas injertadas. Con respecto al impacto del empleo de plantas injertadas en los niveles de compuestos antioxidantes en berenjena prácticamente no existen estudios. Por ello el objetivo de este capítulo es: "evaluar la influencia del empleo de portainjertos sobre el crecimiento, morfología, calidad comercial, comportamiento poscosecha y contenido de antioxidantes en berenjena". 


\section{I.2. MATERIALES Y MÉTODOS}

\subsection{Material vegetal}

Se emplearon frutos de berenjenas violetas (Solanum melongena L.) cv. Monarca, provenientes de plantas injertadas a bisel sobre dos pies:

-Maxifort (Monsanto, Seminis, Suiza): variedad de tomate recomendada comercialmente por su capacidad para mejorar la tolerancia a algunas enfermedades, aumentar el vigor de planta e incrementar el comportamiento al frío.

-Java (Takii, Japón): es una Solanácea híbrida interespecífica de berenjena silvestre (Solanum sp.) Se la recomienda comercialmente por su capacidad para incrementar la precocidad, aumentar la producción y calidad y el comportamiento a baja temperatura. Asimismo, se informa que posee buen comportamiento frente a Verticillium sp y Fusarium sp.

Como controles se usaron plantas de la misma variedad sin injertar (pie franco) y ubicadas dentro del mismo invernadero. Las plantas fueron cultivadas en dos invernaderos de la ciudad de La Plata (Buenos Aires, Argentina), cuyos períodos de cosecha fueron los meses de Noviembre y Abril. El riego y la fertilización se realizaron por goteo dos veces por día, por la mañana y por la tarde. Se trabajó con plantas injertadas y control localizadas en 5 o 6 surcos de la zona media del invernadero. Se efectuó una curva de crecimiento y cosecha de los frutos como se detalla a continuación:

- Curva de crecimiento: se marcaron 100 frutos recién cuajados con cintas de tela de color, considerando a éste como día 0. A los 9, 19, 21 y 24 días luego del cuajado ("Day After Fruit Set", DAFS), se midió la longitud de los frutos de cada combinación portainjertovariedad y sus respectivos controles. Se efectuaron tres marcaciones independientes de frutos, durante el mes de febrero.

- Cosecha: los frutos control y de plantas injertadas se cosecharon en tres estados de crecimiento teniendo en cuenta su longitud: a) de $9 \mathrm{~cm}$, estado I (E1) o "baby", b) de 17 cm, estado II (E2) o comercial, c) de $19 \mathrm{~cm}$, estado III (E3) o sobremaduro. Se cosecharon 150 frutos, para cada estado de crecimiento y combinación portainjerto-variedad y se trasladaron inmediatamente al laboratorio. Los frutos se clasificaron por tamaño, se seleccionaron aquellos libres de defectos, y se lavaron con agua clorada.

Se determinó el calibre, tamaño y peso de los frutos. Se evaluó la tasa respiratoria, contenido de materia seca, color de piel y firmeza. Se obtuvieron secciones transversales 
de $5 \mathrm{~mm}$ de espesor de la zona ecuatorial de los frutos, se fotografiaron, y posteriormente se realizó un análisis de imágenes utilizando un software específico (Image J, Estados Unidos) a fin de determinar el tamaño y el número de semillas. Por último, muestras de las secciones transversales de $1 \mathrm{~cm}$ de espesor de la zona ecuatorial de los frutos, se cortaron en cuartos, se congelaron en nitrógeno líquido, y se almacenaron en freezer a $80{ }^{\circ} \mathrm{C}$ para realizar el análisis del contenido de antioxidantes totales, fenoles totales, y ácido clorogénico (en piel y pulpa), y antocianinas en la piel. Las determinaciones se realizaron como se describe a continuación.

\subsection{Determinaciones analíticas}

\subsubsection{Longitud y diámetro de los frutos}

Se determinó la longitud con una cinta métrica y el diámetro de la zona ecuatorial con un calibre. Las mediciones se realizaron en 20 frutos para cada estado de crecimiento y combinación portainjerto-variedad.

\subsubsection{Tasa respiratoria}

Se colocaron los frutos en un contenedor de vidrio hermético de $3 \mathrm{~L}$ de capacidad, y la producción de $\mathrm{CO}_{2}$ se determinó con un sensor infrarrojo IR (Compu-Flow, Modelo 8650, Alnor CA, Estados Unidos) al inicio y luego de trascurridos $10 \mathrm{~min}$ a $20{ }^{\circ} \mathrm{C}$. Los resultados se expresaron como $\mathrm{mg} \mathrm{CO} / \mathrm{kg} \mathrm{h}$. Se realizaron cuatro repeticiones para los frutos de cada estado de crecimiento y combinación portainjerto-variedad.

\subsubsection{Materia seca}

Se tomaron aproximadamente $2 \mathrm{~g}$ de pulpa de frutos de la zona ecuatorial y se llevaron a estufa a $105^{\circ} \mathrm{C}$ hasta peso constante. El contenido de materia seca (MS) se calculó por diferencia de peso según:

$$
\operatorname{MS}(\%)=100 \times\left(\frac{P i-P f}{P i}\right)
$$

Siendo Pi el peso inicial de la muestra y Pf el peso final. Los resultados se expresaron como porcentaje de materia seca y las determinaciones se realizaron por triplicado para los frutos de cada estado de crecimiento y combinación portainjerto-variedad. 


\subsubsection{Color superficial}

Se evaluó el color en la piel de los frutos de berenjena empleando un colorímetro

(Minolta, Modelo CR-400, Osaka, Japón) obteniendo los parámetros L*, a* y b*. Se analizaron 16 frutos para cada estado de crecimiento y combinación portainjerto-variedad y cada fruto se midió en tres zonas diferentes.

\subsubsection{Resistencia a la compresión (RC)}

Se realizó un ensayo de penetración a $8 \mathrm{~mm}$ de profundidad y velocidad de $1 \mathrm{~mm} / \mathrm{s}$ de la zona ecuatorial del fruto de berenjena colocado en sentido horizontal al eje longitudinal. Se empleó un texturómetro (Texture Analyzer -TA.XT2, Reino Unido) equipado con una sonda plana de $3 \mathrm{~mm}$ de diámetro. Se calculó la resistencia a la compresión (RC, pendiente) en la gráfica de fuerza vs distancia. Los resultados se expresaron en N/mm. Se analizaron 16 frutos para cada estado de crecimiento y combinación portainjertovariedad.

\subsubsection{Número y tamaño de semillas}

Se cortaron los frutos en forma transversal al eje principal en la zona ecuatorial de los frutos. Cada rodaja se dejó pardear durante 30 min y se escaneó en un equipo HP F4480, (Estados Unidos). Los archivos obtenidos se analizaron empleando el Software Image J. Se determinó la cantidad de semillas y el tamaño o área $\left(\mathrm{cm}^{2}\right)$ de las mismas. Las imágenes de las rodajas ya escaneadas se introdujeron al programa, se pasaron a un sistema binario, tal como se muestra en la Figura I.2, para luego aplicarse filtros para reducir el error en las mediciones realizadas por el programa. Se utilizaron 10 frutos de cada estado de crecimiento y combinación portainjerto-variedad.

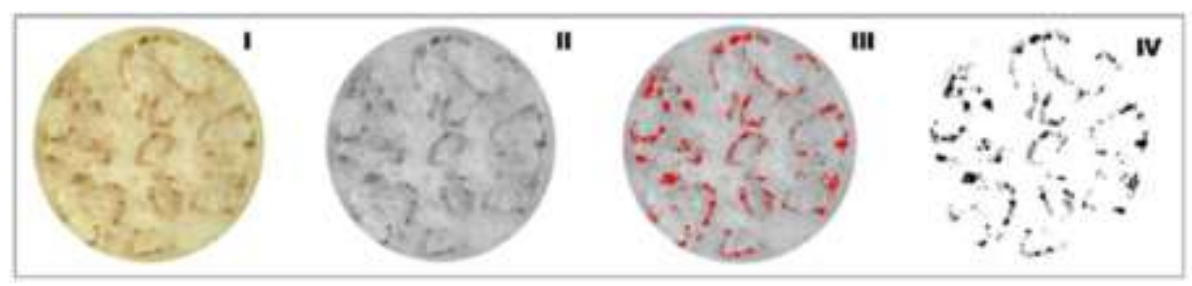

Figura I.2. Secuencia del procesamiento de imágenes de frutos de berenjena (I), en sistema binario (II), en imagen filtrada (III) y en escala de grises (IV) para realizar un análisis morfológico digital.

\subsection{Compuestos antioxidantes}




\subsubsection{Extracción en etanol de compuestos antioxidantes}

Muestras de piel y pulpa congeladas en nitrógeno líquido se trituraron en un molinillo (Peabody, PE-MC9100, China) por separado. Se pesaron 0,5 g de piel o $1 \mathrm{~g}$ de pulpa, y se añadieron $5 \mathrm{~mL}$ de etanol. Se realizaron dos extracciones consecutivas empleando tres ciclos de agitación en vortex: reposo de 1:3 min. La suspensión se centrifugó a 13.000 × $g$ por 10 min a $4{ }^{\circ} \mathrm{C}$ (Sorvall ST 16R, Estados Unidos). Los extractos se emplearon para determinar el contenido de ácido clorogénico, fenoles totales y capacidad antioxidante tanto de piel como de pulpa.

\subsubsection{Compuestos fenólicos}

El contenido de compuestos fenólicos se determinó de acuerdo a Singleton y col. (1999), empleando el reactivo de Folin- Ciocalteu. Para ello, se tomaron $50 \mu \mathrm{L}$ de reactivo diluído $(1: 1 \mathrm{v} / \mathrm{v}$ en agua) y se agregaron a tubos de ensayo conteniendo $100 \mu \mathrm{L}$ de extracto etanólico preparados como se detalló en la sección 3.3.1 y $750 \mu \mathrm{L}$ de agua. Luego de 3 min de reacción a temperatura ambiente se añadieron $100 \mu \mathrm{L}$ de $\mathrm{Na}_{2} \mathrm{CO}_{3} 20 \%(\mathrm{p} / \mathrm{v})$ en $\mathrm{NaOH}$ 0,1 M y $1000 \mu \mathrm{L}$ de agua destilada. La mezcla de reacción se agitó y se incubó durante 90 min en oscuridad y a temperatura ambiente. Finalmente, se midió la absorbancia a $760 \mathrm{~nm}$ en espectrofotómetro (Hitachi U-1900, Japón). El contenido de compuestos fenólicos se calculó utilizando ácido clorogénico (ACG) como estándar. Se prepararon dos extractos para cada estado de crecimiento y combinación portainjertovariedad y cada uno se determinó por triplicado. Los resultados se expresaron como mg $\mathrm{ACG} / \mathrm{kg}$ de peso fresco.

\subsubsection{Capacidad antioxidante (TEAC)}

La determinación se realizó de acuerdo a Arnao y col. (2001). Los extractos se realizaron como se describe en la sección 3.3.1. La solución madre del catión-radical ácido 2,2'azino-bis- (3-etilbenzotiazolin) - 6-sulfónico $\left(\mathrm{ABTS}^{\bullet+}\right.$ ) se preparó pesando $7 \mathrm{mmol} \mathrm{de}$ la sal de amonio de ABTS y 2,45 mmol de persulfato de potasio $\left(\mathrm{K}_{2} \mathrm{~S}_{2} \mathrm{O}_{8}\right)$ en $1000 \mathrm{~mL}$ de agua, se dejó reaccionar 12-16 h en oscuridad a temperatura ambiente. Para el estudio en las muestras, la solución madre fue diluida en etanol hasta obtener una absorbancia de $0,700 \pm 0,02$ medida a $734 \mathrm{~nm}$ en espectrofotómetro. A $1 \mathrm{~mL}$ de esta solución del ión radical $\mathrm{ABTS}^{\bullet+}$ se le adicionaron $20 \mu \mathrm{L}$ del extracto etanólico y $30 \mu \mathrm{L}$ de etanol. La mezcla se dejó reaccionar 6 min y se leyó la absorbancia a $734 \mathrm{~nm}$. Se utilizó Trolox como patrón. Se realizaron tres replicados por cada estado de crecimiento y combinación 
portainjerto-variedad. Los resultados se expresaron como Capacidad Antioxidante Equivalente a Trolox (TEAC) en $\mathrm{mg} / \mathrm{kg}$ de peso fresco.

\subsection{4. Ácido clorogénico (ACG)}

Se determinó espectrofotométricamente a $330 \mathrm{~nm}$ de acuerdo a Luthria (2006) considerando una absortividad molar de 27.025 1/M.cm. Se empleó ACG como patrón. Los extractos se realizaron como se describe en la sección 2.3.1. Se realizaron tres replicados por cada estado de crecimiento y combinación portainjerto-variedad. Los resultados se expresaron en $\mathrm{mg} \mathrm{ACG} / \mathrm{kg}$ de peso fresco.

\subsubsection{Antocianinas}

La extracción y cuantificación de antocianinas de la piel de los frutos se realizó de acuerdo a Concellón y col. (2007) con ligeras modificaciones. Los frutos se pelaron con bisturí y la piel se congeló en nitrógeno líquido y pulverizó en molinillo, se pesaron $0,5 \mathrm{~g}$ y se extrajeron los pigmentos con $10 \mathrm{~mL}$ de metanol: $\mathrm{HCl}(99: 1 \mathrm{v} / \mathrm{v}) 4$ veces consecutivas, se centrifugó a $13.000 \times$ g 10 min a $4{ }^{\circ} \mathrm{C}$ (Sorvall ST 16R). Los sobrenadantes se llevaron a un volumen de $50 \mathrm{~mL}$. Se midió la absorbancia a $540 \mathrm{~nm}$ usando un espectrofotómetro. Las medidas fueron realizadas por duplicado por cada estado de crecimiento y combinación portainjerto-variedad. Considerando una absortividad molar de 29.000 1/M.cm, los resultados se expresaron en equivalentes de delfidina-3-glucósido en $\mathrm{mg} / \mathrm{kg}$ de peso fresco según Saldilova y col. (2006).

\subsection{Análisis estadístico}

Los experimentos se realizaron de acuerdo a un diseño factorial siendo los factores (control o injertado) y el estado de crecimiento (E1, E2 y E3). Cada combinación portainjerto-variedad se analizó con su respectivo control en forma separada. Se verificó el cumplimiento de los criterios de homogeneidad de varianza y normalidad. Los datos se analizaron por medio de ANOVA. Las medias fueron comparadas por el test LSD de Fisher a fin de determinar las diferencias mínimas significativas con un nivel de significancia de $\mathrm{P}<0,05$. Para ello se empleó el software INFOSTAT (Universidad Nacional de Córdoba, Argentina). 


\section{I.3. RESULTADOS Y DISCUSIÓN}

\subsection{Apariencia de los frutos}

En la Figura I.3 se observa la apariencia de los frutos de berenjena provenientes de plantas control (pie franco, sin injertar) e injertadas sobre el pie Maxifort y Java cosechadas según su longitud en tres estados de crecimiento: E1, E2, E3.

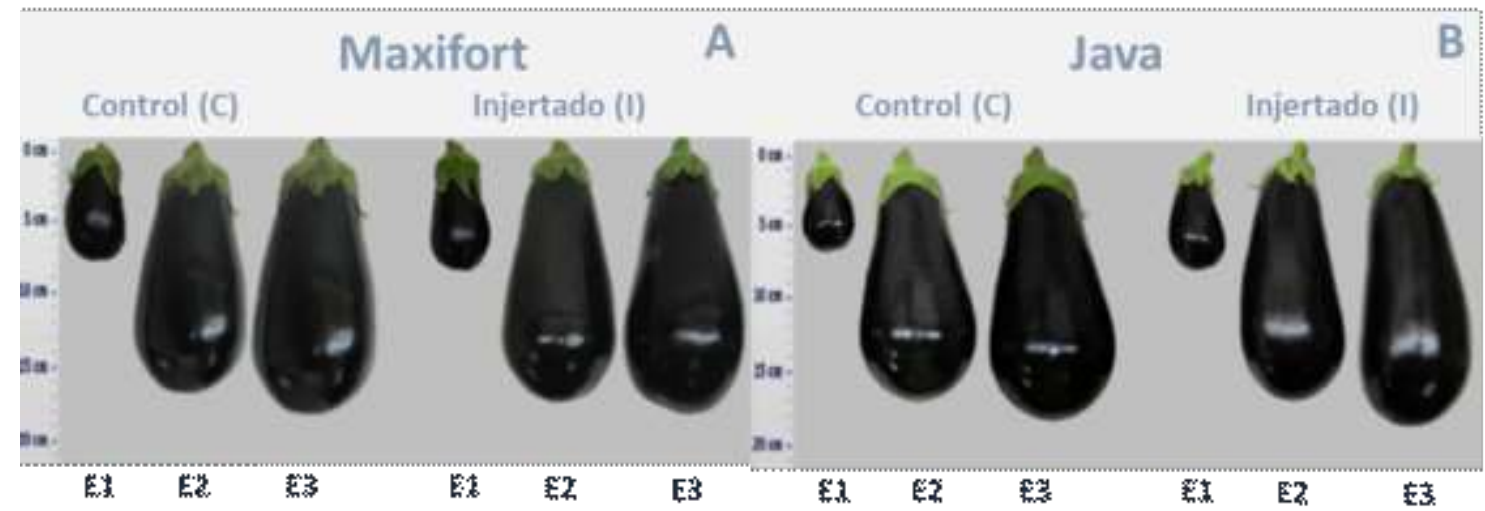

Figura I.3. Frutos de berenjena violeta provenientes de plantas control (C) e injertadas (I) sobre A) pie Maxifort, B) pie Java en tres estados de crecimiento: estado 1 (E1): 9 cm ("baby"), estado 2 (E2): $17 \mathrm{~cm}$ (comercial), estado 3 (E3): $19 \mathrm{~cm}$ (sobremaduro).

Los frutos provenientes de ambas combinaciones de plantas injertadas en E1 no mostraron diferencias morfológicas en cuanto a peso y diámetro respecto a sus controles, aunque la combinación Java-Monarca presentó frutos de menor diámetro o más delgados (Tabla I.1). Para los E2 y E3, los frutos injertados presentaron diferencias morfológicas con sus controles; siendo los provenientes del portainjerto Maxifort frutos más delgados y livianos para una misma longitud. Por su parte los procedentes del pie Java, presentaron también menor diámetro, aunque en este caso el peso no difirió respecto a su control. En los frutos de berenjenas injertadas sobre el pie Java la relación largo/ancho fue un $5 \%$ mayor respecto de los frutos control. Las berenjenas injertadas sobre Maxifort aumentaron esta relación un $45 \%$ más que los frutos controles, lo que significaría que los frutos injertados crecieron en mayor proporción en longitud que en diámetro. Trabajos previos que evaluaban la influencia de la injertación en el tamaño y morfología de los frutos no encontraron diferencias evidentes (Khah, 2012; Cassaniti y col., 2011; Gisbert y col., 2011; Sabatino y col., 2016). En contraposición, en nuestro trabajo se observó una tendencia de los frutos de plantas injertadas a ser más delgados para una misma longitud final. Si bien a priori esto podría deberse a diferencias en la división y expansión celular, sobre todo en frutos E3 en el que predomina el crecimiento celular. Esto implicaría una 
mayor expansión de las células en dirección al eje principal de los frutos por sobre el aumento de tamaño en sentido transversal, aspecto que podría confirmarse por observaciones microscópicas de los tejidos. Más allá del mecanismo involucrado los resultados sugieren que el empleo de los portainjertos evaluados en el presente estudio favoreció el crecimiento longitudinal por sobre el transversal. Estas diferencias fueron significativas en E3 para Maxifort-Monarca y en E2 para Java-Monarca

Tabla I.2 Longitud, diámetro y peso de frutos de berenjena violeta provenientes de plantas control (C) e injertadas (I) con pie Maxifort, y pie Java en tres estados de crecimiento: estado 1 (E1): 9 cm ("baby"), estado 2 (E2): $17 \mathrm{~cm}$ (comercial), estado 3 (E3): $19 \mathrm{~cm}$ (sobremaduro). Letras distintas, para un mismo portainjerto, indican diferencias significativas según el test LSD de Fisher con un nivel de significancia de $\mathrm{P}<0,05$.

\begin{tabular}{|c|c|c|c|c|c|}
\hline & \multirow[b]{2}{*}{ Estado } & \multicolumn{2}{|c|}{ MAXIFORT } & \multicolumn{2}{|c|}{$J A V A$} \\
\hline & & $C$ & $I$ & $C$ & $I$ \\
\hline \multirow[t]{3}{*}{ Longitud (cm) } & E1 & $8,63 \mathbf{c}$ & $8,92 \mathbf{c}$ & $9,23 \mathbf{e}$ & $9,06 \mathbf{e}$ \\
\hline & E2 & $17,37 \mathbf{b}$ & $17,34 \mathbf{b}$ & $16,98 \mathbf{d}$ & $17,68 \mathbf{c}$ \\
\hline & E3 & $19,32 \mathbf{a}$ & $19,09^{\mathbf{a}}$ & $19,19 \mathbf{b}$ & $19,89 \mathbf{a}$ \\
\hline \multirow{3}{*}{$\begin{array}{l}\text { Diámetro } \\
\quad(\mathrm{cm})\end{array}$} & E1 & $4,46 \mathbf{d}$ & $4,49 \mathbf{d}$ & $5,19 \mathbf{d}$ & $4,85 \mathbf{e}$ \\
\hline & E2 & $8,04 \mathbf{b c}$ & $7,87 \mathbf{c}$ & $8,28 \mathbf{b}$ & $7,85 \mathbf{c}$ \\
\hline & E3 & $8,83 \mathbf{a}$ & $8,31 \mathbf{b}$ & $9,08 \mathbf{a}$ & $8,65 \mathbf{a}$ \\
\hline \multirow{3}{*}{$\begin{array}{c}\text { Peso } \\
\text { (g) }\end{array}$} & E1 & $65,86 \mathbf{d}$ & $65,97 \mathbf{d}$ & $85,95 \mathrm{c}$ & $77,49 \mathbf{c}$ \\
\hline & E2 & $308,44 \mathbf{b}$ & $267,97 \mathrm{c}$ & $335,02 \mathbf{b}$ & $318,63 \mathbf{b}$ \\
\hline & E3 & $386,24 \mathbf{a}$ & $323,02 \mathbf{b}$ & $433,37 \mathbf{a}$ & $416,98 \mathbf{a}$ \\
\hline
\end{tabular}

\subsection{Tasa de crecimiento}

El crecimiento involucra un incremento irreversible de materia seca o volumen, dando como resultado un aumento cuantitativo del tamaño y peso del fruto (Krug, 1997). El patrón de crecimiento de los frutos depende de la especie; así los frutos de muchas especies muestran un comportamiento del tipo sigmoide simple (Casierra-Posada y col. 2009); en cambio la mayoría de las especies de carozo son del tipo doble sigmoidea (Coombe, 1976; Casierra-Posada y col., 2007). En el caso de los frutos cítricos la forma dependerá de su origen, si es partenocárpico o sexual, pero en general es una curva sigmoidea (Agustí, 2000). En la Figura I.4 se muestra el crecimiento de los frutos entre los días 8 y 24 luego de la fructificación o DAFS. 


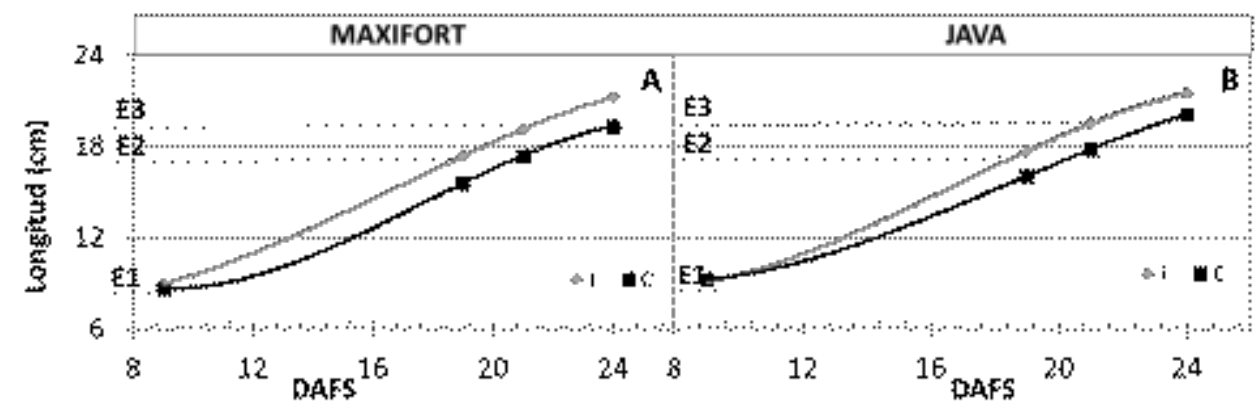

Figura I.4. Curvas de crecimiento de frutos de berenjena provenientes de plantas control (C) e injertadas (I) sobre pie Maxifort y Java, en tres estados de crecimiento: E1 $(9 \mathrm{~cm})$, E2 $(17 \mathrm{~cm})$ y E3 $(19 \mathrm{~cm})$.

En las dos combinaciones portainjerto-variedad estudiadas se observó que la tasa de crecimiento fue mayor para los frutos injertados que para los frutos control. Gisbert y col. (2011) encontraron que el portainjerto híbrido interespecífico de berenjena $S$. melongena con Solanum incanum L. le confirió mayor vigor al vástago, lo que resultó en mayor rendimiento y precocidad de la fruta. También, cultivares de berenjena (Birgah, Black Bell, Black Moon y Longo) sobre portainjertos de especies taxonómicamente cercanas, como Solanum torvum, tuvieron alto vigor y precocidad de la fruta. Este aspecto ya ha sido mencionado en la literatura para tomate, en los cuales también se había empleado el portainjertos Maxifort (Vreck y col., 2011; Petran y col., 2014; Schwarz y col., 2013). En el caso de Java, la información es mucho más limitada. Particularmente para berenjena prácticamente no existen antecedentes sobre los efectos que causan estos portainjertos en la velocidad de crecimiento de los frutos. Para ambos portainjertos, se observó que, durante el período de crecimiento de 16 días analizado, los frutos de plantas injertadas mostraron cerca de $2 \mathrm{~cm}$ más de crecimiento en longitud que los controles. Los mecanismos que sustentan el mayor crecimiento de los frutos en plantas injertadas pueden basarse en un mayor desarrollo radicular que permite un mejor aprovechamiento de recursos (ej. nutrientes, agua) (Haroldsen y col., 2012). De todos modos estudios más recientes muestran que la fisiología de las plantas injertadas implica modificaciones mucho más profundas que incluyen entre otros la regulación de la expersion génica de la copa por parte de la variedad indepedientemente de las variaciones en el aporte de nutrientes o agua que pudieran existir al modificarse el sistema radicular (Cutting y Lyne, 1993; Aloni y col., 2010). Determinar esto en las combinaciones ensayadas requeriría de la realización de estudios básicos al respecto que exceden los objetivos planteados en la presente tesis, pero sin duda sería de sumo interés. Más allá de esto, los resultados indican que tanto Java como Maxifort aumentan la velocidad de crecimiento de frutos cuando se emplean en la injertación de plantas de berenjena. Esto es sin duda 
una ventaja, ya que teniendo presente que los frutos de berenjena se cosechan por tamaño, la mayor velocidad de crecimiento se traduce en un adelanto del momento de cosecha que para el estado E2 representaría unos 4 días.

\subsection{Tasa respiratoria}

La respiración de los frutos de berenjena varía dependiendo de la variedad, y etapa de crecimiento (Zaro y col., 2014). Por ser un fruto no climatérico es de esperar una reducción en la tasa respiratoria (TR) conforme progresa la maduración. Tal como se observó en berenjena control e injertada sobre Maxifort y Java (Figura I.5). Esto ha sido observado también por Makrogianni y col. (2017). De todos modos, no se conoce si el empleo de plantas injertadas afecta la tasa metabólica. Los resultados presentados en la Figura I.5 muestran que los frutos provenientes de plantas injertadas mostraron una menor TR que los controles. Esta tendencia fue consistente tanto para Maxifort como para Java. A excepción del E2 para Maxifort, en los restantes muestreos realizados las diferencias fueron sustanciales y alcanzaron reducciones de entre 50 y $90 \%$ en la TR para los frutos injertados respecto de su control.

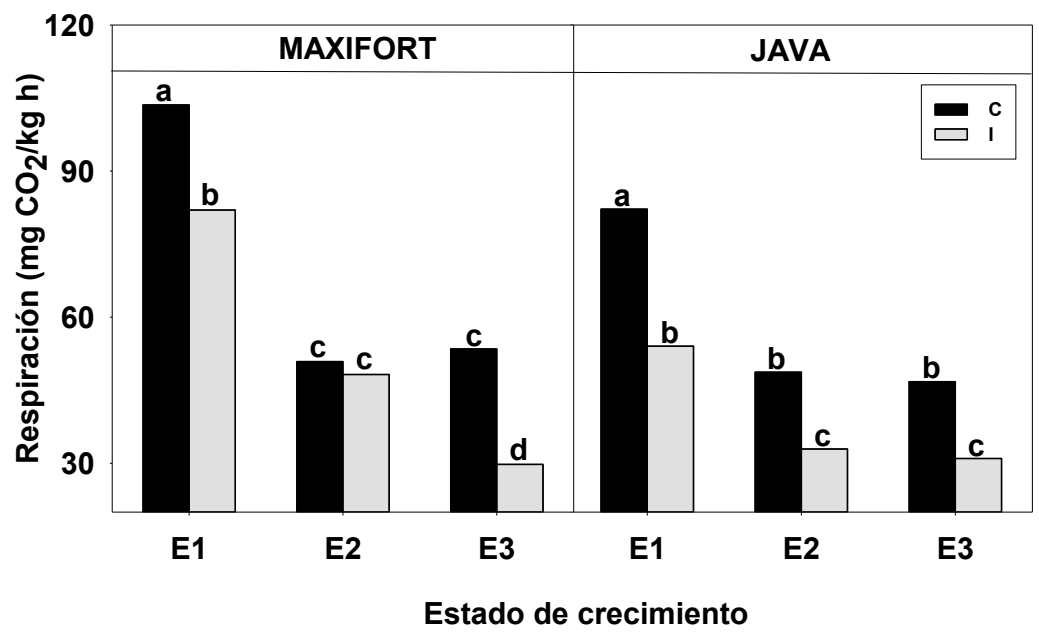

Figura I.5. Tasa respiratoria de frutos de berenjena violeta provenientes de plantas control (C) e injertadas (I) sobre pie Maxifort y pie Java, en tres estados de crecimiento: estado 1 (E1): 9 cm ("baby"), estado 2 (E2): $17 \mathrm{~cm}$ (comercial), estado 3 (E3): $19 \mathrm{~cm}$ (sobremaduro). Letras distintas, para un mismo portainjerto, indican diferencias significativas según el test LSD de Fisher con un nivel de significancia de $\mathrm{P}<0,05$.

El efecto del injerto sobre la respiración resulta de sumo interés puesto que es una variable que ha mostrado correlación positiva elevada con la perecibilidad de los productos frutihortícolas (Toivonen, 2011). El mecanismo fisiológico por el cual ocurre esta reducción no se conoce con certeza en este punto. De todos modos, podría especularse 
una relación con diferencias entre el predominio de procesos de división celular y expansión en frutos estudiados. Bertin (2005) informó, en frutos de tomate, un mecanismo de compensación entre tamaño celular y número de células. Esto redundó en que frutos de igual tamaño final, estado de crecimiento y apariencia puedan variar claramente su volumen celular medio y número de células. En este escenario órganos que para un tamaño dado presentan células pequeñas muestran un mayor requerimiento de manutención y por tanto una tasa respiratoria más elevada (Lambers y col., 2008). En línea con esta posibilidad, Valerga y col. (2018) informaron que frutos de berenjena con similar tamaño, pero distinto tamaño celular medio, mostraron diferencias en su tasa respiratoria hallando una correlación positiva entre número de células y tasa respiratoria. Este es un aspecto que sería de interés explorar, considerando que la injertación modificó tanto la TR como la tasa de crecimiento bajo las mismas condiciones de cultivo y ambientales.

\subsection{Materia seca}

Los frutos de plantas injertadas sobre el pie Maxifort mostraron, para un mismo estado de crecimiento, una similitud en los niveles de materia seca con los respectivos controles (Figura I.6). Sin embargo, a lo largo del crecimiento, tuvieron una variación del contenido de materia seca que fue desde aproximadamente 7 a $6 \%$ entre frutos de E1 y E3, respectivamente. Esta tendencia fue opuesta a la observada en la tasa de crecimiento de los frutos y sugiere que la disminución en la MS podría deberse a un efecto de dilución aparente vinculada a la expansión celular. Miceli y col. (2014) tampoco encontraron diferencias de MS entre plantas de berenjena cv. Birgah control e injertadas sobre $S$. torvum.

Los frutos injertados sobre Java presentaron, para un mismo estado de crecimiento, niveles de materia seca menores a sus respectivos controles. Mientras que, a lo largo del crecimiento, los niveles de MS se mantuvieron constantes y cercanos al $6 \%$ y disminuyeron recién entre E2 y E3. 


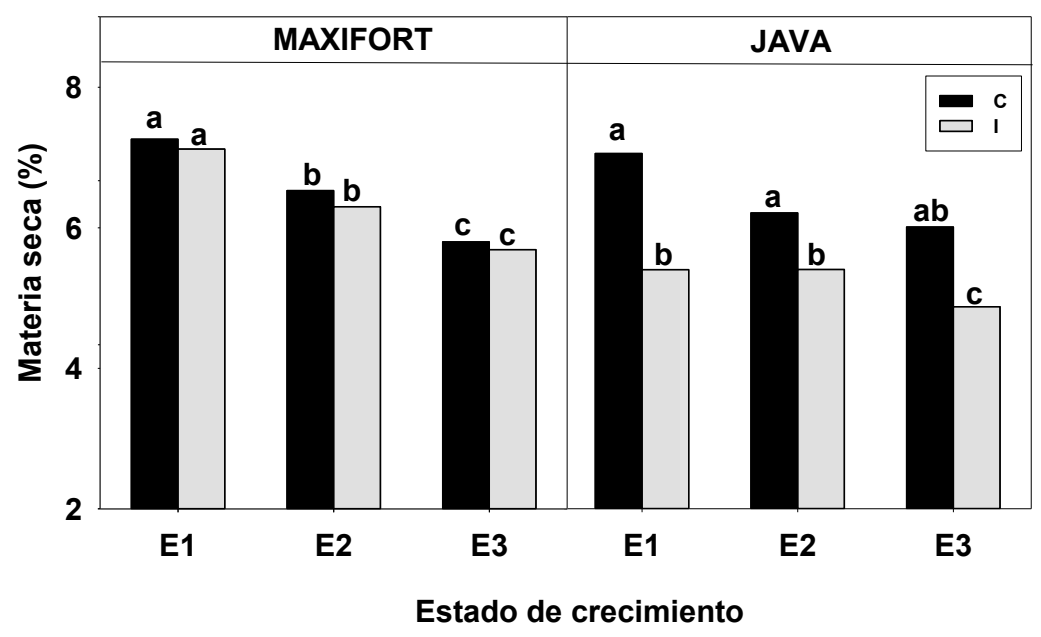

Figura I.6. Contenido de materia seca de frutos de berenjena provenientes de plantas control (C) e injertadas (I) sobre pie Maxifort y pie Java, en tres estados de crecimiento E1 (9 cm), E2 (17 cm) y E3 (19 $\mathrm{cm})$. Letras distintas, para un mismo portainjerto, indican diferencias significativas según el test LSD de Fisher con un nivel de significancia de $\mathrm{P}<0,05$.

\subsection{Color superficial}

Los pigmentos mayoritarios en la piel de berenjena son flavonoides, particularmente antocianinas que le dan el color rojo-azulado característico (Saldilova y col., 2006). Como se observa en la Figura I.7A, los valores de luminosidad mostraron una tendencia decreciente con el crecimiento, lo cual sugiere un oscurecimiento de los frutos. Si bien la berenjena es muy particular en este sentido, ya que su piel es violeta oscuro desde sus inicios, aún así muestra cierto incremento del color conforme la fruta se expande (Zaro y col., 2014). De todos modos, el color logrado dependerá del balance entre numerosos aspectos dentro de los que se destaca la síntesis de novo de antocianos y la dilución aparente debida al crecimiento. Por otra parte, existen muchos otros factores capaces de afectar el color de los frutos ricos en antocianinas tales como modificaciones de $\mathrm{pH}$, iones metálicos o co-pigmentos (Goulas y col., 2012). Más allá de esto, no se observó para este parámetro una diferencia marcada entre plantas control e injertadas. El parámetro a* mostró un incremento durante el crecimiento indicando un aumento del componente rojo del color de piel (Figura I.7B). En este caso, se observó un mayor aumento en berenjenas de plantas injertadas. Esto muestra que los frutos provenientes de plantas injertadas manifestaron un cambio hacia colores más rojizos con el crecimiento. Esto concuerda con lo informado por Kacjan Maršić y col. (2014) y Miceli y col. (2014) que informaron que los frutos de berenjena de plantas injertadas mostraron un color de piel más oscuro. Finalmente, el parámetro $\mathrm{b}^{*}$ (variación amarillo-azul) presento valores negativos $\mathrm{y}$ 
cercanos a cero. De este modo, tampoco mostró diferencias entre los frutos control e injertados (Figura I.7C).

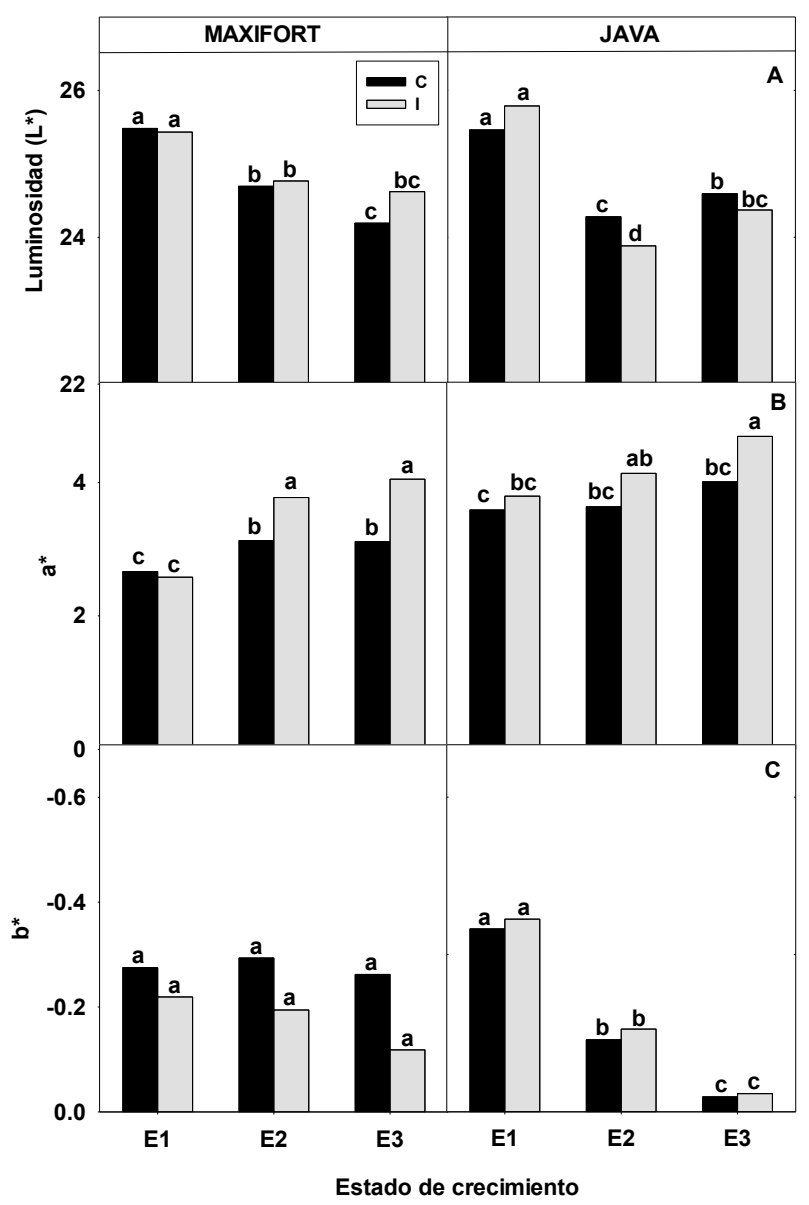

Figura I.7. Parámetros de color de piel: A) Luminosidad $\left(\mathrm{L}^{*}\right)$, B) $\mathrm{a}^{*}$ C) $\mathrm{b}^{*}$ de frutos de berenjena provenientes de plantas control (C) e injertadas (I) sobre pie Maxifort y pie Java, en tres estados de crecimiento E1 $(9 \mathrm{~cm})$, E2 $(17 \mathrm{~cm})$ y E3 $(19 \mathrm{~cm})$. Letras distintas, para un mismo portainjerto, indican diferencias significativas según el test LSD de Fisher con un nivel de significancia de $\mathrm{P}<0,05$.

\subsection{Resistencia a la compresión ( $\mathrm{RC}$ )}

La textura de un fruto es muy importante y es una de las determinaciones que los compradores propenden a realizar más allá de la apreciación visual a la hora de decidir la compra. La textura se ve afectada por la turgencia celular, composición de la pared celular y por aspectos morfológicos y estrucutrales (Sams, 1999). Diversos factores externos pueden modificar los valores de textura afectando la calidad final del producto. Como se observa en la Figura I.8, el portainjerto Maxifort presentó una reducción en la RC entre los estados E1 y E2, pero el empleo del portainjerto no tuvo efectos sobre este atributo. 
Mientras que, en Java no se observaron diferencias en la RC ni durante el crecimiento ni en respuesta a la injertación.

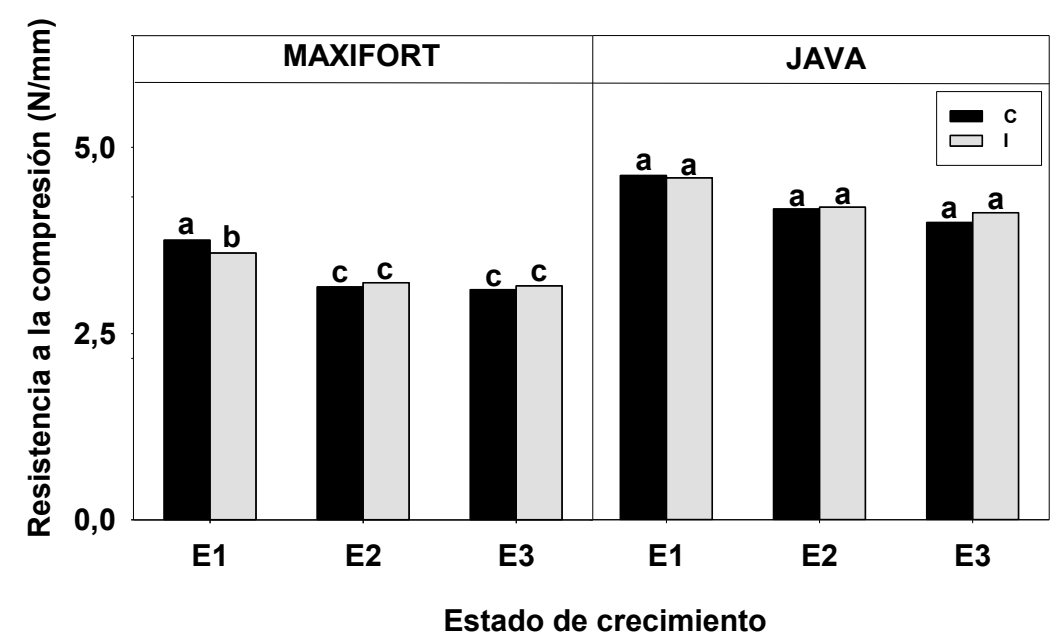

Figura I.8. Resistencia a la compresión (RC) de frutos de berenjena provenientes de plantas control (C) e injertadas (I) sobre pie Maxifort y pie Java, cosechadas en tres estados de crecimiento E1 (9 cm), E2 (17 $\mathrm{cm})$ y E3 $(19 \mathrm{~cm})$. Letras distintas, para un mismo portainjerto, indican diferencia significativa según el test LSD de Fisher con un nivel de significancia de $\mathrm{P}<0,05$.

\subsection{Número y tamaño de semillas}

La semilla es el principal órgano reproductivo de la gran mayoría de las plantas superiores (Doria, 2010). Todos aquellos vegetales en los que las semillas se consumen junto al resto de los tejidos, pueden ver afectado su sabor y aceptabilidad de forma negativa o positiva. En frutos de berenjena, el número y tamaño de semillas son parámetros importantes. En términos generales frutos con mayor número y tamaño de semillas resultan menos agradables por su sabor amargo (Du y col., 2016). En el presente trabajo el número de semillas no mostró diferencias entre frutos de plantas control e injertadas (Tabla I.2). Conforme avanzó el crecimiento de los frutos, si bien se observó un incremento del tamaño de las semillas, tampoco se evidenciaron diferencias marcadas entre frutos provenientes de plantas control o injertadas.

En síntesis, los resultados muestran que, para las combinaciones estudiadas en el presente trabajo, la técnica de injertación no provocó variaciones significativas en la formación y crecimiento de semillas de los frutos. Estos resultados difieren de los informados por Khah (2006), quien halló que frutos de berenjena de plantas injertadas sobre pies de tomate presentaron menor número de semillas que el de los frutos control. 
Tabla I.3 Numero y tamaño de semillas de frutos de berenjena provenientes de plantas control (C) e injertadas (I) sobre pie Maxifort y pie Java, en tres estados de crecimiento diferente E1 $(9 \mathrm{~cm})$, E2 $(17 \mathrm{~cm})$ y E3 $(19 \mathrm{~cm})$. Letras distintas, para un mismo portainjerto, indican diferencias significativas según el test LSD de Fisher con un nivel de significancia de $\mathrm{P}<0,05$

\begin{tabular}{c|ccccc}
\hline & \multicolumn{4}{c}{ MAXIFORT } & \multicolumn{2}{c}{ JAVA } \\
\hline & Estado & $\boldsymbol{C}$ & $\boldsymbol{I}$ & $\boldsymbol{C}$ & $\boldsymbol{I}$ \\
\hline $\boldsymbol{N}^{\boldsymbol{o}}$ de semillas & & $82,57 \mathbf{a}$ & $70,2 \mathbf{a b c}$ & $108,98 \mathbf{a}$ & $101,45 \mathbf{a}$ \\
Tamaño de semilla & $\boldsymbol{E} 1$ & $0,015 \mathbf{b}$ & $0,015 \mathbf{b}$ & $0,0086 \mathbf{c}$ & $0,0078 \mathbf{d}$ \\
$(\boldsymbol{c m})$ & $\boldsymbol{E 2}$ & $0,023 \mathbf{a}$ & $0,023 \mathbf{a}$ & $0,0187 \mathbf{b}$ & $0,0187 \mathbf{b}$ \\
& $\boldsymbol{E 3}$ & $0,022 \mathbf{a}$ & $0,022 \mathbf{a}$ & $0,0199 \mathbf{a}$ & $0,0204 \mathbf{a}$ \\
\hline
\end{tabular}

Como ya se mencionó, los portainjertos Maxifort y Java se emplean actualmente en el Cinturón Hortícola de La Plata. Ambos portainjertos se recomiendan por su resistencia a bajas temperaturas de cultivo y por adaptarse mejor a los patógenos de suelo que aquí se encuentran. El portainjerto Maxifort ha sido empleado y estudiado en mayor magnitud en la bibliografía (Vreck y col., 2011; Petran y col., 2014; Schwarz y col., 2013) que el portainjerto Java. Este último carece de estudios previos, por lo que se decidió su empleo para evaluar en detalle los efectos en los niveles de compuestos antioxidantes.

\subsection{Compuestos antioxidantes}

\subsubsection{Compuestos antioxidantes en piel}

A fin de realizar una evaluación más detallada de la composición de los frutos se realizaron determinaciones de compuestos antioxidantes. Estas determinaciones se llevaron a cabo para las plantas injertadas sobre Java y su respectivo control. En los últimos años se han desarrollado varias técnicas relativamente rápidas de 'screening' para tener una aproximación. Actualmente es muy común recurrir a diferentes metodologías de análisis de compuestos antioxidantes dado que sus resultados no son siempre totalmente coincidentes. Dos de las metodologías más empleadas son las desarrolladas por Arnao y col. (2001) también conocidas como TEAC y la descripta por Singleton y col (1999) que emplea el reactivo de Folin-Ciocalteu. La primera se basa en la capacidad de los compuestos antioxidantes, presentes en una muestra que se desea dosar, de neutralizar a un ión-radical coloreado $\left(\mathrm{ABTS}^{\bullet+}\right)$, cuya disminución puede ser fácilmente medida en forma espectrofotométrica. Mientras que, la segunda aprovecha la capacidad de los antioxidantes fenólicos para reducir al reactivo en una reacción redox y formar un complejo coloreado. En berenjena, los antioxidantes son principalmente conformados por 
compuestos fenólicos, tanto en la piel como en la pulpa de los frutos (Cao y col., 1996; Zaro y col., 2014). En este trabajo, la capacidad antioxidante, TEAC, de la piel de los frutos mostró un patrón comparable con el contenido de compuestos fenólicos en función del crecimiento de los mismos. Así, se observó una tendencia claramente decreciente entre frutos E1 y E2 para permanecer prácticamente constante hacia frutos E3 (Figura I.9A y B). La pérdida de capacidad antioxidante ocurrió mayoritariamente entre los estados E1 y E2, ya que perdió prácticamente un 40-50 \% de los antioxidantes. En frutos tales como melón, mango, manzana, arándano (Abu-Goukh y col, 2005, 2011; Kondo y col., 2002; Vicente y col., 2009; Castrejón y col., 2008) también es habitual que el contenido de compuestos fenólicos disminuya con el avance del crecimiento y la maduración. Podría pensarse que la síntesis de compuestos fenólicos se ha disminuído e incluso anulado, pero como los frutos están en pleno proceso de crecimiento en tamaño esto resultaría en una menor concentración de metabolitos por g de tejido (dilución), más que una degradación o metabolismo de estos compuestos (Renard y col., 2007; Lewis y col., 1999).

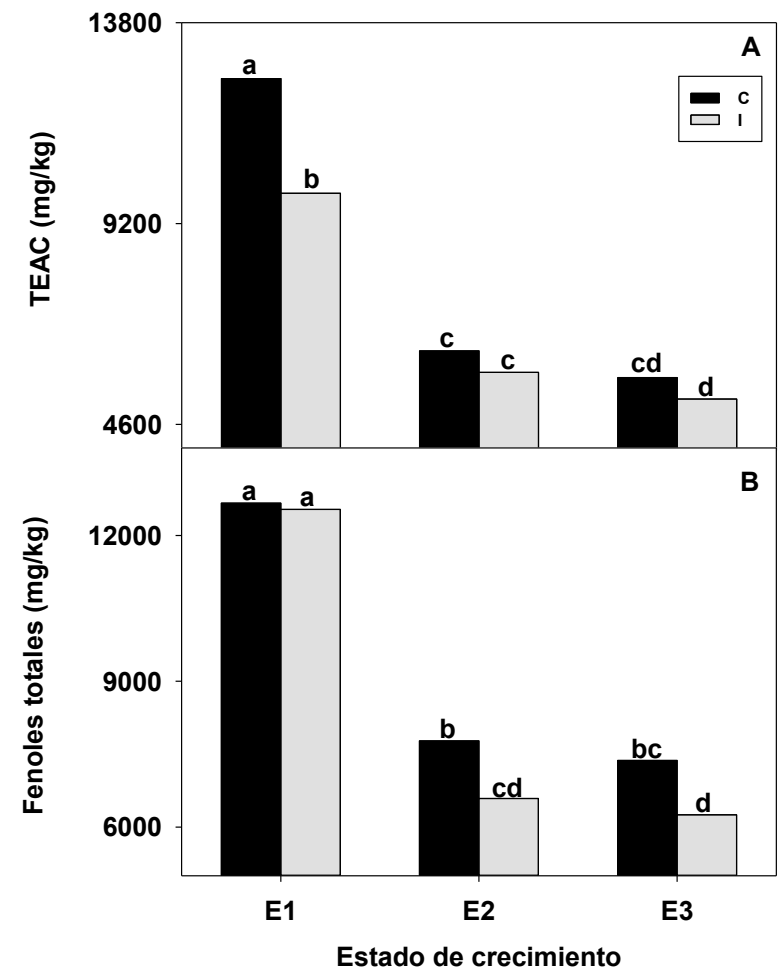

Figura I.9. A) Capacidad antioxidante (TEAC) y B) Fenoles totales en piel de frutos de berenjena provenientes de plantas control (C) e injertadas (I) cosechadas en tres estados de crecimiento diferente E1 $(9 \mathrm{~cm})$, E2 $(17 \mathrm{~cm})$ y E3 $(19 \mathrm{~cm})$. Letras distintas indican diferencias significativas según el test LSD de Fisher con un nivel de significancia de $\mathrm{P}<0,05$. 
En el caso de berenjena en la medida que se avanzó en los estados se observó también un menor contenido de compuesto fenolicos en los frutos de plantas injertadas por el método de Folin-Ciocalteu, pero no así de capacidad antiocidante por TEAC. De todos modos, es importante mencionar que las berenjenas, de plantas injertadas mostraron una tendencia general a presentar menores valores de capacidad y contenido de antioxidante. Esto coincide con lo informado por Moncada y col. (2013) en distintos cultivares de berenjena injertados en Solanum torvum. En esta línea, Sabatino y col. (2016) y Kacjan Maršić y col. (2014) encontraron que los injertos en berenjena, en condiciones ambientales desfavorables, acumularon menor contenido de los principales grupos de compuestos fenólicos.

Los compuestos fenólicos en la pulpa y la piel de berenjena violeta se dividen en tres grandes grupos: ácidos hidroxicinámicos, flavonoles y antocianinas (Kacjan Maršić y col., 2014). En piel, los compuestos bioactivos predominantes son las antocianinas derivadas de la delfinidin-3-rutinósido, y el ácido clorogénico, siendo este último el principal antioxidante en la pulpa (Zaro y col., 2014). La concentración de antocianinas en los frutos de berenjena violeta es alta en comparación con la de otras frutas y hortalizas del mismo color, por ejemplo, la berenjena contiene 2 veces más antocianinas que las uvas y 7 veces más que las cebollas rojas ( $\mathbf{L i}$ y col., 2018). Los cambios de estos compuestos durante el crecimiento de los frutos ya han sido descriptos para otros cultivares. En este trabajo, se observó que los frutos de plantas injertadas mostraron un nivel entre 13 y 30 \% inferior a los frutos control, dependiendo del estado. Kacjan Maršić y col. (2014) encontraron una alta dependencia del injerto en las concentraciones de antocianinas, y observaron un menor contenido de estos compuestos en frutos de plantas injertadas. Estos autores sugieren que ello podría ser una consecuencia de frutas más sombreadas, debido a que las plantas injertadas presentaron mayor vigor y crecimiento que influyó negativamente en la concentración de antocianinas ya que como es conocido, la biosíntesis de antocianinas está regulada y potenciada por la luz (Li y col., 2018). Es de destacar que los niveles de antocianinas permanecieron constantes en frutos controles durante el crecimiento de E1 a E3, a diferencia de los frutos injertados que mostraron un aumento del $24 \%$ desde E1 a E2 y permanecieron constantes hasta E3 (Figura I.10A). A diferencia de otros frutos en los que el aumento de antocianos es exponencial durante la maduración; las berenjenas ya presentan cerca del $80 \%$ del total en el estado E1 o "baby" lo que se traduce en un muy ligero aumento hacia los frutos E3. 
Por su parte el ACG mostró un marcado descenso durante el proceso de crecimiento, en especial entre frutos E1 y E2 donde disminuyó entre un 40-50 \%, para luego permanecer prácticamente constante hacia frutos E3. Es de resaltar que los frutos E2 y E3 de plantas injertadas alcanzaron menores valores respecto de los frutos control (Figura I.10B).

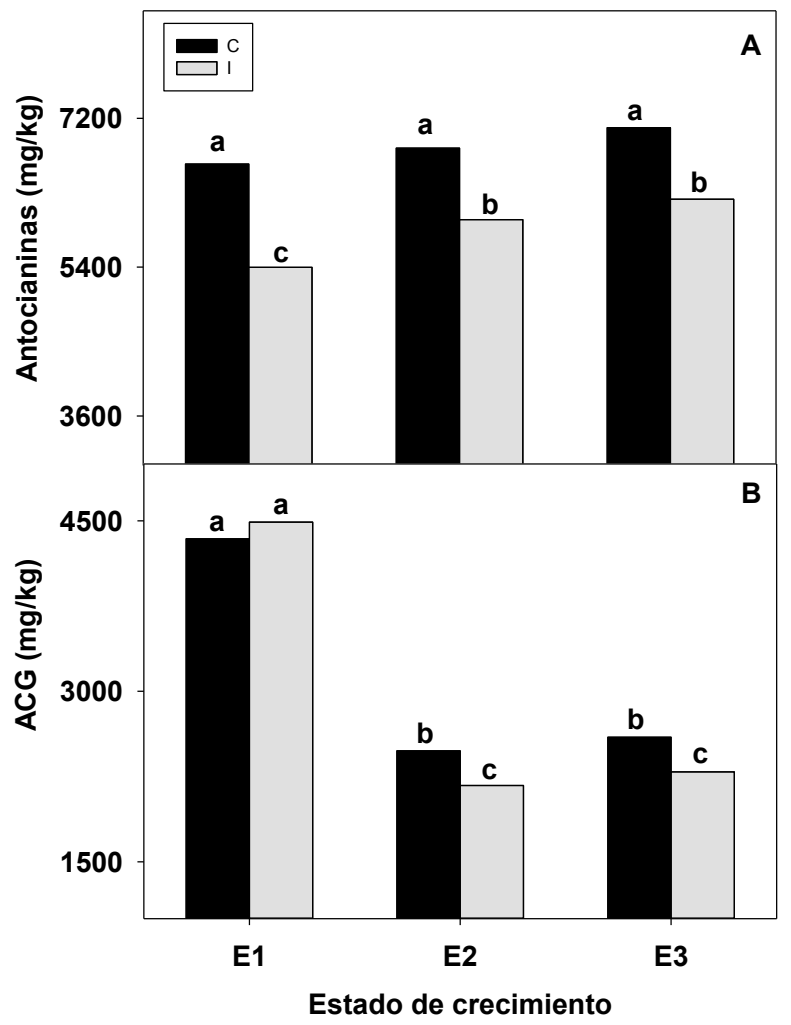

Figura I.10. A) Antocianinas y B) ácido clorogénico (ACG) en piel la de frutos de berenjena provenientes de plantas control (C) e injertadas (I) cosechadas en tres estados de crecimiento E1 $(9 \mathrm{~cm})$, E2 $(17 \mathrm{~cm}) \mathrm{y}$ E3 $(19 \mathrm{~cm})$. Letras distintas indican diferencias significativas según el test LSD de Fisher con un nivel de significancia de $\mathrm{P}<0,05$.

Un aspecto de interés fue observar que la injertación afectó tanto el contenido de antocianinas como de ácido clorogénico en la piel.

Cuando estos niveles y tendencias se comparan con los niveles de TEAC se puede apreciar que, ante el avance del crecimiento y en particular entre los frutos E1 y E2, la gran disminución de $\mathrm{ACG}$ es determinante en ocasionar la gran disminución de los niveles de TEAC y contenido de fenoles totales. Si bien el alto porcentaje de antocianinas en piel aportan en gran medida a los niveles TEAC y de fenoles totales, su aumento fue de sólo un 5-10 \% entre frutos E1 y E2, lo que no modificó sustancialmente la tendencia a la disminución de los mismos. Finalmente, la injertación afectó tanto el contenido como capacidad antioxidante en la piel de berenjena mostrando, en general, menores niveles. 


\subsubsection{Compuestos antioxidantes en pulpa}

La capacidad antioxidante o TEAC de la pulpa fue máxima para el estado E1 (Figura I.11A), luego la tendencia fue descendente en la medida que avanzó el crecimiento del fruto. Ese descenso en los E2 y E3 llegó al 30 \% y 40 \%, respectivamente, siendo aún más bajo en los frutos de plantas injertadas. El contenido de compuestos fenólicos totales mostró la misma tendencia que el TEAC (Figura I.11B) tanto durante el crecimiento como en respuesta a la injertación. Dado que el ACG es el principal antioxidante de la pulpa de frutos de berenjena los cambios en este compuesto acompañaron a los observados en las determinaciones de TEAC (Figura I.11C). Así, la concentración de compuestos fenólicos avanzaría de forma opuesta al crecimiento de los frutos. El contenido de ACG también muestra una primer gran disminución en estados tempranos del desarrollo de tomate (Choi y col., 2010) y papa (Lewis y col., 1999). En concordancia con ello, Renard y col (2007) hallaron en manzanas una correlación entre el fin de la biosíntesis activa de polifenoles y el inicio de la expansión celular, con la consecuente caída del contenido de compuestos fenólicos en pulpa. También en frutilla, se ha hallado que la enzima PAL, clave en la biosíntesis de compuestos fenólicos, posee picos de máxima actividad al inicio y final de los estados de crecimiento (Halbwirth y col., 2006), los cuales proveen de compuestos fenólicos simples al inicio y antocianos que otorgan el color rojo al final de este período. A partir de las determinaciones realizadas en el presente trabajo, resulta difícil establecer en forma inequívoca las causas por las cuales los frutos de plantas injertadas mostraron una tendencia a acumular menores niveles de antioxidantes. Estas diferencias podrían atribuirse a múltiples factores dado que en el fruto en desarrollo coexisten procesos de dilución por crecimiento, biosíntesis, polimerización y degradación dependiendo del compuesto considerado, tejido y etapa del proceso de formación (Lewis y col., 1999).

De todos modos, el hecho de que la injertación haya aumentado el vigor y la velocidad de crecimiento y que los componentes del extracto seco medidos (MS total y antioxidantes) hayan mostrado en forma recurrente tendencia a presentar menores niveles, permite al menos hipotetizar que el aumento en la velocidad de crecimiento haya redundado en una mayor dilución aparente en los frutos de plantas injertadas de los sólidos totales. Esto requiere mayores estudios que podrían incluir la evaluación de la actividad de enzimas biosintéticas y un análisis más detallado de los procesos de división y expansión celular en los frutos en respuesta a la técnica de injertación. 
Más allá de esto, los resultados del presente trabajo muestran claramente que la injertación de berenjena cv. Monarca sobre pie Java resulta en una reducción en los niveles de antocianos y ACG en piel y de ACG en pulpa que redunda en una reducción de la capacidad antioxidante de los frutos.

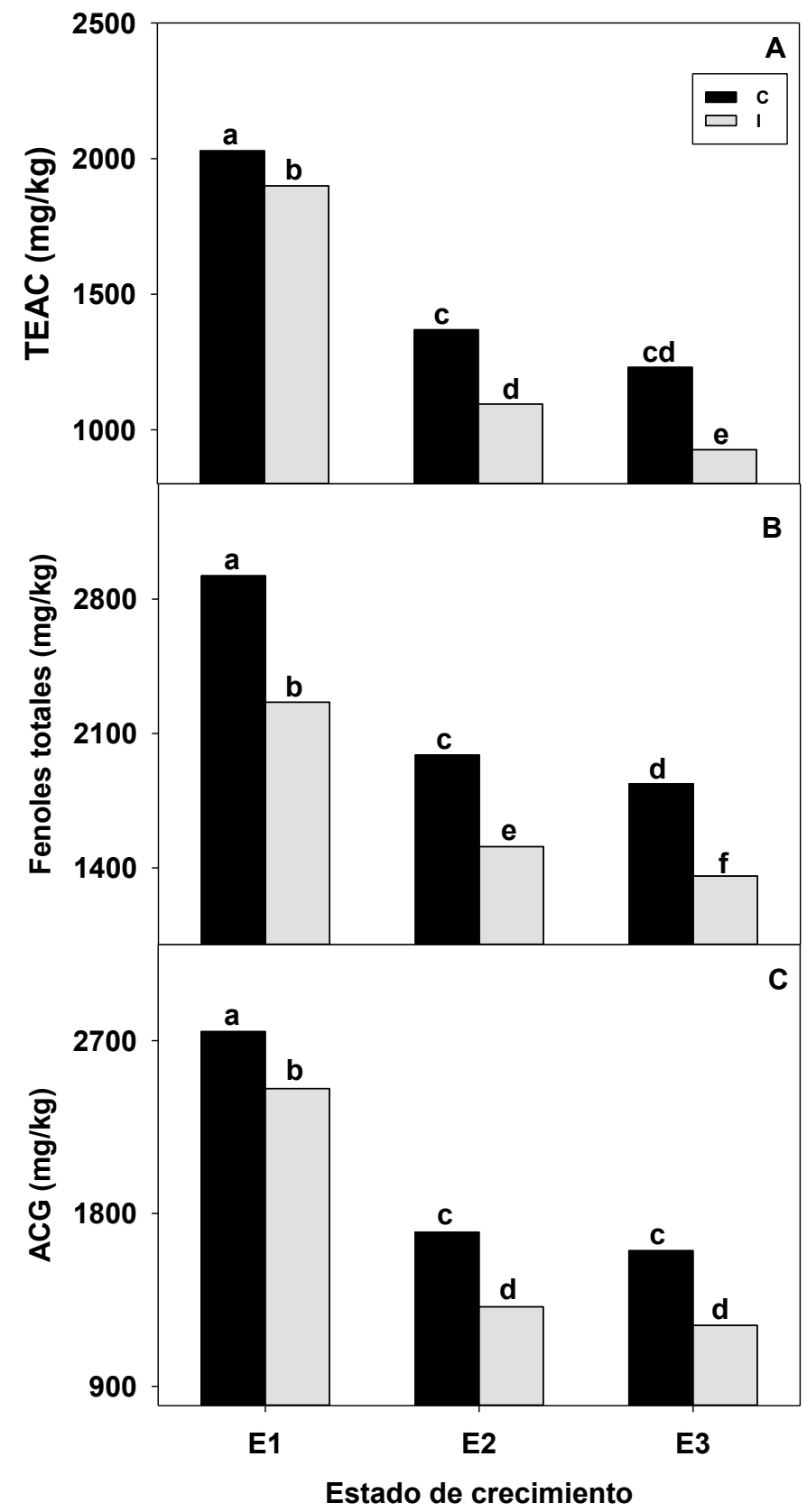

Figura I.11. A) Capacidad antioxidante (TEAC), B) Fenoles totales y C) ácido clorogénico (ACG) en pulpa de frutos de berenjena provenientes de plantas control (C) e injertadas (I) cosechadas en tres estados de crecimiento E1 $(9 \mathrm{~cm})$, E2 $(17 \mathrm{~cm})$ y E3 $(19 \mathrm{~cm})$. Letras distintas indican diferencias significativas según el test LSD de Fisher con un nivel de significancia de $\mathrm{P}<0,05$. 


\section{I.4. CONCLUSIONES}

En el presente capítulo se determinó el efecto del uso de portainjertos sobre el crecimiento, morfología, calidad comercial y compuestos bioactivos de frutos de berenjena violeta. Los frutos provenientes de plantas injertadas crecieron a una mayor velocidad alcanzando su longitud comercial en menor tiempo, lo que favoreció su cosecha anticipada respecto de los frutos control. Para ambos portainjertos estudiados (Maxifort y Java) los frutos de plantas injertadas mostraron una tendencia a presentar una menor tasa respiratoria y materia seca y un color algo más rojizo que sus respectivos controles sin injertar. La injertación no afectó la resistencia a la compresión mecánica de los frutos ni el número y tamaño de semillas. Finalmente, en el caso del cv. Monarca injertado sobre el pie Java se demostró que dichos frutos mostraron una tendencia a presentar niveles inferiores de capacidad antioxidante, fenoles totales y ácido clorogénico, tanto en piel como en pulpa.

En síntesis, los resultados sugieren que el uso de portainjertos posee influencia en el crecimiento y en algunos atributos morfológicos y composicionales de frutos de berenjena violeta. 


\section{Capítulo II}

Influencia del empleo de portainjerto sobre la calidad, comportamiento poscosecha y susceptibilidad al daño por frío en frutos de berenjena 


\section{II.1. INTRODUCCIÓN}

\subsection{Daño por frío}

La refrigeración es la tecnología poscosecha más empleada para lograr beneficios asociados a mantener la calidad de las frutas y hortalizas. De todas maneras, los beneficios están limitados debido a que algunos productos son sensibles al daño por frío (DPF) y pueden aparecer desórdenes fisiológicos, frío bioquímicos y físicos. La susceptibilidad a este tipo de daño depende del cultivar, de la temperatura y del tiempo de exposición a las bajas temperaturas, del grado de madurez, y de las temperaturas previas a la cosecha (Wang, 1994). Este fenómeno es observado principalmente en frutas y hortalizas de origen tropical o subtropical tales como: cítricos, palta, ananá, mango, melón, banana, berenjena, tomate, pimiento, pepino, etc.

En general, los mecanismos que inducen a lesiones por bajas temperaturas se asocian con cambios en la integridad y funcionalidad de las membranas celulares y con la producción de especies reactivas de oxígeno (EROs):

i-Cambios en la integridad y funcionalidad de las membranas celulares: La naturaleza física de los lípidos de membrana es la responsables de la habilidad de adaptación de las plantas a las condiciones ambientales. En el caso del desarrollo de daño por frío estaría involucrado un evento inicial denominado "transición de fase", en el que los lípidos hallados en forma de líquido cristalino, ante temperaturas menores a la crítica, evolucionan hacia una fase tipo gel-sólido (Lyons, 1973). Estos cambios generan modificaciones en el funcionamiento normal de las membranas que incluyen: alteración de reacciones enzimáticas, desbalance de procesos metabólicos, alteración de la actividad de proteínas de membranas, pérdida de la permeabilidad, generación de EROs, la peroxidación de ácidos grasos, la degradación de fosfolípidos y galactolípidos y acumulación de metabolitos tóxicos (Figura II.1). Mientras que, con la exposición prolongada a las bajas temperaturas, finalmente se produce el daño y muerte celular, haciéndose visible en el producto a partir de lesiones superficiales, pardeamiento interno, lentitud en los procesos de maduración, entre otros (Aghdam y Bodbodak, 2013). Asimismo, suele ocurrir la aparición de pudriciones en las zonas afectadas, por la infección secundaria de ciertos microorganismos (Salveit, 2003; Toivonen, 2011). Puede internamente haber una fuga de agua intracelular, iones y metabolitos, (Sharom y col., 
1994). La principal consecuencia de todos estos eventos es la pérdida de la funcionalidad de la biomembrana (Sevillano y col., 2009).

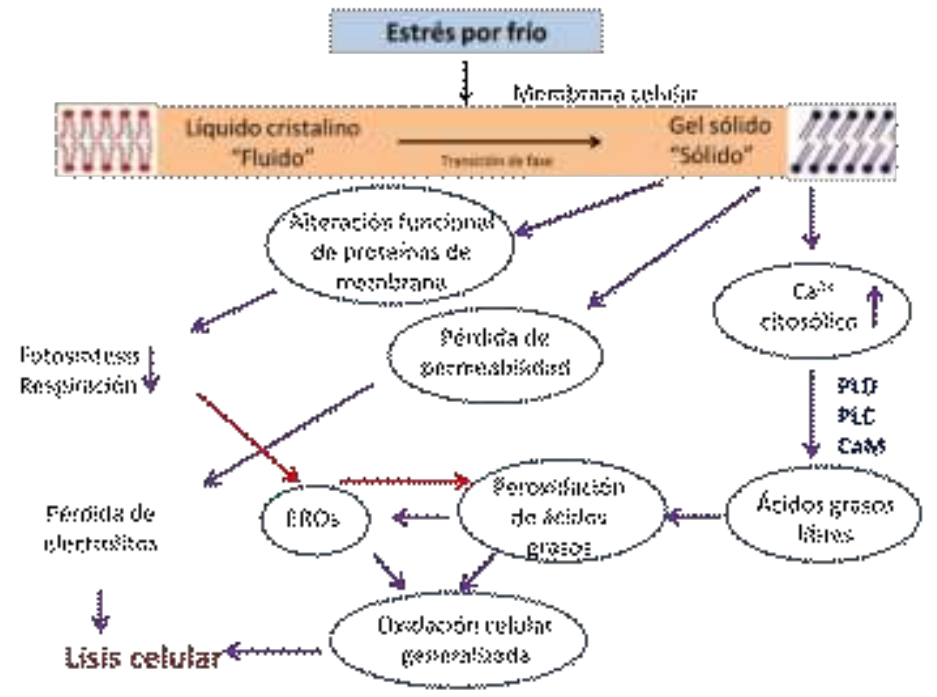

Figura II.1. Cambios en la integridad y funcionalidad de las membranas celulares asociados a lesiones por bajas temperaturas (Chilling stress). Adaptado de Aghdam y Bodbodak, (2013).

ii-Estrés oxidativo. Producción de EROs: Las EROs son producidas por el metabolismo celular normal como ya se indicó en la sección 1.3.1 de la Introducción General. Ante un desbalance entre las EROs y el sistema de detoxificación enzimático y químico, se produce el estrés oxidativo. En general, esta situación se produce por diversas situaciones de estrés biótico y abiótico, y el daño por baja temperatura no es una excepción a esta regla. La pérdida de integridad de la membrana se ve impulsada por procesos oxidativos, ya que el estrés por frío aumenta los niveles de EROs que estimulan la peroxidación de lípidos en las membranas celulares (Sevillano y col., 2009). El sistema de defensa de las plantas puede actuar activando los genes que codifican para proteínas involucradas en el transporte de electrones y cuya reducción del oxígeno es atribuida a la actividad de una oxidasa alternativa en vez de la vía citocrómica (Moller, 2001) y así conducir a un aumento de la resistencia contra el DPF a través del mantenimiento del equilibrio entre la producción de EROs y la actividad general del sistema antioxidante (Purvis, 1997). Por otro lado, las plantas superiores también pueden inducir la actividad o la expresión génica para los sistemas enzimáticos (SOD, CAT, POD, GPX, etc) y químicos (compuestos fenólicos, carotenoides, ácido ascórbico, etc.) que captan EROs (Moller, 2001). La mayor actividad del sistema antioxidante conduce a la reducción de las EROs, por lo tanto, mejora la integridad de la membrana y, en última instancia, induce resistencia a los estreses abióticos como el estrés por baja temperatura (Mittler, 2002). 
Diversas frutas y hortalizas sufren DPF cuando son almacenados por debajo de la temperatura recomendada. Los síntomas visibles característicos dan lugar a: la formación de depresiones del tejido por debajo de la piel (síntoma conocido como "pitting" del inglés "con hoyos") frecuente en cítricos y pepinos; incapacidad para desarrollar una coloración uniforme observable en tomates; incremento de la respiración; aumento de la susceptibilidad a podredumbres comunes en tomates; amarronamiento y harinosidad de la pulpa y pérdida de jugo común en frutas de carozo, llevando finalmente a grandes pérdidas poscosecha durante la comercialización (Wang, 1994). En frutos de berenjena, los síntomas surgen al ser almacenados a temperaturas menores a los $10-12{ }^{\circ} \mathrm{C}$ y $\operatorname{los}$ principales síntomas son el pardeamiento de la pulpa y semillas, punteado o escaldaduras superficiales, pérdida de solutos, aparición de olores desagradables y aumento de pudriciones (Molinar y col., 1996; Cantwell y Suslow, 2000; Concellón y col., 2005). El grado de daño es función de la temperatura, así como del tiempo de exposición (Purvis, 2002; Saltveit, 2003).

Una mayor resistencia al DPF confiere al vegetal la posibilidad de ser almacenado a bajas temperaturas y que los síntomas de daño se vean retrasados e incluso inhibidos.

\subsection{Uso de portainjertos: Efectos sobre la fisiología de la planta entera, características fenotípicas de la copa y de los productos cosechados}

La injertación puede considerarse una técnica en la que se forma un individuo con más de un genotipo que variará dependiendo de la porción considerada (portainjerto: variedad). La mayoría de las plantas se injertan sin problemas sobre sí mismas, con menor eficacia se injertarán sobre especies estrechamente relacionadas, y rara vez lo harán con especies menos emparentadas. Para una unión exitosa se conoce que las auxinas y citoquininas juegan un rol importante (Figura II.2A). Los injertos incompatibles a menudo fallarán inmediatamente debajo de la zona de unión por formación de una unión débil y falta de conexiones vasculares (Figura II.2B). 


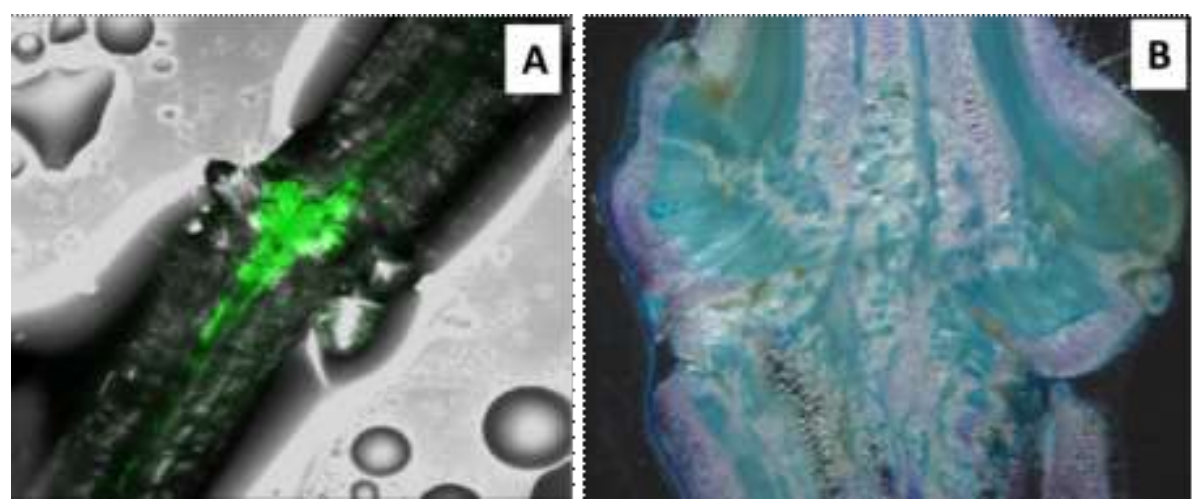

Figura II.2. A) Expresión de genes vinculados con el metabolismo de citoquininas visualizado mediante la proteína verde fluorescente (GFP) 8 días luego de la injertación. B) Sección de la zona de unión de un injerto de tomate revelando la formación de callo y nuevo tejido vascular xilemático entre el portainjerto y la variedad. Adaptado de Melnyk y Meyerowitz, (2015).

En el capítulo anterior pudo observarse que en el caso de las combinaciones estudiadas de berenjena violeta esto se traduce en algunos cambios en la velocidad de crecimiento, la morfología y composición de los frutos. De esa observación se desprende que el pie o portainjerto ejerce efectos sobre la copa o variedad injertada. Estas respuestas pueden ser el resultado de dos grandes grupos de efectos que en algunos casos resulta difícil de delimitar: por un lado, los efectos directos vinculados con cambios en la morfo-físiología radicular, y por otra parte, aquellos cambios indirectos, derivados del portainjerto que implican modificaciones en la fisiología de la planta entera según se describe a continuación:

i-Efectos derivados de cambios en la morfo-fisiología radicular: En este grupo se incluyen aquellas características que resultan en forma directa de la incorporación de un sistema radicular diferente al de la variedad. Algunos ejemplos podrían ser variaciones en el anclaje de la planta, en el volumen y ramificación y función radicular que afectan la capacidad de exploración del suelo y que por ejemplo pueden modificar la eficiencia de uso de agua y/o absorción de nutrientes, cambios en el vigor, otorgar resistencia a adversidades bióticas (ej. como la resistencia a filoxera en vides injertadas o la mejora en la respuesta a nematodos o enfermedades del suelo) (Schwarz y col., 2010).

ii. Cambios indirectos, derivados del portainjerto que implican modificaciones en la fisiología de la planta entera: en la actualidad se conoce que existen múltiples interacciones entre el portainjerto y la variedad aún luego de que se ha logrado una compatibilidad satisfactoria, y que exceden al suministro ascendente de agua y nutrientes minerales y el flujo descendente de fotosintatos. Dentro de estos cambios podemos describir el intercambio de señales hormonales (Cutting y Lyne, 1993; Aloni y col., 
2010); el transporte de diferentes formas de ARN y proteínas (Haroldsen y col., 2012). Y a continuación se presentan brevemente algunos de estos mecanismos:

-Ácidos nucleicos: Históricamente, los ácidos nucleicos se creían autónomos de cada célula y por tanto no se consideraba que pudieran cruzar barreras celulares para ejercer efectos más allá de su sitio de síntesis. En el caso del ADN genómico no hay evidencia marcada de movilidad más que el de virus basados en esta molécula. Solo se ha descrito el movimiento de ADN cloroplástico a zonas inmediatamente adyacentes a las de realización de injertos (Stegemann y Bock, 2009). En el caso del ARN se ha demostrado que los procesos de tráfico dentro de la planta son frecuentes; de hecho, juegan un rol central en procesos normales del desarrollo vegetal. Estos procesos, por lo tanto, son selectivos y altamente regulados. El líquido floemático suele contener transcriptos de ARN y proteínas de unión a esta molécula. Por ejemplo, en el caso de calabaza y pepino injertado sobre pie de calabaza se han encontrado ARNm que codifican para genes que participan en la regulación de la senescencia provenientes del portainjerto en la variedad (Harlodsen y col., 2012). En forma más reciente se han identificado pequeños ARN no codificantes como moléculas móviles en las plantas. Este tipo de ARN de cadena pequeña posee menos de 200 nucleótidos. La idea de que estos pequeños ARN están implicados en la regulación de la fisiología del desarrollo dentro de células individuales como forma autónoma y como señalización a largas distancias, es cada vez más aceptada (Buhtz $\mathbf{y}$ col., 2010).

-Proteínas: Además de los ARN, las proteínas pueden ser transportadas por largas distancias. Por ejemplo, investigadores de la Universidad de Florida han desarrollado un portainjertos que entrega péptidos antimicrobianos que permiten el control de enfermedades fúngicas y bacterianas en las variedades (Dutt y col., 2007; Gray y col., 2007).

-Fitohormonas: se conoce que la translocación de auxinas, citoquininas y ABA son necesarios para lograr la compatibilidad de pie y copa (Melnyk y Meyerowitz, 2015).

\section{3. ¿El empleo de portainjertos posee influencia sobre la poscosecha?}

Si bien ha existido un aumento en el interés en la comprensión del efecto del injertado en especies frutihortícolas en los últimos años, los estudios han focalizado mayoritariamente en aspectos agronómicos tales como control del vigor y adversidades bióticas y abióticas durante la etapa de cultivo. Contrariamente, relativamente pocos trabajos han analizado la influencia que ejerce el empleo de diversos portainjertos sobre el comportamiento 
poscosecha (Tabla II.1). Como es esperable, y al igual que ocurrió con el empleo de la técnica de injertación con fines comerciales, los estudios son más frecuentes para especies frutales perennes.

Tabla II.1 Algunos efectos resultantes del empleo de portainjertos sobre parámetros de calidad de frutas y hortalizas durante el almacenamiento poscosecha descritos en la literatura.

\begin{tabular}{|c|c|c|c|}
\hline Producto & Genotipo & Efectos observados & Referencia \\
\hline Pomelo & $\begin{array}{l}\text {-cv Star ruby y Red Ruby } \\
\text { sobre mandarino } \\
\text { Cleopatra y/o citrumelo } \\
\text { Swingle. }\end{array}$ & $\begin{array}{l}\text { Ambos cultivares sobre Cleopatra } \\
\text { mostraron mayor pérdida de peso. }\end{array}$ & $\begin{array}{l}\text { Machado y col., } \\
2015 .\end{array}$ \\
\hline$U v a$ & $\begin{array}{c}\text {-cv Thompson Seedless } \\
\text { en portainjertos Dogridge, } \\
\text { Salt Creek, } 1613 \text { C y St. } \\
\text { George. }\end{array}$ & $\begin{array}{l}\text { El portainjerto afectó la } \\
\text { deshidratación de las bayas, el } \\
\text { oscurecimiento del pedicelo. }\end{array}$ & $\begin{array}{l}\text { Somkuvar y col., } \\
2008 .\end{array}$ \\
\hline \multirow{3}{*}{ Manzana } & $\begin{array}{l}\text {-cv Jonagold sobre } \\
\text { diferentes portainjetos. }\end{array}$ & $\begin{array}{c}\text {-Frutos sobre M9 mostraron } \\
\text { menos producción de etileno en el } \\
\text { almacenamiento que sobre PB-4 o } \\
\text { P } 22 \text {. }\end{array}$ & $\begin{array}{l}\text { Tomala y col., } \\
2008 .\end{array}$ \\
\hline & & & \\
\hline & $\begin{array}{c}\text {-cv Jonica sobre } \\
\text { portainjertos } \\
\text { M9, M26, P22, P59 y } \\
\text { P60. }\end{array}$ & $\begin{array}{l}\text {-P22, P59 y P60 mostraron menos } \\
\text { bitter pit, menor ablandamiento } \\
\text { durante el almacenamiento. }\end{array}$ & $\begin{array}{l}\text { Skrzynski y } \\
\text { Gastol, } 2007 .\end{array}$ \\
\hline Cereza & $\begin{array}{l}\text {-cv Regina sobre } \\
\text { portainjertos vigoroso y } \\
\text { semi-enanizante. }\end{array}$ & $\begin{array}{l}\text { El portainjerto vigoroso resultó en } \\
\text { frutos con mayor deterioro del } \\
\text { color del pedúnculo y menor } \\
\text { contenido de sólidos solubles. }\end{array}$ & $\begin{array}{l}\text { Dziedzic y col., } \\
2017 .\end{array}$ \\
\hline $\begin{array}{l}\text { Melón } \\
\text { reticulado }\end{array}$ & $\begin{array}{c}\text {-cv Athena sobre } 2 \\
\text { híbridos interespecificos } \\
\text { de zapallo Strong Tosa y } \\
\text { Tetsukabuto }\end{array}$ & $\begin{array}{l}\text { El empleo del portainjerto Strong } \\
\text { Tosa' aumentó la vida útil del } \\
\text { producto en forma marcada. }\end{array}$ & Zhao y col., 2011. \\
\hline Sandía & $\begin{array}{l}\text {-cv Tri-X } 3136 \text { sobre } 6 \\
\text { portainjertos de Lagenaria } \\
\text { y } 2 \text { de pepino. }\end{array}$ & $\begin{array}{l}\text { Los portainjertos L43, L46 y L48 } \\
\text { de Lagenaria fueron los más } \\
\text { promisorios para reducir la } \\
\text { pérdida de peso, y ablandamiento } \\
\text { y mantener el color. }\end{array}$ & $\begin{array}{l}\text { Suarez-Hernández } \\
\text { y col., } 2017 .\end{array}$ \\
\hline Berenjena & $\begin{array}{l}\text {-cv Tsakoniki sobre } S \\
\text { torvum y } S \text { sisymbrifolium }\end{array}$ & $\begin{array}{l}\text { Los frutos de plantas injertadas } \\
\text { mostraron menos Vit } \mathrm{C} \text { y firmeza, } \\
\text { reducción en algunos parámetros } \\
\text { sensoriales, pero no se afectó la } \\
\text { aceptabilidad global. }\end{array}$ & $\begin{array}{l}\text { Arvanitoyannis y } \\
\text { col., } 2005 .\end{array}$ \\
\hline
\end{tabular}

Así se ha descrito, que el empleo de diferentes portainjertos afectó la vida útil, ablandamiento, pérdida de peso, susceptibilidad a enfermedades en productos como pomelo, uva, manzana y cereza (Tabla II.1). Para especies hortícolas existen unos pocos trabajos: melón reticulado, sandía y berenjena. En el caso de sandía se informó que el portainjerto afecta tanto la calidad a cosecha como el comportamiento en el 
almacenamiento (Suarez-Hernández y col., 2017). En este caso, se halló que el empleo de portainjertos de Lagenaria fue más efectivo para reducir la deshidratación y el ablandamiento, aunque los frutos mostraron un color de pulpa algo más claro. En melón reticulado el empleo de portainjerto aumentó la vida útil (Zhao y col., 2011).En berenjena existe un solo reporte que estudia alteraciones en la poscosecha. Estos autores observaron que la injertación sobre $S$. torvum o $S$. sysimbrifolium mostró una tendencia a presentar menor puntaje en algunos atributos sensoriales, menor firmeza y contenido de vitamina C que los frutos control (Arvanitoyannis y col., 2005).

Como se mencionó anteriormente uno de los desórdenes fisiológicos más frecuentes en el almacenamiento de frutos durante la poscosecha es el daño por frío (Kader, 2005). Llamativamente, no se han realizado estudios para identificar portainjertos que pueden aliviar la incidencia o severidad de este desorden en la poscosecha de los frutos. Sí se ha evaluado el uso de portainjertos para mejorar la tolerancia de plantas frutales al frío en condiciones de cultivo, como es el caso de naranjo (Zhang y col., 2014). De esta manera se logra el crecimiento y producción de cultivos expuestos a bajas temperaturas ambientales y así anticipar cosechas con el fin de lograr un mejor precio del vegetal ante la falta de oferta del producto en el mercado. Para ello, se han empleado variedades de plantas con mayor resistencia a las bajas temperaturas, las cuales son empleadas como portainjertos de la variedad o copa que se quiere producir (Schwarz y col., 2010). En general, se han estudiado especies silvestres tolerantes a las bajas temperaturas o particularmente accesiones que crecen en lugares de elevada altitud con grandes variaciones de temperaturas entre el día y la noche (Tachibana, 1982; Venema y col., 2005). En línea con estos estudios es importante mencionar, que el DPF en frutos durante la poscosecha se ha relacionado en numerosas ocasiones con la sobreproducción de EROs y que varios estudios han informado la reducción de la severidad al problema, como consecuencia de tratamientos exógenos con poliaminas y ABA de las raíces (Wang, 1993; Serrano y Valero, 2018). En tal sentido, pareciera posible considerar que ciertos portainjertos puedan del mismo modo que afectan la fisiología de la variedad, modificar la susceptibilidad a condiciones de estrés que puedan presentarse en los productos durante la poscosecha. En este sentido, y cómo ya se mencionó en el capítulo anterior, el portainjerto Java utilizado en este trabajo es resistente a las bajas temperaturas de cultivo, y podría esperarse que éste afecte el comportamiento del fruto ante condiciones de estrés por bajas temperaturas durante el almacenamiento poscosecha. De todos modos, esto resulta, al menos por el momento, especulativo y debe establecerse experimentalmente. 
El primer paso consiste en evaluar fenotípicamente el comportamiento de frutos provenientes de plantas injertadas durante la poscosecha en diferentes condiciones de almacenamiento. Es asi que, se propone como objetivo del presente capítulo: "analizar la influencia de portainjertos sobre la calidad comercial, comportamiento poscosecha y susceptibilidad al daño por frio en frutos de berenjena violeta". 


\section{II.2. MATERIALES Y MÉTODOS}

\subsection{Material vegetal $\mathrm{y}$ almacenamiento}

Se emplearon frutos de berenjena violeta (Solanum melongena L.) cv Monarca cosechados a partir de plantas injertadas “a bisel” sobre el pie de la variedad Java, y frutos provenientes de plantas de berenjenas $c v$ Monarca no injertadas que se emplearon como control. Ambos tipos de frutos fueron producidos en un invernadero de la ciudad de La Plata (Buenos Aires, Argentina) durante los meses de noviembre-abril y fueron cosechados en febrero-marzo. El riego y la fertilización se realizaron por goteo. Se regaron y fertilizaron dos veces por día, por la mañana y por la tarde. Se seleccionaron y cosecharon, de cada tipo de planta, 100 frutos de tamaño comercial $(\mathbf{E 2}=17 \mathrm{~cm}$ de longitud) que fueron transportados inmediatamente al laboratorio, se clasificaron por tamaño y se eliminaron los frutos con defectos, se lavaron como se detalló en la sección I.2.1 y los frutos se colocaron de a pares en bandejas de plástico envueltas con film PVC perforado. Se emplearon al menos 80 frutos de cada tipo (control y de plantas injertadas) y se almacenaron a $0{ }^{\circ} \mathrm{C}$ (temperatura de daño por frío) y a $10{ }^{\circ} \mathrm{C}$ (temperatura recomendada) por 0, 7, 14, 21 y 28 días. Se determinó el índice de daño, pérdida de peso, color superficial y resistencia a la compresión como se indicó en la sección I.2.2. En cada día de muestreo durante el almacenamiento se guardaron muestras a $-80{ }^{\circ} \mathrm{C}$ con las que se realizó posteriormente el análisis del contenido de antioxidantes totales, fenoles totales y ácido clorogénico en piel y pulpa, así como antocianinas en piel como se detalla en la sección I.2.3

\subsection{Determinaciones analíticas}

\subsection{1. Índice de escaldaduras}

Los síntomas de daños externos se analizaron visualmente según Concellón y col. (2004) con ligeras modificaciones sobre frutos almacenados a $0{ }^{\circ} \mathrm{C}$. El índice de escaldaduras se calculó con una escala hedónica de cinco grados en orden creciente de incidencia de escaldaduras, expresada en porcentaje del fruto afectado: $1=(0-20 \%), 2=(21-40 \%), 3=$ $(41-60 \%), 4=(61-80 \%), 5=(>80 \%)$. Frutos con un índice mayor a 3 se consideraron no consumibles. Las observaciones se realizaron en 16 frutos para cada tipo de fruto y día de almacenamiento. El índice se realizó utilizando la fórmula 


$$
\text { Índice de escaldaduras }=\frac{\left.\sum \text { (nivel de daño } * N^{\circ} \text { de frutos en el nivel }\right)}{N^{\circ} \text { total de frutos }}
$$

Para el tratamiento estadístico de los datos, los mismos se transformaron utilizando la función arcsen ID descrita por Kone y col. (2017) y Legendre y Legendre (1998). Luego de analizar la homogeneidad de varianzas se realizó el análisis de ANOVA.

\subsubsection{Pérdida de peso}

Se pesaron todos los frutos de berenjena al inicio, durante y al final del período de almacenamiento, en balanza digital (KERN 572, Buenos Aires, Argentina). Los resultados fueron calculados como porcentaje de pérdida de peso con la siguiente ecuación:

$$
\text { Pérdida de peso }(\%)=100 \times\left[\frac{P i-P f}{P i}\right]
$$

Donde Pi y Pf son el peso inicial y el peso final de los frutos. Se pesaron 16 frutos para cada tipo de fruto, temperatura y tiempo de almacenamiento.

\subsubsection{Color de pulpa}

Se cortaron 3 rodajas de la zona ecuatorial del fruto e inmediatamente se midió el color en la pulpa, empleando un colorímetro (Minolta, Model CR-400, Osaka, Japón) obteniendo los parámetros $\mathrm{L}^{*}, \mathrm{a}^{*}, \mathrm{y} \mathrm{b}^{*}$. Las determinaciones se realizaron por triplicado en 16 frutos para cada tipo de fruto, temperatura y tiempo de almacenamiento.

\subsubsection{Resistencia a la compresión (RC)}

Se realizó un ensayo de penetración empleando un texturómetro (Texture Analyzer TA.XT2. Reino Unido) tal como se explicó en la sección I.2.2.5. Los resultados se expresaron como la velocidad de deformación (en $\mathrm{N} / \mathrm{mm}$ ). Las determinaciones se realizaron por triplicado en 16 frutos para cada tipo de fruto, temperatura y tiempo de almacenamiento.

\subsection{Compuestos antioxidantes}

\subsubsection{Extracción en etanol de compuestos antioxidantes}

Los extractos etanólicos se realizaron como se detalló en la sección I.2.3.1. Los mismos se emplearon para determinar el contenido de ácido clorogénico y capacidad antioxidante. 
Se prepararon dos extractos para cada tipo de fruto, temperatura y tiempo de almacenamiento.

\subsubsection{Capacidad antioxidante (TEAC)}

La determinación se realizó de acuerdo a Arnao y col. (2001) y del mismo modo que en la sección I.2.3.3. Se utilizó Trolox como estándar. Se realizaron tres replicados por cada tipo de fruto, temperatura y tiempo de almacenamiento. Los resultados se expresaron como Capacidad Antioxidante Equivalente a Trolox (TEAC) en mg/kg.

\subsection{3. Ácido clorogénico (ACG)}

Se determinó espectrofotométricamente como se mencionó en la sección I.2.3.4 Se empleó ACG como patrón. Las medidas se realizaron por duplicado para cada tipo de fruto, temperatura y tiempo de almacenamiento. Los resultados se expresaron en $\mathrm{mg}$ de $\mathrm{ACG} / \mathrm{kg}$.

\subsubsection{Antocianinas}

La extracción y cuantificación de pigmentos se determinó de la misma manera que la explicada en la sección I.2.3.5. Las medidas fueron realizadas por duplicado para cada tipo de fruto, temperatura y tiempo de almacenamiento. Los resultados se expresaron en equivalentes de delfinidin-3-glucósido en $\mathrm{mg} / \mathrm{kg}$ según Saldilova y col. (2006).

\subsection{Análisis estadístico}

Los experimentos se realizaron de acuerdo a un diseño factorial. Los datos se analizaron por medio de ANOVA. Las medias fueron comparadas por el test LSD de Fisher a fin de determinar las diferencias mínimas significativas con un nivel de significancia de $\mathrm{P}<0,05$ empleando el software INFOSTAT. 


\section{II.3. RESULTADOS Y DISCUSIÓN}

\subsection{Efecto del portainjerto sobre el comportamiento poscosecha en} almacenamiento a $10{ }^{\circ} \mathrm{C}$

\subsubsection{Apariencia y color de pulpa}

Durante el período poscosecha se producen reacciones bioquímicas en los productos frutihortícolas, por ende, existen cambios de calidad (Valero y Serrano, 2010) como la pérdida de peso o el deterioro del producto que conducen a la disminución de la calidad organoléptica y comercial. Estos factores se ven significativamente reducidos ante el empleo de la refrigeración, empleando temperaturas recomendadas para cada tipo de vegetal. Para el caso de berenjena, esta temperatura resulta ser de $10-12{ }^{\circ} \mathrm{C}$ (Cantwell y Suslow, 2000).

La apariencia interna y externa de los frutos provenientes de plantas injertadas o control almacenados a la temperatura recomendada de $10{ }^{\circ} \mathrm{C}$ se muestran en la Figura II.3. E1 principal síntoma de deterioro durante la poscosecha de los frutos fue la deshidratación. Visualmente no se observaron diferencias marcadas en el deterioro poscosecha entre ambos tipos de fruto. Es así que los frutos control e injertados permanecieron hasta el dia 21 sin presencia de pitting en la piel y mostraron buen brillo en el cáliz, con ausencia de hongos y pudriciones. La pulpa no mostró avances de deterioro, ni pardeamiento visible en ningún tipo de fruto. 


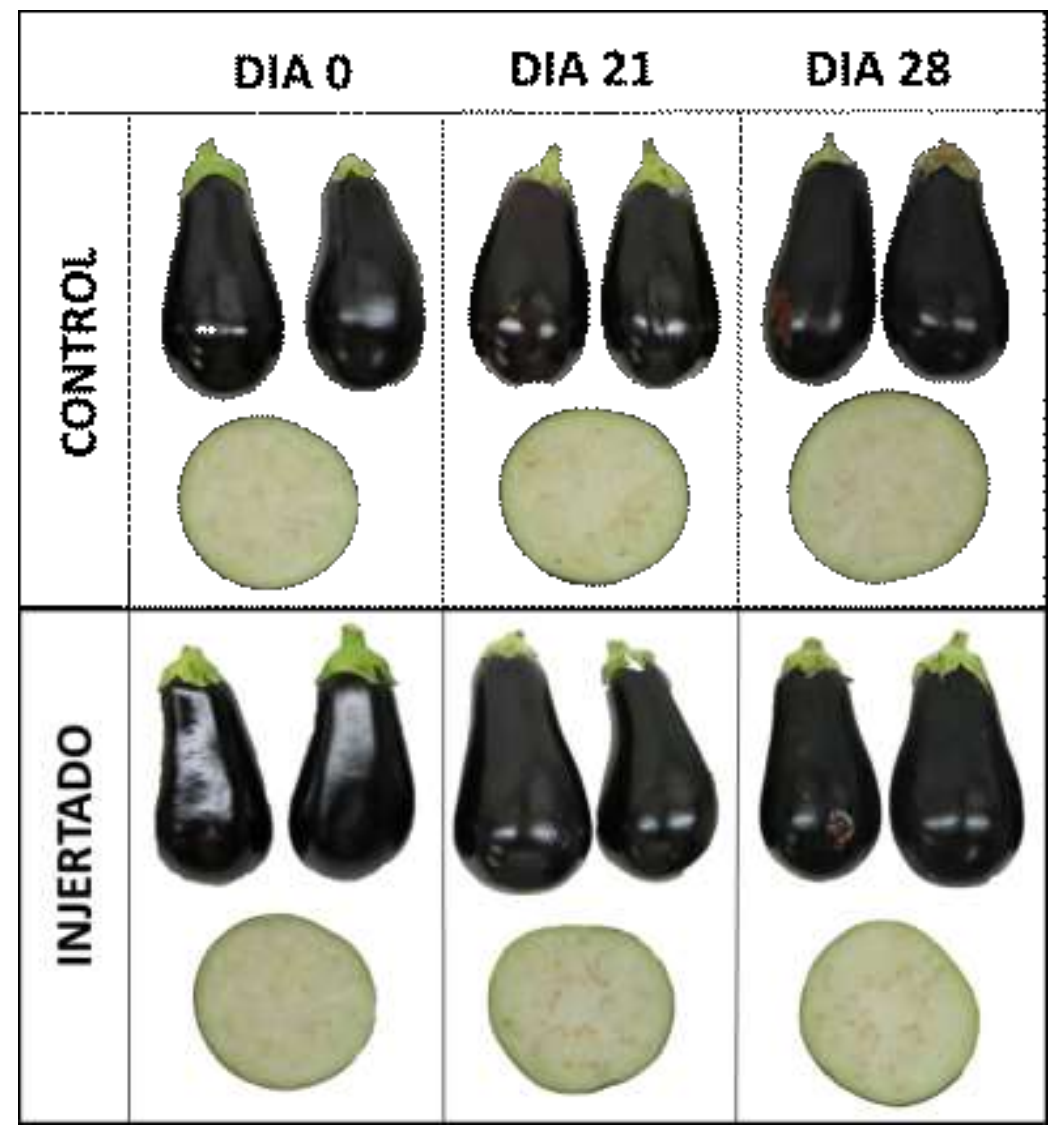

Figura II.3. Apariencia de frutos de berenjenas provenientes de plantas control e injertadas almacenadas a $10^{\circ} \mathrm{C}$ por 0,21 y $28 \mathrm{~d}$.

El parámetro de color $L^{*}$ que denota la luminosidad ha mostrado ser adecuado para observar alteraciones del color cuando las tonalidades de base son blancas o muy claras. Así, en la literatura se ha encontrado buena correlación con la aparición de manchas o pardeamiento de pulpa (Concellón y col., 2007, 2012). Coincidentemente con la apariencia interna de los frutos mostrada recientemente, la luminosidad ( $\mathrm{L}^{*}$ ) no reveló prácticamente variación entre frutos provenientes de plantas injertadas y control, inclusive a tiempos largos de almacenamiento a $10{ }^{\circ} \mathrm{C}$ (Figura II.4). A su vez, ambos tipos de fruto permanecieron prácticamente sin diferencias hasta el final del almacenamiento. De esta manera, se comprueba con una medida objetiva que esta combinación pie-variedad no modifica la luminosidad inherente a la pulpa, y que a esta temperatura no se produce pardeamiento interno en la pulpa en los dos tipos de fruto. 


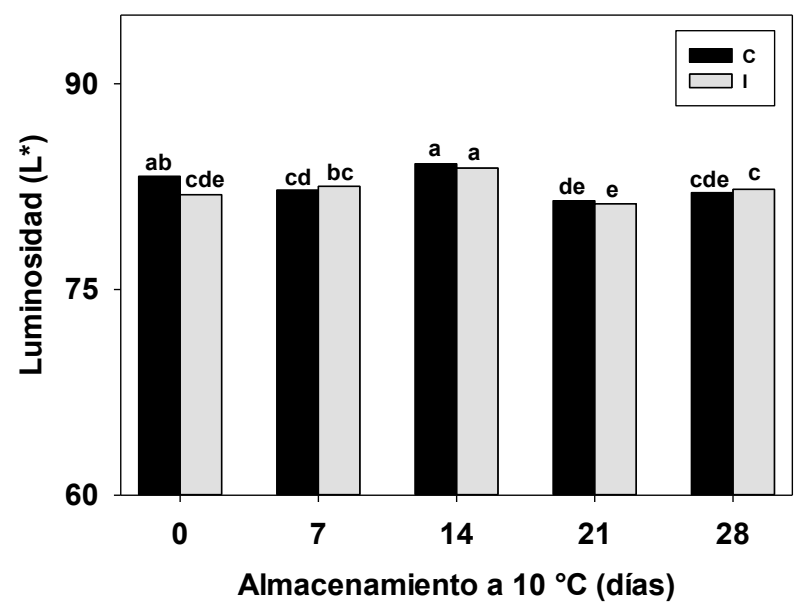

Figura II.4. Luminosidad ( $\left.\mathrm{L}^{*}\right)$ de frutos de berenjena provenientes de plantas control (C) e injertadas (I) almacenadas a $10^{\circ} \mathrm{C}$ durante $0,7,14,21$ y 28 días. Letras distintas indican diferencia significativa según el test LSD de Fisher con un nivel de significancia de $\mathrm{P}<0,05$.

\subsubsection{Resistencia a la compresión y pérdida de peso}

Existe una relación directa entre la pérdida de peso y la calidad del producto, según Valero y Serrano (2010), se considera un producto de baja calidad aquel que presenta principalmente pérdida de turgencia, viéndose afectados también la textura. La turgencia es una condición necesaria para la apariencia fresca de la fruta, ya que los consumidores no aceptan una fruta blanda, opaca y/o arrugada.

La resistencia a la compresión (RC) al inicio del almacenamiento no se vió modificada por el tipo de fruto (FiguraII.5A). Esto difiere con lo hallado por Moncada y col. (2013) y Miceli y col. (2014) quienes observaron que frutos provenientes de plantas injertadas recién cosechados fueron significativamente menos firmes que sus controles. De todos modos, estos autores no evaluaron los cambios durante el almacenamiento refrigerado. En el presente estudio se observó una reducción de la RC luego de 7 días de almacenamiento, alcanzando valores cercanos a $3 \mathrm{~N} / \mathrm{mm}$ en ambos grupos de frutos estudiados. Más allá de ello, la combinación Java-Monarca no modificó la RC durante el almacenamiento de los frutos a $10^{\circ} \mathrm{C}$. Sin embargo, el empleo de la técnica de injertación sobre otros pies ha mostrado diferencias en la turgencia de los frutos de berenjena. Así, Arvanitoyannis y col. (2005), encontraron que frutos de berenjena de la variedad “Tsakoniki” injertadas sobre pies S. torvum y S. sisymbriifolium fueron más blandos que sus respectivos controles luego del almacenamiento a $10^{\circ} \mathrm{C}$, indicando que el portainjerto utilizado pudo modificar este parámetro. 
La pérdida de peso se incrementó con el almacenamiento. Los frutos provenientes de plantas injertadas almacenados a $10{ }^{\circ} \mathrm{C}$ presentaron una pérdida de peso levemente mayor que los frutos control (FiguraII.5B), aunque no fue estadísticamente diferente. Se alcanzaron valores de 3,4-3,7\% al final del almacenamiento. Esa pérdida no fue tan severa como para limitar su vida poscosecha ya que, en berenjena, las pérdidas de peso que limitan su comercialización deben ser mayores al 7-10\% del peso fresco (Mohammed y Brecht., 2002).

En función de los resultados antes mencionados se observa que la injertación sobre el pie Java no causó modificaciones significativas en la apariencia externa o interna, el pardeamiento de pulpa, y el ablandamiento durante el almacenamiento por 28 días a 10 ${ }^{\circ} \mathrm{C}$.

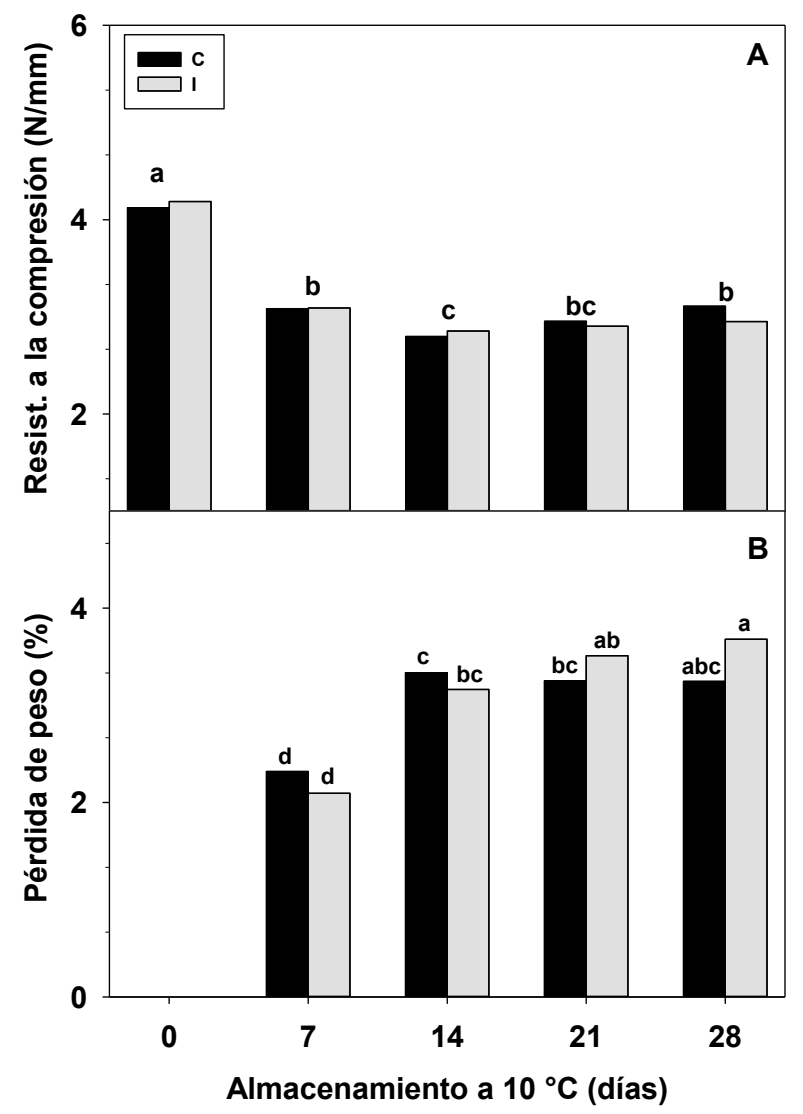

Figura II.5. A) Resistencia a la compresión y B) pérdida de peso de frutos de berenjena provenientes de plantas control (C) e injertadas (I) almacenadas a $10{ }^{\circ} \mathrm{C}$ durante $0,7,14,21$ y 28 días. Letras distintas indican diferencia significativa según el test LSD de Fisher para: A) el factor tiempo de almacenamiento, B) la interacción tiempo*tipo de fruto, con un nivel de significancia de $\mathrm{P}<0,05$.

\subsubsection{Compuestos bioactivos en piel}

Como se describió en el capítulo I, al momento de cosecha, la capacidad antioxidante de la piel de los frutos de berenjena provenientes de plantas injertadas fue menor a la de los 
frutos control (Figura II.6A). De todos modos, resulta de interés mencionar que no se encontraron estudios previos que evalúen el contenido de compuestos antioxidantes y comportamiento poscosecha de frutos de berenjena provenientes de plantas injertadas.

En esta parte del trabajo se pudo inferir que durante las dos semanas iniciales del almacenamiento a $10{ }^{\circ} \mathrm{C}$ hubo un aumento en los valores de TEAC de la piel de berenjena alcanzando valores comparables para ambos tipos de frutos. De forma similar, en trabajos previos, Massolo y col. (2011) y Concellón y col. (2012) encontraron un incremento de los compuestos fenólicos en frutos de berenjena durante los primeros días de almacenamiento a $10{ }^{\circ} \mathrm{C}$. Uno de los primeros pasos crucial en la biosíntesis de fenólicos es catalizado por la enzima fenilalanina amonio-liasa (PAL). Massolo y col. (2011) informaron una mayor actividad PAL en almacenamiento a baja temperatura. Se ha demostrado en varios sistemas que la enzima PAL es inducida por estrés a baja temperatura (Sanchez-Ballesta y col., 2000; Lafuente y col., 2001; Hyodo y col., 2017). Particularmente en berenjenas, se ha reportado un aumento de PAL durante la refrigeración (Kozukue y col., 1979). A tiempos más largos de almacenamiento, se observó un avance de los procesos degradativos que disminuyó los compuestos antioxidantes (Figura II.6A). A los 21 días los frutos de plantas injertadas mantuvieron un nivel significativamente superior de TEAC que los controles, pero estas diferencias desaparecieron al día 28. Al analizarse los cambios en el contenido de antocianinas de la piel de berenjena se observó que este grupo de flavonoides se mantuvo casi sin cambios hasta el día 14 y sin diferencias entre frutos provenientes de plantas injertadas o control (Figura II.6B). Hacia el final del almacenamiento, se observó un descenso siendo levemente mayor en frutos de plantas injertadas. El contenido de ACG mostró variaciones que reflejaron lo hallado para los niveles de TEAC, presentando a los 7 y 14 días un incremento en el contenido de este compuesto fenólico que osciló entre un 15-20 \% para los frutos provenientes de plantas injertadas y entre 20-25\% para los frutos de plantas control (Figura II.6C). A estos tiempos, el contenido de ACG fue levemente inferior en los frutos de plantas injertadas que sus respectivos controles. Mientras que, el contenido de ACG, fue comparable entre ellos al final del almacenamiento. 


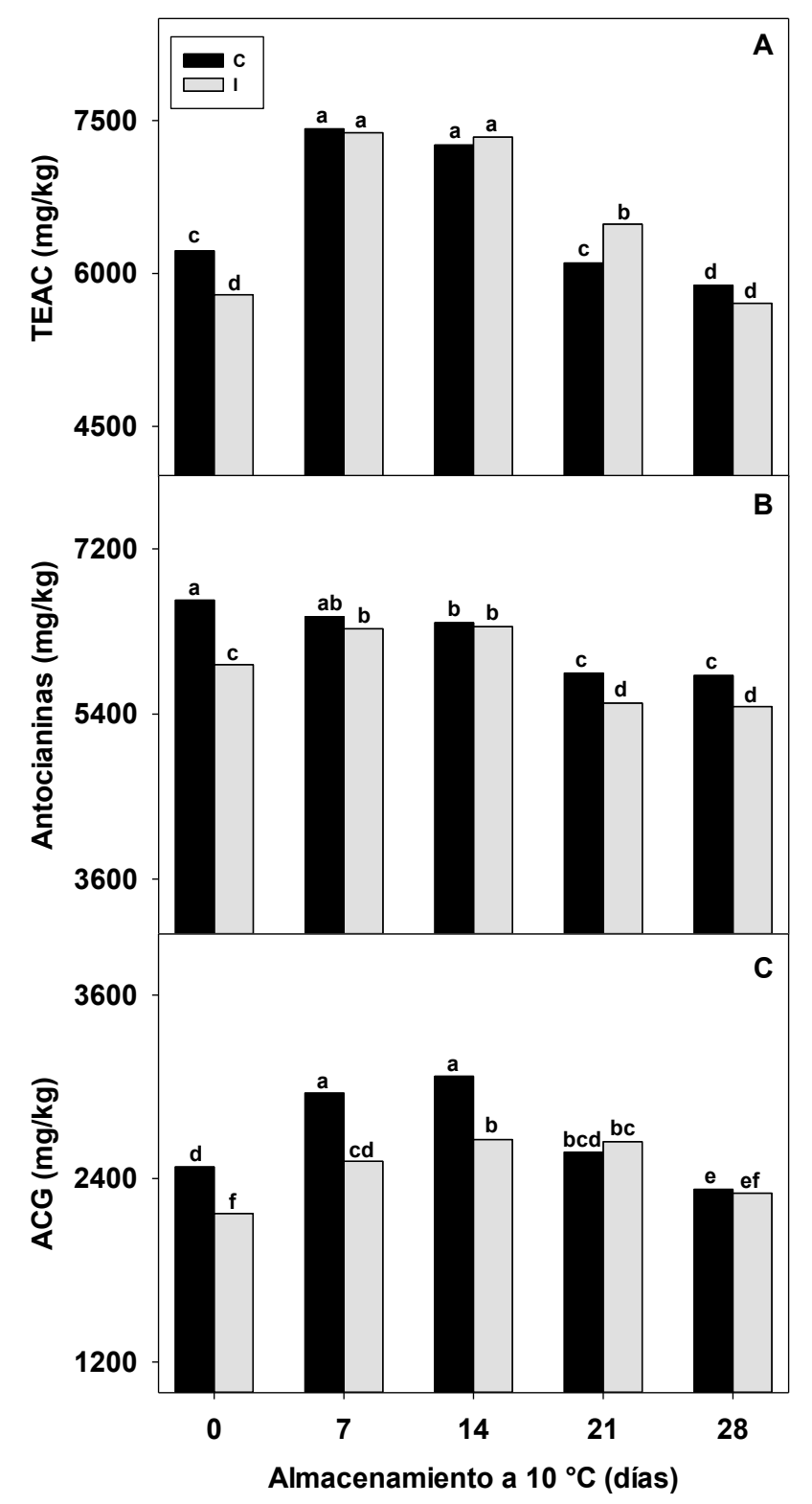

Figura II.6. A) Capacidad antioxidante equivalente a trolox (TEAC), B) Antocianinas y C) Ácido clorogénico (ACG) en piel de frutos de berenjenas provenientes de plantas control (C) e injertadas (I) almacenadas a $10{ }^{\circ} \mathrm{C}$ durante $0,7,14,21$ y 28 días. Letras distintas indican diferencia significativa según el test LSD de Fisher con un nivel de significancia de $\mathrm{P}<0,05$.

Los resultados encontrados muestran que, en la piel de berenjena, la biosíntesis de ACG continúa durante la poscosecha de frutos almacenados a $10^{\circ} \mathrm{C}$ durante los primeros 14 días, para luego predominar los procesos degradativos y reducir el contenido de antioxidantes totales y principalmente antocianinas y ACG. 


\subsubsection{Compuestos bioactivos en pulpa}

Durante el almacenamiento a $10{ }^{\circ} \mathrm{C}$, el TEAC en la pulpa de los frutos permaneció prácticamente sin diferencias hasta el día 21 en los frutos control y 28 en los injertados. Aunque los frutos control presentaron entre un 10-12\% más de antioxidantes que los frutos provenientes de plantas injertadas (Figura II.7A).

En la pulpa, el ACG, presentó un incremento a los 7 días y a partir de allí una tendencia descendente en el tiempo (Figura II.7B). A lo largo de prácticamente todo el almacenamiento, los frutos provenientes de plantas injertadas presentaron menor contenido de este compuesto fenólico que los frutos control.

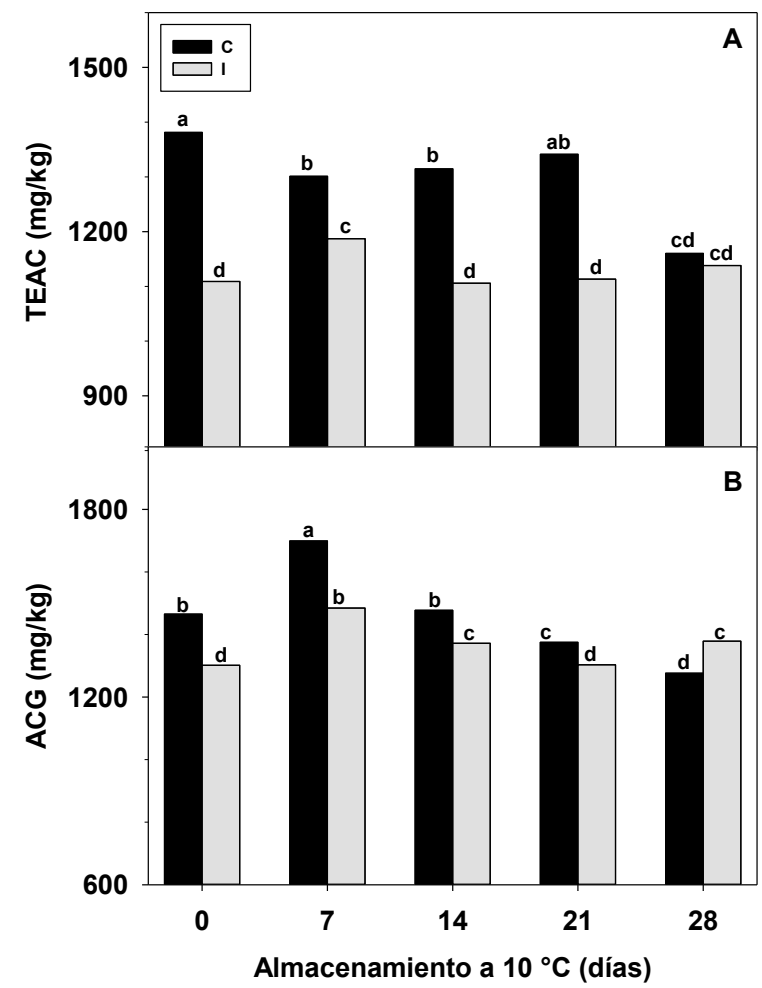

Figura II.7. A) Capacidad antioxidante equivalente a trolox (TEAC), B) Ácido clorogénico (ACG) en pulpa de frutos de berenjenas provenientes de plantas control (C) e injertadas (I) almacenadas a $10{ }^{\circ} \mathrm{C}$ durante 0 , 7, 14, 21 y 28 días. Letras distintas indican diferencia significativa según el test LSD de Fisher con un nivel de significancia de $\mathrm{P}<0,05$.

Estos resultados demuestran que la combinación Java-Monarca no afectó mayoritariamente el comportamiento de los frutos de berenjena durante el almacenamiento a la temperatura de $10^{\circ} \mathrm{C}$. No se observaron mayores alteraciones en la apariencia o susceptibilidad a la deshidratación, color de pulpa, resistencia a la compresión, e incluso en la capacidad y contenido de antioxidantes en la piel de los frutos. 
Sólo se halló menor contenido y estabilidad de ACG, tanto en piel como en pulpa de frutos de plantas injertadas y almacenadas a temperatura recomendada.

Es de destacar, que el empleo de este portainjerto fue recomendado para ser empleado a bajas temperaturas de cultivo, hecho que permitía el crecimiento de las plantas ante condiciones ambientales adversas para las mismas. Sin embargo, no se ha estudiado si esta mayor resistencia a las bajas temperaturas es translocada sólo desde la raíz a la planta o también implica la afluencia de ciertos metabolitos de interés a los frutos y que le permitan tener una mayor resistencia al daño por frío ante el almacenamiento a temperaturas por debajo de la recomendada. Así, en la siguiente etapa de este capítulo se evaluará el comportamiento de frutos de esta combinación pie-variedad ante un almacenamiento poscosecha a $0^{\circ} \mathrm{C}$.

\subsection{Efecto del portainjerto sobre el comportamiento poscosecha en}

\section{almacenamiento a $0{ }^{\circ} \mathrm{C}$ (temperatura de daño por frío)}

\subsubsection{Apariencia, síntoma de daño y pardeamiento de pulpa}

El color y apariencia de la piel del fruto es un factor que influye en la preferencia del consumidor y la decisión de compra. Por lo que, la aparición de síntomas de deterioro es clave en la determinación del precio del producto y disminución de la aceptabilidad de los mismos en el mercado. La temperatura de $0{ }^{\circ} \mathrm{C}$ causa daño por frío en frutos de berenjena, cuyos síntomas comienzan a ser visibles dependiendo de la susceptibilidad de cada cultivo. Aquí, comenzaron a percibirse a partir del dia 14, en los frutos control el pitting y las primeras escaldaduras en el exterior, internamente se observo pardeamiento de semillas. Los mismos fueron incrementando con el tiempo a una velocidad diferente según se tratara de frutos control o de plantas injertadas. Así los frutos control se dañaron de forma anticipada y en mayor medida que los frutos de plantas injertadas. Estos últimos mostraron una mejor apariencia externa e interna respecto de los frutos control manifestando menor pardeamiento interno de pulpa a partir del día 14, y menores daños superficiales a partir del día 21 (Figura II.8).

El principal daño superficial a esta temperatura fueron las escaldaduras en la piel de los frutos, las cuales se manifiestan como manchas marrones, húmedas y con depresiones en la piel (Concellón y col., 2007). De una manera subjetiva se calificó el nivel de incidencia de escaldaduras en un índice de 1 a 5 en orden creciente de deterioro (\% de zona del fruto 
afectada). Si bien estadísticamente no se hallaron diferencias entre frutos control o injertados, se visualiza que los frutos control presentaron mayor índice de escaldaduras que los frutos injertados (Figura II.9A).

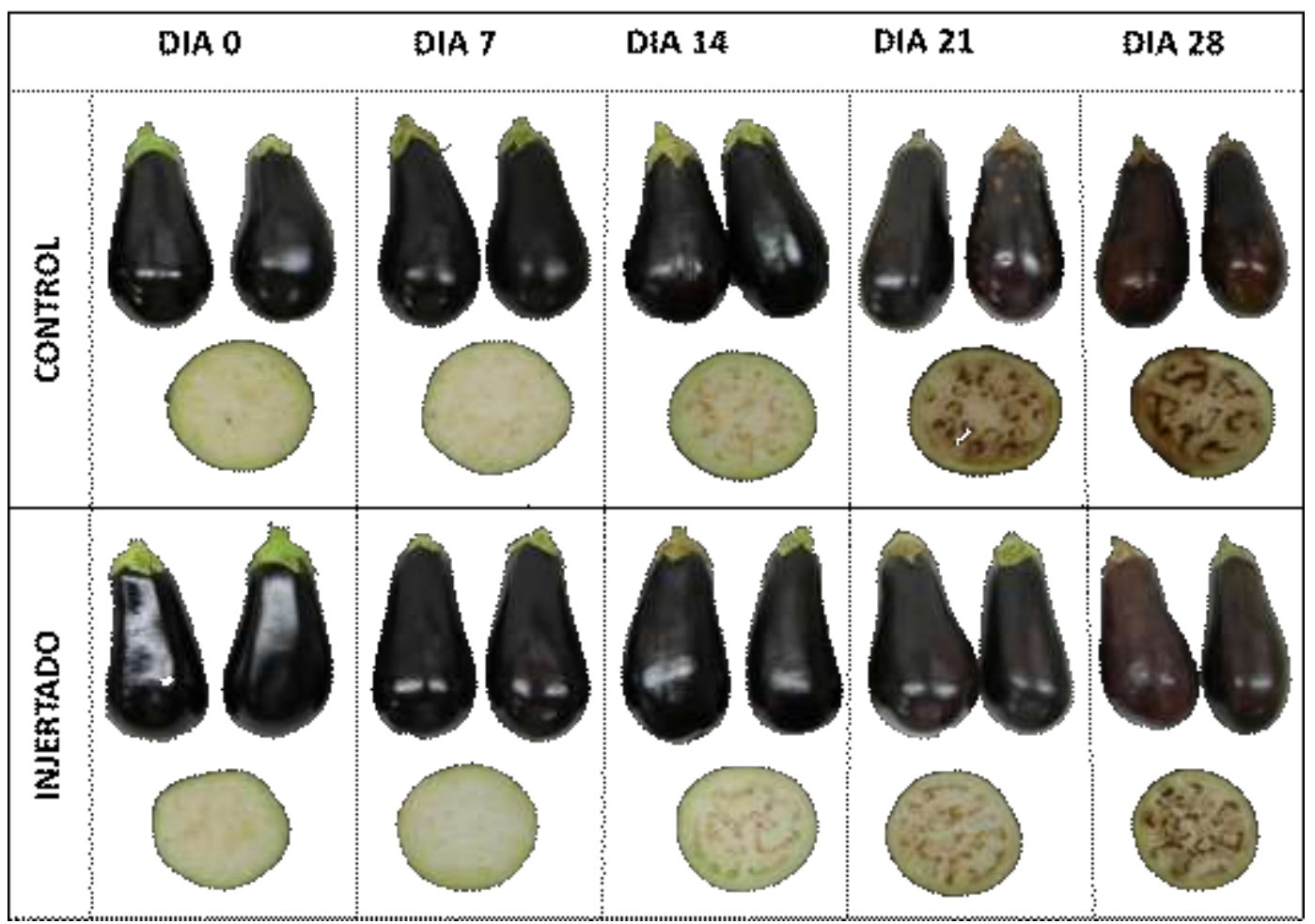

Figura II.8. Apariencia externa e interna de frutos de berenjena provenientes de plantas control e injertadas almacenadas a $0{ }^{\circ} \mathrm{C}$ por $0,7,14,21$ y $28 \mathrm{~d}$.

A partir del día 21 los frutos control presentaron un índice de daño por escaldaduras superior a 3 , indicando que más del $40 \%$ de la superficie de estos frutos presentaba daño y que, por lo tanto, los frutos ya no eran consumibles. Sin embargo, a este tiempo, los frutos provenientes de plantas injertadas aún se encontraban consumibles y con una menor presencia de escaldaduras. Se verificó un retraso de 7 días en el avance del deterioro superficial en frutos de plantas injertadas.

El pardeamiento de la pulpa es una de las principales causas de pérdida de calidad poscosecha en berenjena y que antecede a los síntomas superficiales o externos (PérezGilabert y García-Carmona, 2000). Se manifiesta, en primera instancia, alrededor de la semilla como principal síntoma de daño interno para luego extenderse al resto de la pulpa (Concellón y col., 2012). Como ya se mencionó, el parámetro de color L* es adecuado para mostrar la luminosidad de la pulpa y es sumamente sensible al desarrollo de color marrón o aparición de pardeamiento. Hasta los 7 días, los frutos presentaron pocas variaciones en cuanto al pardeamiento de pulpa independientemente de si eran de plantas 
injertadas o control (Figura II.9B). A partir del día 14, la pulpa de los frutos de plantas injertadas se mantuvo significativamente más luminosa indicando un menor pardeamiento, mientras que los frutos control disminuyeron notoriamente su valor de $\mathrm{L}^{*}$ con el avance del almacenamiento, observándose una pulpa $28 \%$ más oscura a los 28 días de almacenamiento.

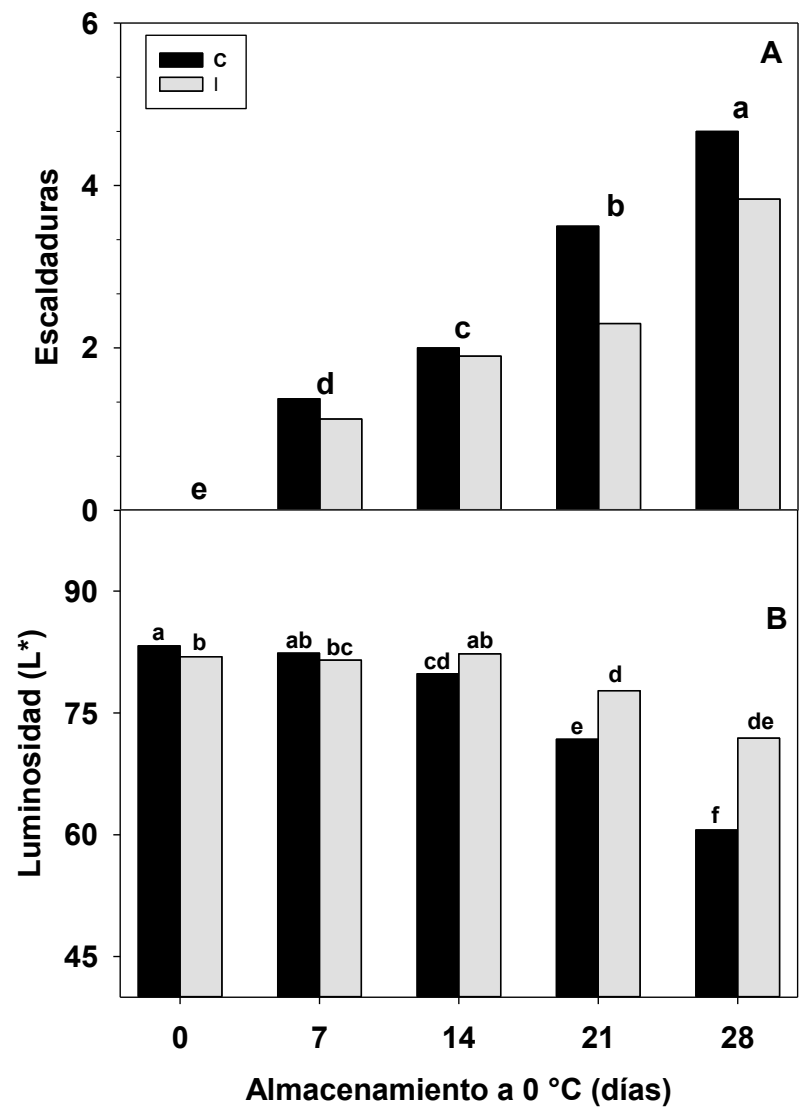

Figura II.9. A) Escaldaduras de la piel y B) Luminosidad (L*) de la pulpa de berenjenas provenientes de plantas control (C) e injertadas (I) almacenadas a $0{ }^{\circ} \mathrm{C}$ durante $0,7,14,21$ y 28 días. Letras distintas indican diferencia significativa según el test LSD de Fisher para: A) el factor tiempo de almacenamiento, B) la interacción tiempo*tipo de fruto, con un nivel de significancia de $\mathrm{P}<0,05$.

En términos generales los frutos provenientes de plantas injertadas fueron menos susceptibles al pardeamiento interno, mostrando un retraso de 7 días respecto de frutos control, ya que presentaban un valor de $\mathrm{L}^{*}=78$ y 72 al día 21 y 28 , respetivamente, similar al de los frutos control al día 14 y 21. Se han informado efectos similares en frutos sensibles al pardeamiento. Así, el portainjerto empleado en duraznos, también influyó en la calidad de los frutos almacenados a $0^{\circ} \mathrm{C}$, ya que aquellos provenientes de cultivares de Seleção Viamão y Umezeiro presentaron menor pardeamiento enzimático en la pulpa (Barreto y col., 2018). 


\subsubsection{Resistencia a la compresión y pérdida de peso}

Los frutos provenientes de plantas injertadas almacenados a $0{ }^{\circ} \mathrm{C}$ presentaron, al inicio del almacenamiento y hasta el día 14, una resistencia a la compresión constante y similar a la de los frutos control; a diferencia de lo ocurrido a $10{ }^{\circ} \mathrm{C}$ donde se observó una disminución del $50 \%$ al día 7. Hacia el final del almacenamiento, los frutos de plantas injertadas retuvieron una mejor firmeza y fueron un $11 \%$ y un $45 \%$ más firmes que los frutos control al día 21 y 28 del almacenamiento, respectivamente (Figura II.10A).

Los frutos almacenados a $0{ }^{\circ} \mathrm{C}$ presentaron una menor pérdida de peso (Figura II.10B) respecto de los almacenados a $10^{\circ} \mathrm{C}$ (Figura II.6B), ya que a temperaturas más bajas hay una menor actividad metabólica. Durante el almacenamiento a $0{ }^{\circ} \mathrm{C}$, no hubo prácticamente diferencias entre la pérdida de peso de frutos provenientes de plantas injertadas y control (Figura II.10B), ambos alcanzaron valores inferiores al $1 \%$.

Estos resultados indicarían que los cambios en la firmeza no son debidos a la pérdida de agua o deshidratación de los frutos sino a un cambio en la estructura del tejido. Durante el almacenamiento a $0{ }^{\circ} \mathrm{C}$, los frutos de plantas injertadas presentaron mejor calidad y menor porcentaje de escaldaduras por lo que podría inferirse que hubo menor daño celular en los tejidos de estos frutos y la consecuente mayor firmeza. Previamente, se ha estudiado que ciertos procesos bioquímicos se ven afectados por la técnica de injertación y terminan favoreciendo la tolerancia al estrés por frío. Así, la injertación de naranjo sobre Poncirus trifoliata ha permitido extender el cultivo a zonas más marginales desde el punto de vista climático y con mayores riesgos de heladas (Zhang y col., 2014). Particularmente, se ha hallado que la tolerancia se asocia con un RNAm que reduce la expresión de ACC oxidasa reprimiendo la síntesis de etileno y que promueve la biosíntesis de poliaminas y una mejora en la capacidad de detoxificar EROs (Zhang $\mathbf{y}$ col., 2016). Las poliaminas son metabolitos involucrados en la respuesta al estrés biótico y abiótico, y a su vez, su metabolismo estaría relacionado con la menor pérdida de firmeza de los frutos dado su carácter catiónico y por el cual puede formar complejos con estructuras aniónicas tales como las pectinas de la pared celular (González-Aguilar y col., 2004; Tiecher y col., 2013; Liu y col., 2015). Este hecho podría estar sucediendo en las berenjenas de plantas injertadas y con ello lograr la mejor retención de la firmeza durante el almacenamiento. 


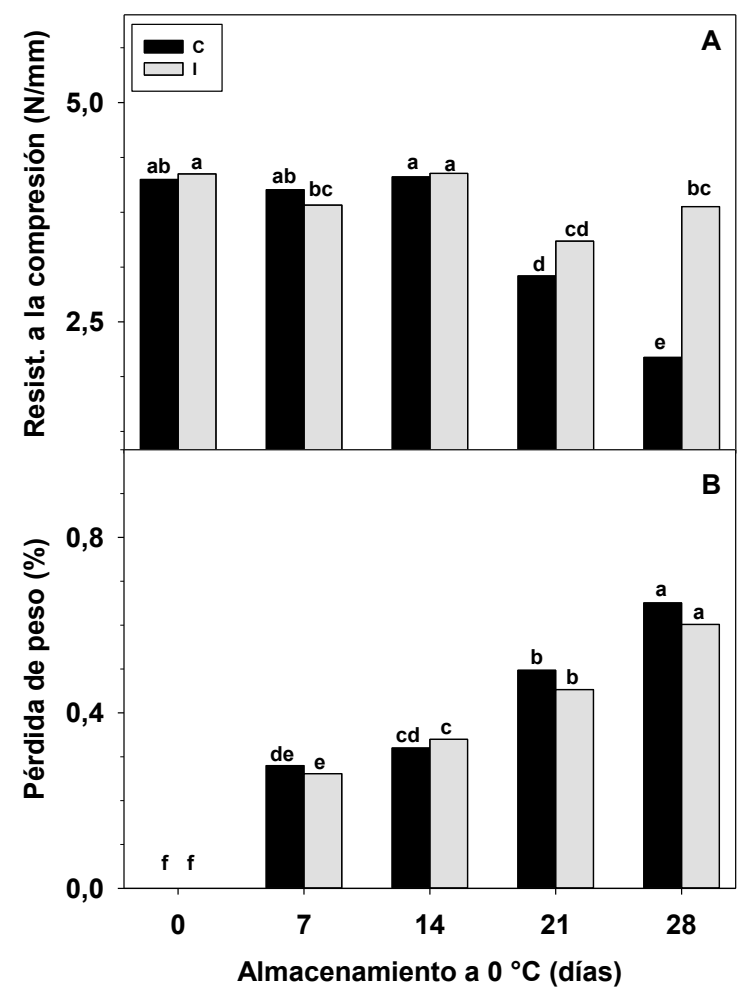

Figura II.10. A) Resistencia a la compresión y B) pérdida de peso de frutos de berenjena provenientes de plantas control (C) e injertadas (I) almacenadas a $0{ }^{\circ} \mathrm{C}$ durante $0,7,14,21$ y 28 días. Letras distintas indican diferencia significativa según el test LSD de Fisher con un nivel de significancia de $\mathrm{P}<0,05$.

\subsubsection{Compuestos bioactivos en piel}

Estudios efectuados en plantas de pepino injertadas sobre portainjertos resistentes y sensibles al frío, se halló que la diferencia entre ambos residía en la diferencia en la acumulación de EROs. (Zhou y col., 2004, 2006, 2007; Rhee y col., 2007). En plantas de tomate, se halló que el injerto podía prevenir casi por completo la acumulación de $\mathrm{H}_{2} \mathrm{O}_{2}$ inducida por el frío en las hojas (Rivero y col., 2003). Sin embargo, los estudios sobre los efectos que alcanzan a los frutos, y si éstos terminan adquiriendo también una mayor tolerancia al frío, son prácticamente nulos.

$\mathrm{Al}$ analizar la capacidad antioxidante y los principales compuestos antioxidantes de la piel se encontró una tendencia general descendente con el almacenamiento a $0{ }^{\circ} \mathrm{C}$. En lo que respecta a la capacidad antioxidante total equivalente a Trolox o TEAC se puede observar que, si bien disminuyó avanzaba el almacenamiento, los frutos de plantas injertadas presentaron una mayor retención de la capacidad antioxidante que los controles, alcanzando valores de aproximadamente 10-15\% más altos en los días 21 y 28 (Figura II.11A). En la piel, se hallan principalmente compuestos fenólicos, siendo el contenido de antocianinas 2/3 superior al del ácido clorogénico. Al momento de cosecha 
el contenido de compuestos antociánicos en la piel de los frutos provenientes de plantas injertadas fue un 16\% menor en relación a los frutos controles (Figura II.1B). Por otro lado, en el almacenamiento, los frutos injertados lograron retener las antocianinas en mayor medida que los controles coincidiendo con la mayor retención de la capacidad antioxidante total en la piel. Concellón y col. (2012) y Wang y Stretch, (2001) también encontraron una correlación positiva entre el contenido de antocianinas durante el almacenamiento a baja temperatura y la capacidad antioxidante de cultivares de berenjena y arándanos.

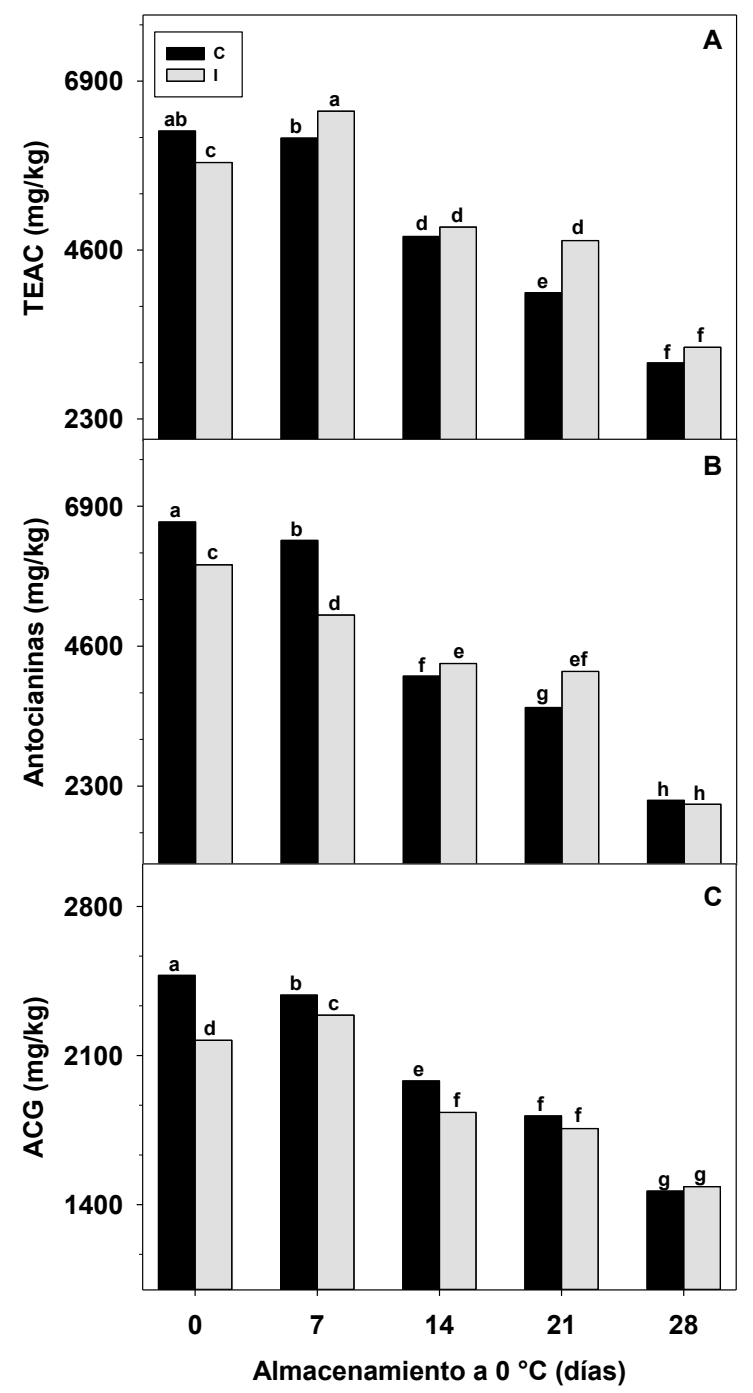

Figura II.11. A) Capacidad antioxidante equivalente a trolox (TEAC), B) Antocianinas y C) Ácido clorogénico (ACG) en piel de frutos de berenjenas provenientes de plantas control (C) e injertadas (I) almacenadas a $0^{\circ} \mathrm{C}$ durante $0,7,14,21$ y 28 días. Letras distintas indican diferencia significativa según el test LSD de Fisher con un nivel de significancia de $\mathrm{P}<0,05$.

El contenido de ácido clorogénico, fue afectado por la combinación pie-variedad (Figura II.11C). Si bien los niveles de ACG en frutos de plantas injertadas fue menor durante los 
primeros 14 días de almacenamiento, la velocidad de disminución durante el almacenamiento fue más leve respecto de la observada en frutos control, lo que termina ocasionando una mejor retención de este potente antioxidante y con valores comparables a los 21 y 28 días a los hallados en frutos control.

No se han reportado en la bibliografía estudios de estos compuestos antioxidantes en almacenamiento poscosecha de frutos de berenjena de plantas injertadas. Aquí se halló que esta combinación Java-Monarca logró mantener de una manera más eficiente el contenido de compuestos bioactivos en la piel de los mismos a temperaturas por debajo de las recomendadas para berenjenas y que le ocasionan DPF.

\subsubsection{Compuestos bioactivos en pulpa}

Al analizar los compuestos bioactivos en la pulpa de los frutos al inicio del almacenamiento, los frutos de plantas injertadas presentaron menor capacidad antioxidante que los frutos control (Figura II.12A). Durante el almacenamiento, los niveles de TEAC mostraron una tendencia general descendente, aunque los frutos de plantas injertadas mostraron una menor velocidad logrando retener mejor los niveles de capacidad antioxidante. Así, se visualiza un retraso de 7 días en la disminución de TEAC ya que al día 21 estos frutos presentaron valores levemente inferiores a los frutos control al día 14. Este hecho, se verifica al comparar niveles de TEAC de frutos injertados a los $28 \mathrm{~d}$ comparables al de frutos control a los $21 \mathrm{~d}$.

El ACG también se retuvo en mayor medida en los frutos injertados, logrando hacia el final del almacenamiento una acumulación del 30\% y $60 \%$ en los días 21 y 28 , respectivamente, superando ampliamente al contenido de los frutos control (Figura II.12B). 


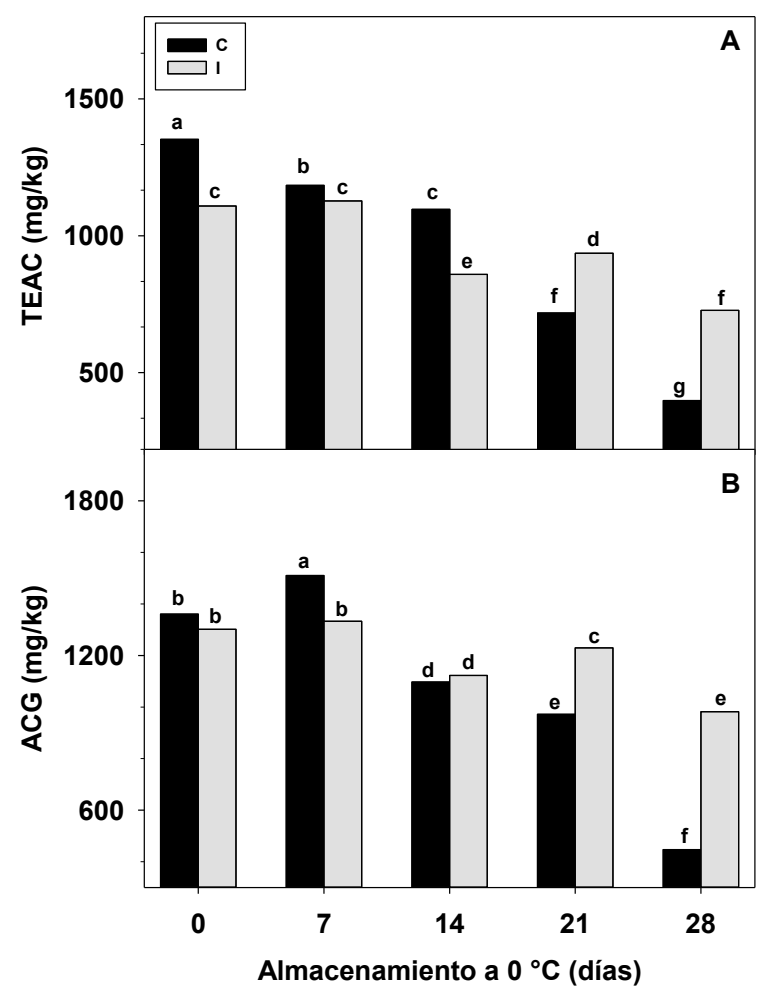

Figura II.12. A) Capacidad antioxidante equivalente a trolox (TEAC), B) ácido clorogénico (ACG) en pulpa de frutos de berenjenas provenientes de plantas control (C) e injertadas (I) almacenadas a $0{ }^{\circ} \mathrm{C}$ durante 0 , 7, 14, 21 y 28 días. Letras distintas indican diferencia significativa según el test LSD de Fisher con un nivel de significancia de $\mathrm{P}<0,05$.

La tecnología del injerto genera un estrés en las plantas que activaría el sistema de defensa antioxidante para eliminar las EROs, manteniendo el equilibrio del sistema redox celular (Baxter y col., 2013). En plantas de tomate injertadas se observó un incremento de las enzimas peroxidasa (POD) y catalasa (CAT) que estarían implicadas en el desarrollo del injerto para hacer frente al estrés oxidativo (Fernández-García y col., 2004). Asimismo, como se mencionó anteriormente, se sabe que existen múltiples interacciones entre el portainjerto y la copa o variedad. Además de transportarse nutrientes y fotoasimilados, se produce un intercambio de señales hormonales (Cutting y Lyne, 1993; Aloni y col., 2010); transporte de diferentes formas de ARN y proteínas (Haroldsen y col., 2012), que se translocan de los portainjertos a la copa, y que también podrían llegar a los frutos y otorgarles ese comportamiento diferente frente al estrés causado por el almacenamiento a bajas temperaturas durante la poscosecha.

Con el fin de avanzar en estos aspectos, mayores estudios deben efectuarse sobre frutos de plantas injertadas. 


\section{II.4. CONCLUSIONES}

Los frutos de berenjena violeta $c v$ Monarca cosechados de plantas injertadas sobre pie Java y almacenados a $10{ }^{\circ} \mathrm{C}$, presentaron pocas diferencias en el comportamiento poscosecha en cuanto a pérdida de peso, color de pulpa, resistencia a la compresión y fueron comercializables hasta el último día del almacenamiento de igual manera que los frutos control. Durante el almacenamiento a $10{ }^{\circ} \mathrm{C}$, los frutos provenientes de plantas injertadas mostraron un contenido y capacidad antioxidante que fue relativamente similar en la piel y menor en la pulpa al hallado en frutos control.

Los frutos de berenjena violeta cv. Monarcas cosechados de plantas injertadas sobre pie Java almacenados a $0^{\circ} \mathrm{C}$ presentaron un retraso de los síntomas de daño por frío que se visualizó tanto en un menor daño superficial como menor pardeamiento de la pulpa. Asimismo, se observó una mayor firmeza que los frutos control hacia el final del almacenamiento. Durante el almacenamiento a $0{ }^{\circ} \mathrm{C}$, todos $\operatorname{los}$ antioxidantes tanto en piel como en pulpa mostraron una disminución a lo largo del almacenamiento. Sin embargo, los frutos de plantas injertadas mostraron una mayor retención de los mismos, tanto en piel como en pulpa, siendo tal vez la razón por la cual se logra el retraso de los síntomas de daño por frío y con ello la mejor calidad poscosecha a temperatura de daño por frío. En síntesis, los frutos provenientes de plantas injertadas mostraron un comportamiento similar a los frutos control en el almacenamiento a $10^{\circ} \mathrm{C}$ (temperatura recomendada). En cambio, el empleo de la tecnología de injerto logró producir frutos más resistentes al daño por frío que lograron mantener mejor la calidad comercial y los compuestos bioactivos en el almacenamiento a $0{ }^{\circ} \mathrm{C}$ (temperatura de daño por frío). 


\section{Capítulo III}

Efecto de tratamientos de acondicionamiento a baja temperatura (LTC) sobre el daño por frío y contenido de antioxidantes en genotipos de berenjena (violeta y rayada) y en dos estados de crecimiento. 


\section{III.1. INTRODUCCIÓN}

Si bien en las últimas décadas ha habido grandes avances tecnológicos en el estudio de la poscosecha, la refrigeración continúa siendo aún el tratamiento más eficaz y económico para reducir el deterioro poscosecha de frutas y hortalizas, asegurando el mantenimiento de la calidad y el valor nutritivo (Artés y col., 1998). Los efectos beneficiosos del almacenamiento a baja temperatura son múltiples e incluyen una reducción del crecimiento de microrganismos patógenos y deteriorantes, la disminución en pérdida de agua y en la producción y sensibilidad al etileno, el retraso en síntomas de pardeamiento enzimático, el descenso de la tasa metabólica de los productos, el retraso en la maduración y senescencia.

De todas maneras, como ya se mencionó, el aprovechamiento al máximo de los beneficios de la refrigeración se encuentra en algunos productos limitados debido a que son sensibles al DPF (Purvis, 2002; Saltveit, 2003).

En el capítulo anterior se pudo observar que factores previos a la cosecha como el empleo de combinaciones portainjerto-copa apropiadas puede tener influencia sobre la susceptibilidad al DPF de los frutos. Más allá de esto, en el área de poscosecha la búsqueda de tratamientos que permitan reducir la incidencia y severidad al DPF ha sido una actividad constante y de gran interés. A partir de ello se han evaluado diversas técnicas orientadas a aliviar el DPF en vegetales como el empleo de tratamientos con agentes químicos protectores como el ácido salicílico (Aghdam y col., 2014; Sayyari y col., 2011), el metil jasmonato (Cao y col., 2009; Zhang y col., 2012) y poliaminas (Ahmad y Ali. 2019; Wannabussapawich, y Seraypheap, 2018), entre otros. Los tratamientos de acondicionamiento a baja temperatura (LTC), los tratamientos térmicos de alta temperatura (Lurie, 1998; González-Aguilar y col., 2000), el calentamiento intermitente (Liu y col., 2018; Artés y col., 1998), el almacenamiento en atmósferas modificadas y controladas (Rodríguez- Aguilera y Oliveira, 2009; Ramírez- Acosta y col., 2018).

Si bien varios de los métodos químicos mostraron buenos resultados a escala de laboratorio su implementación a nivel comercial es aún reducida probablemente debido al creciente interés en minimizar el empleo de químicos en la poscosecha y a variaciones en la respuesta en función de las variedades y principios activos que dificultan la realización de recomendaciones generales para su empleo (Lurie, 1998). Los tratamientos físicos basados en el empleo de radiación UV tampoco se utilizan con este 
fin a nivel comercial más alla de que se ha descrito cierta capacidad protectora contra el DPF en algunos frutos. Con respecto a las técnicas basadas en el empleo de alta temperatura, ya sea en forma contínua o intermitente, ocurre algo similar que con los tratamientos químicos, esto es, un buen número de trabajos científicos que muestran resultados auspiciosos, pero que no resultan fáciles y/o rentables a la hora de escalar a situaciones productivas (Liu y col., 2018). Asi, por ejemplo, los tratamientos de calentamiento intermitente, basados en una oscilación de la temperatura que evite que los mismos superen el umbral de daños celulares irreversibles, han mostrado ser efectivos, aunque resultan costosos o difíciles de aplicar (Artés y col., 1998). Con relación a los tratamientos con calor o tratamiento térmicos de alta temperatura la situación no es muy diferente; su empleo comercial específicamente para reducir el DPF también es escaso y las aplicaciones difundidas para esta técnica han sido exitosas mayoritariamente cuando su objetivo central ha sido el control de plagas cuarentenarias como la mosca de los frutos en mango y papaya (McCollum y col., 1993; Paull y Chen, 2000).

Lo antes mencionado pone de manifiersto que muchas de las metodologías disponibles para reducir el DPF han tenido escasa difusión finalmente en la industria. Dos excepciones a ello podrían ser el uso de AM y AC que se utiliza en algunos casos para tal fin como por ejemplo en duraznos enviados a mercados distantes para reducir la harinosidad o el empleo del inhibidor de la acción del etileno 1-metilciclopropeno (1MCP) que se ha difundido para reducir escaldaduras superficiales (un desorden por almacenamiento en frío en frutos de pepita). De todos modos, estas estrategias son costosas en muchos casos y se justifican en el caso de productos de exportación como es el caso de la pera y manzana en nuestro país. Por lo tanto, la evaluación de metodologías simples y aplicables en la poscosecha continúa siendo, a pesar de los numerosos estudios realizados, un desafío.

En este escenario el acondicionamiento a baja temperatura (LTC) una de las primeras estrategias estudiadas para reducir el DPF pareciera ser aún una metodología con potencial valor práctico (Jin y col., 2009; Chaudhary y col., 2014; Zhou y col., 2015; Kashash y col., 2016; Zhang y col., 2017). Esta técnica basada en mantener a los productos por un período a temperaturas bajas pero superiores al umbral de DPF ha mostrado mejorar la tolerancia de los productos como mango, durazno, palta, granada, pomelo y pera cuando se los coloca en forma subsecuente a temperaturas más bajas (Tabla III.1). Las condiciones empleadas para los tratamientos con LTC varian en función del producto considerado, pero mayoritariamente consisten en el almacenamiento 
a $5-12{ }^{\circ} \mathrm{C}$ por pocos días en forma previa a la transferencia de los productos a temperaturas aún más bajas (Wang, 1993).

Tabla III.1 Tratamientos de acondicionamiento (LTC) utilizados en algunos productos frutihorticolas en poscosecha

\begin{tabular}{|c|c|c|}
\hline PRODUCTO & TRATAMIENTO & AUTOR \\
\hline Durazno & LTC $12{ }^{\circ} \mathrm{C} 6 \mathrm{~d}$, almac. a $0{ }^{\circ} \mathrm{C} 30 \mathrm{~d}$ & $\begin{array}{l}\text { Zhao y col., } \\
2012 \text { - }\end{array}$ \\
\hline $\begin{array}{c}\text { Granada (punica } \\
\text { granatum) cv wonderful }\end{array}$ & $\begin{array}{l}\text { LTC } 15^{\circ} \mathrm{C} \text { durante } 10 \text { días alm } 2 \text { y } 4 \text { semanas a } 1{ }^{\circ} \mathrm{C} \\
\text { almac a } 0{ }^{\circ} \mathrm{C} 54 \mathrm{~d}\end{array}$ & $\begin{array}{l}\text { Kashash y col., } \\
2018\end{array}$ \\
\hline $\begin{array}{c}\text { Mango (mangifera indica) } \\
\text { cv. Guifei, de maduración } \\
\text { temprana }\end{array}$ & $12^{\circ} \mathrm{C} 24 \mathrm{~h}$, almac. a $5^{\circ} \mathrm{C} 25 \mathrm{~d}$ & $\begin{array}{l}\text { Zhang y col., } \\
2017\end{array}$ \\
\hline $\begin{array}{l}\text { Níspero (eriobotrya } \\
\text { japónica) cv luoyangqin }\end{array}$ & LTC $5{ }^{\circ} \mathrm{C} 6 \mathrm{~d}$, almac. a $0{ }^{\circ} \mathrm{C} 54 \mathrm{~d}$ & Cai y col., 2006 \\
\hline $\begin{array}{c}\text { Palta (persea americana) } \\
\text { cv hass }\end{array}$ & $\begin{array}{l}\text { LTC } 4,6,8,10,12 \text { y } 15^{\circ} \mathrm{C} \text { durante un período de } 0 \text {, } \\
1,2,3,4 \text { o } 5 \mathrm{~d} \text { almacenamiento de } 3 \text { semanas a } 0^{\circ} \mathrm{C} \text {. }\end{array}$ & $\begin{array}{l}\text { Woolf y col., } \\
2003\end{array}$ \\
\hline $\begin{array}{l}\text { Pera (pyrus bretschneideri } \\
\quad \text { rehd cv huangguan) }\end{array}$ & LTC $10{ }^{\circ} \mathrm{C} 3 \mathrm{~d}$, almac. a $0^{\circ} \mathrm{C}$ x 30 y $60 \mathrm{~d}$ & Li y col., 2017 \\
\hline $\begin{array}{c}\text { Pomelo (citrus paradisii) } \\
\text { cv star ruby }\end{array}$ & LTC $16^{\circ} \mathrm{C} 7 \mathrm{~d}$, almac. a $2^{\circ} \mathrm{C} \times 12$ semanas & $\begin{array}{l}\text { Chaudhary y } \\
\text { col., } 2014\end{array}$ \\
\hline $\begin{array}{l}\text { Berenjena (solanum } \\
\text { melongena) cv "brigitte" }\end{array}$ & $13^{\circ} \mathrm{C} 3$ días, almac a $4{ }^{\circ} \mathrm{C}$ x $14 \mathrm{~d}$ & Shi y col., 2018 \\
\hline
\end{tabular}

En el caso de berenjena existe un reporte reciente sobre el empleo de LTC con resultados auspiciosos (Shi y col., 2018), en el cual efectúan tratamientos a $13{ }^{\circ} \mathrm{C}$ por 3 días antes de transferir los frutos a $4{ }^{\circ} \mathrm{C}$. En ese trabajo, los autores encontraron que los tratamientos de acondicionamiento incrementaron la actividad de enzimas antioxidantes como peroxidasa y catalasa. De todos modos, no se evaluó en detalle la importancia de los tratamientos en el sistema antioxidante no enzimático. Si bien estos resultados resultan auspiciosos existen varios aspectos que no se conocen respecto a su empleo en frutos de berenjena tales como cual es la eficacia de esta metodología en otros genotipos de berenjena diferentes de la violeta o si existen respuestas positivas en diferentes estados de crecimiento, aspectos que se abordarán en el presente capítulo para el cual se planteó como objetivo: "determinar el efecto de tratamientos de acondicionamiento a baja temperatura (LTC) sobre la tolerancia al daño por frío y contenido de antioxidantes en berenjena rayada y violeta en dos estados de crecimiento". 


\section{III.2. MATERIALES Y MÉTODOS}

\subsection{Material vegetal $\mathrm{y}$ almacenamiento}

Se emplearon frutos de berenjena de genotipo violeta cv. Barcelona y rayada cv. Angela, producidas en el mismo invernadero en la ciudad de La Plata (Buenos Aires, Argentina) entre los meses de noviembre-abril y se cosecharon en abril. El riego y la fertilización se realizaron por goteo dos veces por día, por la mañana y por la tarde. Las demás prácticas de manejo se realizaron acorde a los métodos convencionales de producción. Los frutos de ambos genotipos de berenjena se seleccionaron y cosecharon en dos estados de crecimiento diferente en función de su longitud: estado 1 (E1): $9 \mathrm{~cm}$, y estado 2 (E2): 17 $\mathrm{cm}$ (comercial). Se cosecharon 72 frutos para cada estado de crecimiento de cada una de las variedades y se trasladaron inmediatamente al laboratorio. Una vez en el laboratorio los frutos se seleccionaron, descartando aquellos con defectos, se lavaron como se indicó en la sección I.0. Luego los frutos se separaron por tamaño en bandejas, los E1 se colocaron de a 5 por bandeja y los de tamaño comercial de a 2 en bandejas de plástico rígido. Las bandejas se cubrieron con film de PVC perforado. Muestras de 30-40 frutos se aclimataron por 48 horas a $10^{\circ} \mathrm{C}$ para luego trasladarse a $5{ }^{\circ} \mathrm{C}$ por el resto del período de almacenamiento y se llamaron LTC. Un segundo grupo de 30-40 frutos se almacenaron directamente a $5{ }^{\circ} \mathrm{C}$ y se emplearon como control (C). Se tomaron muestras al inicio del ensayo y luego de 14 y 17 d. Se determinó la pérdida de peso, el contenido de materia seca, el color superficial y de pulpa y la firmeza. Los frutos de berenjena se pelaron finamente con bisturí y la piel se congeló en nitrógeno líquido. Por otra parte, se tomaron muestras de secciones transversales de los frutos de $1 \mathrm{~cm}$ de espesor en la zona ecuatorial sin piel y se congelaron en nitrógeno líquido. Las muestras se almacenaron a $80{ }^{\circ} \mathrm{C}$ hasta su uso para el análisis de antioxidantes totales, fenoles totales, y ácido clorogénico en la piel y en la pulpa y de antocianinas en la piel como se detalla en la sección 2.3.

\subsection{Determinaciones analíticas}

\subsubsection{Pérdida de peso}

Se pesaron todos los frutos y se efectuaron los cálculos como se indicó en la sección II.2.2.2. Se pesaron 9 frutos para cada tratamiento, estado y genotipo. 


\subsubsection{Materia seca}

Se realizó tal como se describió en la sección I.2.2.3. Los resultados se expresaron como porcentaje de peso fresco y las determinaciones se realizaron por triplicado para los frutos de cada tratamiento, estado y genotipo.

\subsubsection{Color de piel}

Se evaluó el color en la piel del fruto de berenjena del mismo modo que en la sección I.2.2.4. Las determinaciones se realizaron por triplicado en 9 frutos para cada tratamiento, estado y genotipo.

\subsubsection{Color de pulpa}

Se cortaron 3 rodajas de la zona ecuatorial del fruto como se describió en la sección II.2.2.3. Las determinaciones se realizaron por triplicado en 9 frutos para cada tratamiento, estado y genotipo.

\subsubsection{Resistencia a la compresión}

Se realizó un ensayo de penetración empleando un texturómetro (Texture Analyzer TA.XT2. Reino Unido) tal como se presentó en la sección I.2.2.5. Los resultados se expresaron en $\mathrm{N} / \mathrm{mm}$. Las determinaciones se realizaron por triplicado en 9 frutos para cada tratamiento, estado y genotipo.

\subsection{Compuestos antioxidantes}

\subsubsection{Extracción en etanol de compuestos antioxidantes}

Los extractos etanólicos se realizaron como se detalló en la sección I.2.3.1. Los mismos se emplearon para determinar el contenido de ácido clorogénico, fenoles totales y capacidad antioxidante. Se prepararon dos extractos para cada tratamiento, estado y genotipo.

\subsubsection{Compuestos fenólicos}

El contenido de compuestos fenólicos se determinó de acuerdo a Singleton y col. (1999), empleando el reactivo de Folin- Ciocalteu tal como se explicó en la sección I.2.3.2. El contenido de compuestos fenólicos se calculó utilizando ácido clorogénico (ACG) como 
estándar. Las medidas se realizaron por triplicado para cada tratamiento, estado y genotipo. Los resultados se expresaron como $\mathrm{mg}$ ACG/kg de peso fresco

\subsubsection{Capacidad antioxidante (TEAC)}

La determinación se realizó de acuerdo a Arnao y col. (2001) y del mismo modo que en la sección I.2.3.3. Se utilizó Trolox como patrón. Se realizaron tres replicados por cada tratamiento, estado y genotipo. Los resultados se expresaron como Capacidad Antioxidante Equivalente a Trolox (TEAC) en mg/kg de peso fresco.

\subsection{4. Ácido clorogénico (ACG)}

Se determinó espectrofotométricamente como se mencionó en la sección I.2.3.4. Se empleó ACG como patrón. Las medidas se realizaron por duplicado para cada tratamiento, estado y genotipo. Los resultados se expresaron en $\mathrm{mg}$ ACG/kg de peso fresco.

\subsubsection{Antocianinas}

La extracción y cuantificación de pigmentos se determinó según se describió en la sección I.2.3.5. Las medidas fueron realizadas por duplicado para cada tratamiento, estado y genotipo. Los resultados se expresaron en equivalentes de delphidin-3-glucósido en $\mathrm{mg} / \mathrm{kg}$ de peso fresco según Saldilova y col. (2006).

\subsubsection{Caracterización de antocianinas por HPLC}

Los extractos preparados como se describe en la sección I.2.3.5, se concentraron en un evaporador rotatorio (Büchi R-124, Labortechnik AG, Flawil, Suiza) hasta un volumen final de $1 \mathrm{~mL}$. Seguidamente se filtraron con un filtro de nylon de $45 \mu \mathrm{m}$ y $20 \mu \mathrm{L}$ fueron inyectados para el análisis por HPLC en un equipo modular (CA, Estados Unidos) equipado con un desgasificador por vacío, una bomba binaria (Waters 1525), y un detector de arreglo de diodos (DAD, Waters 2998). El sistema se conectó a un controlador y adquisidor de datos Empower. Se utilizó una columna Symmetry C18 (Waters, $250 \times$ 4,6 $\mathrm{mm}, 5 \mu \mathrm{m}$ de diámetro de partícula) y una fase móvil hidro-orgánica compuesta por $5 \%(\mathrm{v} / \mathrm{v})$ de ácido fórmico (A) y metanol (B). El gradiente de elución elegido fue el utilizado por Wu y col. (2004): 0-2 min: 5 \% B; 2-10 min: 5-20\% B; 10-15 min: 20 \% B; 15-30 min: 20-30 \% B; 30-35 min: 30 \% B; 35-45 min: 5 \% B. El caudal de fase móvil 
se mantuvo en $0,5 \mathrm{~mL} / \mathrm{min}$ y la detección se realizó a $540 \mathrm{~nm}$. Se analizaron por duplicado las muestras según genotipo.

\subsection{Análisis estadístico}

Los experimentos se realizaron de acuerdo a un diseño factorial. Los datos se analizaron por medio de ANOVA. Las medias fueron comparadas por el test LSD de Fisher a fin de determinar las diferencias mínimas significativas con un nivel de significancia de $\mathrm{P}<0,05$ empleando el software INFOSTAT (Córdoba, Argentina). 


\section{III.3. RESULTADOS Y DISCUSIÓN}

\subsection{Calidad a cosecha}

Para los estados E1 y E2, los frutos violetas presentaron un diámetro y peso levemente mayor que los frutos rayados, cosechados a igual longitud (Tabla III.1). La luminosidad de la pulpa de los frutos rayados, independientemente del estado, mostró mayores valores de L* y por tanto una pulpa más clara que los frutos violetas. En tanto, el color de piel de los frutos de genotipo rayado mostró un significativo aumento del $\mathrm{L}^{*}$ con el estado de crecimiento producto de que las vetas de color violáceo se afinan y se separan más en un fruto más grande. En cambio, los frutos del genotipo violeta no cambiaron su color en la medida que aumentaron de tamaño, sino que mantuvieron un color bien oscuro.

Tabla III.1 Peso, diámetro longitud y luminosidad $\left(\mathrm{L}^{*}\right)$ de pulpa y piel a cosecha de frutos de berenjenas rayada y violeta en estado de crecimiento 1 y 2 (E1 y E2). Letras distintas indican diferencia significativa para cada estado de crecimiento según el test LSD de Fisher con un nivel de significancia de $\mathrm{P}<0,05$.

E1

\begin{tabular}{l|cccc}
\multicolumn{1}{c}{} & $\boldsymbol{R A Y A D A}$ & VIOLETA & $\boldsymbol{R A Y A D A}$ & VIOLETA \\
\hline Peso & $68,31 \mathbf{c}$ & $78,07 \mathbf{c}$ & $263,93 \mathbf{b}$ & $285,7 \mathbf{a}$ \\
Diámetro & $4,39 \mathbf{d}$ & $4,86 \mathbf{c}$ & $6,66 \mathbf{b}$ & $7,71 \mathbf{a}$ \\
Longitud & $9,17 \mathbf{b}$ & $8,99 \mathbf{b}$ & $17,08 \mathbf{a}$ & $17,02 \mathbf{a}$ \\
$L^{*}$ pulpa & $87,16 \mathbf{a}$ & $86,55 \mathbf{b}$ & $86,77 \mathbf{a b}$ & $85,36 \mathbf{c}$ \\
$L^{*}$ piel & $37,39 \mathbf{b}$ & $24,07 \mathbf{c}$ & $42,34 \mathbf{a}$ & $23,03 \mathbf{c}$ \\
\hline
\end{tabular}

\subsection{Calidad durante el almacenamiento a $0{ }^{\circ} \mathrm{C}$}

\subsubsection{Apariencia externa e interna, color de piel y de pulpa}

La susceptibildiad de frutos al DPF es marcadamente dependiente del tipo comercial y del cultivar considerado y del estado de crecimiento (Mohammed y Brecht, 2003). Así, por ejemplo, se ha informado que las berenjenas japonesas violetas son más sensibles al frío que las de tipo violeta americano (Cantwell y Suslow, 2000). En el caso de algunos tipos como berenjena rayada prácticamente no hay información disponible en la literatura. Con respecto al estado de crecimiento y las consecuencias del almacenamiento refrigerado por debajo de $0{ }^{\circ} \mathrm{C}$, las berenjenas americanas violetas han mostrado ser un caso bastante particular. A diferencia de los demás frutos estudiados en los que estados tempranos de crecimiento son los más sensibles al DPF tales como tomate, pimiento, 
pepino (Valenzuela y col., 2017), la susceptibilidad a este desorden en berenjena desciende a medida que los frutos crecen y maduran (Zaro, 2014). Esto se ha reportado para frutos americanos violetas, pero no existe información respecto a otros genotipos. En este trabajo de tesis y en función de la observación visual y las fotos tomadas a los frutos se realizó un esquema que muestra el avance del daño en la parte externa de los frutos durante el período de almacenamiento a temperatura de DPF. Como se observa en la Figura III.1, los frutos rayados control ya mostraron incidencia del DPF a los 14 días y los síntomas superficiales (escaldaduras) fueron más notorios en frutos E1 que E2. Sin embargo, aquellos tratados con LTC retrasaron la aparición de síntomas y las diferencias fueron menos marcadas entre frutos E1 y E2. Por otro lado, los frutos violeta control prácticamente no desarrollaron escaldaduras en el E1 a lo largo de los 17 días, mientras que los del E2 ya mostraron escalduras a los 14 días. Este hecho, vuelve a demostrar que este genotipo de berenjena violeta se está comportando de manera diferente, esto es, presenta menor susceptibilidad al DPF en su estado más inmaduro o E1 respecto del estado más maduro o E2. A su vez, el tratamiento LTC retrasó también notablemente la aparición de síntomas en las berenjenas violetas, tanto en E1 como E2.

El LTC es una herramienta para mejorar la tolerancia al DPF. Esto ha sido informado en frutos como níspero (Cai y col., 2006), pera (Wang y col., 2017), pomelo (Chaudhary y col., 2017), mango (Zhang y col., 2017), palta (Woolf y col., 2003) y granada (Kashash y col., 2016). Recientemente, Shi y col. (2018) encontraron beneficios con tratamientos de LTC en berenjena manteniendo los frutos 3 d a $13{ }^{\circ} \mathrm{C}$ antes de transferirlos a $4{ }^{\circ} \mathrm{C}$. Si bien estos tratamientos mejoraron mucho la respuesta respecto a las berenjenas control resulta al menos llamativa la temperatura empleada para el acondicionamiento ya que los frutos de berenjena pueden mantenerse a $10^{\circ} \mathrm{C} \sin \mathrm{DPF}$ por lo que podrían haberse realizado los tratamientos en condiciones de menor temperatura con una consecuente mejora en la vida útil de los productos. En tal sentido, la eficacia del tratamiento de acondicionamiento a temperatura de $10^{\circ} \mathrm{C}$ hallado en el presente trabajo de tesis y por un tiempo más corto que el informado por Shi y col. (2018) podría ser potencialmente de interés práctico. Con relación a la eficacia de tratamientos de LTC en diferentes estados de crecimiento y genotipos de berenjena no existen antecedentes.

Los resultados del presente experimento mostraron que el tratamiento LTC retrasó los síntomas de DPF en ambos genotipos de berenjena (violeta y rayada). A su vez, la susceptibilidad al DPF de ambos genotipos de berenjena difiere con el estado de crecimiento y/o madurez, presentando la berenjena violeta una tendencia inversa a la 
hallada habitualmente en frutos que se cosechan inmaduros dado que los frutos de menor avance en el crecimiento, más inmaduros o E1 son menos susceptibles al DPF que los frutos más grandes, maduros o E2.

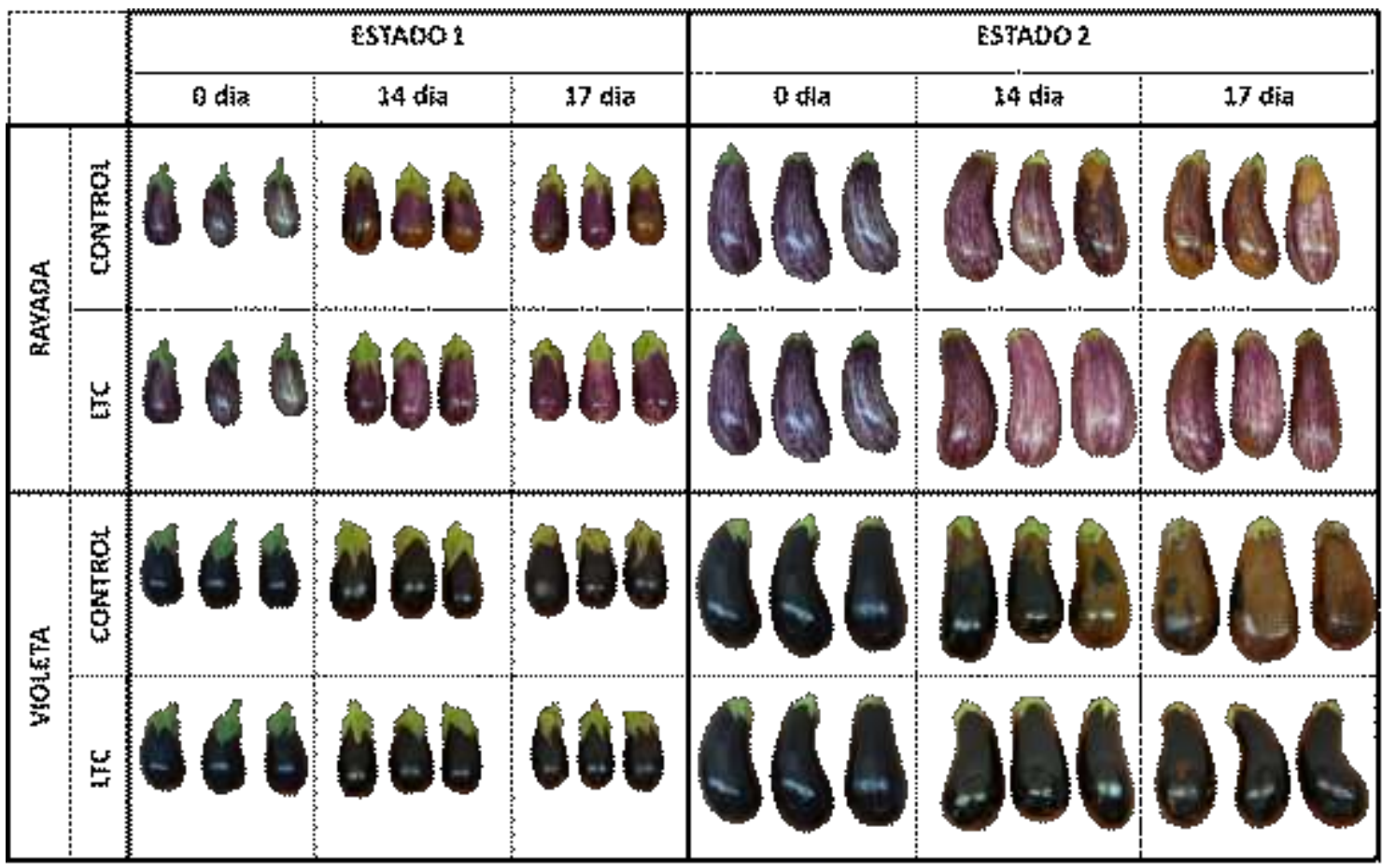

Figura III.1. Apariencia externa de frutos de berenjena rayada y violeta control o acondicionados a $10{ }^{\circ} \mathrm{C}$ por $48 \mathrm{~h}$ rayada y violeta (LTC), en estado 1 (E1) y estado 2 (E2) y posteriormente almacenados a $5^{\circ} \mathrm{C}$ por 0,14 y 17 días.

Al analizarse el color de la piel se observaron diferencias entre genotipos (Figura III.2

A y B). Las diferencias más claras se observaron con el parámetro b* cuyo incremento indicó un viraje de los tonos azules a los amarillos pardos. En los frutos E1 se observó una disminución del $\mathrm{L}^{*}$ y un aumento de $\mathrm{b}^{*}$ en la berenjena rayada control probablemente por el pardeamiento de las zonas claras superficiales, a diferencia de los frutos tratados con LTC que mostraron mucha menor incidencia. Por su parte, en línea con la manifestación externa de los síntomas de DPF, las berenjenas violetas E1 o "baby" control y tratadas no presentaron marcadas diferencias en estos parámetros de color dado que no se visualizaron escaldaduras en ningún fruto. En los frutos en estado de desarrollo avanzado E2 se observó un progresivo aumento para ambos genotipos en los valores de b* conforme avanzó el tiempo de almacenamiento. Este incremento que acompañó el desarrollo de escaldaduras con tonos marrones amarillentos en la superficie fue significativamente retrasado por los tratamientos de LTC tanto en las berenjenas rayadas 
como violetas. Particularmente, en estas últimas la inhibición del amarillamiento superficial por los tratamientos de acondicionamiento fue muy evidente.

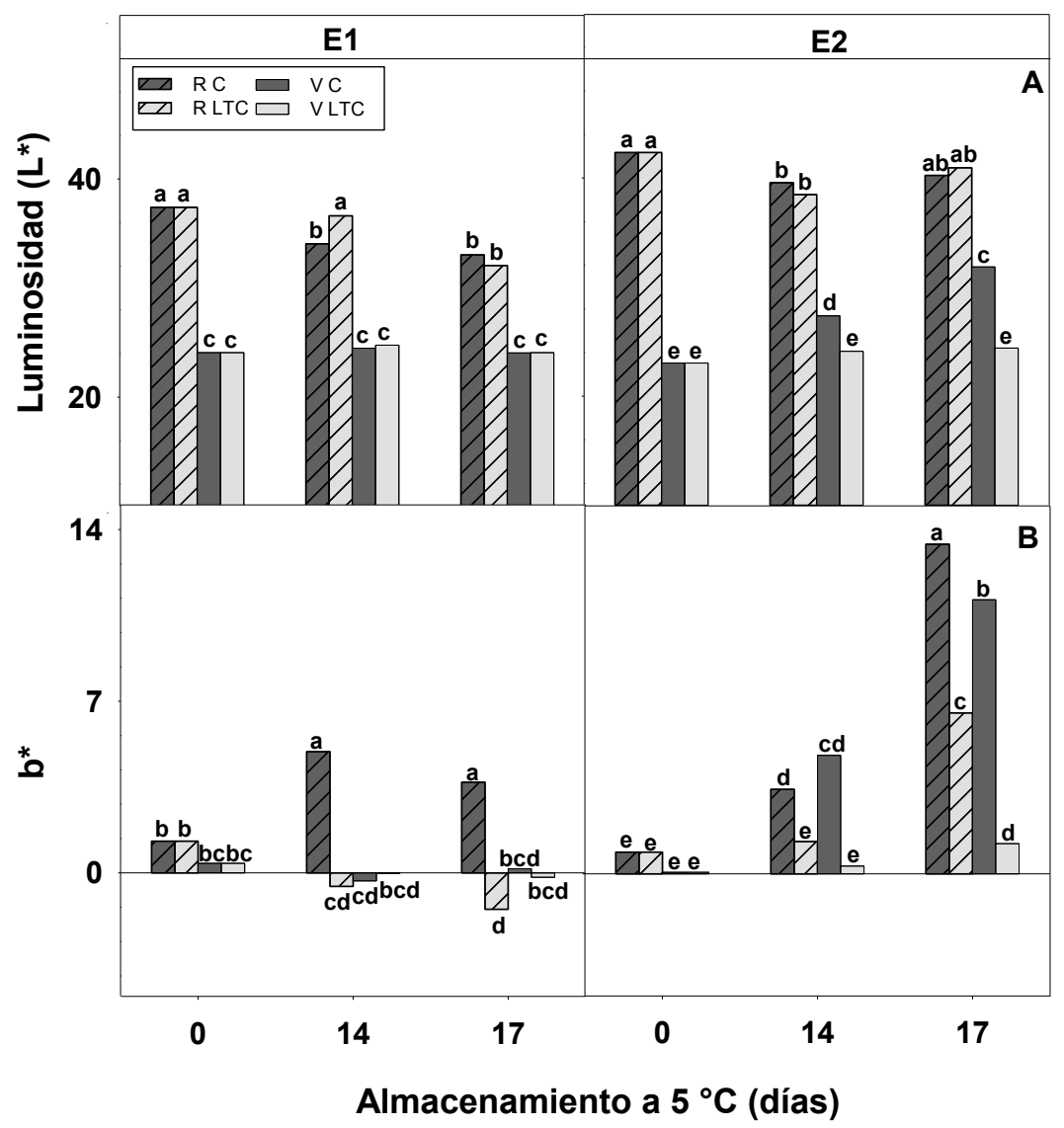

Figura III.2. Color de piel A) Luminosidad ( $\left.\mathrm{L}^{*}\right)$ y B) $\mathrm{b}^{*}$ de frutos de berenjena rayada y violeta control (R C y V C) o acondicionados a $10{ }^{\circ} \mathrm{C}$ por 48 h (R LTC y V LTC), en estado 1 (E1) y estado 2 (E2) y posteriormente almacenados a $5{ }^{\circ} \mathrm{C}$ por 0,14 y 17 días. Letras distintas indican diferencias significativas para cada estado de crecimiento según el test LSD de Fisher con un nivel de significancia de $\mathrm{P}<0,05$.

Los frutos también mostraron diferencias evidentes en su apariencia interna (Figura III.3). En general, independientemente del estado de crecimiento y variedad, se pudo observar un oscurecimiento conforme avanzó el tiempo de almacenamiento, confirmado con un descenso contínuo en los valores de L* de pulpa (Figura III.4).

Los frutos E1 tratados con LTC y de ambos genotipos presentaron menor daño interno, manteniendo el valor de L* casi sin cambios (Figura III.4), mostrando sólo un leve pardeamiento de semillas, mientras que los controles presentaron pardeamiento de semillas y manchas internas; disminuyeron su luminosidad marcadamente; siendo mucho más intenso el daño interno en frutos rayados. Las berenjenas violetas LTC mostraron también pulpas más claras o casi sin pardeamiento comparadas con su control, aunque las 
diferencias no fueron tan marcadas como en las berenjenas rayadas. Los frutos E2 violetas fueron mas susceptibles al pardeamiento y por tanto al igual que ocurrió al analizarse los síntomas externos de DPF los tratamientos de acondicionamiento LTC se mostraron más eficaces para reducir el pardeamiento interno que en los frutos rayados.

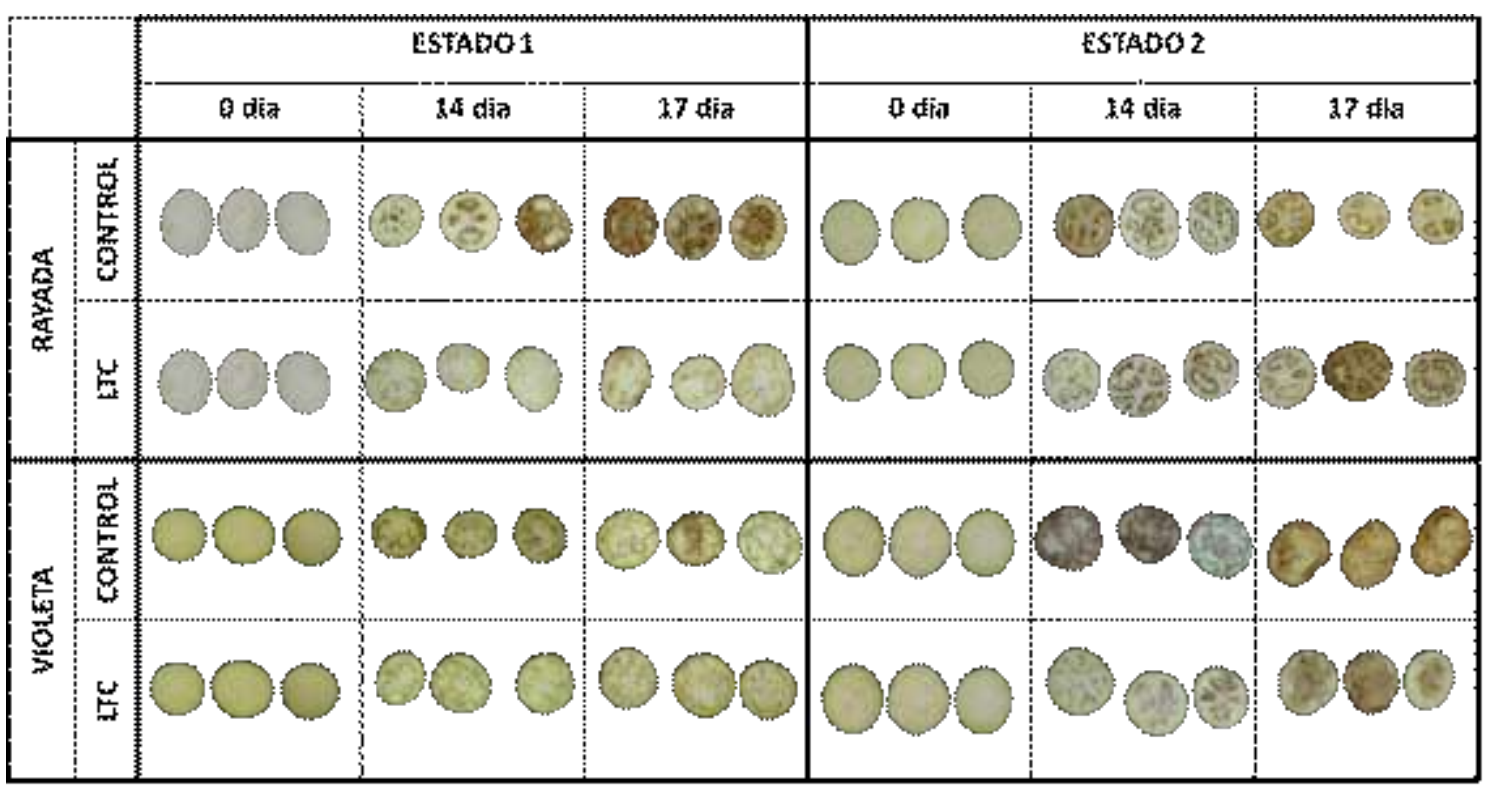

Figura III.3. Apariencia interna de frutos de berenjena rayada y violeta control o acondicionados a $10{ }^{\circ} \mathrm{C}$ por $48 \mathrm{~h}$ rayada y violeta (LTC), en estado 1 (E1) y estado 2 (E2) y posteriormente almacenados a $5{ }^{\circ} \mathrm{C}$ por 0,14 y 17 días.

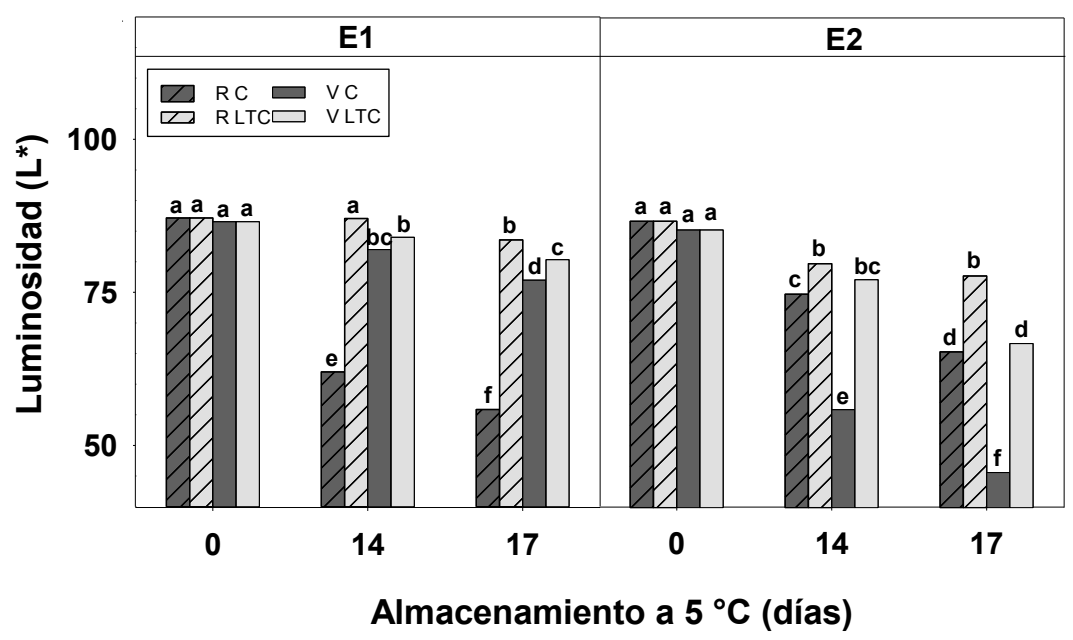

Figura III.4. Luminosidad de pulpa de frutos de berenjena rayada y violeta control ( $\mathrm{R} \mathrm{C} \mathrm{y} \mathrm{V} \mathrm{C)} \mathrm{o}$ acondicionados a $10^{\circ} \mathrm{C}$ por $48 \mathrm{~h}$ (R LTC y V LTC), en estado 1 (E1) y estado 2 (E2) y posteriormente almacenados a $5{ }^{\circ} \mathrm{C}$ por 0,14 y 17 días. Letras distintas indican diferencias significativas para cada estado de crecimiento según el test LSD de Fisher con un nivel de significancia de $\mathrm{P}<0,05$.

Una de las alteraciones que se inducen como consecuencia del DPF en vegetales es la reducción de la funcionalidad y finalmente la ruptura de las membranas celulares (Sheng 
y col., 2016; Cheng y col., 2015). Esto podría resultar tanto como consecuencia de una sobreproducción de EROs capaces de dañar los lípidos de membrana en forma oxidativa como por cambios en la fluidez de las mismas que se han relacionado con el grado de insaturación de los ácidos grasos que la constituyen. La contribución relativa de cada uno de estos procesos a la fecha se desconoce. De todos modos, en un estudio reciente Shi y col. (2018) asociaron la mejora en la respuesta al frío en berenjenas acondicionadas con una menor peroxidación lipídica y un aumento de enzimas capaces de detoxificar peróxido de hidrógeno aportando indicios sobre la relevancia del mecanismo oxidativo como central en el desarrollo del DPF. Algunos estudios han sugerido que los mecanismos por los cuales el LTC podría mejorar la tolerancia a las bajas temperaturas es la modificación en el grado de insaturación de lípidos de membrana con una consecuente reducción en la temperatura de transición de sólido a gel de la misma. En favor de esta hipótesis se ha informado que el LTC en otros frutos aumenta la expresión de genes que codifican para desaturasas de ácidos grasos (Sapitnitskaya y col., 2006). En línea con la asociación de LTC y los cambios composicionales de membrana algunos autores han sugerido que el aumento en la relación de fosfolípidos a esteroles también podría mejorar la funcionalidad de las membranas a bajas temperaturas. Wang y col. (2017) informaron que el LTC en peras "Nanguo" inhibió la expresión de fosfolipasa PLD, responsable del clivaje de fosfolípidos, y esto se correlacionó con una menor alteración de lípidos en el almacenamiento. Independientemente del mecanismo que lo ocasione, el daño de membranas afecta irreversiblemente a las células eliminando la compartimentalización celular e induciendo reacciones indeseables como la oxidación enzimática de fenoles catalizadas por polifenol oxidasas (PPO) responsable de los síntomas visibles de pardeamiento (Amaki y col., 2011; Wang y col., 2013).

\subsubsection{Pérdida de peso, materia seca y resistencia a la compresión}

Como puede observarse en la Figura III.5 los frutos E1 presentaron pérdidas de peso 1$2 \%$ por encima de los frutos de tamaño comercial, aunque no se observaron diferencias entre genotipos. Esto puede deberse a que estos frutos presentaban una mayor actividad metabólica y respiración que los frutos E2 (Zaro y col., 2014b) Para el tamaño comercial E2, en general, las pérdidas de peso fueron inferiores al $1 \%$. En este caso los frutos rayados sometidos al tratamiento de LTC, presentaron una pérdida de peso levemente mayor a los controles. En las berenjenas violetas E2 el tratamiento de acondicionamiento no tuvo efectos sobre la pérdida de peso. 


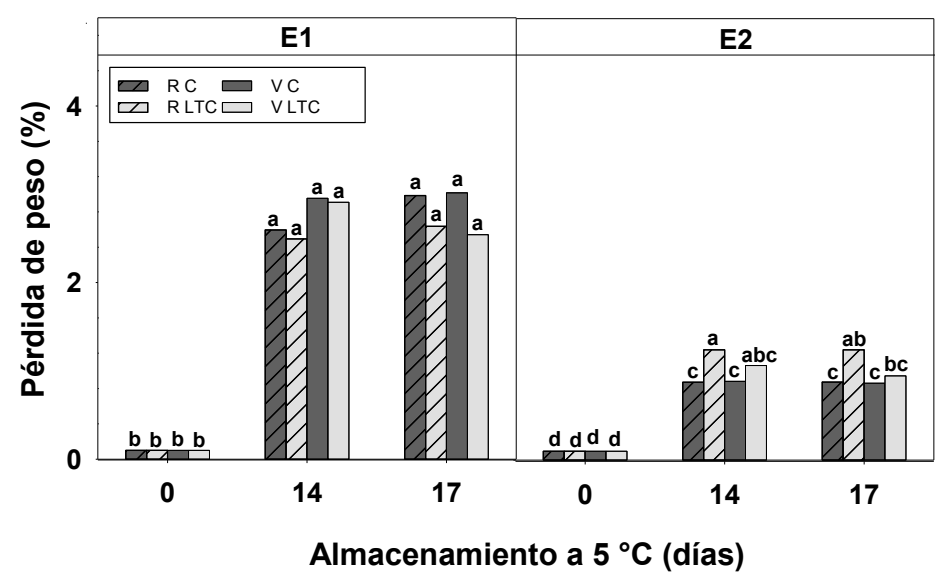

Figura III.5. Pérdida de peso de frutos de berenjena rayada y violeta control ( $\mathrm{R} \mathrm{C} \mathrm{y} \mathrm{V} \mathrm{C)} \mathrm{o} \mathrm{acondicionados}$ a $10{ }^{\circ} \mathrm{C}$ por $48 \mathrm{~h}$ (R LTC y V LTC), en estado 1 (E1) y estado 2 (E2) y posteriormente almacenados a $5{ }^{\circ} \mathrm{C}$ por 0,14 y 17 días. Letras distintas indican diferencias significativas para cada estado de crecimiento según el test LSD de Fisher con un nivel de significancia de $\mathrm{P}<0,05$.

El contenido de materia seca fue mayor en frutos violetas $(6 \%)$, respecto de los rayados (5\%) para ambos estados de crecimiento, y prácticamente se mantuvo a lo largo del almacenamiento (Figura III.6). Los tratamientos de LTC no provocaron modificaciones en el nivel de MS.

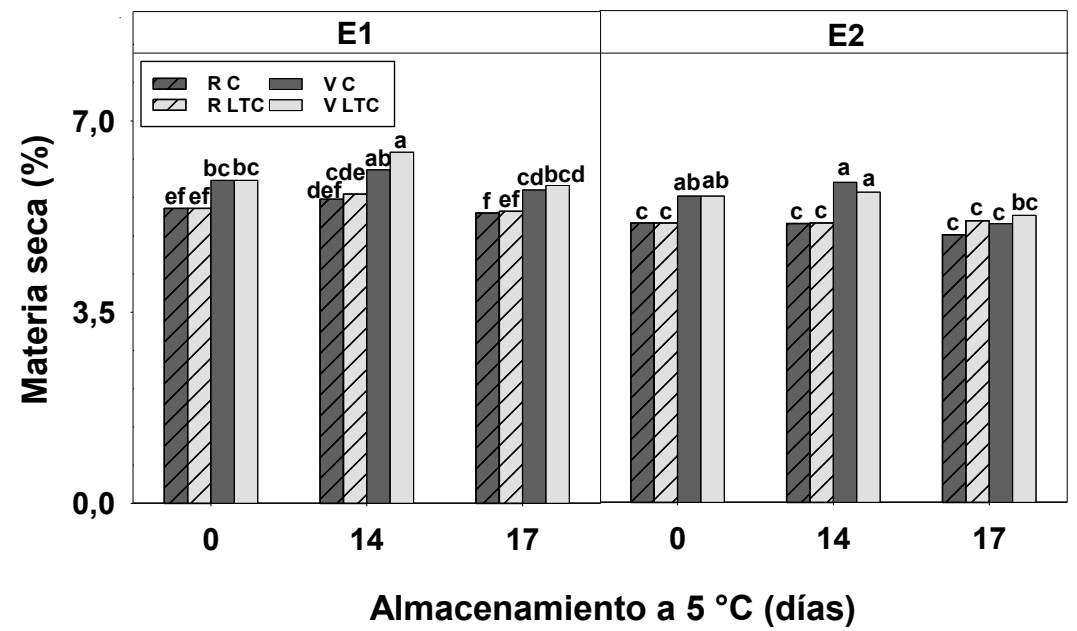

Figura III.6. Materia seca de frutos de berenjena rayada y violeta control ( $\mathrm{R} \mathrm{C} \mathrm{y} \mathrm{V} \mathrm{C)} \mathrm{o} \mathrm{acondicionados} \mathrm{a}$ $10{ }^{\circ} \mathrm{C}$ por $48 \mathrm{~h}$ (R LTC y V LTC), en estado 1 (E1) y estado 2 (E2) y posteriormente almacenados a $5{ }^{\circ} \mathrm{C}$ por 0,14 y 17 días. Letras distintas indican diferencias significativas para cada estado de crecimiento según el test LSD de Fisher con un nivel de significancia de $\mathrm{P}<0,05$.

La resistencia a la compresión $(\mathrm{RC})$ mostró algunas diferencias para los frutos $\mathrm{E} 1 \mathrm{o}$ "baby". Así, los frutos rayados control disminuyeron los niveles de RC durante el almacenamiento notando un ablandamiento de los mismos (Figura III.7). En cambio, los 
frutos rayados LTC no presentaron variación de su firmeza. Así mismo, los frutos violetas tampoco vieron modificada su firmeza. Contrariamente, en los frutos de tamaño comercial E2, la RC se redujo durante el almacenamiento acompañando un ablandamiento de los frutos. Este descenso fue más marcado para frutos violetas que rayados en línea con la susceptibilidad al frío de los genotipos. El tratamiento de LTC en ambos casos, logró retrasar la pérdida de firmeza inducida por el DPF de forma muy notoria en el almacenamiento. Similares resultados han sido observados en otros frutos como kiwi (Yang y col., 2013).

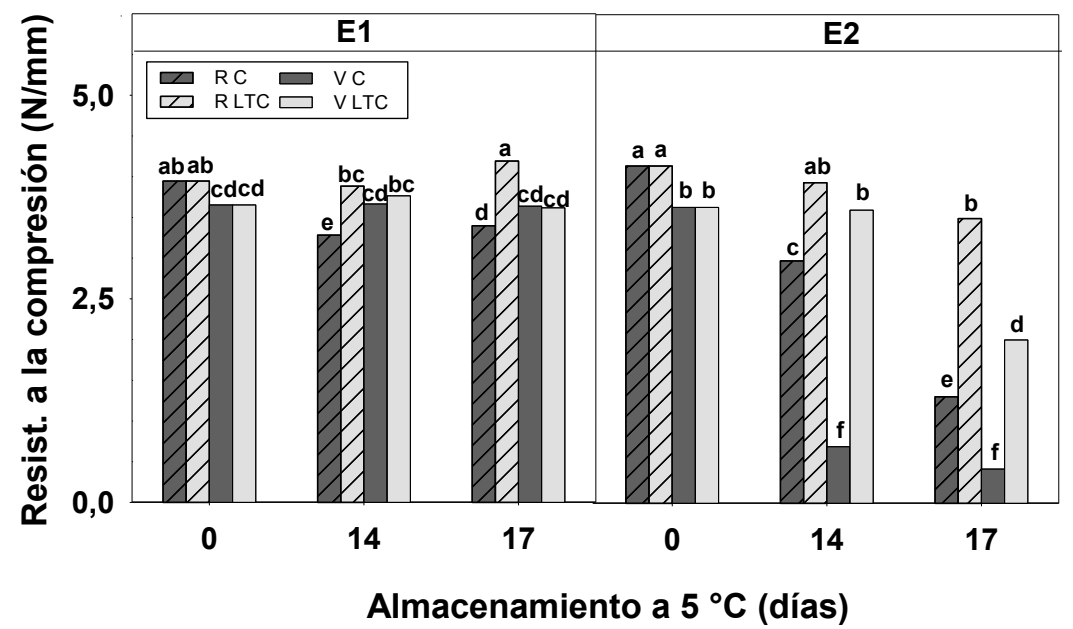

Figura III.7. Resistencia a la compresión de frutos de berenjena rayada y violeta control (R C y V C) o acondicionados a $10^{\circ} \mathrm{C}$ por $48 \mathrm{~h}$ (R LTC y V LTC), en estado 1 (E1) y estado 2 (E2) y posteriormente almacenados a $5^{\circ} \mathrm{C}$ por 0,14 y 17 días. Letras distintas indican diferencias significativas para cada estado de crecimiento según el test LSD de Fisher con un nivel de significancia de $\mathrm{P}<0,05$.

\subsection{Compuestos antioxidantes en la piel}

La capacidad antioxidante (TEAC) en piel se muestra en la Figura III.8A. Se puede observar que, al momento de la cosecha, el genotipo violeta posee mayores niveles de TEAC respecto del genotipo rayado; siendo $4(6600 \mathrm{mg} / \mathrm{kg}$ vs $1600 \mathrm{mg} / \mathrm{kg})$ y 2,5 veces mayor (5600 mg/kg vs $2200 \mathrm{mg} / \mathrm{kg}$ ) para frutos E1 y E2, respectivamente. Esta diferencia puede ser explicada, en principio, por la diferencia de color cuyo origen está dado por la presencia de pigmentos antociánicos. En términos generales, durante el almacenamiento, el TEAC descendió en el tiempo tanto para frutos rayados como violetas y para frutos E1 o "baby" y E2 o comercial convencional. Para el estado E2, el tratamiento logró reducir ligeramente la pérdida de antioxidantes sólo en berenjena rayada al día 14. Mientras que, para el E2, el TEAC en los frutos sometidos al tratamiento LTC de ambos genotipos disminuyó en menor medida que los frutos control. 
Los niveles de fenoles totales tuvieron la misma tendencia general durante el almacenamiento que los niveles de TEAC (Figura III.8B). Asímismo, el LTC logró reducir la degradación de fenoles en el almacenamiento. Estos resultados son coincidentes con los informados por Shi y col. (2018) quienes reportaron que en berenjenas de la variedad Brigitte, el tratamiento con LTC disminuyó el contenido fenólico total de los frutos. Si bien los frutos tratados con LTC también mostraron un descenso en los niveles de fenoles conforme avanzó el tiempo de almacenamiento, éste fue de menor proporción, especialmente en los frutos violeta E2.

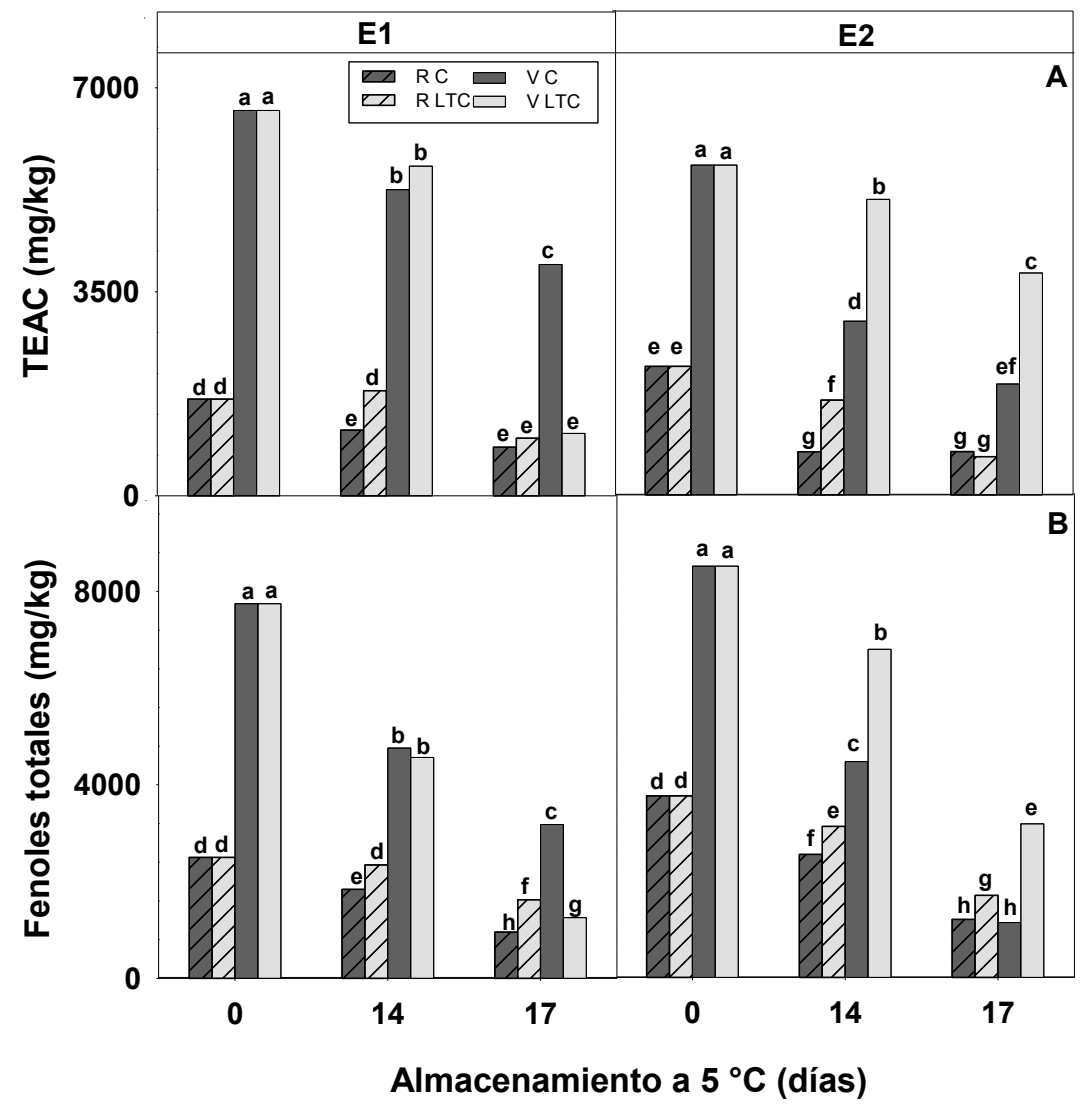

Figura III.8. A) Capacidad antioxidante equivalente a trolox (TEAC) y B) Fenoles totales en piel de frutos de berenjena rayada y violeta control (R C y V C) o acondicionados a $10{ }^{\circ} \mathrm{C}$ por $48 \mathrm{~h}$ (R LTC y V LTC), en estado 1 (E1) y estado 2 (E2) y posteriormente almacenados a $5{ }^{\circ} \mathrm{C}$ por 0,14 y 17 días. Letras distintas indican diferencias significativas para cada estado de crecimiento según el test LSD de Fisher con un nivel de significancia de $\mathrm{P}<0,05$.

La menor pérdida de fenoles podría relacionarse tanto con la mayor integridad de membranas en los frutos tratados como con una inhibición de la enzima PPO, la cual ha sido informada en berenjenas sometidas a LTC (Fan y col., 2016; Shi y col., 2018). Si bien el efecto inhibitorio del LTC sobre el pardeamiento es sin duda interesante, se conoce que la actividad PPO no es el factor limitante de estas reacciones en berenjena, sino más 
bien, se debería a la mejor integridad celular que permite a la enzima permanecer en compartimentos separados respecto de los compuestos fenólicos, sus sustratos (Concellón y col., 2007; Zaro, 2014). La identidad de las antocianinas que otorgan el color a las berenjenas violetas ha sido informada en varios trabajos, siendo derivados de la delfinidina, tales como NAS o D3R, como se mencionó en la sección 1.1.5 de la Introducción general (Matsuzoe y col., 1999; Matsubara y col., 2005; Wu y Prior, 2005). Sin embargo, no se hallan reportes de la identidad de las mismas en berenjenas rayadas.

En virtud de ello, se realizó un análisis por HPLC-DAD (Figura III.9) para hallar las antocianinas presentes en ambos genotipos y se lograron visualizar 4 picos, tanto para berenjena rayada como para violeta, coincidiendo todos ellos con los hallados por Zaro y col. (2014) para berenjena violeta, variedades Monarca y Perla Negra. El pico 1, correspondiente a delfinidina 3-rutinósido-5-galactósido, presentó un mayor \% relativo en la berenjena rayada respecto de la violeta. El pico 4, delfinidina 3-rutinósido o D3R, fue la antocianina mayoritaria en ambos genotipos, aunque con valores de 72 y $65 \%$ para los genotipos violeta y rayado, respectivamente. Una vez comprobada la similitud de antocianinas presentes en cada genotipo, se continuó analizando la variación del contenido de las mismas de forma espectrofotométrica (Figura III.9A).

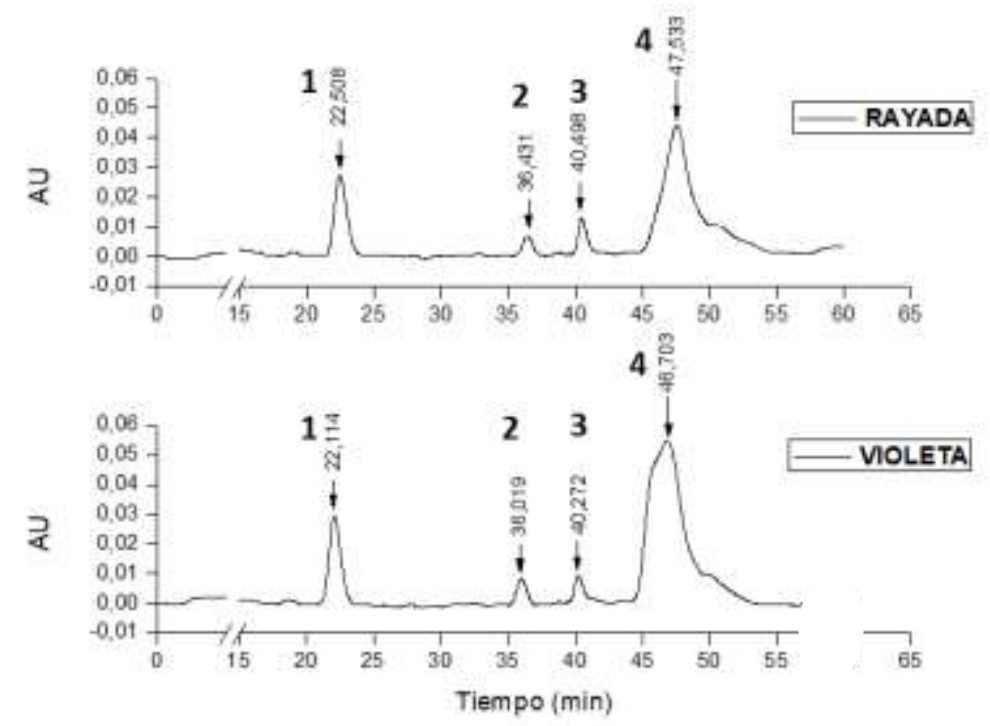

Figura III.9. Perfil representativo de HPLC de las antocianinas presentes en la piel de berenjenas rayada y violeta. Pico 1: delfinidina 3-rutinósido-5-galactósido, Pico 2: delfinidina 3-rutinósido-5-glucósido, Pico 3: delfinidina 3-glucósido y Pico 4: delfinidina 3-rutinósido.

Zaro y col. (2014) hallaron que la berenjena violeta mostraba un contenido de antocianinas que se incrementaba conforme el fruto crecía ligado a la planta. Un 
comportamiento similar fue hallado aquí, tanto para el genotipo violeta como el rayado que presentaron a cosecha (dia 0 ) un contenido de antocianinas menor en el E1 respecto del E2 (Figura III.10A). A su vez, es de destacar que la berenjena violeta presentó un contenido $\sim 2$ veces mayor de antocianinas respecto al genotipo rayado $(1285 \mathrm{mg} / \mathrm{kg} v \mathrm{~s}$ $707 \mathrm{mg} / \mathrm{kg}$, y $2907 \mathrm{mg} / \mathrm{kg}$ vs $1442 \mathrm{mg} / \mathrm{kg}$ ) en E1 y E2, respectivamente.

Para el caso de ACG, su principal compuesto fenólico derivado del ácido hidroxinámico, la tendencia es inversa: un mayor nivel de ACG en la piel de frutos E1 respecto de E2, tanto para el genotipo violeta como rayado. Sin embargo, es de destacar que a su vez, el genotipo violeta posee mayores niveles de ACG que el genotipo rayado (a cosecha o dia 0), siendo dicha relación 3,5 (6745 mg/kg vs $1909 \mathrm{mg} / \mathrm{kg})$ y 2,2 veces $(2509 \mathrm{mg} / \mathrm{kg} v s$ $1150 \mathrm{mg} / \mathrm{kg}$ ) en frutos E1 y E2, respectivamente (Figura III.10B).

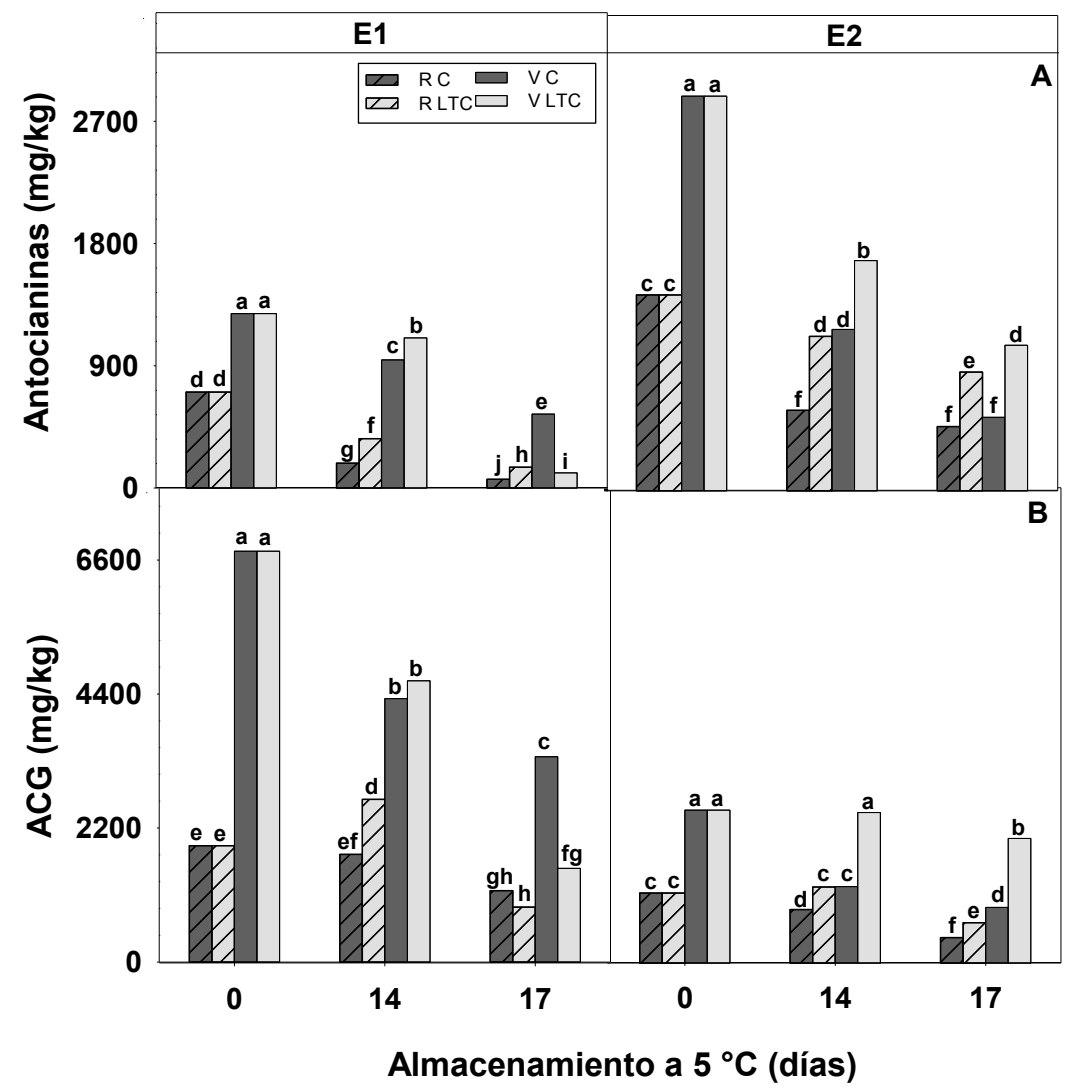

Figura III.10. A) Antocianinas y B) Ácido clorogénico (ACG) en piel de frutos de berenjena rayada y violeta control (R C y V C) o acondicionados a $10^{\circ} \mathrm{C}$ por $48 \mathrm{~h}$ (R LTC y V LTC), en estado 1 (E1) y estado 2 (E2) y posteriormente almacenados a $5{ }^{\circ} \mathrm{C}$ por 0,14 y 17 días. Letras distintas indican diferencias significativas para cada estado de crecimiento según el test LSD de Fisher con un nivel de significancia de $\mathrm{P}<0,05$.

Al relacionar el contenido de estos compuestos fenólicos con los niveles de TEAC a cosecha, se puede confirmar que el contenido de ACG es quien determina que los frutos 
violetas posean mayor capacidad antioxidante que los rayados y no sean las antocianinas como se hipotetizó anteriormente.

Durante el almacenamiento, los frutos E1 y E2 de berenjena rayada y violeta mostraron variaciones en el contenido de antocianinas (Figura III.1A) y ACG (Figura III.10B) similar al registrado en los resultados del dosaje de capacidad antioxidante por TEAC (Figura III.8A). A su vez, el tratamiento LTC fue efectivo en retrasar la disminución de antioxidantes en frutos E1 rayados y en frutos E2 de ambos genotipos, reteniendo los compuestos fenólicos principales (antocianinas y ACG) por mayor tiempo.

\subsection{Compuestos antioxidantes en la pulpa}

Al igual que en el genotipo de berenjena violeta, también en berenjena rayada los niveles de TEAC (Figura III.11A) están aportados por los compuestos fenólicos (Figura III.11B) y en particular por el ACG (Figura III.11C). Es de destacar, que a cosecha (día 0) los frutos violetas poseen 1,4 veces más ACG que los frutos rayados en el E1, mientras que el contenido fue similar en frutos E2.

A lo largo del almacenamiento, se observó una paulatina disminución en los niveles de TEAC, compuestos fenólicos y ACG, aunque en los frutos tratados con LTC la disminución fue más leve logrando retener en mejor medida dichos niveles tanto en frutos E1 como en E2. A su vez, resulta interesante destacar que el tratamiento LTC en los frutos E1 presentó diferencias significativas con su control sólo en el genotipo rayado, mientras que en estado comercial o E2 el LTC fue efectivo para ambos genotipos. En lo que respecta al ACG, los frutos violetas E2 y tratados con LTC lograron retener en más del 90 \% su nivel hasta el día 17 (Figura III.12). Este mayor contenido de CGA, compuesto antioxidante por excelencia, podría ser el responsable de la mejor apariencia de los frutos, mejor integridad del tejido y menor pardeamiento de la pulpa. 


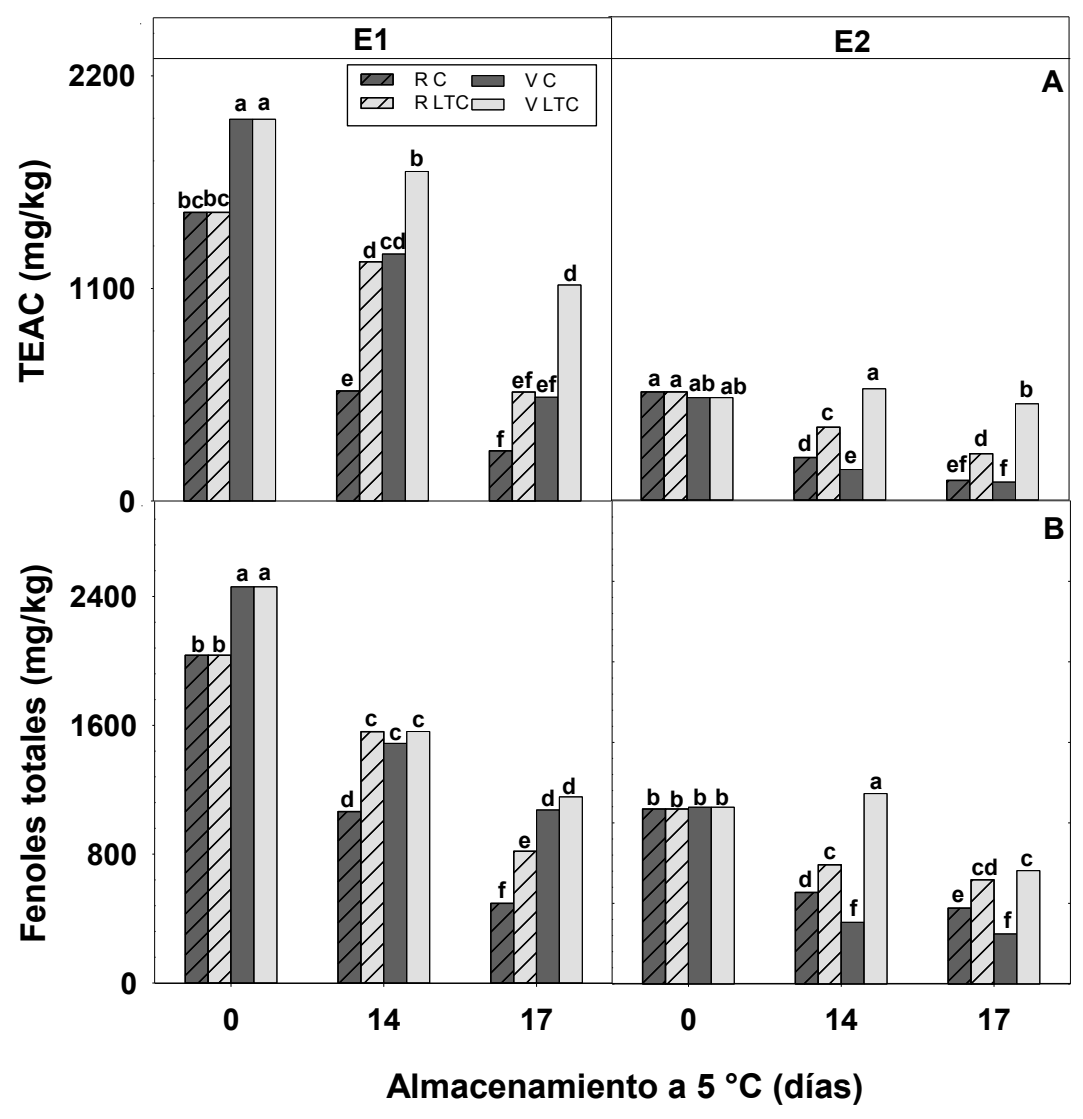

Figura III.11. A) Capacidad antioxidante equivalente a trolox (TEAC) y B) Fenoles totales en pulpa de frutos de berenjena rayada y violeta control (R C y V C) o acondicionados a $10{ }^{\circ} \mathrm{C}$ por $48 \mathrm{~h}$ ( $\mathrm{R} \mathrm{LTC} \mathrm{y} \mathrm{V} \mathrm{LTC),}$ en estado 1 (E1) y estado 2 (E2) y posteriormente almacenados a $5{ }^{\circ} \mathrm{C}$ por 0,14 y 17 días. Letras distintas indican diferencias significativas para cada estado de crecimiento según el test LSD de Fisher con un nivel de significancia de $\mathrm{P}<0,05$.

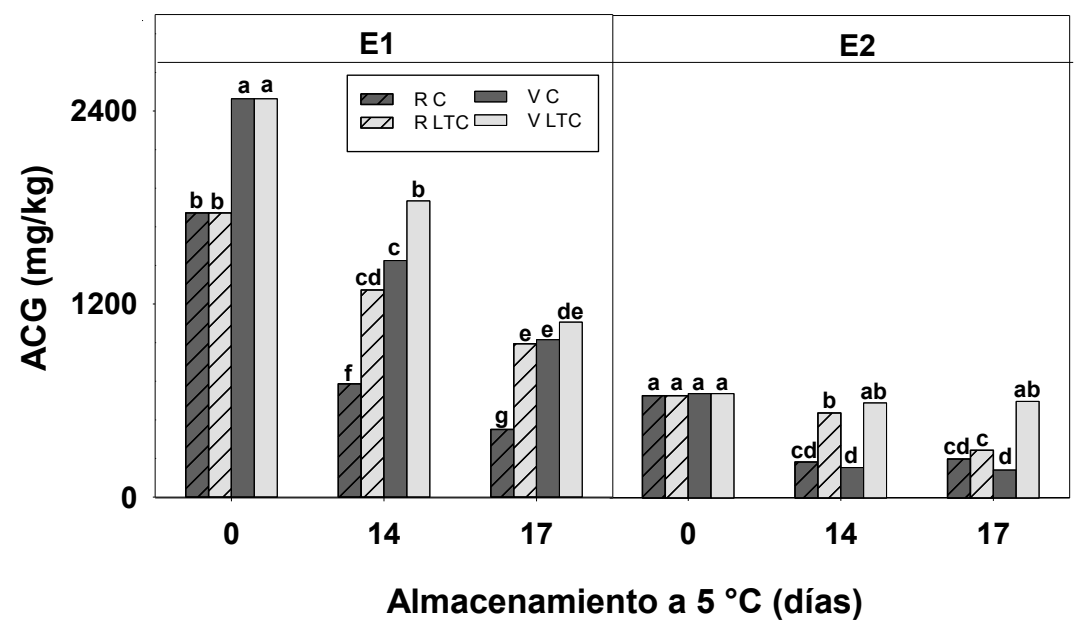

Figura III.12. ACG en pulpa de frutos de berenjena rayada y violeta control (R C y V C) o acondicionados a $10{ }^{\circ} \mathrm{C}$ por $48 \mathrm{~h}$ (R LTC y V LTC), en estado 1 (E1) y estado 2 (E2) y posteriormente almacenados a $5{ }^{\circ} \mathrm{C}$ por 0,14 y 17 días. Letras distintas indican diferencias significativas para cada estado de crecimiento según el test LSD de Fisher con un nivel de significancia de $\mathrm{P}<0,05$. 
Los resultados muestran que el tratamiento LTC es un tratamiento eficaz para incrementar la tolerancia al frío en frutos de berenjena de ambos genotipos, violeta y rayado. Dentro de los beneficios resultantes de dicho tratamiento se destaca la reducción en la incidencia y severidad de escaldaduras en la piel, el control del pardeamiento de pulpa y la protección que estarían ejerciendo los antioxidantes de naturaleza fenólica. Si bien ya existía un trabajo previo evaluando esta tecnología de poscosecha en berenjena (Shi y col., 2018), en dicho estudio no se analizó la eficacia en diferentes estados de crecimiento ni su consistencia en más de un genotipo.

El presente estudio muestra que el LTC, en los frutos E1 presentó diferencias significativas con su control sólo en el genotipo rayado, mientras que en estado comercial o E2 el LTC fue efectivo para ambos genotipos, violeta y rayado. Otro aspecto de interés del tratamiento de LTC empleado aquí es que fue un tercio más corto que el informado por Shi y col. (2018) lo que podría dar mayor visto de aplicación práctica. 


\section{III.4. CONCLUSIONES}

Los genotipos de berenjena violeta y rayada mostraron diferencia de susceptibilidad al daño por frío. La berenjena violeta se comportó de forma diferente a lo tradicionalmente observado en frutos que se cosechan inmaduros. Esto es, fueron menos susceptibles al daño por frío en frutos más inmaduros o de menor crecimiento (E1) respecto de los cosechados con madurez comercial (E2). En cambio, la berenjena rayada presentó un comportamiento más habitual: más susceptible al daño por frío en frutos E1 respecto de E2.

El empleo de la tecnología de acondicionamiento a baja temperatura (LTC) o acondicionado a $10^{\circ} \mathrm{C}$ por 2 días previo al almacenamiento a $5{ }^{\circ} \mathrm{C}$ (temperatura de daño por frío) retrasó marcadamente los síntomas de daño por frío en berenjena de ambos genotipos, violeta y rayada. Los frutos tratados con LTC mostraron una significativa reducción en el número y tamaño de escaldaduras superficiales y en el pardeamiento de la pulpa y de las semillas. El LTC mantuvo la firmeza, no afectó la pérdida de peso y mejoró la retención de antioxidantes en piel y pulpa.

Los tratamientos fueron más eficaces en frutos E1 o "baby" para berenjena rayada y en estados avanzados de crecimiento o E2 en berenjena violeta y rayada.

En síntesis, los resultados hallados al efectuar el tratamiento de acondicionamiento LTC $\left(10^{\circ} \mathrm{C}\right.$ por 2 días) resultaron de utilidad para reducir la susceptibilidad al daño por frío de frutos de berenjena de ambos genotipos, rayada y violeta, y en ambos estados de crecimiento, E1 y E2. 


\section{Capítulo IV}

Efecto de la dosis e intensidad de radiación $U V$-B sobre la calidad y el contenido de compuestos bioactivos en brócoli mínimamente procesado. 


\section{IV.1. INTRODUCCIÓN}

\subsection{Brócoli}

\subsubsection{Origen y variedades}

El brócoli (Brassica oleracea L. var. Itálica) es originario de Asia occidental y Europa (Figura IV.1.A). Pertenece a la familia de las Crucíferas al igual que la coliflor, el repollo el repollito de Bruselas y el kale (Figura IV.1.B, C, D, E).

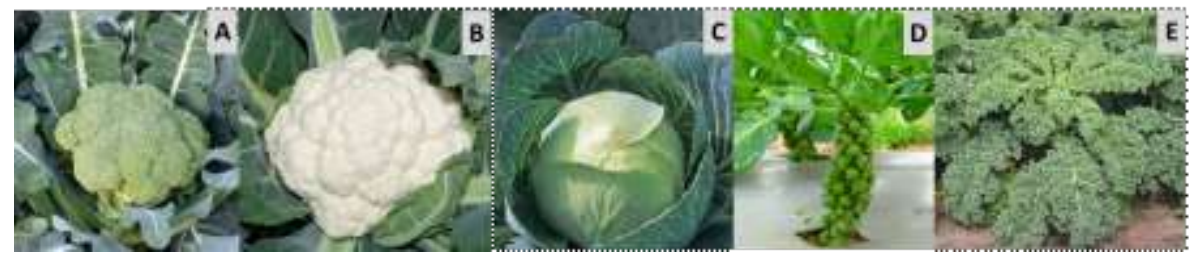

Figura IV.1. Principales especies de Brasicáceas de interés comercial A) Brassica oleracea L. var. Itálica L, B) Brassica oleracea var. Botrytis, C) Brassica oleracea var. Capitata L., D) Brassica oleracea var. Gemmifera L., E) Brassica oleracea var. Sabellica.

La parte comestible del brócoli es su inflorescencia formada por yemas florales hipertrofiadas color verde asociada con sus respectivos pedúnculos, que en conjunto recibe el nombre de pella, cabeza o cogollo.

\subsubsection{Producción}

Según cifras de FAOSTAT, se producen alrededor de 20 millones de Tn de brócoli y coliflor en 1,33 millones de ha. El mayor productor en términos de volumen es China, con casi 9 millones de Tn, siguiéndole India, con unos 8,2 millones de Tn. En Europa particularmente en España, el brócoli ha tenido un reciente crecimiento, con destino a satisfacer la demanda de los países de la Unión Europea tanto en forma fresca como congelada. En EEUU el crecimiento del cultivo ha sido notable. Según el Departamento de Agricultura estadounidense (USDA) en dos décadas el consumo de brócoli ha pasado de 0,7 a $3 \mathrm{~kg} /$ habitante/año.

En Argentina, el cultivo del brócoli presenta un desarrollo productivo creciente. La zona del conurbano bonaerense es donde se concentra el $60 \%$ de la producción, seguida por Santa Fe y Córdoba con una participación aproximada de 15 \% cada una (Aprea, 2008; Castro, 2017). La comercialización se realiza principalmente en fresco, aunque más recientemente han adquirido interés otras formas de presentación como ramilletes frescos 
cortados (cuarta gama) o congelados. El aumento en la popularidad de este producto se ha asociado en buena parte con sus cualidades nutritivas y con propiedades beneficiosas para la salud que se le han atribuido como la protección contra ciertos tipos de cáncer y el control de bacterias patógenicas como Helicobacter pylori. (Lee y col., 2008; Vig y col., 2009)

\subsubsection{Morfología}

Son plantas bienales, con sistema radicular pivotante, con raíces secundarias y superficiales, hojas erguidas, onduladas, con nervaduras marcadas, tallo principal erecto y fuerte que va a llevar la inflorescencia o parte comestible. Puede producir otras inflorescencias laterales más pequeñas que salen de las axilas de las hojas del tallo principal. La inflorescencia principal, puede llegar a medir $20 \mathrm{~cm}$ de diámetro, distinguiéndose colores diferentes según variedades: moradas, rojizas, blancas o amarillentas, siendo la más común la verde oscura en el tallo y verde azulado en el extremo. Las flores son amarillas de unos $2,5 \mathrm{~cm}$ de diámetro y se agrupan en racimos desarrollados a partir del tallo principal y de sus ramificaciones. La polinización es cruzada y entomófila. El fruto es una silicua, dehiscente y glabra, de $10 \mathrm{~cm}$ de longitud, 4 a $5 \mathrm{~cm}$ de ancho y contiene unas 20 semillas redondeadas y pequeñas.

En el desarrollo del brócoli se pueden considerar las siguientes fases:

- $\quad$ Fase juvenil: donde la planta solamente desarrolla hojas y raíces.

- De inducción floral: pasados entre 10-15 días dependiendo del cultivar con temperaturas bajas entre $10-15{ }^{\circ} \mathrm{C}$ (período de vernalización), la planta, inicia la formación del cogollo o cabeza; al mismo tiempo, siguen brotando hojas.

De formación de inflorescencias: en la yema terminal se desarrolla la inflorescencia terminal o principal y, al mismo tiempo, en las yemas axilares de las hojas ocurre la fase de inducción floral con la formación de nuevas inflorescencias (inflorescencias laterales). Se dejan de formar hojas y las más jóvenes pasan a envolver el cogollo para su protección.

- De floración y fructificación: los tallos que sustentan las partes de la inflorescencia inician un crecimiento en longitud, con apertura de las flores finalizando en la formación de las silicuas. 


\subsubsection{Valor nutricional}

El brócoli tiene un importante valor nutritivo, es rico en fibras $(2,6 \mathrm{~g} / 100 \mathrm{~g}$ peso fresco), es una importante fuente de vitaminas A y $\mathrm{C}$ y minerales (Fe, $\mathrm{Ca}, \mathrm{Mg}, \mathrm{K}$ ) (Tabla IV.1). Una porción de $100 \mathrm{~g}$ de inflorescencias de brócoli aporta el $50 \%$ de las necesidades diarias de vitamina $\mathrm{A}$ y dos veces los requerimientos diarios de vitamina $\mathrm{C}$ para un adulto. Por su alto contenido en fibras solubles, el brócoli ayuda a combatir la diabetes, ya que ralentiza la absorción de glucosa en el intestino; y el cáncer de colon, debido a que acelera el tránsito intestinal. Asimismo, por su bajo contenido en calorías es recomendado en dietas para control de peso. Finalmente, por su alto contenido en potasio, previene el debilitamiento de arterias e hipertensión (Stoppani y Francescangeli, 2000).

Tabla IV.1 Composición nutricional de brócoli cada $100 \mathrm{~g}$ de producto (USDA, 2018).

\begin{tabular}{|c|c|c|c|c|c|c|c|}
\hline \multicolumn{2}{|c|}{ MACROCOMPONENTES } & \multicolumn{2}{|c|}{ MINERALES } & \multicolumn{2}{|c|}{ VITAMINAS } & \multicolumn{2}{|c|}{ LIIPIDOS } \\
\hline Agua (g) & 89 & Calcio (mg) & 47 & $\begin{array}{l}\text { Vitamina C } \\
(\mathrm{mg})\end{array}$ & 89 & Saturados (g) & 0,114 \\
\hline Energía (kcal) & 34 & Hierro (mg) & 0,73 & Tiamina (mg) & 0,07 & $\begin{array}{l}\text { Monoinsat. } \\
\text { (g) }\end{array}$ & 0,03 \\
\hline Proteína $(g)$ & 2,8 & $\begin{array}{l}\text { Magnesio } \\
\quad(\mathrm{mg})\end{array}$ & 21 & $\begin{array}{l}\text { Riboflavina } \\
\text { (mg) }\end{array}$ & 0,12 & Poliinsat. (g) & 0,112 \\
\hline Lípidos totales (g) & 0,4 & Fosforo (mg) & 66 & Niacina (mg) & 0,64 & $\begin{array}{c}\text { Grasas trans } \\
(\mathrm{g})\end{array}$ & 0 \\
\hline $\begin{array}{c}\text { Hidratos de carbono } \\
\text { (g) }\end{array}$ & 6,6 & Potasio (mg) & 316 & $\begin{array}{l}\text { Vitamina B6 } \\
(\mathrm{mg})\end{array}$ & 0,175 & $\begin{array}{l}\text { Colesterol } \\
\quad(\mathrm{mg})\end{array}$ & 0 \\
\hline Fibra $(g)$ & 2,6 & Sodio (mg) & 33 & Folatos $(\mu \mathrm{g})$ & 63 & & \\
\hline \multirow[t]{4}{*}{ Azucares totales $(g)$} & 1,7 & Zinc (mg) & 0,4 & $\begin{array}{l}\text { Vitamina } A, \\
(\mu \mathrm{g})\end{array}$ & 31 & & \\
\hline & & & & $\begin{array}{l}\text { Vitamina A, } \\
\text { (IU) }\end{array}$ & 623 & & \\
\hline & & & & $\begin{array}{l}\text { Vitamina } E \\
(\mu g)\end{array}$ & 0,8 & & \\
\hline & & & & $\begin{array}{l}\text { Vitamina } \mathrm{K} \\
(\mu \mathrm{g})\end{array}$ & 102 & & \\
\hline
\end{tabular}

De todos modos, la reputación del brócoli como una "super-hortaliza: se relaciona con otros componentes secundarios que contribuyen en forma central a sus propiedades funcionales. El brócoli posee un alto contenido de antioxidantes, dentro de los que se destacan el ácido ascórbico, los carotenoides y compuestos fenólicos. Dentro de este último grupo predominan los derivados del ácido hidroxicinámico, tales como: los ácidos clorogénico, neo-clorogénico, $p$-cumárico, cafeico, ferúlico, sinápico, (Figura 9) ya sea en forma libre o glicosilada (Nicoletto y col., 2016; Vallejo y col., 2003; Martínez- 
Hernández y col., 2011). Por su parte dentro de los carotenoides se destaca la luteína que representa entre 50 y 75\% del total de estos compuestos (Nunn y col., 2006).

Sin embargo, el grupo de fitoquímicos que más atención ha generado en el brócoli y otras crucíferas por estar limitados a esta familia de Angiospermas y por sus propiedades beneficiosas para la salud son los glucosinolatos (GS) (Tian y col., 2005; MartínezHernández y col., 2013a). Los GS constituyen un grupo diverso caracterizado estructuralmente por presentar un grupo de isotiocianato sulfatado conjugado con una tioglucosa y un radical (Tabla IV.2). Ese radical puede ser de tipo alifático, indólico, aromático, entre otros, y que generan cerca de 120 compuestos diferentes de GS.

Tabla IV.2 Estructura básica, clasificación y nombre de los glucosinolatos presentes en brócoli. Adaptado de Tian y col. (2005).

\begin{tabular}{|c|c|c|c|}
\hline $\begin{array}{l}\text { Grupo } \\
\text { glucosinolato }\end{array}$ & Estructura del $R$ & Nombre Trivial & Nombre IUPAC \\
\hline \multirow{3}{*}{$\begin{array}{l}\text { Alifático } \\
\text { (olefínico) }\end{array}$} & \multirow{3}{*}{$\begin{array}{l}\mathrm{H}_{2} \mathrm{C}=\mathrm{CH}-\mathrm{CH}_{2}- \\
\mathrm{H}_{2} \mathrm{C}=\mathrm{CH}-\left(\mathrm{CH}_{2}\right)_{2}- \\
\mathrm{H}_{2} \mathrm{C}=\mathrm{CH}-\mathrm{CH}_{-}-\mathrm{CH}_{2}- \\
\stackrel{\mathrm{OH}}{\mathrm{OH}}\end{array}$} & Sinigrina & 2-propenil glucosinolato \\
\hline & & Gluconapina & 3-Butenil glucosinolato \\
\hline & & Progoitrina & $\begin{array}{l}\text { 2-hidroxi-3-butenil } \\
\text { glucosinolato }\end{array}$ \\
\hline \multirow{4}{*}{$\begin{array}{l}\text { Alifático } \\
\text { (con azufre) }\end{array}$} & \multirow{4}{*}{$\begin{array}{l}\mathrm{H}_{3} \mathrm{C}-\mathrm{S}-\left(\mathrm{CH}_{2}\right)_{4}- \\
\mathrm{H}_{3} \mathrm{C}-\mathrm{SO}-\left(\mathrm{CH}_{2}\right)_{3}- \\
\mathrm{H}_{3} \mathrm{C}-\mathrm{SO}-\left(\mathrm{CH}_{2}\right)_{4}- \\
\mathrm{H}_{3} \mathrm{C}-\mathrm{SO}-\left(\mathrm{CH}_{2}\right)_{5}-\end{array}$} & Glucoerucina & 4-metiltiobutil glucosinolato \\
\hline & & Glucoiberina & $\begin{array}{l}\text { 3-metilsulfinilpropil } \\
\text { glucosinolato }\end{array}$ \\
\hline & & Glucorafanina & $\begin{array}{l}\text { 4-metilsulfinilbutil } \\
\text { glucosinolato }\end{array}$ \\
\hline & & Glucoalisina & $\begin{array}{l}\text { 5-metilsulfinilpentil } \\
\text { glucosinolato }\end{array}$ \\
\hline \multirow[t]{3}{*}{ Indólicos } & & Glucobrasicina & Indol-3-ilmetil glucosinolato \\
\hline & & Neoglucobrasicína & $\begin{array}{l}\text { 1-metoxindol-3ilmetil } \\
\text { glucosinolato }\end{array}$ \\
\hline & H & $\begin{array}{l}\text { 4- } \\
\text { metoxiglucobrasicína }\end{array}$ & $\begin{array}{l}\text { 4-metoxiindol-3-ilmetil } \\
\text { glucosinolato }\end{array}$ \\
\hline
\end{tabular}


En el caso de brócoli, los principales GS poseen radicales alifático e indólico, siendo glucorafanina y glucobrasicina, respectivamente los mayoritarios (Figura IV.13) (Martínez-Hernández y col., 2013b). Los GS están localizados en vacuolas, y ante la ruptura celular son hidrolizados por la enzima mirosinasa ( $\beta$-tioglucosida glucohidrolasa) localizada en citoplasma. Esta reacción libera la glucosa que estabiliza a los GS generando a partir de la molécula original varios productos de descomposición como isotiocianatos, tiocianatos y nitrilos los que parecen ser responsable de muchas de las propiedades de estos compuestos (Jones y col., 2010) tanto en la propia planta (ej, defensa frente a plagas, enfermedades y herbívoros) como en los consumidores (pungencia de los productos, propiedades anticarcinogénica particularmente de colon, recto y próstata) (Farnham y col., 2004; Mi y col., 2007; Hayes y col., 2008; Traka y col., 2010).

\subsubsection{Manejo del cultivo}

El cultivo de brócoli se realiza con la técnica de desarrollo de plantín y posterior trasplante. El marco de plantación varía con la zona, el tipo de suelo y la época de cultivo. Se encuentran variedades de ciclo corto (90 días), intermedio (90 y 110 días) y largo (más de 110 días) entre siembra y cosecha. Si bien el cultivo puede realizarse en diferentes épocas del año se destaca la calidad en primaveras frescas y en otoños benignos (Maroto y Baixauli Soria, 2017).

\subsubsection{Cosecha y calidad comercial}

La primera recolección se realiza para cosechar la inflorescencia principal. La cabeza debe ser firme a la presión de la mano, compacta, y de color verde. Al romperse la dominancia apical, se produce en la planta de brócoli un brote o crecimiento secundario. Para el consumo fresco, las inflorescencias deberán cortarse con un tallo de 5 a $10 \mathrm{~cm}$ y atarse en manojos que se clasificarán como chicos (hasta $0,5 \mathrm{~kg})$, medianos $(0,5 \mathrm{a} 2 \mathrm{~kg})$ y grandes (más de $2 \mathrm{~kg}$ ). Para la industria del congelado no influye el tamaño de la inflorescencia ya que ésta se troza en tamaño variable entre 2 y $5 \mathrm{~cm}$ de diámetro.

\subsubsection{Senescencia y degradación de clorofilas}

La senescencia es una de las etapas finales del desarrollo de un vegetal. La degradación de clorofila es el primer síntoma visible de la senescencia, aunque los procesos de desensamblaje de los cloroplastos y remobilizacion de proteínas se inician mucho antes que la aparición de los síntomas (Yamauchi, 2015). Las moléculas de clorofila están 
formadas por un anillo tetrapirrólico (porfirina) con un ión magnesio $\left(\mathrm{Mg}^{2+}\right)$ en el centro de estos anillos y posee una larga cadena lateral hidrofóbica de 20 carbonos (fitol) (Figura IV.2A). Los dos tipos principales de clorofilas son la clorofila $a$ y la clorofila $b$, que difieren en que la primera posee un grupo metilo donde la segunda posee un formilo. Esta pequeña diferencia en estructura química provoca un considerable cambio en el espectro de absorción de ambos compuestos (Figura IV.2B), lo cual permite cuantificarlas por separado (Buchanan y col, 2000; Taiz y Zeiger, 1998).
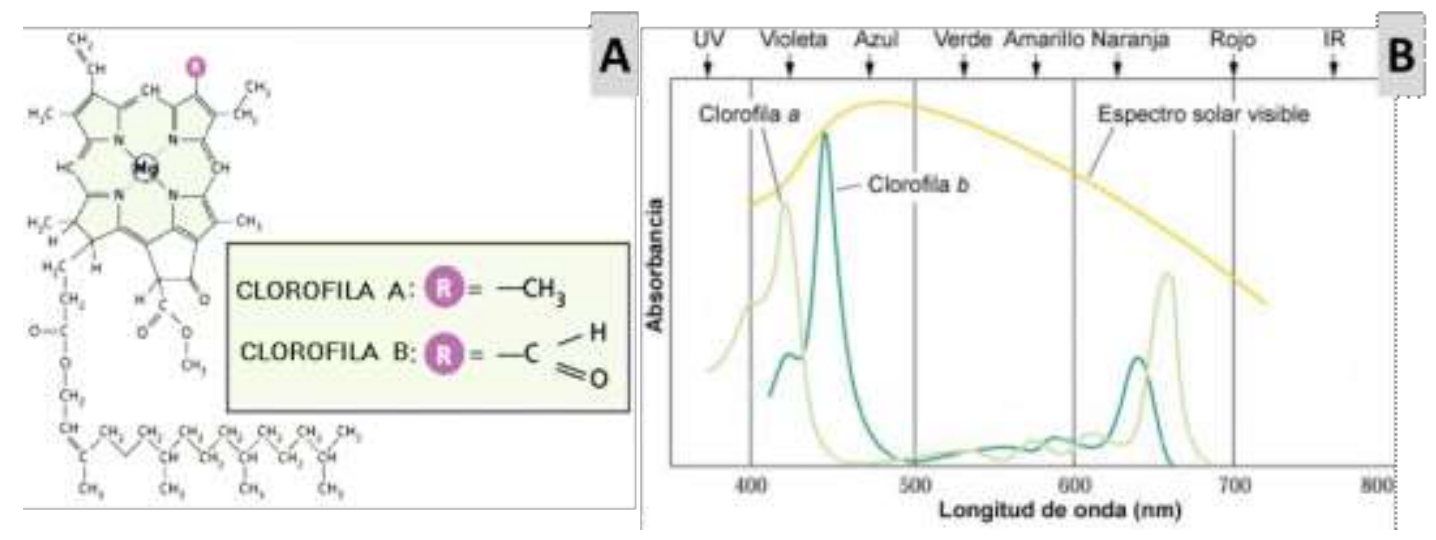

Figura IV.2. A) Estructura de clorofila $a$ y $b$, B) Espectro de absorción las clorofilas $a$ y $b$. Se muestra el espectro de luz solar visible. Adaptado de Buchanan y col. (2000).

La ruta propuesta de degradación de la clorofila comienza con la conversión de la Chl-b a Chl-a (Horie y col., 2009). Luego, la Chl-a continúa una serie de pasos que se muestran en la Figura IV. 3. La primera reacción es la eliminación del fitol catalizada por la enzima clorofilasa, y que genera el clorofílido-a (Chlide) de un color verde vívido (Roca y Minguez-Mosquera, 2003). Posteriormente, se produce la remoción del ión central de $\mathrm{Mg}^{2+}$ por la enzima $\mathrm{Mg}$ dequelatasa (MDS) para generar feofórbido-a (Pheo) de color verde oliva (Shioi y col., 1996). Más recientemente se ha puesto en duda la linearidad de esta ruta catabólica que propone se podría liberar el $\mathrm{Mg}^{2+}$ antes de la remoción del fitol (Tang y col., 2000) para generar feofitina (Phy) de color amarillo pardo por acción de la enzima feofitinasa. Adicionalmente se ha sugerido que la clorofila $a$ puede ser degradada por otras enzimas, como una peroxidasa en presencia de compuestos fenólicos y $\mathrm{H}_{2} \mathrm{O}_{2}$ (Yamauchi y col., 2004). 


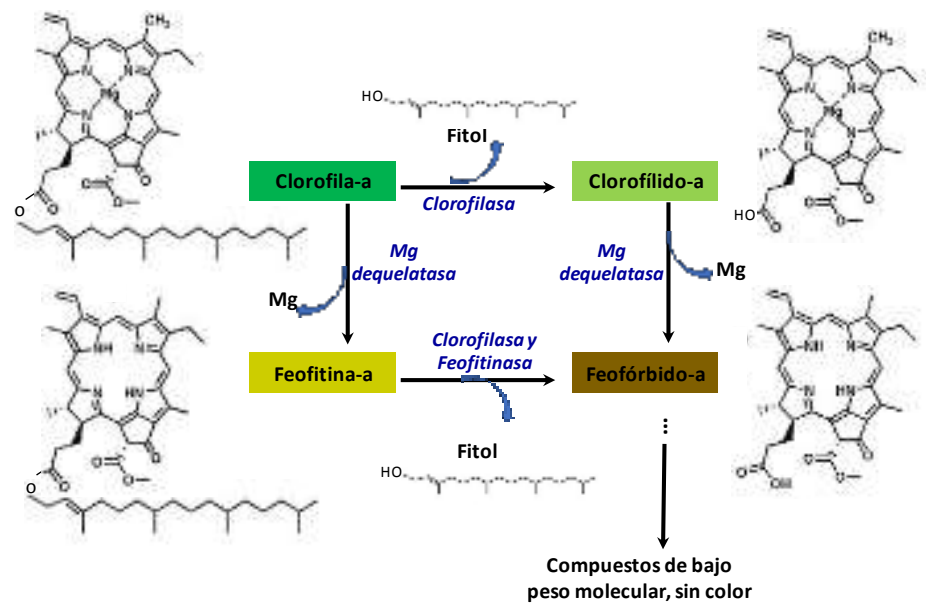

Figura IV.3. Ruta de degradación de la clorofila. Adaptado de Aiamla y col. (2012) y Smolikova y col. (2017).

Durante la senescencia también, se produce una importante degradación y movilización de proteínas, que provoca una acumulación de aminoácidos libres y amoníaco. Luego ocurre una disminución en la integridad estructural y funcional de las membranas celulares, resultado del metabolismo acelerado de los lípidos (Thompson y col., 1998).

\subsubsection{Manejo poscosecha de brócoli}

Las cabezas de brócoli tienen tasas de respiración muy alta (Cantwell y Suslow, 2002). Por su parte, si bien las inflorescencias poseen una tasa de producción de etileno muy baja la sensibilidad a este compuesto es muy elevada. Así por ejemplo el contacto con $2 \mathrm{ppm}$ de etileno a $10{ }^{\circ} \mathrm{C}$ reduce la vida en góndola en un $50 \%$ (Cantwell y Suslow, 2002). La refrigeración en el brócoli permite conseguir una vida útil más prolongada. Se recomienda una temperatura de $0{ }^{\circ} \mathrm{C}$ y una $\mathrm{HR}>95 \%$ para optimizar la vida de almacenamiento (2128 días). El brócoli se puede almacenar adecuadamente en atmósferas conteniendo 1-2 \% $\mathrm{O}_{2}$ con $5-10 \% \mathrm{CO}_{2}$ (Yamauchi y Watada, 1998).

\subsection{Niveles de compuestos antioxidantes en brócoli: ¿Es posible promover su}

\section{acumulación mediante tratamientos de poscosecha?}

En la última década, ha aumentado el interés en la evaluación de los métodos físicos de poscosecha que podrían mantener o incluso mejorar la calidad de los vegetales, al tiempo que evitan el uso de aditivos químicos (Vicente y Lurie, 2014). La irradiación UV se ha utilizado durante varios años en la industria alimentaria, principalmente con fines de desinfección (materiales de embalaje y agua) (Civello y col., 2006). Más recientemente, se comenzó a evaluar el uso directo de los tratamientos con UV en las superficies de los 
alimentos (Vicente y Lurie, 2014). Para estas aplicaciones, la radiación UV-C se ha elegido generalmente, dado su mayor efecto germicida (Civello y col., 2006). Sin embargo, se sabe que otras regiones dentro del espectro UV inducen respuestas fisiológicas en vegetales (Venditti y D'hallewin, 2014).

Se ha informado que los tratamientos con UV-B retrasan la maduración y la senescencia. La exposición a UV-B retrasó el amarillamiento en el brócoli almacenado a $15{ }^{\circ} \mathrm{C}$ (Aiamla-or y col., 2009; Aiamla-or y col., 2010). Si los tratamientos también son beneficiosos en las inflorescencias refrigeradas mínimamente procesadas no se ha probado. También se ha demostrado que la irradiación UV provoca la acumulación de antioxidantes en algunos productos (Jansen y col., 2010). Las peras expuestas al sol que reciben mayor luz UV-B generalmente muestran un nivel de antocianina más alto que las frutas sombreadas (Sun y col., 2014). Se han reportado mayor contenido de ácidos fenólicos y flavonoides en tomates sometidos a irradiación UV-B después de la cosecha (Castagna y col., 2014). Se ha demostrado que la inducción de respuestas defensivas contra la radiación UV-B también depende del origen geográfico de los genotipos (Jansen y col., 2010). La investigación que comprende los efectos que las condiciones de irradiación ejercen sobre el resultado de los tratamientos con rayos UV aún está en curso. Varios estudios han analizado el efecto de la radiación UV-B antes de cosechar cultivos y han caracterizado su papel en la fisiología de las plantas. Sin embargo, esto puede diferir notablemente de las respuestas que ocurren en los órganos recolectados. La mayoría de los estudios realizados hasta ahora han caracterizado los efectos de los tratamientos de dosis de irradiación UV en diferentes productos (Lemoine y col., 2007; Lemoine y col., 2008; Aiamla-or y col., 2009; Avena-Bustillos y col., 2012). Sin embargo, la intensidad de la irradiación como un factor importante que determina el resultado de los tratamientos UV en la retención de la calidad ha sido menos estudiada. Cote y col. (2013) informaron que para una dosis fija $\left(4,1 \mathrm{~kJ} / \mathrm{m}^{2}\right)$ los tratamientos con UV-C de alta intensidad fueron más efectivos para prevenir la descomposición poscosecha y el ablandamiento de la frutilla que los de exposición a baja intensidad. No se ha determinado la influencia de la intensidad de la radiación UV-B en la senescencia y el contenido de antioxidante de brócoli cosechado. Por lo que se plantea como objetivo de este último capítulo del presente trabajo de tesis: "evaluar el efecto de la intensidad y dosis con radiación $U V$-B sobre la calidad visual y retención de compuestos bioactivos de importancia nutricional en brócoli mínimamente procesado". 


\section{IV.2. MATERIALES Y MÉTODOS}

\subsection{Efecto de la intensidad y dosis de radiación UV-B sobre la calidad de brócoli mínimamente procesado y refrigerado}

\subsubsection{Material vegetal y almacenamiento}

Se cosecharon cabezas de brócoli (Brassica oleracea L.) de cultivo a campo de una finca de La Plata (Buenos Aires, Argentina). Las mismas fueron seleccionadas para eliminar las cabezas sobremaduras o con defectos visibles de forma, color o compacidad. Se cortaron en ramilletes y colocaron en bandejas de plástico rígido en aproxidamente $180 \mathrm{~g}$ de ramilletes por bandeja para luego ser irradiadas con luz UV-B. Luego de ser irradiadas, 3 bandejas de cada tratamiento con un peso promedio de $180 \mathrm{~g}$ cada una, se recubrieron con film PVC perforado y se llevó a almacenamiento en oscuridad en cámaras a $4{ }^{\circ} \mathrm{C}$ durante 17 días. Los controles no fueron irradiados, se empaquetaron y almacenaron como se detalló anteriormente. Al inicio y al final del almacenamiento, se determinó la pérdida de peso y color de las inflorescencias. Por otro lado, se colectaron las yemas florales de los ramilletes con bisturí, se congelaron en nitrógeno líquido y se almacenaron a $-80{ }^{\circ} \mathrm{C}$ para realizar posteriormente el análisis del contenido de clorofila y derivados, y antioxidantes totales y fenoles totales.

\subsubsection{Tratamiento con luz $U V-B$}

Se trabajó con un banco con 4 lámparas UV-B (QFS-40, Philips) con encendido independiente (Figura IV.4A). Se verificó el rango de longitudes de onda que abarcaba la irradiancia de las lámparas empleando un espectrómetro (AvaSpec, ULS3648-UBS2U25A con fibra óptica FC-UVIR200-2, Estados Unidos), comprobándose que estaba centrada y con el mayor porcentaje entre los 290-320 nm que corresponden a luz UV-B, y un ligero porcentaje entre 320-390 nm de luz UV-A (Figura IV. 4). 


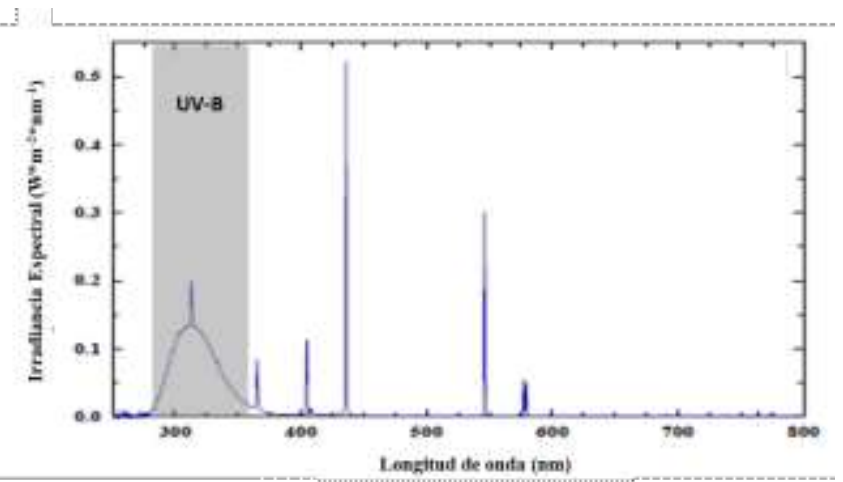

Figura IV.4. Irradiancia espectral de las lámparas empleadas en el rango de longitud de onda de 280-800 $\mathrm{nm}$. Recuadro de color entre 290-320 nm se distingue el rango de luz UV-B.

Se empleó un radiómetro (UVITEC, RX-003, Francia) para registrar la intensidad (Figura IV.4B). Las muestras se colocaron en bandejas en estantes a distancias regulables $(30 \mathrm{~cm}$ y $15 \mathrm{~cm})$ respecto de las lámparas (Figura IV.4C).
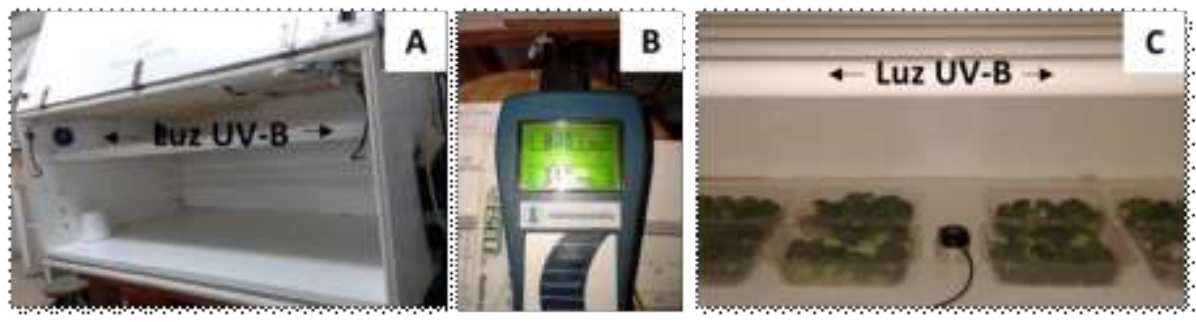

Figura IV.4. A) Equipo de tratamiento UV-B, B) radiómetro y C) disposición del producto y sonda del radiómetro dentro del equipo.

Se ensayaron diferentes intensidades, que se lograron encendiendo distinto número de lámparas y distancia entre ellas y la muestra; y diferentes dosis, que se alcanzaron dejando las muestras expuestas por un cierto tiempo. Así, se ensayaron intensidades: Baja=3,2 $\mathrm{W} / \mathrm{m}^{2}$ (2 lámp, $30 \mathrm{~cm}$ ), Media = 4,0 W/m² (4 lámp, $30 \mathrm{~cm}$ ) y Alta = 5,0 W/m² (4 lámp, 15 $\mathrm{cm}$ ) y con dosis de $2,4,8$ y $12 \mathrm{~kJ} / \mathrm{m}^{2}$ para cada una de ellas. Los tiempos necesarios para alcanzar las distintas dosis se detallan en la Tabla IV.2. Los respectivos controles no fueron irradiados. 
Tabla IV.3 Tiempos de exposición a luz UV-B de brócoli mínimamente procesado sin tratar (control) y tratado a las intensidades Baja $\left(\mathbf{B}=3,2 \mathrm{~W} / \mathrm{m}^{2}\right)$, Media $\left(\mathbf{M}=4,0 \mathrm{~W} / \mathrm{m}^{2}\right)$ y Alta $\left(\mathbf{A}=5,0 \mathrm{~W} / \mathrm{m}^{2}\right)$ y con dosis de $2,4,8$ y $12 \mathrm{~kJ} / \mathrm{m}^{2}$ de luz UV-B.

INTENSIDAD

TIEMPO DE EXPOSICIÓN (MIN)

\begin{tabular}{|c|c|c|c|c|c|c|c|}
\hline \multirow[b]{3}{*}{ Control } & \multirow{3}{*}{$\begin{array}{c}\left(W / m^{2}\right) \\
0\end{array}$} & \multirow{3}{*}{$\begin{array}{c}\text { Lamp } \\
\text { encendidas } \\
-\end{array}$} & \multirow{3}{*}{$\begin{array}{c}\text { Distancia } \\
\text { (cm) } \\
-\end{array}$} & \multicolumn{4}{|c|}{ Dosis $\left(k J / m^{2}\right)$} \\
\hline & & & & 2 & 4 & 8 & 12 \\
\hline & & & & - & - & - & - \\
\hline$B$ & 3,2 & 2 & 30 & 10 & 20 & 45 & 65 \\
\hline$M$ & 4,0 & 4 & 30 & 7 & 15 & 32 & 48 \\
\hline$A$ & 5,0 & 4 & 15 & 6 & 12 & 25 & 39 \\
\hline
\end{tabular}

2.2. Efecto de la intensidad y dosis de radiación UV-B sobre la estimulación de compuestos antioxidantes a tiempos cortos y estabilidad luego del almacenamiento congelado

\subsubsection{Material vegetal y almacenamiento}

Se cosecharon cabezas de brócoli y procesaron según se detalló previamente en la sección 2.1.1. Se trataron con luz UV-B (sección 2.1.2) y 3 bandejas de cada tratamiento (180 g cada una), se recubrieron con film PVC perforado y se llevaron a almacenamiento en oscuridad en cámaras a $20^{\circ} \mathrm{C}$. En un primer ensayo se almacenaron por 2, 6 y $18 \mathrm{~h}$. En un segundo ensayo, las muestras irradiadas a las intensidades y dosis mencionadas recientemente, se dejaron a $20{ }^{\circ} \mathrm{C}$ por $6 \mathrm{~h}$ para luego ser transferidas a $-18{ }^{\circ} \mathrm{C}$ en freezer comercial (Diplomatic, Argentina) durante 30 días. Se colectaron las yemas florales de los ramilletes y preservaron como ya se mencionó (sección 2.1.1), para realizar posteriormente el análisis de antioxidantes totales (sección 2.3.4).

\subsubsection{Tratamiento con luz $U \boldsymbol{V}-\boldsymbol{B}$}

Se trabajó con el mismo banco que se detalló en la sección 2.1.2 que contenía 4 lámparas UV-B (QFS-40, Philips) con encendido independiente y estante regulable. Las muestras mínimamente procesadas colocadas en bandejas de PVC se trataron de la siguiente manera:

a) Tratamiento con baja intensidad $\left(3,2 \mathrm{~W} / \mathrm{m}^{2}\right)$ y baja dosis $\left(2 \mathrm{~kJ} / \mathrm{m}^{2}\right)$ : B2,

b) Tratamiento con baja intensidad $\left(3,2 \mathrm{~W} / \mathrm{m}^{2}\right)$ y alta dosis $\left(12 \mathrm{~kJ} / \mathrm{m}^{2}\right)$ : B12,

c) Tratamiento con alta intensidad $\left(5 \mathrm{~W} / \mathrm{m}^{2}\right)$ y baja dosis $\left(2 \mathrm{~kJ} / \mathrm{m}^{2}\right)$ : $\mathbf{A 2}$,

d) Tratamiento con alta intensidad $\left(5 \mathrm{~W} / \mathrm{m}^{2}\right)$ y alta dosis $\left(12 \mathrm{~kJ} / \mathrm{m}^{2}\right)$ : $\mathbf{A 1 2}$, 


\subsection{Determinaciones analíticas}

\subsubsection{Pérdida de peso}

La pérdida de peso fue determinada por diferencia de pesada de las bandejas a día inicial y final del almacenamiento, en balanza digital (KERN 572). Tres replicados fueron evaluados para cada tratamiento y tiempo de almacenamiento. Los resultados fueron calculados como porcentaje de pérdida de peso según se detalla a continuación:

$$
\text { Pérdida de peso }(\%)=100 \times(\mathrm{Pi}-\mathrm{Pf})) /(\mathrm{Pi})
$$

Donde Pi y Pf son el peso inicial y final de la muestra, respectivamente.

\subsubsection{Color superficial}

Se utilizó un colorímetro (Minolta, modelo CR-400, Japón) obteniendo los valores de a*, b* y L*. Se calculó el ángulo Hue como arco tangente de b*/a*. Se realizaron 20 medidas a cada bandeja para cada tratamiento y tiempo de almacenamiento.

\subsubsection{Compuestos fenólicos}

La determinación de compuestos fenólicos fue realizada de acuerdo con Obied y col. (2005). Para ello se trituró brócoli congelado en nitrógeno líquido en un molinillo, se pesó aproximadamente 1,2 g del triturado y se agregó $10 \mathrm{~mL}$ de etanol (96\% v/v), se agitó en vortex durante $30 \mathrm{seg}$ y luego se llevó a centrifuga a $13.000 \times \mathrm{g}$, durante $10 \mathrm{~min}$ a $4{ }^{\circ} \mathrm{C}$, se separó el sobrenadante para realizar los análisis posteriores.

El contenido de compuestos fenólicos totales se determinó de acuerdo a Singleton y col. (1999), empleando el reactivo de Folin-Ciocalteu según se detalló en la sección I.2.3.2. En esta oportunidad, se emplearon $100 \mu \mathrm{L}$ de extracto etanólico para un volumen final de $3 \mathrm{~mL}$. Se prepararon dos extractos para cada tratamiento, y cada uno se midió por triplicado. Se empleó ácido clorogénico (ACG) como estándar y los resultados se expresaron como mg ACG/kg de peso fresco.

\subsubsection{Capacidad Antioxidante (TEAC)}

El extracto se realizó como se detalló en la sección I.2.3.3. Las determinaciones se realizaron de acuerdo a Arnao y col. (2001) como se detalló en la sección I.2.3.3. En esta oportunidad se emplearon $10 \mu \mathrm{L}$ del extracto y $1 \mathrm{~mL}$ de solución del radical $\mathrm{ABTS}^{\bullet+}$. Se 
utilizó Trolox como patrón. Se realizaron tres extractos por cada tratamiento y tiempo de almacenamiento. Los resultados se expresaron como Capacidad Antioxidante Equivalente a Trolox (TEAC) en $\mathrm{mg} / \mathrm{kg}$ de peso fresco.

\subsubsection{Pigmentos clorofilicos}

La extracción y cuantificación de la clorofila y sus derivados se efectuó de acuerdo a Yang y col. (1998) con algunas modificaciones como se detalla en la Figura IV.5. Para ello, las yemas florales de brócoli congelado en nitrógeno líquido se trituraron en molinillo, se pesó $1 \mathrm{~g}$ y se colocó en un tubo de ensayo conteniendo $5 \mathrm{~mL}$ acetona:agua (80:20), luego se vorteó por $1 \mathrm{~min}$ repitiendo 4 veces, se centrifugó a $3.000 \times g$ por 5 min a $2{ }^{\circ} \mathrm{C}$ (Sorvall ST 16R), se colectó y reservó el sobrenadante. Se procedió a una segunda extracción del pellet en igual condición. Se centrifugaron y se juntaron ambos sobrenadantes. Esta muestra se empleó para la determinación del contenido total de clorofila y sus derivados en forma espectrofotométrica. Posteriormente a $5 \mathrm{~mL}$ de extracto obtenido como se detalló anteriormente se le agregó un volumen de $5 \mathrm{~mL}$ de hexano, se vorteó por $1 \mathrm{~min}$ repitiendo 4 veces y luego se centrifugó a $3.000 \times g$ durante 5 min a 2 ${ }^{\circ} \mathrm{C}$. Se formaron dos fases, la superior contenía los componentes menos polares (retienen el fitol) disueltos en hexano, la inferior poseía los componentes más polares (defitilados) de la mezcla en acetona: agua. A la fracción hexano se la dividió en dos según Varela (1983): a) se le agregó $\mathrm{Na}_{2} \mathrm{SO}_{4}$ con el objetivo de deshidratar el hexano para determinar el contenido de clorofila en hexano (Varela, 1983).

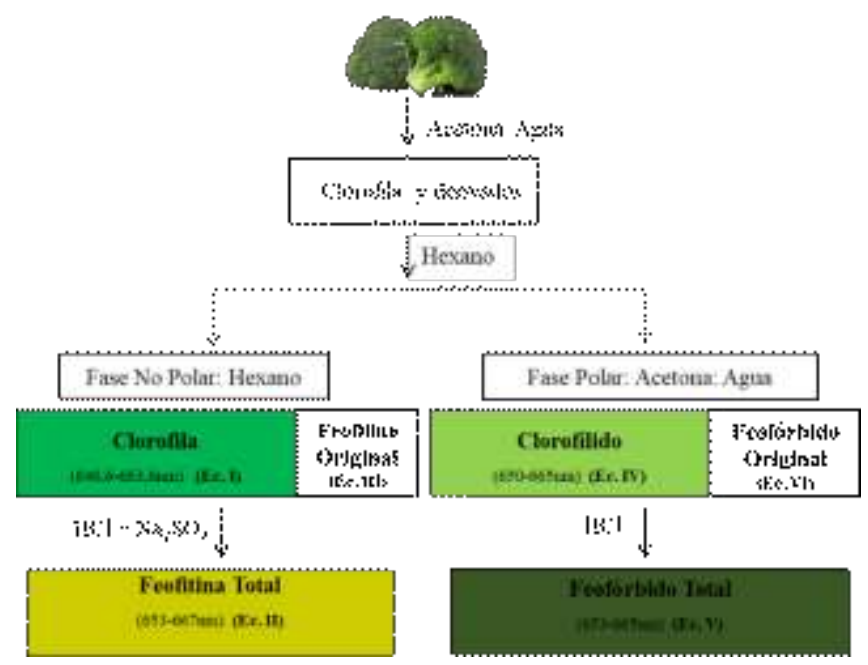

Figura IV.5. Esquema de realización de extractos para la determinación de pigmentos clorofílicos y derivados. 
Se midió la absorbancia a $663,6 \mathrm{~nm}$ y $646,6 \mathrm{~nm}$ y se calculó el contenido de clorofila usando los coeficientes de extinción molar correspondientes en hexano según la ecuación I Tabla IV.2; b) se la acidificó con $20 \mu \mathrm{L} \mathrm{HCl}$ al $25 \% \mathrm{v} / \mathrm{v}$, para remover el $\mathrm{Mg}^{+2} \mathrm{de}$ forma química, se agregó $\mathrm{Na}_{2} \mathrm{SO}_{4}$ como desecante y se midió la absorbancia a $667 \mathrm{~nm}$ y $653 \mathrm{~nm}$ para obtener el contenido de feofitina total (phy) según la ecuación II (Tabla IV.2, Lichtenthaler, 1987). La feofitina original contenida en el extracto, se calculó de forma indirecta por relación entre absorbancias antes y después de la acidificación según la ecuación III (Tabla IV.2) (Lorenzen y Jefrey, 1980). Se midió la absorbancia de la fase acetona: agua a $665 \mathrm{~nm}$ y $650 \mathrm{~nm}$ para cuantificar clorofílidos según la ecuación IV (Tabla IV.2) (Yang y col., 1998). Esa misma fracción se acidificó con $20 \mu \mathrm{L} \mathrm{HCl} 25$ \% $\mathrm{v} / \mathrm{v}$, para remover el $\mathrm{Mg}^{+2}$ de forma química. Se midió la absorbancia a $665 \mathrm{~nm}$ y $653 \mathrm{~nm}$ para determinar el contenido de feofórbido total (pheo) (ecuación V) (Lorenzen y Jefrey, 1980). Para calcular el contenido de feofórbido original se restó el feofórbido proveniente de clorofílidos (ecuación IV) al contenido de feofórbido total según la ecuación III (Tabla IV.2).

Tabla IV.4 Ecuaciones para la determinación de contenido de pigmentos clorofílicos.

\begin{tabular}{|c|c|c|c|c|c|}
\hline COMPUESTO & $\begin{array}{c}\text { PESO } \\
\text { MOLEC. } \\
(G / M O L)\end{array}$ & $\begin{array}{c}\text { SOLVENTE } \\
\text { EXTRACCIÓN }\end{array}$ & $\begin{array}{c}\text { LONGITUD } \\
\text { DE ONDA } \\
(N M)\end{array}$ & & ECUACIÓN \\
\hline $\begin{array}{c}\text { Clorofila a (chl } \\
\text { a) }\end{array}$ & 892 & Hexano & $663-646$ & I & $\begin{array}{c}\mathrm{Chl}_{\mathrm{a}}=12.25 \mathrm{~A}_{663.6-2}-2.55 \mathrm{~A}_{646.6} \\
(\mu \mathrm{g} / \mathrm{mL})\end{array}$ \\
\hline $\begin{array}{l}\text { Feofitina total a } \\
(\text { phy a })\end{array}$ & 871 & Hexano & $667-653$ & II & $\begin{array}{c}\text { Phy total } \mathrm{a}=22,42 \mathrm{~A}_{667}-6,81 \\
\mathrm{~A}_{653}(\mu \mathrm{g} / \mathrm{mL})\end{array}$ \\
\hline $\begin{array}{l}\text { Phy a } \\
\text { original }\end{array}$ & 871 & Hexano & $667-653$ & III & Phy $y_{\text {total a- }}$ phy $y_{\text {chl a }}{ }^{(1)}$ \\
\hline $\begin{array}{l}\text { Clorofilido a } \\
\text { (chlide a) }\end{array}$ & 614 & $\begin{array}{l}\text { Acetona:agua } \\
\quad(80: 20)\end{array}$ & $665-650$ & IV & Chlide $_{\mathrm{a}}=\mathrm{A}_{665} * 8,2(\mu \mathrm{g} / \mathrm{mL})$ \\
\hline $\begin{array}{l}\text { Feoforbido total } \\
\text { a (pheo a) }\end{array}$ & 591 & $\begin{array}{l}\text { Acetona:agua } \\
\quad(80: 20)\end{array}$ & $665-653$ & $\mathrm{~V}$ & $\begin{array}{c}\text { Pheo total } \mathrm{a}=22.42 \mathrm{~A}_{665}-6,81 \\
\mathrm{~A}_{653}(\mu \mathrm{g} / \mathrm{mL})\end{array}$ \\
\hline $\begin{array}{l}\text { Pheo a } \\
\text { original }\end{array}$ & 591 & $\begin{array}{l}\text { Acetona:agua } \\
(80: 20)\end{array}$ & $665-653$ & VI & Pheo total a- pheo chlide a $^{(2)}$ \\
\hline
\end{tabular}

(1) Phy $_{\text {chl a }}=\mathrm{Chl}_{\mathrm{a}}(\mathrm{ug} / \mathrm{mL}) \times(871 / 892)$

${ }^{(2)}$ pheo $_{\text {chlide a }}=$ Chlide $_{\mathrm{a}}(\mathrm{ug} / \mathrm{mL}) \times(591 / 614)$

\subsubsection{Glucosinolatos (GS)}

Los GS se extrajeron y cuantificaron según Cargnel y col. (2014) con pequeñas modificaciones. Muestras liofilizadas (entre 10 y $15 \mathrm{mg}$ ) se trituraron en mortero y se 
transfirió a un tubo Eppendorf. Se adicionó 1,2 mL de metanol 70 \% conteniendo 0,125 $\mu \mathrm{mol}$ de sinigrina (2-propenil-glucosinolato, Sigma-Aldrich, EE. UU.) como patrón interno. Las muestras se incubaron durante 1 min a $70^{\circ} \mathrm{C}$ en un baño de agua y se centrifugaron a $12.000 \times g$ durante $2 \mathrm{~min}$; se adicionaron dos alícuotas más de metanol al $70 \%$ para repetir el procedimiento de extracción y se combinaron los sobrenadantes. Después de la extracción, los sobrenadantes se transfirieron a columnas rellenas con 600 $\mu \mathrm{L}(75 \mathrm{mg}$ ) de DEAESephadex A-25 (previamente equilibrada con $800 \mu \mathrm{L}$ de agua MilliQ); las columnas cargadas se lavaron con $600 \mu \mathrm{L}$ de metanol $70 \%$ y $600 \mu \mathrm{L}$ de agua MilliQ. Para desulfonar los GS retenidos en la columna, se resuspendieron $25 \mu \mathrm{L}$ de solución de arilsulfatasa (Sigma-Aldrich; H-1 de Helix pomatia), preparada como describe Graser y col. (2001) en $600 \mu \mathrm{L}$ de acetato de sodio $0,02 \mathrm{M}$, se añadieron $\mathrm{x} \mathrm{mL}$ de buffer $\mathrm{pH} 4,0$, y las columnas se incubaron durante la noche a temperatura ambiente. Después de la incubación, los desulfoglucosinolatos se eluyeron con $600 \mu \mathrm{L}$ de agua MilliQ y se analizaron en un equipo de HPLC (Knauer Euroline) equipado con columna Restek Pinnacle II C18 (5 $\mu \mathrm{m}, 4.6 \times 150$ mm) empleando fase móvil A (agua) y B (20 \% de acetonitrilo) en un gradiente de $1 \%$ de B a 0 min, $10 \%$ B en 10 min, $75 \%$ B en 22 a $24 \mathrm{~min}$, con un tiempo equilibrado de $10 \mathrm{~min}$, y una velocidad de flujo de $1 \mathrm{~mL} / \mathrm{min}$. El volumen de inyección fue de $20 \mu \mathrm{L}$ y la elución se controló con un detector de arreglo de diodos a $229 \mathrm{~nm}$. Para calcular las concentraciones molares de GSs individuales, se utilizaron factores de respuesta relativos para corregir la diferencia de absorbancia entre el patrón interno y estos compuestos.

\subsection{Análisis estadístico}

Los experimentos se realizaron de acuerdo a un diseño factorial. Los datos se analizaron por medio de ANOVA y las medias se compararon con el test de LSD a fin de determinar las diferencias mínimas significativas a un nivel de significancia de $\mathrm{P}<0,05$. 


\section{IV.3. RESULTADOS Y DISCUSIÓN}

\subsection{Efecto de la intensidad y dosis de radiación UV-B sobre la calidad de brócoli}

\section{mínimamente procesado y almacenado en refrigeración}

El almacenamiento refrigerado extiende notablemente el período de vida útil de los productos y es estrictamente necesario en aquellos vegetales que han sido objeto de un procesamiento mínimo como en este trabajo. Así, se trató los ramilletes de brócoli mínimamente procesado con radiación UV-B, buscando cubrir una variada gama de intensidades y dosis, como tratamiento poscosecha previo a la refrigeración. Los ramilletes se trataron con intensidad baja-B, media-M y alta-A, y con dosis de 2, 4, 8 y $12 \mathrm{~kJ} / \mathrm{m}^{2}$. Posteriormente, se los almacenó a $4{ }^{\circ} \mathrm{C}$ por 17 días y se analizó el efecto de la radiación UV-B aplicada sobre los distintos parámetros de calidad de los ramilletes. En la Figura IV.6 se observa la apariencia de las bandejas conteniendo los ramilletes controles y tratados con las distintas intensidades y dosis.

CXITOF.

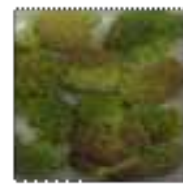

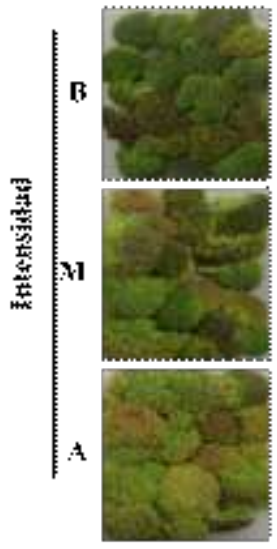

I

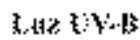

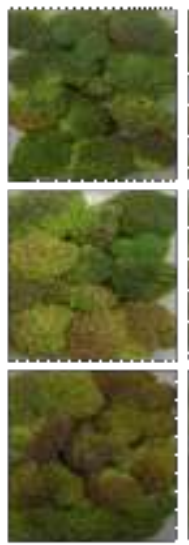

4

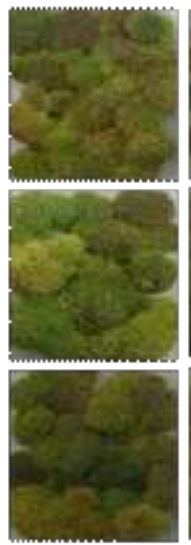

s.

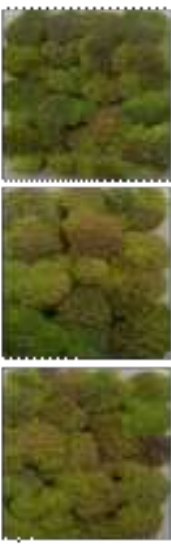

12

3).sik

Figura IV.6. Apariencia de brócoli mínimamente procesado control y tratado con intensidades de

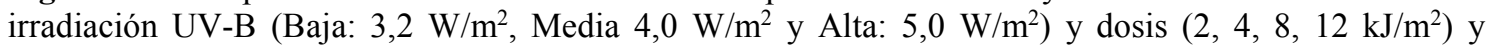
almacenados a $4{ }^{\circ} \mathrm{C}$ durante 17 días.

La intensidad baja $\left(3,2 \mathrm{~W} / \mathrm{m}^{2}\right)$ y dosis 2 y $4 \mathrm{~kJ} / \mathrm{m}^{2}$ mostraron resultados similares entre sí y con mayor retención del color verde de los ramilletes. Sin embargo, el resto de las combinaciones intensidad: dosis desarrollaron un color más amarillento-marrón y en cierta forma similar a los ramilletes control. Estos resultados están en concordancia con otros autores que proponen a la radiación UV-B como alternativa poscosecha para el 
retraso de senescencia. Precisamente, se ha ensayado tratamientos en lima (Kaewsuksaeng y col., 2011), en lechuga (Caldwell y Britz, 2006) y cebolla (Dissanayake y col., 2008). Mientras que, empleando cabezas de brócoli entera, los tratamientos UV-B efectivos en preservar la calidad poscosecha han sido $8.8 \mathrm{~kJ} / \mathrm{m}^{2}$ a $15^{\circ} \mathrm{C}$ (Aiamla y col., 2010) y $19,1 \mathrm{~kJ} / \mathrm{m}^{2}$ a $4{ }^{\circ} \mathrm{C}$ (Aiamla y col., 2019), aunque en ambos casos emplearon una intensidad de $7,3 \mathrm{~W} / \mathrm{m}^{2}$, mayor a la empleada aquí.

\subsubsection{Pérdida de peso}

Los ramilletes de brócoli mínimamente procesados y tratados con UV-B, en general, mostraron una menor pérdida de peso que el control después del almacenamiento a $4{ }^{\circ} \mathrm{C}$ (Figura IV.7). La mayor reducción en la pérdida de peso se encontró en las muestras tratadas con dosis de 2 y $4 \mathrm{~kJ} / \mathrm{m}^{2}$ para las intensidades baja $\left(3,2 \mathrm{~W} / \mathrm{m}^{2}\right)$ o media $(4,0$ $\left.\mathrm{W} / \mathrm{m}^{2}\right)$, respectivamente.

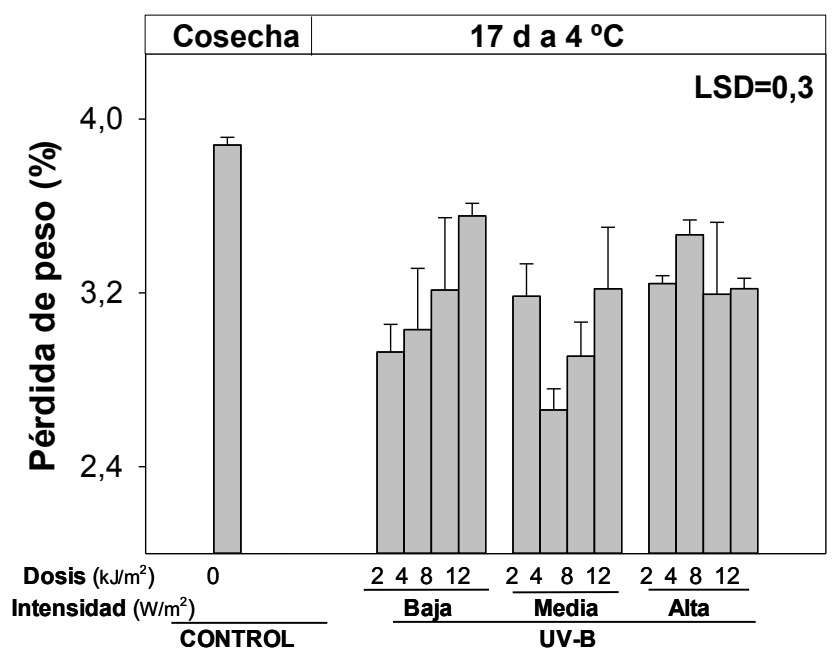

Figura IV.7. Pérdida de peso en brócoli mínimamente procesado control y tratado con intensidades de irradiación UV-B (Baja: 3,2 W/m², Media 4,0 W/m² y Alta: 5,0 W/m²) y dosis $\left(2,4,8,12 \mathrm{~kJ} / \mathrm{m}^{2}\right.$ ) y almacenados a $4{ }^{\circ} \mathrm{C}$ durante $17 \mathrm{~d}$. Las barras de error representan la desviación estándar de la media. Se muestra el valor de LSD.

Se ha informado una reducción de la deshidratación en el brócoli tratado con UV-C. (Lemoine y col., 2008), así como en otros productos, por lo que podría extrapolarse a lo sucedido aquí, para UV-B. Manzocco y Nicoli (2015) sugirieron que la irradiación UVC puede reducir la pérdida de agua mediante la formación de una fina capa seca en la superficie del producto que a su vez puede restringir el flujo de vapor de agua. También, la mejor integridad del tejido en productos irradiados con UV, en los que se retrasa la 
senescencia, puede contribuir a explicar la pérdida de agua reducida (Lemoine y col., 2008).

\subsubsection{Color superficial}

El amarillamiento es el principal factor que contribuye al deterioro del brócoli durante el almacenamiento poscosecha (Büchert y col., 2011). En trabajos previos en brócoli irradiado con UV-B y UV-C se mostró que el resultado en la retención de color es marcadamente dependiente de la dosis de irradiación (Aiamla-or y col., 2009; Lemoine y col., 2007).

Sin embargo, no se ha determinado si la intensidad de irradiación tiene o no un papel significativo en los efectos observados. Los ramilletes mostraron un amarillamiento significativo después del almacenamiento que se explica a partir de la caída en los valores de Hue (Figura IV.8A) y el incremento del valor de la luminosidad L* (Figura IV.8B) respecto de la cosecha.

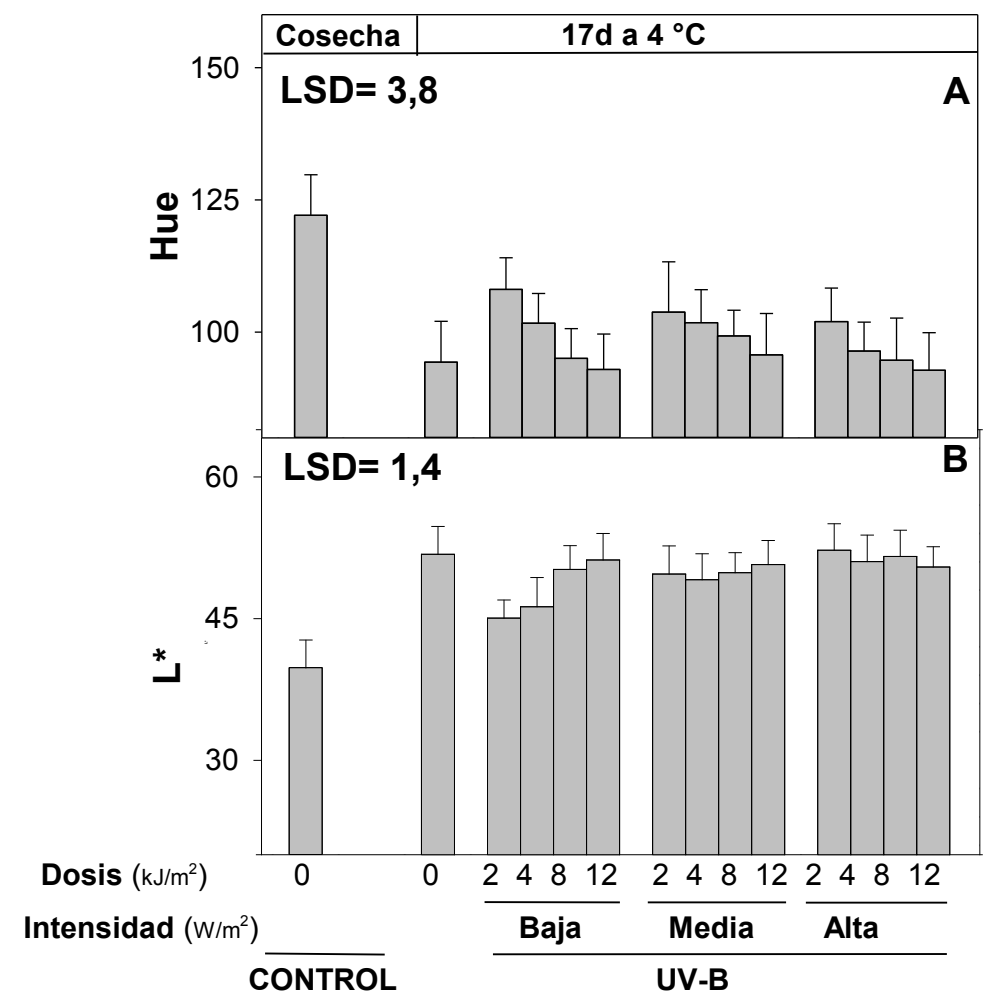

Figura IV.8. Parámetros de color A) Hue y B) luminosidad ( $\mathrm{L}^{*}$ ) de brócoli mínimamente procesado control y tratado con intensidades de irradiación UV-B (Baja: 3,2 W/m², Media 4,0 W/m² y Alta: 5,0 W/m²) y dosis $\left(2,4,8,12 \mathrm{~kJ} / \mathrm{m}^{2}\right)$ y almacenados a $4{ }^{\circ} \mathrm{C}$ durante $17 \mathrm{~d}$. Las barras de error representan la desviación estándar de la media. Se muestra el valor de LSD.

Los resultados mostraron que el efecto de la exposición a UV-B en la retención de color es también altamente dependiente de la intensidad de irradiación utilizada. El empleo de 
baja intensidad y dosis de 2 y $4 \mathrm{~kJ} / \mathrm{m}^{2}$ mostraron la mayor retención de las tonalidades verdes (mayor Hue y menor L*). Mientras que, a intensidades UV-B medias y altas, el efecto sobre la retención de color fue insignificante e independiente de la dosis aplicada. Estos resultados difieren de los reportados por Aiamla-or y col. (2010), que encontraron que la exposición a $4,4 \mathrm{~kJ} / \mathrm{m}^{2}$ de UV-B fue menos efectiva que los tratamientos con dosis de 8,8 y $13,1 \mathrm{~kJ} / \mathrm{m}^{2}$, aunque en ese caso las intensidades fueron $50 \%$ más altas que la intensidad media probada en nuestro estudio y las cabezas de brócoli se almacenaron a $15^{\circ} \mathrm{C}$. En síntesis, para los tratamientos UV-B de baja intensidad, la dosis tuvo un marcado efecto en la retención del color. Los mejores resultados se observaron en los ramilletes de brócoli tratados con dosis bajas $\left(2 \mathrm{o} 4 \mathrm{~kJ} / \mathrm{m}^{2}\right)$.

\subsubsection{Pigmentos clorofilicos}

Para obtener más información sobre el papel de las condiciones de tratamiento UV en el color del brócoli, determinamos los cambios en los niveles de clorofila-a (Chl-a) y sus derivados, clorofilido-a (Chlide a), feofitina-a (Phy a) y feofórbido-a (Pheo a). Durante el almacenamiento a $4{ }^{\circ} \mathrm{C}$, el brócoli control perdió $46 \%$ de Chl-a, mientras que a los que se les aplicó UV-B perdieron entre un 30-70 \% independientemente del tratamiento aplicado (Figura IV. 9A). Los tratamientos con una alta intensidad de UV-B indujeron una mayor pérdida (56-70 \%) de Chl-a que el control. Por ello, el color similar observado entre control y las muestras irradiadas UV-B puede deberse a la acumulación de Chlidea (Figura IV.9B), que a pesar de su mayor solubilidad en agua inducida por la eliminación del fitol muestra propiedades ópticas similares a las de Chl-a, manteniendo tonalidades de color verde.

Los tratamientos más efectivos, en términos de retención de color, fueron los de baja intensidad y dosis de 2 y $4 \mathrm{~kJ} / \mathrm{m}^{2}$, debido probablemente a que estos tratamientos perdieron un $\sim 41$ y $30 \%$, respectivamente, de Chl-a al final del período de almacenamiento (Figura IV. 9A). 


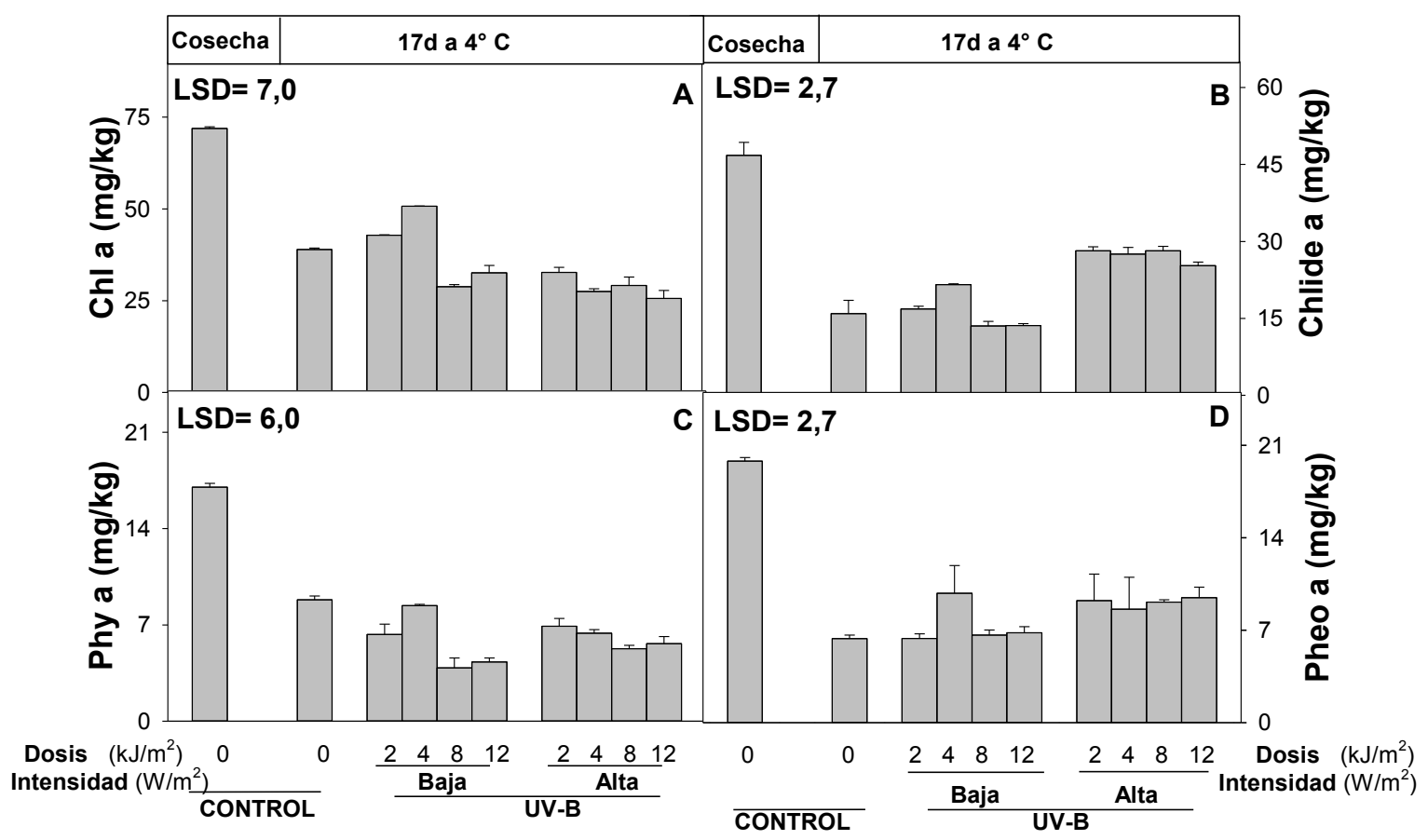

Figura IV.9. Pigmentos clorofílicos: A) Clorofila $a$, B) clorofilido $a$, C) feofitina $a$ y D) feofórbido $a$ en brócoli mínimamente procesado control y tratado con intensidades de irradiación UV-B (Baja: 3,2 W/m² y Alta: $\left.5,0 \mathrm{~W} / \mathrm{m}^{2}\right)$ y dosis $\left(2,4,8,12 \mathrm{~kJ} / \mathrm{m}^{2}\right)$ y almacenados a $4{ }^{\circ} \mathrm{C}$ durante $17 \mathrm{~d}$. Las barras de error representan la desviación estándar de la media. Se muestra el valor de LSD.

Finalmente, el tratamiento de baja intensidad y dosis de $4 \mathrm{~kJ} / \mathrm{m}^{2}$ retuvo el nivel más alto de Chl-a. Estos resultados concuerdan con las tonalidades más verdes mostradas previamente en el color (Figura IV.9). Curiosamente y dentro de los resultados de baja intensidad, las muestras de $4 \mathrm{~kJ} / \mathrm{m}^{2}$ también acumularon niveles más altos de Chlide-a y Pheo-a (Figura IV.9B y D) que el control. Trabajos previos, sugirieron que la eliminación del fitol era el primer paso comprometido en el catabolismo de la clorofila, y luego era removido el $\mathrm{Mg}^{+2}$ para producir Pheo-a de color verde-oliva (Amir-Shapira y col., 1987; Matile y col., 1999). Se informó que las enzimas clorofilasa y la magnesiodequelatasa estaban involucradas, respectivamente, en estos pasos durante el desmontaje normal de cloroplastos (Langmeier y col., 1993; Kaewsuksaeng y col., 2007). Más recientemente, la identificación de las enzimas feofitinasas de plantas (PPH) sugirió que la eliminación directa del átomo de $\mathrm{Mg}^{+2}$ central de la Chl-a también puede ser una ruta in vivo importante para la degradación de Chl. Esto es respaldado por el fenotipo de permanencia del color verde de los mutantes inactivados de PPH en Arabidopsis (Schelbert y col., 2009). Hasta el momento, sigue sin establecerse la importancia relativa de las diferentes vías catabólicas de Chl en la mayoría de los productos en los que la pérdida de color verde es el principal índice de calidad. Aiamla-or y col. (2010, 2012, 2019) sugirieron que la 
irradiación UV-B puede modular la actividad de las enzimas degradantes de Chl e incluso reprimir sus genes en los primeros días pos-tratamiento con UV-B. En resumen, los resultados de nuestro trabajo sugieren que los tratamientos con UV-B de alta intensidad en dosis que varían entre 2 y $12 \mathrm{~kJ} / \mathrm{m}^{2}$ favorecieron la pérdida del fitol de la Chl-a para dar Chlide-a y posteriormente aumentar el contenido de Pheo-a. Por el contrario, la exposición a baja intensidad de UV-B en dosis de $4 \mathrm{~kJ} / \mathrm{m}^{2}$ redujo el amarillamiento del brócoli al retener mayores niveles de Chl-a principalmente, como así también los de Chlide-a y Pheo-a, sugiriendo un retraso en la degradación integral de Chl-a y con ello un retraso en la senescencia.

\subsubsection{Capacidad antioxidante y compuestos fenólicos}

Varios trabajos han sugerido que las condiciones de estrés leve inducidas por la radiación UV-B podrían ser una estrategia tecnológica valiosa para aumentar la capacidad antioxidante de los productos frescos y transformarlos en biofábricas. Se han informado mayores contenidos de antioxidantes fenólicos luego de tratamientos con UV-B en zanahorias recién cortadas (Avena-Bustillos y col., 2012), uvas (Martínez-Lüscher y col., 2014) y tomate (Castagna y col., 2014). Sin embargo, las respuestas informadas en la literatura son muy variables según el producto considerado y el tratamiento aplicado (Ribeiro y Alvarenga, 2012; Jansen y col., 2010). En el caso del brócoli, tratamientos con radiación UV-C $\left(8 \mathrm{~kJ} / \mathrm{m}^{2}\right)$ han incrementado ligeramente el contenido de compuestos fenólicos y capacidad antioxidante respecto de la cosecha, luego de 21 días a $4{ }^{\circ} \mathrm{C}$ (Lemoine y col., 2007).

El efecto de UV-B sobre el estado antioxidante de los ramilletes de brócoli ha sido poco estudiado. Se informó una mayor acumulación de flavonoides en los brotes de brócoli (Mewis y col., 2012; Topcu y col., 2015), pero se sabe que las respuestas a la exposición a UV dependen de la etapa ontogénica del vegetal (Schreiner y col., 2009). Por otro lado, con la aplicación de radiación UV-B en brócoli entero y luego de 3 d de almacenamiento a $15{ }^{\circ} \mathrm{C}$ los compuestos fenólicos se incrementaban (Formica-Oliveira y col., 2017) o permanecían constante (Du y col., 2014). Sin embargo, no ha sido reportado la influencia de la radiación UV-B sobre el comportamiento de los antioxidantes de brócoli al emplear temperaturas recomendadas para una correcta extensión de la vida útil. 


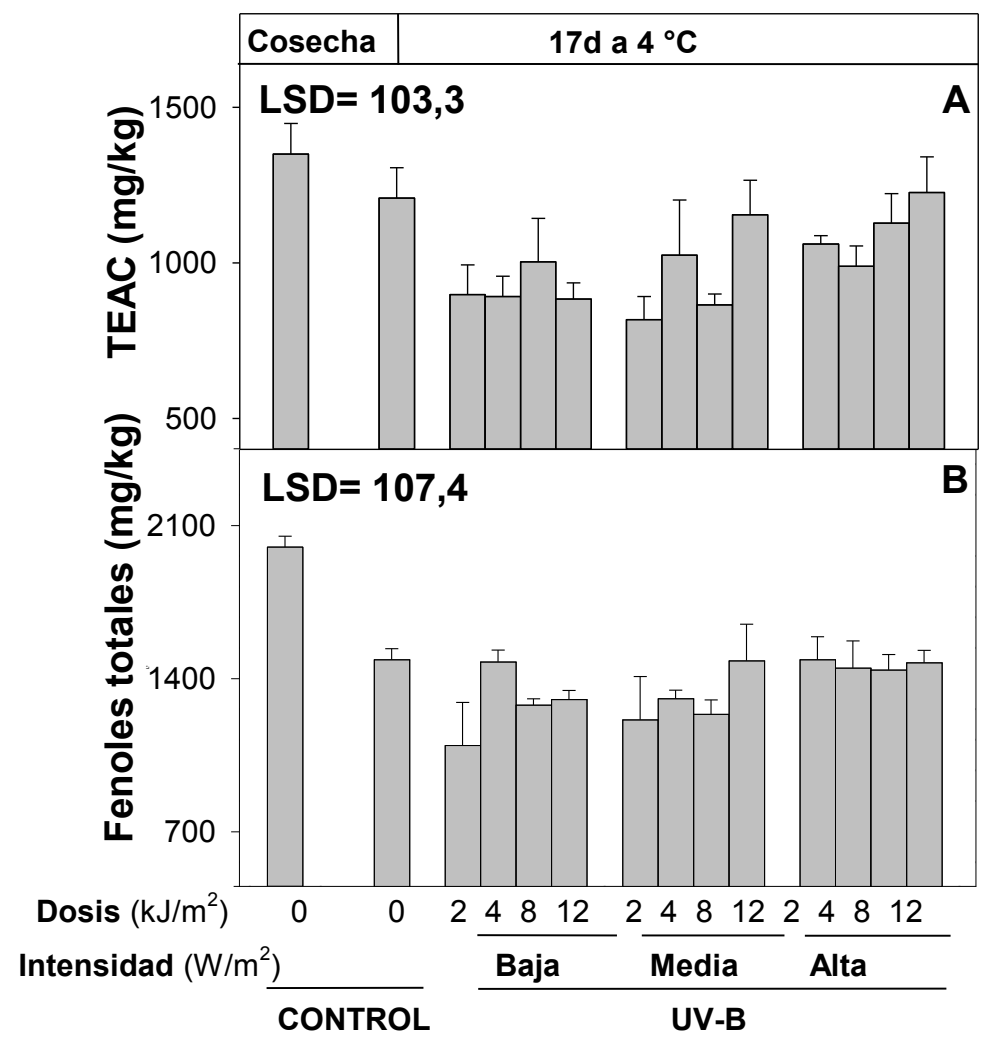

Figura IV.10. A) Capacidad antioxidante equivalente a trolox (TEAC) y B) compuestos fenólicos totales en brócoli mínimamente procesado control y tratado con intensidades de irradiación UV-B (Baja: $3,2 \mathrm{~W} / \mathrm{m}^{2}$, Media $4,0 \mathrm{~W} / \mathrm{m}^{2}$ y Alta: $\left.5,0 \mathrm{~W} / \mathrm{m}^{2}\right)$ y dosis $\left(2,4,8,12 \mathrm{~kJ} / \mathrm{m}^{2}\right)$ y almacenados a $4{ }^{\circ} \mathrm{C}$ durante $17 \mathrm{~d}$. Las barras de error representan la desviación estándar de la media. Se muestra el valor de LSD.

En este trabajo, el TEAC y el nivel de compuestos fenólicos de los ramilletes de brócoli control disminuyeron (12\% y $26 \%$, respectivamente) durante el almacenamiento (Figura IV.10A y B). A diferencia de lo que se ha informado en otros productos, ninguno de los 12 tratamientos con UV-B evaluados en este trabajo mejoró la capacidad antioxidante del brócoli después del almacenamiento poscosecha y más bien la disminuyó. Tratamientos con $12 \mathrm{~kJ} / \mathrm{m}^{2}$ e intensidad de irradiación media $\left(3,6 \mathrm{~W} / \mathrm{m}^{2}\right)$ o alta $\left(4,0 \mathrm{~W} / \mathrm{m}^{2}\right)$ mantuvieron, después de 17 días de almacenamiento refrigerado, niveles similares de TEAC que el control. Los incrementos en TEAC y antioxidantes ante la exposición a luz UV-B reportada por otros autores no fue hallada en nuestros estudios pudiendo tal vez haber sido un aumento inicial y transiente que no llego a ser detectado. Por ello se conducirán ensayos con muestreos a tiempos cortos post-tratamiento. 


\subsection{Efecto de la intensidad y dosis de radiación UV-B sobre la estimulación de} compuestos a tiempos cortos y estabilidad luego de un almacenamiento a $-18^{\circ} \mathrm{C}$ de brócoli mínimamente procesado

Los vegetales han sido propuestos como biofábricas de compuestos bioactivos en respuesta a distintos tipos de estrés abiótico (Formica-Oliveira y col., 2017; CisnerosZevallos, 2003). Como ya se mencionó, varios estudios han informado que el estrés leve podría inducir un rápido estallido de especies reactivas de oxígeno (EROs), que a su vez activan el sistema de defensa y así pueden desencadenar la acumulación de antioxidantes u otras moléculas protectoras (Soheila, 2000). Sin embargo, la comprensión fisiológica de las respuestas de las plantas al estrés abiótico rara vez ha sido explotada en la industria alimentaria. En algunos casos, esta respuesta ha sido transitoria, y los tejidos recuperaron los niveles basales de los metabolitos provocados poco después de eliminar el factor estresante (Mittler, 2002). Por ejemplo, las proteínas de choque térmico (HSPs) con la función de la chaperona se regulan rápidamente (durante $3 \mathrm{~h}$ ) en los tejidos de las plantas refrigeradas y/o expuestos al calor y disminuyen cuando las muestras se transfieren a temperaturas normales (Lurie, 1998). Con el fin de evaluar si tal respuesta estaba ocurriendo en el brócoli tratado con UV-B evaluamos los cambios en parámetros de calidad como el color, contenido de glucosinolatos y antioxidantes en tiempos cortos posirradiación (0, 2, 6 y $18 \mathrm{~h})$. Se acotaron los estudios a los extremos de intensidad y dosis de radiación UV-B, siendo analizadas las intensidades baja y alta, a dosis de 2 y $12 \mathrm{~kJ} / \mathrm{m}^{2}$.

\subsubsection{Color superficial}

Dada la corta vida poscosecha de brócoli almacenado a temperatura ambiente es de vital importancia constatar la posible variación del color. A su vez, la radiación UV-C causa un ligero viraje del color hacia tonalidades doradas en productos que poseen clorofilas como las uvas (González-Barrio y col., 2005), hecho que aún no ha sido estudiado ante la exposición a UV-B a tiempos cortos. Aiamla-or y col. (2019) han analizado la variación del color, pero luego de $24 \mathrm{~h}$, y no hallaron variaciones hasta 2 días de almacenamiento a $25^{\circ} \mathrm{C}$.

En este trabajo, ninguno de los tratamientos evaluados fue visualmente distinguible a las $2,6,18 \mathrm{~h}$ a $20{ }^{\circ} \mathrm{C}$. Estos resultados fueron confirmados por los parámetros de color Hue y L* evaluados en los ramilletes de brócoli a cosecha y después de $0,2,6,18$ h postratamiento con radiación UV-B (Figura IV.11A y B). 


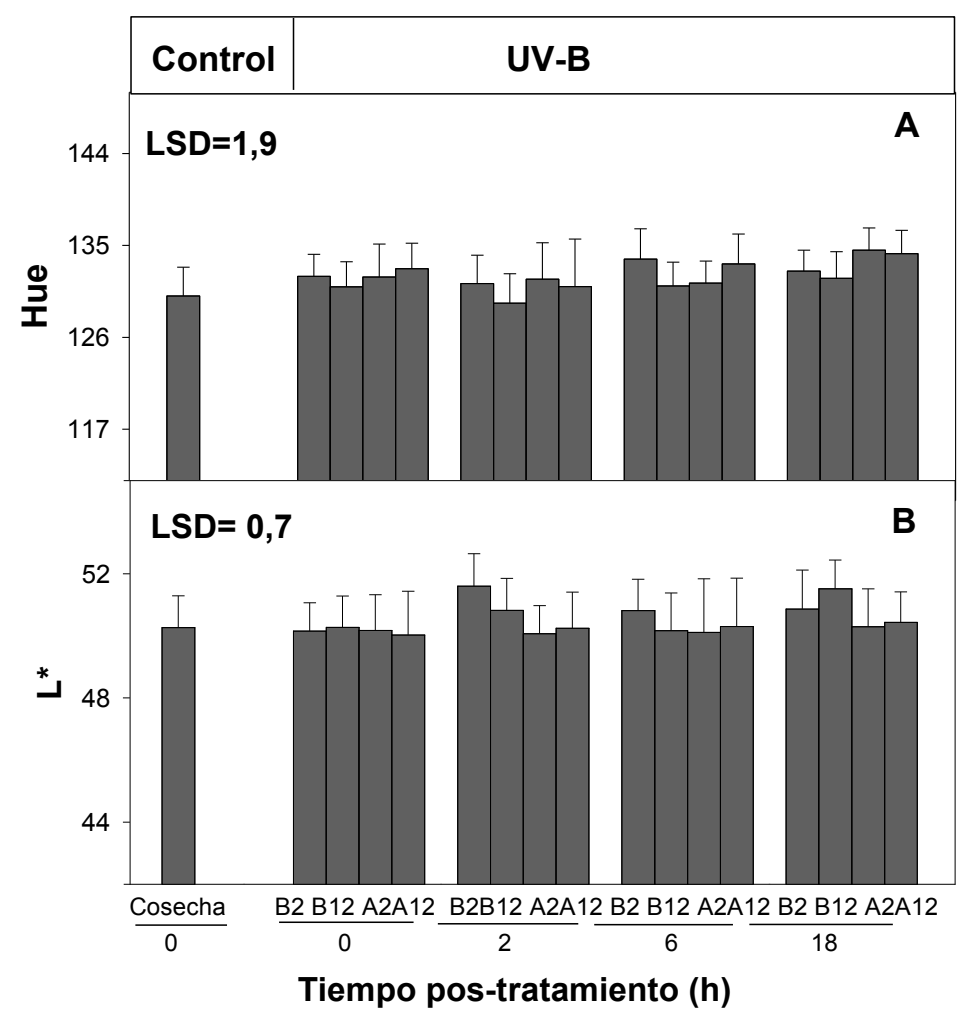

Figura IV.11. Color A) Hue y B) luminosidad ( $\left.\mathrm{L}^{*}\right)$ en brócoli mínimamente procesado control (C) y tratado con intensidades de irradiación UV-B (Baja: $3,2 \mathrm{~W} / \mathrm{m}^{2}$, Alta: $\left.5,0 \mathrm{~W} / \mathrm{m}^{2}\right)$ y dosis $\left(2\right.$ o $12 \mathrm{~kJ} / \mathrm{m}^{2}$ ) B2, B12, A2 y A12 y analizados a tiempos cortos pos-tratamiento $(0,2,6$ y $18 \mathrm{~h})$ a $20^{\circ} \mathrm{C}$. Las barras de error representan la desviación estándar de la media. Se muestra el valor de LSD.

\subsubsection{Glucosinolatos}

Se detectaron 11 compuestos en la corrida cromatográfica realizada por HPLC-DAD de las muestras control (Figura IV.12A) y tratadas con radiación UV-B de baja y alta intensidad (Figura IV.12B y C). Se empleó sinigrina (pico 5) como estándar interno en cada una de las corridas cromatográficas. Con el fin de obtener un indicio de los posibles GS presentes en brócoli se realizó una comparación bibliográfica con el perfil de picos cromatográficos reportados por otros autores que se muestra en la Tabla IV.3. Los GS alifáticos (GS-a) fueron detectados a menores tiempos de retención y luego se observaron los GS-indólicos (GS-i). Dentro de los primeros (GS-a) se pudo hallar la presencia de los siguientes compuestos minoritarios: glucoiberina (pico 1), progoitrina (pico 2), glucoalisina (pico 3), gluconapina (pico 4), glucobrasicanapina (pico 8), mientras que el GS-a mayoritario fue: glucorafanina (pico 6). Por su parte entre los GS-i se identificaron la 4-hidroxiglubrasicina (pico 7), la 4-metoxiglucobrasicina (pico 10) en trazas, y la glucobrasicina (pico 9) y la neoglubrasicina (pico 11) como mas abundantes. Si bien los valores relativos entre los distintos GS varían con la variedad de brócoli empleada, al igual que en el presente trabajo varios autores hallaron como GS-a mayoritario a 
glucarafanina (pico 6) y como GS-i a glucobrasicina (pico 9) y neoglucobrasicína (pico 11) (Kushad y col., 1999; Tian y col., 2005; Rybarczyk-Plonska y col. 2016).

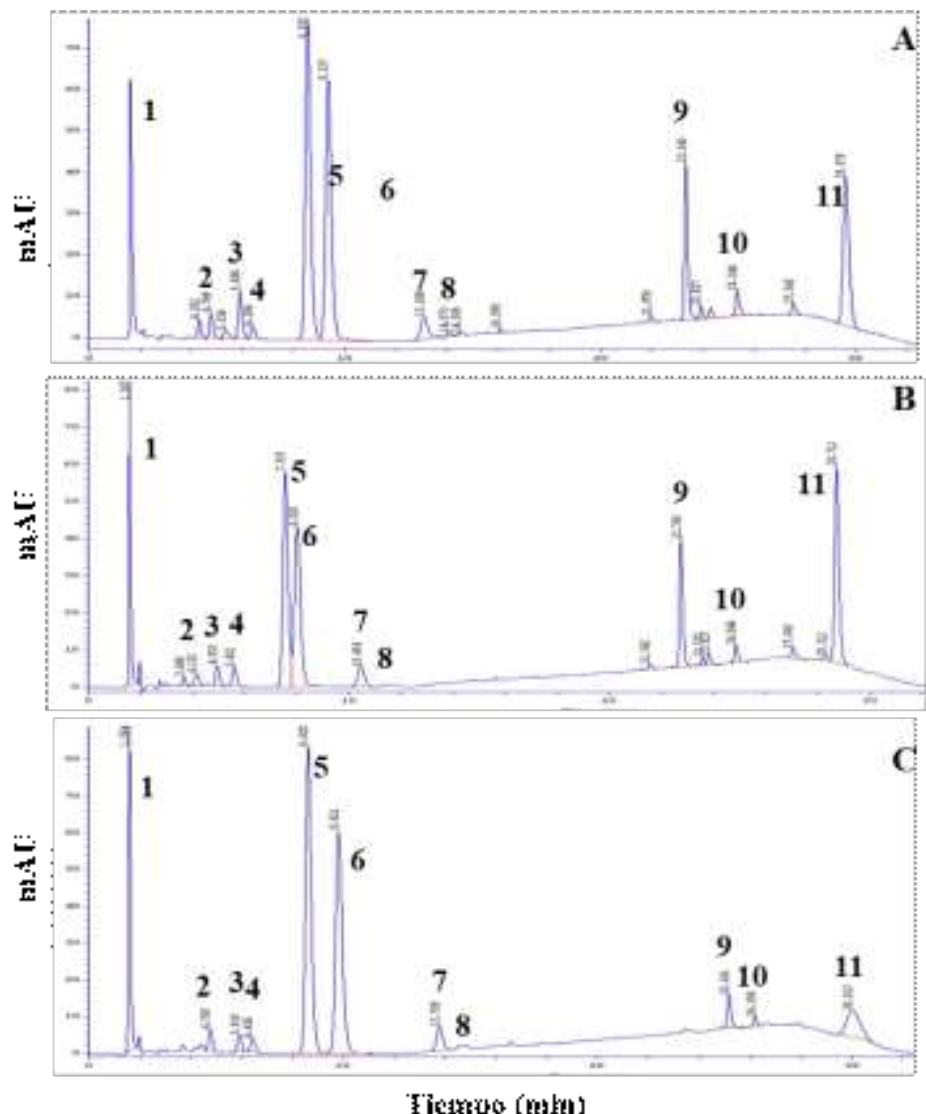

Figura IV.12. Cromatograma HPLC-DAD obtenido a $229 \mathrm{~nm}$ de extractos de muestras de brócoli A) control B) Alta intensidad: $5,0 \mathrm{~W} / \mathrm{m}^{2}$ y dosis $2 \mathrm{~kJ} / \mathrm{m}^{2}$ (A2) y C) Baja intesidad: $3,2 \mathrm{~W} / \mathrm{m}^{2}$ y dosis $12 \mathrm{~kJ} / \mathrm{m}^{2}$ (B12). El pico $\mathrm{N}^{\mathrm{o}} 5$ corresponde a la sinigrina empleada como como estándar interno.

Analizando los grupos en forma conjunta se observó que los glucosinolatos alifáticos fueron tres veces mayores que los indólicos al momento de la cosecha (Figura IV.13A). Algunos estudios reportaron un aumento de la acumulación de GS en respuesta al estrés abiótico (Variyar y col. 2014). En el caso de radiación UV las respuestas dependen mucho de las condiciones de irradiación. En brotes de brócoli, Rybarczyk-Plonska y col. (2016) encontraron que tanto el contenido total de GS alifáticos como de indólicos, no se modificaron durante el almacenamiento a 0 o $4{ }^{\circ} \mathrm{C}$, e incluso cuando los brotes se transfirieron a 10 o $18{ }^{\circ} \mathrm{C}$ durante 3 días con una combinación de luz visible y tratamiento con radiación UV-B durante 12 h por día. 
Tabla IV.5 Glucosinolatos analizados por HPLC-DAD de brócoli control a cosecha. Los picos resaltados son los hallados en mayor porcentaje.

\begin{tabular}{|c|c|c|c|c|c|}
\hline NO. & $\begin{array}{l}t_{R}(*) \\
(\min )\end{array}$ & $\begin{array}{c}\text { COMPARACIÓN } \\
\text { BIBLIOGRAFICA }\end{array}$ & NOMBRE IUPAC & $\begin{array}{c}C L A S I F . \\
\quad G S\end{array}$ & REFERENCIAS* \\
\hline 1 & 4,35 & glucoiberina & $\begin{array}{l}\text { 3-metilsulfinilpropil } \\
\text { glucosinolato }\end{array}$ & Alifático & $(1-2-4-5-6)$ \\
\hline 2 & 4,95 & progoitrina & $\begin{array}{l}\text { 2-hidroxi-3-butenil } \\
\text { glucosinolato }\end{array}$ & Alifático & $(1-2-3-4-6)$ \\
\hline 3 & 6,12 & glucoalisina & $\begin{array}{l}\text { 5-metilsulfinilpentil } \\
\text { glucosinolato }\end{array}$ & Alifático & $(1-2-4-5-6)$ \\
\hline 4 & 6,62 & gluconapina & $\begin{array}{c}\text { 3-Butenil } \\
\text { glucosinolato }\end{array}$ & Alifático & $(1-2-3-4-6)$ \\
\hline 5 & 8,85 & sinigrina & $\begin{array}{l}\text { 2-propenil } \\
\text { glucosinolato }\end{array}$ & Alifático & \\
\hline 6 & 10,17 & glucorafanina & $\begin{array}{l}\text { 4-metilsulfinilbutil } \\
\text { glucosinolato }\end{array}$ & Alifático & $(1-2-4-5-6)$ \\
\hline 7 & 14,15 & 4-hidroxiglubrasicína & $\begin{array}{l}\text { 4-hidroxiindol-3- } \\
\text { ilmetil glucosinolato }\end{array}$ & Indólico & $(2-4-5)$ \\
\hline 8 & 15,03 & glucobrasicanapina & $\begin{array}{l}\text { 4-pentenil } \\
\text { glucosinolato }\end{array}$ & Alifático & $(1-2)$ \\
\hline 9 & 25,23 & glucobrasicina & $\begin{array}{l}\text { Indol-3-ilmetil } \\
\text { glucosinolato }\end{array}$ & Indólico & $(1-2-3-4-5-6)$, \\
\hline 10 & 26,18 & $\begin{array}{c}4- \\
\text { metoxiglucobrasicína }\end{array}$ & $\begin{array}{l}\text { 4-metoxiindol-3- } \\
\text { ilmetil glucosinolato }\end{array}$ & Indólico & $(1-2-4-5-6)$ \\
\hline 11 & 30,50 & neoglucobrasicína & $\begin{array}{l}\text { 1-metoxindol- } \\
\text { 3ilmetil } \\
\text { glucosinolato }\end{array}$ & Indólico & $(1-2-3-4-5-6)$ \\
\hline
\end{tabular}

*Referencias: (1)-Fernandez León y col., 2012, (2)- Kushad, y col., 1999, (3)-Kusznierewicz y col., 2013, (4)Mewis, y col., 2012, (5)-Rybarczyk-Plonska y col. 2016, (6)-Tian y col., 2005.

Wang y col. (2011) encontraron contenidos más altos de GS en hojas de Arabidopsis thaliana después de $1 \mathrm{~h}$ de exposición a rayos UV-B, a pesar de una disminución significativa, sobre todo de GS indólicos, después de 12 h de exposición a la radiación UV-B. En este trabajo, para la intensidad alta y dosis de $2 \mathrm{~kJ} / \mathrm{m}^{2}$ (A2, Figura IV.13A) se redujo el contenido de GS totales después de $2 \mathrm{~h}$, aunque tuvo un aumento posterior. Los valores más altos en los niveles de GS totales se lograron después de $18 \mathrm{~h}$ del tratamiento UV-B a intensidades y dosis B12 y A2, siendo los GS alifáticos los que más aportaron a dicho incremento.

El GS alifático glucorafanina (pico 6) es el principal compuesto de importancia en el brócoli por reducir el riesgo de cáncer (Cieslik y col. 2007) y mostró aquí la mayor inducción luego de $18 \mathrm{~h}$ en respuesta a la exposición UV-B, a la intensidad y dosis B12 y A2 (Figura IV.13B). Mewis y col. (2012) también encontraron un incremento rápido 
y preferencial de GS alifáticos en brotes de brócoli irradiados con UV-B $\left(0,3 \mathrm{~kJ} / \mathrm{m}^{2}\right)$. Propusieron una marcada inducción de genes implicados en los pasos posteriores de la biosíntesis de GS y especialmente en aquellos relacionados con los GS alifáticos.

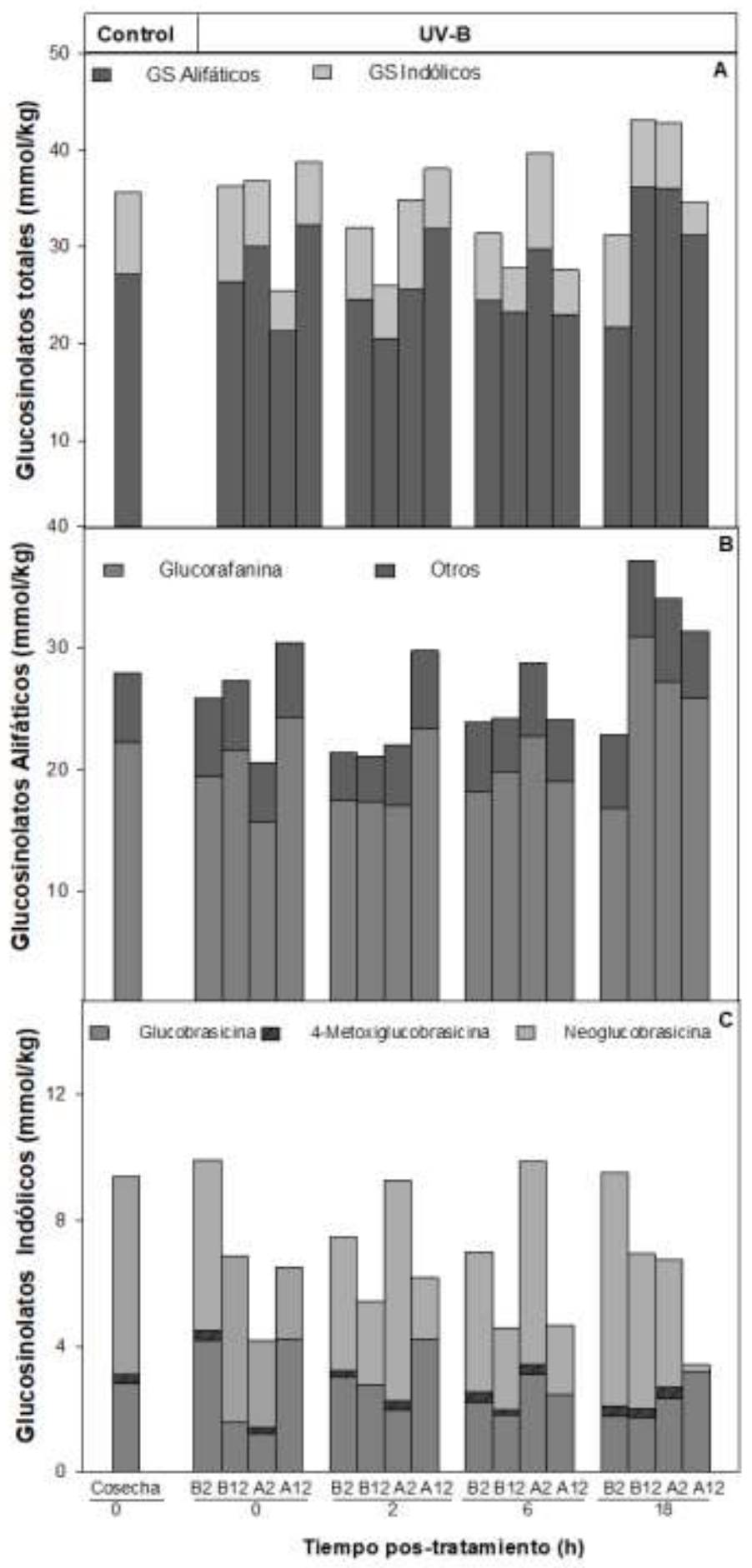

Figura IV.13. A) Glucosinolatos totales, B) alifáticos y C) indólicos de brócoli mínimamente procesado control y tratado con intensidades de irradiación UV-B (Baja: 3,2 W/m², Alta: 5,0 W/m²) y dosis (2 y 12 $\left.\mathrm{kJ} / \mathrm{m}^{2}\right)$ denominados B2, B12, A2 y A12 y analizados a tiempos cortos pos-tratamiento $(0,2,6$ y $18 \mathrm{~h})$ a 20 ${ }^{\circ} \mathrm{C}$. 
Los GS indólicos, resultaron los minoritarios, aunque se destacaron en orden de importancia: neoglucobrasicina (pico 11) y glucobrasicina (pico 9) y en mucha menor escala 4-metoxiglucobrasicina (pico 10) (Figura IV.13C). Las variaciones observadas a tiempos cortos pos-tratamientos no fueron uniformes entre estos compuestos. Más allá de ello, en general, todos recuperaron los valores a cosecha luego de $18 \mathrm{~h}$ pos-tratamiento, a excepción de glucobrasicina a intensidad y dosis B2, y de neoglubrasicina ante el tratamiento A12.

\subsubsection{Capacidad antioxidante y compuestos fenólicos}

Para todos los tratamientos, excepto los de menor intensidad y dosis o B2, la capacidad antioxidante TEAC disminuyó rápidamente después del tratamiento de irradiación con UV-B (Figura IV.14A). Curiosamente, la capacidad antioxidante comenzó a aumentar luego en los cuatro tratamientos ensayados. Los valores de TEAC alcanzaron un máximo, superior al valor inicial, a partir de las 2 y 6 h después del tratamiento para irradiación con intensidades baja y alta, respectivamente. En tiempos más largos, las muestras tendieron a recuperar los valores iniciales de TEAC. Más específicamente, las muestras de brócoli expuestas a alta intensidad de radiación UV-B mostraron un aumento significativo cercano al $30 \%$ de la capacidad antioxidante después de 6 y $18 \mathrm{~h}$ con respecto a los valores iniciales de cosecha. Si bien con algunas diferencias, en general los cambios en los compuestos fenólicos de brócoli (Figura IV. 14B) siguieron un patrón similar al observado en TEAC, sugiriendo que estos compuestos serían el principal grupo de antioxidantes estimulado por los tratamientos. Trabajos anteriores han informado que la irradiación UV puede inducir enzimas clave en la vía de los fenilpropanoide como la fenilalanina amonio liasa (PAL) y chalcona sintasa (Nigro y col., 2000; TomásBarberán y Espín, 2001; Pombo y col., 2011). Tratamientos UV-B en espárragos aumentaron los niveles de PAL dentro de las 2 h (Eichholz y col., 2012). La falta de correlación completa entre compuestos fenólicos y TEAC indica que UV-B también puede modular otros grupos antioxidantes.

Los resultados de este trabajo indican que son factibles una mejor retención de color y obtención de antioxidantes fenólicos en el brócoli mediante tratamientos con UV-B, aunque el marco de tiempo para estos efectos y las condiciones de irradiación requeridas son claramente diferentes. Así, tratamientos con UV-B a bajas dosis e intensidades podrían ser útiles para retrasar la degradación de la clorofila y senescencia después de un almacenamiento prolongado. Mientras que, la exposición a UV-B de alta intensidad 
puede ser utilizada como un tratamiento para inducir una rápida capacidad antioxidante en una instancia previa a otros tratamientos de procesamiento efectuados para preservar el vegetal durante un tiempo prolongado, como puede ser la conservación por congelación.

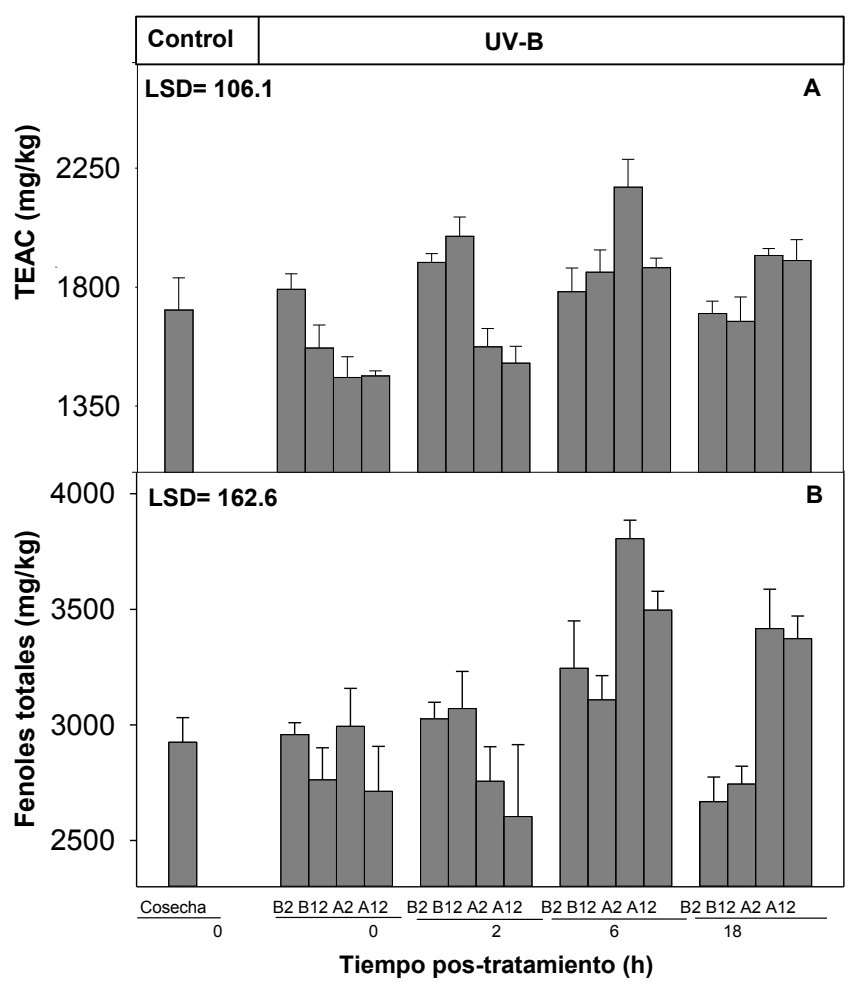

Figura IV.14. A) Capacidad antioxidante equivalente a trolox (TEAC) y B) compuestos fenólicos totales en brócoli mínimamente procesado control y tratado con intensidades de irradiación UV-B (Baja: 3,2 W/ $/ \mathrm{m}^{2}$, Alta: $\left.5,0 \mathrm{~W} / \mathrm{m}^{2}\right)$ y dosis $\left(2\right.$ y $\left.12 \mathrm{~kJ} / \mathrm{m}^{2}\right)$ denominados B2, B12, A2 y A12 y analizados a tiempos cortos postratamiento $(0,2,6$ y $18 \mathrm{~h})$ a $20^{\circ} \mathrm{C}$. Las barras de error representan la desviación estándar de la media. Se muestra el valor de LSD.

\subsubsection{Capacidad antioxidante en almacenamiento congelado durante 30 días}

Siendo el tiempo de $6 \mathrm{~h}$ pos-tratamiento aquel que mostró niveles de compuestos fenólicos y capacidad antioxidante TEAC superior respecto de los niveles presentados a cosecha, se seleccionó esta condición para un segundo ensayo. Así, muestras tratadas con las mismas dosis e intensidades de UV-B y congeladas luego de $6 \mathrm{~h}$ postratamiento, se congelaron y se almacenaron a $-18^{\circ} \mathrm{C}$ por 30 días simulando al procesamiento empleado industrialmente y durante la distribución para este producto. La conservación por congelación es hoy una de las tecnologías más empleadas para preservar la calidad nutricional y microbiológica de los vegetales a tiempos largos de almacenamiento (Skrede, 1996). Preserva vitamina C, carotenoides, compuestos fenólicos y capacidad 
antioxidante de crucíferas como repollitos de bruselas (Kapusta-Duch y col., 2013) e incluso de brócoli (Hudson y col., 1985, Alanis-Garza y col., 2015). Luego del almacenamiento congelado, los brócolis controles y tratados (Figura IV.15) mantuvieron los niveles relativos de capacidad antioxidante TEAC logrados al inicio del almacenamiento. En ese sentido las muestras irradiadas antes del congelado con el tratamiento de alta intensidasd y baja dosis A2 manuvo un status de antioxidantes superior en un $\sim 30 \%$ al resto de los tratamientos y de los ramilletes control.

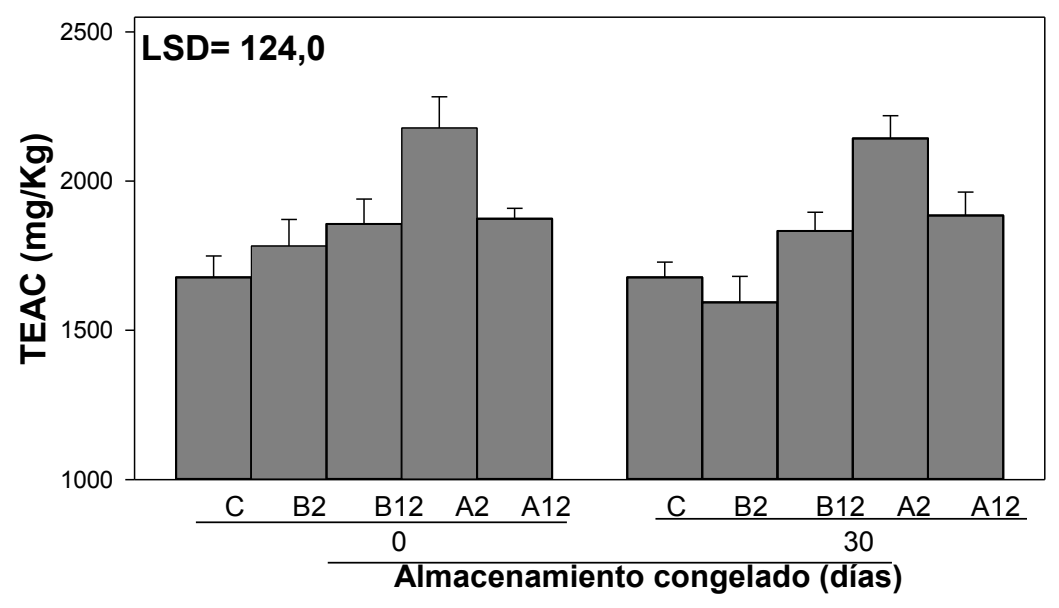

Figura IV.15. Capacidad antioxidante equivalente a trolox (TEAC) de brócoli mínimamente procesado control (C) y tratado con dosis de 2 y $12 \mathrm{~kJ} / \mathrm{m}^{2}$ a las intensidades baja (B) y alta (A) de luz UV-B luego de $6 \mathrm{~h}$ pos tratamiento almacenado a $-18^{\circ} \mathrm{C}$ por 30 días. Las barras de error representan la desviación estándar de la media. Se muestra el valor de LSD dentro de la figura. 


\section{IV.4. CONCLUSIONES}

Los resultados muestran que la aplicación de tratamientos con irradiación UV-B fue efectiva en mantener la calidad de brócoli mínimamente procesado, lográndose distintos resultados según las condiciones de tratamiento y almacenamiento empleadas. A bajas intensidades y dosis de UV-B $\left(3,2 \mathrm{~W} / \mathrm{m}^{2}\right.$ y $\left.2-4 \mathrm{~kJ} / \mathrm{m}^{2}\right)$ se observó un retraso en la degradación de clorofila, retención del color verde y menor pérdida de peso, sin alterar el contenido y capacidad antioxidante y compuestos fenólicos de brócoli almacenado a 4 ${ }^{\circ} \mathrm{C}$, permitiendo así extender el período de vida útil a 17 días.

A alta intensidad y baja dosis $\left(5 \mathrm{~W} / \mathrm{m}^{2}\right.$ y $\left.2 \mathrm{~kJ} / \mathrm{m}^{2}\right)$ se observó una respuesta rápida de los compuestos bioactivos, los cuales respondieron incrementando su contenido luego de $6 \mathrm{~h}$ para los compuestos fenólicos y 18 h para los glucosinolatos alifáticos, principalmente. Esto permitió explorar la alternativa de emplear la radiación UV-B como un tratamiento previo a un posible procesamiento posterior. Así, dicho aumento en el brócoli procesado se mantuvo luego de 30 días de ser congelado.

En síntesis, la aplicación de radiación UV-B logró buenos resultados dependiendo de las condiciones empleadas. Tratamientos con baja intensidad y baja dosis de radiación resultaron efectivos como complemento de la refrigeración a $4{ }^{\circ} \mathrm{C}$, impactando positivamente en la retención del color. Por su parte la exposición a radiación UV-B de alta intensidad y baja dosis fue efectiva para aumentar la capacidad antioxidante en forma transiente. Este tipo de tratamiento podría tener interés como estrategia para promover la acumulación de antioxidantes en los productos que sean sometidos a tratamientos ulteriores de estabilización metabólica como los congelados. 


\section{CONCLUSIONES FINALES}

Los resultados sugieren que el uso de portainjertos posee influencia en el crecimiento y en algunos atributos morfológicos y composicionales de frutos de berenjena violeta. Dada la cualidad de los portainjertos empleados de ser recomendados para su cultivo en condiciones de baja temperatura, se comprobó que los frutos de plantas injertadas no vieron afectada su calidad y antioxidantes durante un almacenamiento refrigerado a temperatura recomendada. Mientras que, estos frutos mostraron un retraso de los síntomas de daño por frío respecto de los frutos de plantas sin injertar, permitiendo hipotetizar que tal vez dicha resistencia al daño por frío se deba a información translocada desde dicho pie.

En poscosecha, el tratamiento de acondicionamiento a baja temperatura (LTC) de 2 días a $10{ }^{\circ} \mathrm{C}$ previo al almacenamiento a $5{ }^{\circ} \mathrm{C}$ logró retrasar los síntomas de daño por frío de berenjena tanto del genotipo violeta como del rayado, y en dos estados de crecimiento: "baby" y comercial convencional debido tal vez a la mejor retención de compuestos antioxidantes. Finalmente, la aplicación de radiación UV-B de distinta dosis e intensidad logró buenos resultados al ser aplicado sobre ramilletes de brócoli mínimamente procesados. Así, tratamientos con baja intensidad y baja dosis UV-B retuvieron el color durante el almacenamiento refrigerado. Por su parte, tratamientos de alta intensidad y baja dosis lograron un aumento transiente de compuestos bioactivos a tiempos cortos. 


\section{BIBLIOGRAFÍA}

Abu-Goukh, A. A., Mohamed, H. E., y Garray, H. E. B. (2005). Physico-chemical changes during growth and development of mango fruit. University of Khartoum Journal of Agricultural Sciences, 13(2), 179-191.

Abu-Goukh, A. B. A., Baraka, A. F., y Elballa, M. M. A. (2011). Physico-chemical changes during growth and development of 'Galia'cantaloupes. II. Chemical changes. Agriculture and Biology Journal of North America, 2(6), 952-963.

Aghdam, M. S., Bodbodak, S. (2013). Physiological and biochemical mechanisms regulating chilling tolerance in fruits and vegetables under postharvest salicylates and jasmonates treatments. Scientia Horticulturae, 156, 73-85.

Aghdam, M. S., y Bodbodak, S. (2014). Postharvest heat treatment for mitigation of chilling injury in fruits and vegetables. Food and Bioprocess Technology, 7(1), 37-53.

Aguilera-Otíz, M., del Carmen Reza-Vargas, M., Chew-Madinaveita, R. G., y Meza-Velázquez, J. A. (2011). Propiedades funcionales de las antocianinas. Biotecnia, 13(2), 16-22.

Agustí, M. (2000). Citricultura. Primera edición. Editorial MundiPrensa, Madrid. pp.161.

Ahmad, A., y Ali, A. (2019). Improvement of postharvest quality, regulation of antioxidants capacity and softening enzymes activity of cold-stored carambola in response to polyamines application. Postharvest Biology and Technology, 148, 208-217.

Ahmadi, L., Hao, X., y Tsao, R. (2018). The effect of greenhouse covering materials on phytochemical composition and antioxidant capacity of tomato cultivars. Journal of the Science of Food and Agriculture, 98, 4427-4435.

Aiamla-or S., Shigyo M., y Yamauchi N. (2019). UV-B treatment controls chlorophyll degradation and related gene expression in broccoli (Brassica oleracea L. Italica Group) florets during storage. Scientia Horticulturae, 243, 524-527.

Aiamla-or S., Yamauchi N., Takino S., y Shigyo M. (2010). Effect of UV-A and UV-B irradiation on broccoli (Brassica oleracea L. Italica Group) floret yellowing during storage. Postharvest Biology and Technology, 54, 177-179.

Aiamla-or, S., Nakajima, T., Shigyo, M., Y Yamauchi, N. (2012). Pheophytinase activity and gene expression of chlorophyll-degrading enzymes relating to UV-B treatment in postharvest broccoli (Brassica oleracea L. Italica Group) florets. Postharvest Biology and Technology, 63(1), 60-66.

Aiamla-or, S., Yamauchi, N., Takino, S., y Shigyo, M. (2009). Effect of UV-A and UV-B irradiation on broccoli (Brassica oleracea L. Italica Group) floret yellowing during storage. Postharvest Biology and Technology, 54(3), 177-179.

Alanís-Garza, P. A., Becerra-Moreno, A., Mora-Nieves, J. L., Mora-Mora, J. P., y Jacobo-Velázquez, D. A. (2015). Effect of industrial freezing on the stability of chemopreventive compounds in broccoli. International Journal of Food Sciences and Nutrition, 66(3), 282-288.

Aloni, B., Cohen, R., Karni, L., Aktas, H., y Edelstein, M. (2010). Hormonal signaling in rootstockscion interactions. Scientia Horticulturae, 127(2), 119-126.

Al-Saikhan, M. S., Howard, L. R., y Miller Jr, J. C. (1995). Antioxidant activity and total phenolics in different genotypes of potato (Solanum tuberosum L.). Journal of Food Science, 60(2), 341343.

Amaki, K., Saito, E., Taniguchi, K., Joshita, K., y Murata, M. (2011). Role of chlorogenic acid quinone and interaction of chlorogenic acid quinone and catechins in the enzymatic browning of apple. Bioscience, Biotechnology, and Biochemistry, 75(5), 829-832.

Amir-Shapira, D., Goldschmidt, E. E., y Altman, A. (1987). Chlorophyll catabolism in senescing plant tissues: in vivo breakdown intermediates suggest different degradative pathways for citrus fruit and parsley leaves. Proceedings of the National Academy of Sciences, 84(7), 1901-1905. 
Anónimo. (2011). El cultivo de la berenjena. http://www.infoagro.com/hortalizas/berenjena.

Aprea, A.M. (2008). Cultivo de las Crucíferas: Brócoli y Coliflor. Boletín Hortícola, 39, 29-32.

Ariza, M. T., Martínez-Ferri, E., Domínguez, P., Medina, J. J., Miranda, L., y Soria, C. (2015). Effects of harvest time on functional compounds and fruit antioxidant capacity in ten strawberry cultivars. Journal of Berry Research, 5(2), 71-80.

Arnao, M B, Cano, A, y Acosta, M. (2001). The hydrophilic and lipophilic contribution to total antioxidant activity. Food Chemistry, 73, 239-244.

Artés, F., Garcia, F., Marquina, J., Cano, A., y Fernández-Trujillo, J. P. (1998). Physiological responses of tomato fruit to cyclic intermittent temperature regimes. Postharvest Biology and Technology, 14(3), 283-296.

Arvanitoyannis I. S., Khah E., Christakou E.C., y Bletsos F.A. (2005). Effect of grafting and modified atmosphere packaging on eggplant quality parameters during storage. International Journal Food Science Technology, 40, 311-322.

Asada, K. (1999). The water-water cycle in chloroplasts: scavenging of active oxygens and dissipation of excess photons. Annual Review of Plant Biology, 50(1), 601-639.

Avena-Bustillos RJ., Du W., Woods, R., Olson, D., Breksa III AP., y McHugh TH. (2012). Ultraviolet-B light treatment increases antioxidant capacity of carrot products. Journal of the Science of Food and Agriculture, 92, 2341-2348.

Bai, J., Baldwin, E. A., Goodner, K. L., Mattheis, J. P., y Brecht, J. K. (2005). Response of four apple cultivars to 1-methylcyclopropene treatment and controlled atmosphere storage. HortScience, 40(5), 1534-1538.

Baxter, A., Mittler, R., y Suzuki, N. (2013). ROS as key players in plant stress signalling. Journal of Experimental Botany, 65(5), 1229-1240.

Bertin, N. (2005). Analysis of the tomato fruit growth response to temperature and plant fruit load in relation to cell division, cell expansion and DNA Endoreduplication. Annals of Botany, 95(3), 439-447.

Bisbis, M. B., Gruda, N., y Blanke, M. (2018). Potential impacts of climate change on vegetable production and product quality-A review. Journal of Cleaner Production, 170, 1602-1620.

Bletsos, F., y Olympios, C. (2008). Rootstocks and grafting of tomatoes, peppers and eggplants for soil-borne disease resistance, improved yield and quality. The European Journal of Plant Science and Biotechnology, 2(1), 62-73.

Bogusz Jr, S., Libardi, S. H., Dias, F. F., Coutinho, J. P., Bochi, V. C., Rodrigues, D., y Godoy, H. T. (2018). Brazilian Capsicum peppers: capsaicinoid content and antioxidant activity. Journal of the Science of Food and Agriculture, 98(1), 217-224.

Bravo, S., García-Alonso, J., Martín-Pozuelo, G., Gómez, V., Santaella, M., Navarro-González, I., y Periago, M. J. (2012). The influence of post-harvest UV-C hormesis on lycopene, $\beta$-carotene, and phenolic content and antioxidant activity of breaker tomatoes. Food Research International, 49(1), 296-302.

Buchanan, B.; Gruissem, W.; y Jones, R. (2000). Biochemistry and Molecular Biology of Plants. American Society of Plant Physiologists, pp. 1368.

Büchert, A. M., Civello, P. M., y Martínez, G. A. (2011). Chlorophyllase versus pheophytinase as candidates for chlorophyll dephytilation during senescence of broccoli. Journal of Plant Physiology, 168(4), 337-343.

Buhtz, A., Pieritz, J., Springer, F., y Kehr, J. (2010). Phloem small RNAs, nutrient stress responses, and systemic mobility. BMC Plant Biology, 10(1), 64. 
Cai, C., Xu, C., Shan, L., Li, X., Zhou, C., Zhang, W. y Chen, K. (2006). Low temperature conditioning reduces postharvest chilling injury in loquat fruit. Postharvest Biology and Technology, 41(3), 252-259.

Caldwell, C. R., y Britz, S. J. (2006). Effect of supplemental ultraviolet radiation on the carotenoid and chlorophyll composition of green house-grown leaf lettuce (Lactuca sativa L.) cultivars. Journal of Food Composition and Analysis, 19, 637-644.

Cantwell, M., y Suslow, T. (2000). Indicadores básicos del manejo poscosecha de berenjena. Departamento de Productos Vegetales. Universidad de California, Davis, USA. http:/postharvest.ucdavis.edu/produce/producefacts/veg/eggplant.shtml.

Cantwell, M., y Suslow. T. (2002). Broccoli: Recommendations for Maintaining Postharvest Quality. Consultado en http://postharvest.ucdavis.edu.

Cao, G., Sofic, E., y Prior, R. (1996). Antioxidant capacity of tea and common vegetables. Journal of Agricultural and Food Chemistry, 44(11), 3426-3431.

Cao, S., Zheng, Y., Wang, K., Jin, P., y Rui, H. (2009). Methyl jasmonate reduces chilling injury and enhances antioxidant enzyme activity in postharvest loquat fruit. Food Chemistry, 115(4), 14581463.

Cargnel, M.D., Demkura, P.V., y Ballaré C.L. (2014). Linking phytochrome to plant immunity: low red: far-red ratios increase Arabidopsis susceptibility to Botrytis cinerea by reducing the biosynthesis of indolic glucosinolates and camalexin. New Phytologist, 204, 342-354.

Carocho, M., y Ferreira, I. C. (2013). A review on antioxidants, prooxidants and related controversy: natural and synthetic compounds, screening and analysis methodologies and future perspectives. Food and Chemical Toxicology, 51, 15-25.

Carranco Jáuregui, M. E., Calvo Carrillo, M., y Pérez-Gil Romo, F. (2011). Carotenoides y su función antioxidante: Revisión. Archivos Latinoamericanos de Nutricion, 61(3), 233-241.

Casierra- Posada, F., Cardozo, M. C., y Hernández, J. C. (2007). Análisis del crecimiento en frutos de tomate (Lycopersicon esculentum Mill.) cultivados bajo invernadero. Agronomía Colombiana, 25(2), 299-305.

Casierra Posada, F., y Cardozo, M. C. (2009). Análisis básico del crecimiento en frutos de tomate (Lycopersicon esculentum Mill, cv.'Quindío') cultivados a campo abierto. Revista Facultad Nacional de Agronomía-Medellín, 62(1), 4815-4822.

Cassaniti, C., Giuffrida, F., Scuderi, D., y Leonardi, C. (2011). The effect of rootstock and nutrient solution concentration on eggplant grown in a soilless system. Journal of Food Agriculture y Environment, 9, 252-256.

Castagna, A., Dall'Asta, C., Chiavaro, E., Galaverna, G., y Ranieri, A. (2014). Effect of post-harvest UV-B irradiation on polyphenol profile and antioxidant activity in flesh and peel of tomato fruits. Food and Bioprocess Technology, 7(8), 2241-2250.

Castenmiller, J. J. M. (2000). Spinach as a source of carotenoids, folate and antioxidant activity.

Castrejón, A. D. R., Eichholz, I., Rohn, S., Kroh, L. W., y Huyskens-Keil, S. (2008). Phenolic profile and antioxidant activity of highbush blueberry (Vaccinium corymbosum L.) during fruit maturation and ripening. Food Chemistry, 109(3), 564-572.

Castro, A. (2017). Curso de Horticultura y Floricultura (2017). Facultad de Ciencias Agrarias y Forestales. Universidad Nacional de la Plata. pp. 27.

Censo Agrícola. (2005). Y Censo Nacional Agropecuario. (2002). Secretaria de Agricultura Ganadería y Pesca (SAGPYA), Buenos Aires, Argentina.

Chaudhary, P. R., Jayaprakasha, G. K., Porat, R., y Patil, B. S. (2014). Low temperature conditioning reduces chilling injury while maintaining quality and certain bioactive compounds of 'Star Ruby'grapefruit. Food Chemistry, 153, 243-249. 
Chaudhary, P. R., Yu, X., Jayaprakasha, G. K., y Patil, B. S. (2017). Influence of storage temperature and low- temperature conditioning on the levels of health- promoting compounds in Rio Red grapefruit. Food Science and Nutrition, 5(3), 545-553.

Chen, N. C., y Li, H. M. (1996). Cultivation and breeding of eggplant. In Training Workshop on Vegetable Cultivation and Seed Production. 26 pág.

Chen, Q., Wang, Q., y Fu, M. (2015). Postharvest low temperature conditioning reduces peel browning and improves fruit quality in storage and subsequent shelf life of Huangguan pear. Food and Nutrition Sciences, 6(15), 1351.

Chen, Q., Wang, Q., y Fu, M. (2015). Postharvest low temperature conditioning reduces peel browning and improves fruit quality in storage and subsequent shelf life of Huangguan pear. Food and Nutrition Sciences, 6(15), 1351.

Chen, X., Zhang, M., Tan, J., Huang, S., Wang, C., Zhang, H., y Tan, T. (2017). Comparative transcriptome analysis provides insights into molecular mechanisms for parthenocarpic fruit development in eggplant (Solanum melongena L.). PloS one, 12(6), e 0179491.

Cheng, S., Wei, B., Zhou, Q., Tan, D., y Ji, S. (2015). 1-Methylcyclopropene alleviates chilling injury by regulating energy metabolism and fatty acid content in 'Nanguo'pears. Postharvest Biology and Technology, 109, 130-136.

Choi, S. H., Lee, S. H., Kim, H. J., Lee, I. S., Kozukue, N., Levin, C. E., y Friedman, M. (2010). Changes in free amino acid, phenolic, chlorophyll, carotenoid, and glycoalkaloid contents in tomatoes during 11 stages of growth and inhibition of cervical and lung human cancer cells by green tomato extracts. Journal of Agricultural and Food Chemistry, 58(13), 7547-7556.

Cieslik E., Leszczynska T., Filipiak-Florkiewicz A., Sikora E., y Pisulewski PM. (2007). Effects of some technological processes on glucosinolate contents in cruciferous vegetable. Food Chemistry, 105, 976-981.

Cisneros-Zevallos, L. (2003). The use of controlled postharvest abiotic stresses as a tool for enhancing the nutraceutical content and adding-value of fresh fruits and vegetables. Journal of Food Science, 68(5), 1560-1565.

Civello, P.M., Vicente, A.R., y Martínez, G. A. (2007). UV-C technology to control postharvest diseases of fruits and vegetables. In: Troncoso-Rojas, R., Tiznado-Hernández, M.E., GonzálezLeón, A. (Eds), Recent Advances in Alternative Postharvest Technologies to Control Fungal Diseases in Fruits and Vegetables, pp. 71-102.

Cohen, S., y Naor, A. (2002). The effect of three rootstocks on water use, canopy conductance and hydraulic parameters of apple trees and predicting canopy from hydraulic conductance. Plant, Cell and Environment, 25(1), 17-28.

Colla, G., Rouphael, Y., Leonardi, C., y Bie, Z. (2010). Role of grafting in vegetable crops grown under saline conditions. Scientia Horticulturae, 127(2), 147-155.

Collado, E., Venzke Klug, T., Martínez- Sánchez, A., Artés- Hernandez, F., Aguayo, E., Artés, F, y Gómez, P. A. (2017). Immature pea seeds: effect of storage under modified atmosphere packaging and sanitation with acidified sodium chlorite. Journal of the Science of Food and Agriculture, 97(13), 4370-4378.

Concellón, A. (2003). Daño por frío en frutos no climatéricos. Tesis de doctorado. Doctor en Ciencias Exactas, área Química. Facultad de Ciencias Exactas. Universidad Nacional de La Plata. 202p. http://sedici.unlp.edu.ar.

Concellón, A., Anón, M. C., y Chaves, A. R. (2004). Characterization and changes in polyphenol oxidase from eggplant fruit (Solanum melongena L.) during storage at low temperature. Food Chemistry, 88(1), 17-24. 
Concellón, A., Añón M. C., y Chaves, A. R. (2007). Effect of low temperature storage on physical and physiological characteristics of eggplant fruit (Solanum melongena L.). LWT-Food Science Technolology, 40, 389-396.

Concellón, A., Añón, M. C., y Chaves, A. R. (2004). Characterization and changes in polyphenol oxidase from eggplant fruit (Solanum melongena L.) during storage at low temperature. Food Chemistry, 88(1), 17-24.

Concellón, A., Añón, M. C., y Chaves, A. R. (2005). Effect of chilling on ethylene production in eggplant fruit. Food Chemistry, 92(1), 63-69.

Concellón, A., Zaro, M. J., Chaves, A. R., y Vicente, A. R. (2012). Changes in quality and phenolic antioxidants in dark purple American eggplant (Solanum melongena L. cv. Lucía) as affected by storage at $0 \mathrm{C}$ and $10 \mathrm{C}$. Postharvest Biology and Technology, 66, 35-41.

Coombe, B. G. (1976). The development of fleshy fruits. Annual Review of Plant Physiology, 27(1), 207-228.

Costa, L., Vicente, A.R., Civello, P.M., Chaves, A.R., y Martinez, G.A. (2006a). UV-C treatment delays postharvest senescence in broccoli florets. Postharvest Biology and Technology, 39, 204210.

Cote, S., Rodoni, L., Miceli, E., Concellón, A., Civello, P. M., y Vicente, A. R. (2013). Effect of radiation intensity on the outcome of postharvest UV-C treatments. Postharvest Biology and Technology, 83, 83-89.

Cutting, J. G. M., y Lyne, M. C. (1993). Girdling and the reduction in shoot xylem sap concentrations of cytokinins and gibberellins in peach. Journal of Horticultural Science, 68(4), 619-626.

Dai, J., y Mumper, R. (2010). Plant phenolics: extraction, analysis and their antioxidant and anticancer properties. Molecules, 15(10), 7313-7352.

Daunay, M. C., Lester, R. N., Gebhardt, C., Hennart, J. W., Jahn, M., Frary, A., y Doganlar, S. (2001). Genetic resources of eggplant (Solanum melongena L.) and allied species: a new challenge for molecular geneticists and eggplant breeders (pp. 251-274). Nijmegen University Press, Nijmegan, The Netherlands.

Deepa, N., Kaur, C., George, B., Singh, B., y Kapoor, H. C. (2007). Antioxidant constituents in some sweet pepper (Capsicum annuum L.) genotypes during maturity. LWT-Food Science and Technology, 40(1), 121-129.

Del Valle Leguizamón, G., González León, A., y Báez Sañudo, R. (2005). Antocianinas en uva (Vitis vinifera L.) y su relación con el color. Revista Fitotecnia Mexicana, 28(4), 359-368.

Di Stasio, E., Van Oosten, M. J., Silletti, S., Raimondi, G., Dell'Aversana, E., Carillo, P., y Maggio, A. (2018). Ascophyllum nodosum-based algal extracts act as enhancers of growth, fruit quality, and adaptation to stress in salinized tomato plants. Journal of Applied Phycology, 1-12.

Dissanayake P.K., Yamauchi N., y Shigyo M. (2008). Chlorophyll degradation and resulting catabolite formation in stored Japanese bunching onion (Allium fistulosum L.). Journal of the Science of Food and Agriculture, 88 (11), 1981-1986.

Doria, J. (2010). A general information on seeds: its production, preservation and storage. Cultivos Tropicales, 31(1), 74-85.

Dranca, F., y Oroian, M. (2016). Optimization of ultrasound-assisted extraction of total monomeric anthocyanin (TMA) and total phenolic content (TPC) from eggplant (Solanum melongena L.) peel. Ultrasonics sonochemistry, 31, 637-646.

Du W X., Avena-Bustillos RJ., Breksa AP., y McHugh TH. (2014). UV-B light as a factor affecting total soluble phenolic contentsof various whole and fresh-cut specialty crops. Postharvest Biology and Technology, 93, 72-82. 
Du, L., Bao, C., Hu, T., Zhu, Q., Hu, H., He, Q., y Mao, W. (2016). SmARF8, a transcription factor involved in parthenocarpy in eggplant. Molecular genetics and genomics, 291(1), 93-105.

Durst R, Wrolstad RE. (2001) Separation and Characterization of Anthocyanins by HPLC. In: Handbook of Food Analytical Chemistry. New Jersey: John Wiley y Sons; pp. 33-45.

Duthie, G. G., Gardner, P. T., y Kyle, J. A. (2003). Plant polyphenols: are they the new magic bullet?. Proceedings of the Nutrition Society, 62(3), 599-603.

Dutt, M., Li, Z.T., Kelley, K.T., Dhekney, S. A., Van Aman, M., Tattersall, J., Gray, D.J.(2007). Transgenic rootstock protein transmission in grapevines. Acta Horticulturae, 738, 749.

Dziedzic, E., Błaszczyk, J., y Kaczmarczyk, E. (2017). Postharvest properties of sweet cherry fruit depending on rootstock and storage conditions. Folia Horticulturae, 29(2), 113-121.

Eichholz, I., Rohn, S., Gamm, A., Beesk, N., Herppich, W. B., Kroh, L. W., y Huyskens-Keil, S. (2012). UV-B-mediated flavonoid synthesis in white asparagus (Asparagus officinalis L.). Food Research International, 48(1), 196-201.

EL-Qudah, J. M. (2009). Identification and quantification of major carotenoids in some vegetables. American Journal of Applied Sciences, 6(3), 492.

Fallik, E., Temkin-Gorodeiski, N., Grinberg, S., y Davidson, H. (1995). Prolonged low-temperature storage of eggplants in polyethylene bags. Postharvest Biology and Technology, 5(1-2), 83-89.

Fan, L., Shi, J., Zuo, J., Gao, L., Lv, J., y Wang, Q. (2016). Methyl jasmonate delays postharvest ripening and senescence in the non-climacteric eggplant (Solanum melongena L.) fruit. Postharvest Biology and Technology, 120, 76-83.

FAOSTAT. (2014). http://www.faostat.fao.org/site/567/DesktopDefault.aspx

Farnham, M. W., Wilson, P. E., Stephenson, K. K., y Fahey, J. W. (2004). Genetic and environmental effects on glucosinolate content and chemoprotective potency of broccoli. Plant Breeding, 123(1), $60-65$

Febles Fernández, C., Soto Febles, C., Saldaña Bernabeu, A., y García Triana, B. E. (2002). Funciones de la vitamina E: actualización. Revista Cubana de Estomatología, 39(1), 28-32.

Fernández- García, N., Martínez, V., y Carvajal, M. (2004). Effect of salinity on growth, mineral composition, and water relations of grafted tomato plants. Journal of Plant Nutrition and Soil Science, 167(5), 616-622.

Fernández-León, M. F., Fernández-León, A. M., Lozano, M., Ayuso, M. C., y González-Gómez, D. (2012). Identification, quantification and comparison of the principal bioactive compounds and external quality parameters of two broccoli cultivars. Journal of Functional Foods, 4(2), 465-473.

Ferreira, J. F., Liu, X., y Suarez, D. L. (2019). Fruit yield and survival of five commercial strawberry cultivars under field cultivation and salinity stress. Scientia Horticulturae, 243, 401-410.

Ferreyra, R. M., Viña, S. Z., Mugridge, A., y Chaves, A. R. (2007). Growth and ripening season effects on antioxidant capacity of strawberry cultivar Selva. Scientia Horticulturae, 112(1), 2732.

Flaherty, E. J., Lum, G. B., DeEll, J. R., Subedi, S., Shelp, B. J., y Bozzo, G. G. (2018). Metabolic Alterations in Postharvest Pear Fruit As Influenced by 1-Methylcyclopropene and Controlled Atmosphere Storage. Journal of Agricultural and Food Chemistry, 66(49), 12989-12999.

Formica-Oliveira, A. C., Martínez-Hernández, G. B., Díaz-López, V., Artés, F., y Artés-Hernández, F. (2017). Use of postharvest UV-B and UV-C radiation treatments to revalorize broccoli byproducts and edible florets. Innovative Food Science and Emerging Technologies, 43, 77-83.

Fox, A. J., Del Pozo-Insfran, D., Lee, J. H., Sargent, S. A., y Talcott, S. T. (2005). Ripening-induced chemical and antioxidant changes in bell peppers as affected by harvest maturity and postharvest ethylene exposure. HortScience, 40(3), 732-736. 
Frary, A.; Doganlar, S; y Daunay, M. (2007). Eggplant. En: Genome mapping and molecular breeding in plants, Volume V: Vegetables. Kole, C. (ed). Heidelberg, Germany: Springer-Verlag. pp. 287-313.

Funamoto Y., Yamauchi N., Shigenaga T., y Shigyo M. (2002). Effects of heat treatment on chlorophyll degrading enzymes in stored broccoli (Brassica oleracea L.). Postharvest Biology and Technology, 24, 163-170.

Gajewski, M., y Arasimowicz, D. (2004). Sensory quality of eggplant fruits (Solanum melongena L.) as affected by cultivar and maturity stage. Polish journal of food and nutrition sciences, 13(3), 249-254.

Gao, Q. H., Xu, K., Wang, X. F., y Wu, Y. (2006). Effect of grafting on cold tolerance in eggplant seedlings. In XXVII International Horticultural Congress-IHC2006: International Symposium on Seed Enhancement and Seedling Production, 771, 167-174.

George, B., Kaur, C., Khurdiya, D. S., y Kapoor, H. C. (2004). Antioxidants in tomato (Lycopersium esculentum) as a function of genotype. Food Chemistry, 84(1), 45-51.

Ghasemnezhad, M., Sherafati, M., y Payvast, G. A. (2011). Variation in phenolic compounds, ascorbic acid and antioxidant activity of five coloured bell pepper (Capsicum annum) fruits at two different harvest times. Journal of functional foods, 3(1), 44-49.

Giordano, E., y Quadro, L. (2018). Lutein, zeaxanthin and mammalian development: Metabolism, functions and implications for health. Archives of Biochemistry and Biophysics, 647, 33-40.

Gisbert, C., Prohens, J., Raigón, M. D., Stommel, J. R., y Nuez, F. (2011). Eggplant relatives as sources of variation for developing new rootstocks: Effects of grafting on eggplant yield and fruit apparent quality and composition. Scientia Horticulturae, 128(1), 14-22.

Gisbert, C., Prohens, J., y Nuez, F. (2012). Performance of eggplant grafted onto cultivated, wild, and hybrid materials of eggplant and tomato. International Journal of Plant Production, 5(4), 367380 .

Giuntini, D., Graziani, G., Lercari, B., Fogliano, V., Soldatini, G. F., y Ranieri, A. (2005). Changes in carotenoid and ascorbic acid contents in fruits of different tomato genotypes related to the depletion of UV-B radiation. Journal of Agricultural and Food Chemistry, 53(8), 3174-3181.

González-Aguilar, G. A., Gayosso, L., Cruz, R., Fortiz, J., Báez, R., y Wang, C. Y. (2000). Polyamines induced by hot water treatments reduce chilling injury and decay in pepper fruit. Postharvest Biology and Technology, 18(1), 19-26.

González- Aguilar, G.; Wang, C.Y. y Buta, G.J. (2004). UV- C irradiation reduces breakdown and chilling injury of peaches during cold storage. Journal of the Science of Food and Agriculture, 84(5), 415-422.

González-Barrio, R., Salmenkallio-Marttila, M., Tomás-Barberán, F. A., Cantos, E., y Espín, J. C. (2005). Etiology of UV-C-induced browning in var. Superior white table grapes. Journal of Agricultural and Food Chemistry, 53(15), 5990-5996.

Goulas V., Vicente A.R., y Manganaris G. (2012) Structural diversity of anthocyanins in fruits. In book: Anthocyanins: Structure, biosynthesis and health benefits. Publisher: Nova Sciences. Editors: Noboru Motohashi.

Graser G., Oldham N.J., Brown P.D., Temp U., y Gershenzon J. (2001). The biosynthesis of benzoic acid glucosinolate esters in Arabidopsis thaliana. Phytochemistry, 57, 23-32.

Gray, D., Li, Z., Dhekney, S., Dutt, M., Hopkins, D., y Zimmerman, T. (2007). Field testing of transgenic grapevine for bacterial and fungal disease resistance. HortScience, 42, 858-858.

Gürbüz, N., Uluişik, S., Frary, A., Frary, A., y Doğanlar, S. (2018). Health benefits and bioactive compounds of eggplant. Food Chemistry, 268, 602-610. 
Halbwirth, H., Puhl, I., Haas, U., Jezik, K., Treutter, D., y Stich, K. (2006). Two-phase flavonoid formation in developing strawberry (Fragaria $\times$ ananassa) fruit. Journal of Agricultural and Food Chemistry, 54(4), 1479-1485.

Halliwell, B. (1999). Antioxidant defence mechanisms: from the beginning to the end (of the beginning). Free radical reserch, 31(4), 261-272.

Haroldsen, V.M., Szczerba1, M.W., Aktas, H., Lopez-Baltazar, J., Odias, M.J., Chi-Ham, M.L., Labavitch, J.M., Bennett, A.B., Powell, A.L.T. (2012). Mobility of transgenic nucleic acids and proteins within grafted rootstocks for agricultural improvement. Frontiers in Plant Science, 3, 39.

Hartman, H.T., D.E. Kester, F.T. Davies y R. Geneve. (2002). Plant propagation, principles and practices, 7th ed. Prentice-Hall Ed,

Hayes, J. D., Kelleher, M. O., y Eggleston, I. M. (2008). The cancer chemopreventive actions of phytochemicals derived from glucosinolates. European journal of nutrition, 47(2), 73-88.

Hernández, J. A., y Almansa, M. S. (2002). Short-term effects of salt stress on antioxidant systems and leaf water relations of pea leaves. Physiologia Plantarum, 115(2), 251-257.

Hodges, D. M., y Forney, C. F. (2000). The effects of ethylene, depressed oxygen and elevated carbon dioxide on antioxidant profiles of senescing spinach leaves. Journal of Experimental Botany, 51(344), 645-655.

Horie, Y.; Ito, H.; Kusaba, M.; Tanaka, R.; y Tanaka, A. (2009). Participation of chlorophyll b reductase in the initial step of the degradation of light-harvesting chlorophyll a/b-protein complexes in Arabidopsis. Journal of Biological Chemistry, 284, 17449-17456.

Howard, L. R., Clark, J. R., y Brownmiller, C. (2003). Antioxidant capacity and phenolic content in blueberries as affected by genotype and growing season. Journal of the Science of Food and Agriculture, 83(12), 1238-1247.

Hudson D.E., Dalal A.A., y Pachance P.A. (1985). Retention of vitamins in fresh and frozen broccoli prepared by different cooking methods. Journal of Food Quality, 8, 45-50.

Hyodo, H. (2017). Stress/wound ethylene. In The plant hormone ethylene (pp. 43-63). CRC Press.

Ignat, I., Volf, I., y Popa, V. I. (2011). A critical review of methods for characterisation of polyphenolic compounds in fruits and vegetables. Food Chemistry, 126(4), 1821-1835.

Ishikawa, T., Maruta, T., Yoshimura, K., y Smirnoff, N. (2018). Biosynthesis and Regulation of Ascorbic Acid in Plants. In Antioxidants and Antioxidant Enzymes in Higher Plants, 163-179. Springer, Cham.

Jansen, M. A., Martret, B. L., y Koornneef, M. (2010). Variations in constitutive and inducible UVB tolerance; dissecting photosystem II protection in Arabidopsis thaliana accessions. Physiologia Plantarum, 138(1), 22-34.

Jiang, M., y Zhang, J. (2002). Water stress-induced abscisic acid accumulation triggers the increased generation of reactive oxygen species and up-regulates the activities of antioxidant enzymes in maize leaves. Journal of Experimental Botany, 53(379), 2401-2410.

Jin, P., Wang, K., Shang, H., Tong, J., y Zheng, Y. (2009). Low-temperature conditioning combined with methyl jasmonate treatment reduces chilling injury of peach fruit. Journal of the Science of Food and Agriculture, 89(10), 1690-1696.

Jin, P., Zhang, Y., Shan, T., Huang, Y., Xu, J., y Zheng, Y. (2015). Low-temperature conditioning alleviates chilling injury in loquat fruit and regulates glycine betaine content and energy status. Journal of Agricultural and Food Chemistry, 63(14), 3654-3659.

Jones, R. B., Frisina, C. L., Winkler, S., Imsic, M., y Tomkins, R. B. (2010). Cooking method significantly effects glucosinolate content and sulforaphane production in broccoli florets. Food Chemistry, 123, 237-242. 
Kacjan Maršić, N., Mikulič-Petkovšek, M., y Štampar, F. (2014). Grafting influences phenolic profile and carpometric traits of fruits of greenhouse-grown eggplant (Solanum melongena L.). Journal of Agricultural and Food Chemistry, 62(43), 10504-10514.

Kader, A. (2002). Biología y tecnología poscosecha: Un panorama. En: Tecnología Postcosecha de Cultivos Hortofrutícolas 3ra Edición. Kader, A., Pelayo-Saldivar, C. (eds.). Capítulo 4. Universidad de California. Davis. pp. 43-54.

Kader, A.A. (editor). (2005) Postharvest technology of horticultural crops. Third edition. University of California, Agriculture and Natural Resources, Publication 3311, 535 pp.

Kaewsuksaeng S., Urano Y., Aiamla-or S., Shigyo M., y Yamauchi N. (2011). Effect of UV-B irradiation on chlorophyll-degrading enzyme activities and postharvest quality in stored lime (Citrus latifolia Tan.) fruit. Postharvest Biology and Technology, 61, 124-130.

Kaewsuksaeng, S., Yamauchi, N., Funamoto, Y., Mori, T., Shigyo, M., y Kanlayanarat, S. (2007). Effect of heat treatment on catabolites formation in relation to chlorophyll degradation during storage of Broccoli (Brassica olearacea L. Italica Group) Florets. Journal of the Japanese Society for Horticultural Science, 76(4), 338-344.

Kalt, W. (2005). Effects of production and processing factors on major fruit and vegetable antioxidants. Journal of Food Science, 70(1), 11-19.

Kapusta-Duch J., Borczak B., Kopec A., Filipiak-Florkiewicz A., y Leszczyñska T. (2013). The influence of packaging type and time of frozen storage on antioxidative properties of Brussels sprouts. Journal of Food Processing and Preservation, 1-8.

Kashash, Y., DoronFaigenboim, A., Holland, D., y Porat, R. (2018). Effects of low temperature conditioning and cold storage on development of chilling injuries and the transcriptome of 'Wonderful'pomegranate fruit. International Journal of Food Science and Technology, 53(9), 2064-2076.

Kashash, Y., Mayuoni-Kirshenbaum, L., Goldenberg, L., Choi, H. J., y Porat, R. (2016). Effects of harvest date and low-temperature conditioning on chilling tolerance of 'Wonderful' pomegranate fruit. Scientia Horticulturae, 209, 286-292.

Kaur, C., Kumar, K., Anil, D., y Kapoor, H. C. (2007). Variations in antioxidant activity in broccoli (Brassica oleracea L.) cultivars. Journal of food biochemistry, 31(5), 621-638.

Kaur, C., Nagal, S., Nishad, J., y Kumar, R. (2014). Evaluating eggplant (Solanum melongena L) genotypes for bioactive properties: A chemometric approach. Food Research International, 60, 205-211.

Khah, E. M. (2006). Effect of grafting on growth, performance and yield of aubergine (Solanum melongena L.) in the field and greenhouse.

Khah, E. M. (2012). Effect of grafting on growth, performance and yield of aubergine (Solanum melongena L.) in greenhouse and open-field. International Journal of Plant Production, 5(4), 359366.

Khah, E. M., Kakava, E., Mavromatis, A., Chachalis, D., y Goulas, C. (2006). Effect of grafting on growth and yield of tomato (Lycopersicon esculentum Mill.) in greenhouse and open-field. Journal of Applied Horticulture, 8(1), 3-7.

Knapp, S., Vorontsova, M. S., y Prohens, J. (2013). Wild relatives of the eggplant (Solanum melongena L.: Solanaceae): new understanding of species names in a complex group. PloS one, 8(2), e57039.

Kondo, S., Tsuda, K., Muto, N., y Ueda, J. E. (2002). Antioxidative activity of apple skin or flesh extracts associated with fruit development on selected apple cultivars. Scientia Horticulturae, 96(1-4), 177-185. 
Kone, N., Asare-Bediako, E., Silue, S., Kone, D., Koita, O., Menzel, W., y Winter, S. (2017). Influence of planting date on incidence and severity of viral disease on cucurbits under field condition. Annals of Agricultural Sciences, 62(1), 99-104.

Kozukue, N., Kozukue, E., y Kishiguchi, M. (1979). Changes in the contents of phenolic substances, phenylalanine ammonia-lyase (PAL) and tyrosine ammonia-lyase (TAL) accompanying chillinginjury of eggplant fruit. Scientia Horticulturae, 11(1), 51-59.

Krug, H. (1997). Enviromental influences on development growth and yield. pp. 101-180. In: H.C. Wien (Ed.). The Physiology of Vegetable Crops. CABI. Publishing, London. 662 pág.

Ku, Y. G., Kang, D. H., Lee, C. K., Lee, S. Y., Ryu, C. S., Kim, D. E., y Gorinstein, S. (2018). Influence of different cultivation systems on bioactivity of asparagus. Food chemistry, 244, 349358.

Kumar N., Srivastava G.C., y Dixit K. (2008). Hormonal regulation of flower senescence in roses (Rosa hybrida L.). Plant Growth Regulation, 55, 65-71.

Kurilich, A. C., Jeffery, E. H., Juvik, J. A., Wallig, M. A., y Klein, B. P. (2002). Antioxidant capacity of different broccoli (Brassica oleracea) genotypes using the oxygen radical absorbance capacity (ORAC) assay. Journal of Agricultural and Food Chemistry, 50(18), 5053-5057.

Kushad, M. K., Brown, A. F., Kurilich, A. C., Juvik, J. A., Klein, B. P., Wallig, M. A., y Jeffery, E. H. (1999). Variation of glucosinolates in vegetable crops of Brassica oleracea. Journal of Agricultural and Food Chemistry, 47, 1541-1548.

Kusznierewicz B., Iori R., Piekarska A., Namiesnil J., Bartoszek A. (2013). Convenient identification of desulfoglucosinolates on the basis of mass spectra obtained during liquid chromatographydiode array-electrospray ionization mass spectrometry analysis: Method verification for sprouts of different Brassicaceae species extracts. Journal of Chromatography A, 1278, 108-115.

Kuti, J. O., y Konuru, H. B. (2005). Effects of genotype and cultivation environment on lycopene content in red- ripe tomatoes. Journal of the Science of Food and Agriculture, 85 (12), 20212026.

Kyriacou, M. C., Rouphael, Y., Colla, G., Zrenner, R., y Schwarz, D. (2017). Vegetable grafting: the implications of a growing agronomic imperative for vegetable fruit quality and nutritive value. Frontiers in Plant Science, 8, 741.

Lafuente, M. T., Zacarias, L., Martínez-Téllez, M. A., Sanchez-Ballesta, M. T., y Dupille, E. (2001). Phenylalanine ammonia-lyase as related to ethylene in the development of chilling symptoms during cold storage of citrus fruits. Journal of Agricultural and Food Chemistry, 49 (12), 60206025 .

Laguerre, M., Decker, E. A., Lecomte, J., y Villeneuve, P. (2010). Methods for evaluating the potency and efficacy of antioxidants. Current Opinion in Clinical Nutrition y Metabolic Care, 13(5), 518-525.

Lambers, H., Chapin, F. S., y Pons, T. L. (2008). Photosynthesis. In Plant physiological ecology (pp. 11-99). Springer, New York, NY.

Langmeier, M., Ginsburg, S., y Matile, P. (1993). Chlorophyll breakdown in senescent leaves: demonstration of Mg- dechelatase activity. Physiologia Plantarum, 89(2), 347-353.

Lee, J. M. (1994). Cultivation of grafted vegetables I. Current status, grafting methods, and benefits. Scientia Horticulturae, 29(4), 235-239.

Lee, J. M., Kubota, C., Tsao, S. J., Bie, Z., Echevarria, P. H., Morra, L., y Oda, M. (2010). Current status of vegetable grafting: Diffusion, grafting techniques, automation. Scientia Horticulturae, 127(2), 93-105.

Lee, S. Y., Shin, Y. W., y Hahm, K. B. (2008). Phytoceuticals: mighty but ignored weapons against Helicobacter pylori infection. Journal of digestive diseases, 9(3), 129-139. 
Legendre, P., Legendre, L. (1998). Numerical Ecology, Second English Edition. Developments in Environmental Modelling, 20.

Lemoine M. L., Civello P. M., Chaves A. R., y Martínez G. A. (2008). Effect of combined treatment with hot air and UV-C on senescence and quality parameters of minimally processed broccoli (Brassica oleracea L. cv Italica). Postharvest Biology and Technology, 48(1), 15-21.

Lemoine M. L., Civello P.M., Martínez G. A., y Chaves A. R. (2007). Influence of postharvest UV$\mathrm{C}$ treatment on refrigerated storage of minimally processed broccoli (Brassica oleracea $\mathrm{cv}$ Italica). Journal of the Science of Food and Agriculture, 87, 1132-1139.

Leonardi, C., y Giuffrida, F. (2006). Variation of plant growth and macronutrient uptake in grafted tomatoes and eggplants on three different rootstocks. European Journal of Horticultural Science, 71(3), 97.

Lewis, C. E., Walker, J. R., y Lancaster, J. E. (1999). Changes in anthocyanin, flavonoid and phenolic acid concentrations during development and storage of coloured potato (Solanum tuberosum L) tubers. Journal of the Science of Food and Agriculture, 79(2), 311-316.

Li JR., Yu K., Wei JR., Ma Q., Wang BQ., y Yu D. (2010). Gibberellin retards chlorophyll degradation during senescence of Paris polyphylla. Biologia Plantarum, 54, 395-399.

Li, D., Cheng, Y., Dong, Y., Shang, Z., y Guan, J. (2017). Effects of low temperature conditioning on fruit quality and peel browning spot in 'Huangguan'pears during cold storage. Postharvest Biology and Technology, 131, 68-73.

Li, H., Tsao, R., y Deng, Z. (2012). Factors affecting the antioxidant potential and health benefits of plant foods. Canadian journal of plant science, 92(6), 1101-1111.

Li, J., He, Y. J., Zhou, L., Liu, Y., Jiang, M., Ren, L., y Chen, H. (2018). Transcriptome profiling of genes related to light-induced anthocyanin biosynthesis in eggplant (Solanum melongena L.) before purple color becomes evident. BMC genomics, 19(1), 201.

Lichtenthaler, H. K. (1987). Chlorophylls and carotenoids: pigments of photosynthetic biomembranes. In Methods in enzymology, 148, 350-382. Academic Press.

Liu, H., Jiang, W., Cao, J., y Ma, L. (2018). A combination of 1-methylcyclopropene treatment and intermittent warming alleviates chilling injury and affects phenolics and antioxidant activity of peach fruit during storage. Scientia Horticulturae, 229, 175-181.

Liu, J. H., Wang, W., Wu, H., Gong, X., y Moriguchi, T. (2015). Polyamines function in stress tolerance: from synthesis to regulation. Frontiers in plant science, 6, 827.

Liu, L. H., Zabaras, D., Bennett, L. E., Aguas, P., y Woonton, B. W. (2009). Effects of UV-C, red light and sun light on the carotenoid content and physical qualities of tomatoes during post-harvest storage. Food Chemistry, 115(2), 495-500.

Liu, R. H. (2003). Health benefits of fruit and vegetables are from additive and synergistic combinations of phytochemicals. The American journal of clinical nutrition, 78(3), 517S-520S.

Liu, S., Li, H., Lv, X., Ahammed, G.J., Xia, X., Zhou, J., Shi, K., Asami, T., Yu, J., Zhou, Y., (2016). Grafting cucumber onto luffa improves drought tolerance by increasing ABA biosynthesis and sensitivity. Scientific Reports, 6, 20212.

López-Marín, J., Gálvez, A., Del Amor, F. M., Albacete, A., Fernández, J. A., Egea-Gilabert, C., y Pérez-Alfocea, F. (2017). Selecting vegetative/generative/dwarfing rootstocks for improving fruit yield and quality in water stressed sweet peppers. Scientia Horticulturae, 214, 9-17.

López-Marín, J., González, A., Pérez-Alfocea, F., Egea-Gilabert, C., y Fernández, J. A. (2013). Grafting is an efficient alternative to shading screens to alleviate thermal stress in greenhousegrown sweet pepper. Scientia Horticulturae, 149, 39-46.

Lorenz, O. A., y Maynard, D. N. (1998). Knott's handbook for vegetable growers. New York: Wiley. 
Lorenzen CJ., y Jeffrey SW. (1980). Determination of chlorophyll in seawater. Unesco Technical Papers in Marine Science, 35, 20.

Luckey, T. D. (1980). Hormesis with ionizing radiation (pp. 1-122). Boca Raton: CRC press.

Lurie, S. (1998). Postharvest heat treatments. Postharvest biology and technology, 14(3), 257-269.

Luthria, D. L., y Mukhopadhyay, S. (2006). Influence of sample preparation on assay of phenolic acids from eggplant. Journal of Agricultural and Food Chemistry, 54(1), 41-47.

Lyons, J. M. (1973). Chilling injury in plants. Annual review of plant physiology, 24(1), 445-466.

Machado, F. L. D. C., Costa, J. D. P. D., Teixeira, A. D. S., y Costa, J. M. C. D. (2015). The influence of rootstock and time of harvest on the fruit quality during storage of in two grapefruit cultivars. Acta Scientiarum. Agronomy, 37(3), 339-346.

Makrogianni, D. I., Tsistraki, A., Karapanos, I. C., y Passam, H. C. (2017). Nutritional value and antioxidant content of seed-containing and seedless eggplant fruits of two cultivars grown under protected cultivation during autumn-winter and spring-summer. Journal of the Science of Food and Agriculture, 97(11), 3752-3760.

Mangione, J., y Sánchez, M. (1999). Cultivo y manejo poscosecha de berenjena. Área de Inspección de frutas y hortalizas. Laboratorio de Fitopatología. Mercado Central de Buenos Aires. http://www.mercadocentral.com.ar/site2001/tecnicas/berenjena.zip

Manzocco, L., y Nicoli, M. C. (2015). Surface processing: existing and potential applications of ultraviolet light. Critical reviews in Food Science and Nutrition, 55(4), 469-484.

Maroto, J.V., y Baixauli-Soria, C. (2017). Cultivos Hortícolas al Aire Libre. Serie Agricultura 13. Editorial Cajamar Caja Rural. España. 786 pag.

Martin, C., Zhang, Y., Tonelli, C., y Petroni, K. (2013). Plants, diet, and health. Annual Review of Plant Biology, 64, 19-46.

Martinez, V., Nieves-Cordones, M., Lopez-Delacalle, M., Rodenas, R., Mestre, T. C., GarciaSanchez, F. y Rivero, R. M. (2018). Tolerance to stress combination in tomato plants: New insights in the protective role of melatonin. Molecules, 23(3), 535.

Martínez-Flórez, S., González-Gallego, J., Culebras, J. M., y Tuñón, M. (2002). Los flavonoides: propiedades y acciones antioxidantes. Nutrición Hospitalaria, 17(6), 271-278.

Martínez-Hernández G.B., Artés-Hernández F., Gómez P., y Artés F. (2013b). Induced changes in bioactive compounds of kalian-hybrid broccoli after innovative processing and storage. Journal of Functional Foods, 5, 133-143.

Martínez-Hernández G.B., Artés-Hernández F., Gómez P., y Artés F. (2013a). Comparative behaviour between kailan-hybrid and conventional fresh-cut broccoli throughout shelf-life. LWTFood Science and Technology, 50, 298-305.

Martínez-Hernández G.B., Gómez, P., Pradas, I., Artés, F., y Artés-Hernández, P. (2011). Moderate UV-C pretreatment as a quality enhancement tool in fresh-cut Bimi ${ }^{\circledR}$ broccoli. Postharvest Biology and Technology, 62, 327-337.

Martínez-Lüscher, J., Torres, N., Hilbert, G., Richard, T., Sánchez-Díaz, M., Delrot, S., y Gomès, E. (2014). Ultraviolet-B radiation modifies the quantitative and qualitative profile of flavonoids and amino acids in grape berries. Phytochemistry, 102, 106-114.

Martins, S., Mussatto, S. I., Martínez-Avila, G., Montañez-Saenz, J., Aguilar, C. N., y Teixeira, J. A. (2011). Bioactive phenolic compounds: production and extraction by solid-state fermentation. A review. Biotechnology Advances, 29(3), 365-373.

Massolo, J., Concellón, A., Chaves, A., y Vicente, A. (2011). 1-Methylcyclopropene (1-MCP) delays senescence, maintains quality and reduces browning of non-climacteric eggplant (Solanum melongena L.) fruit. Postharvest Biology and Technology. 59(1), 10-15. 
Matile, P., Hörtensteiner, S., y Thomas, H. (1999). Chlorophyll degradation. Annual Review of Plant Biology, 50(1), 67-95.

Matsubara, K., Kaneyuki, T., Miyake, T., y Mori, M. (2005). Antiangiogenic activity of nasunin, an antioxidant anthocyanin, in eggplant peels. Journal of Agricultural and Food Chemistry, 53(16), $6272-6275$.

Matsuzoe, N., Yamaguchi, M., Kawanobu, S., Watanabe, Y., Higashi, H., y Sakata, Y. (1999). Effect of dark treatment of the eggplant on fruit skin color and its anthocyanin component. Journal of the Japanese Society for Horticultural Science, 68(1), 138-145.

Maverakis, E., Miyamura, Y., Bowen, M. P., Correa, G., Ono, Y., y Goodarzi, H. (2010). Light, including ultraviolet. Journal of autoimmunity, 34(3), J247-J257.

MCBA. Corporación del mercado central de Buenos Aires. Secretaría de comercio interior. Precios de hortalizas del 27/6/2013. Acceso 2013. En: http://www.mercadocentral.gob.ar

McCollum, T. G., D'Aquino, S., y McDonald, R. E. (1993). Heat treatment inhibits mango chilling injury. HortScience, 28(3), 197-198.

Melnyk, C. W., Schuster, C., Leyser, O., y Meyerowitz, E. M. (2015). A developmental framework for graft formation and vascular reconnection in Arabidopsis thaliana. Current Biology, 25(10), 1306-1318.

Mennella, G., Lo Scalzo, R., Fibiani, M., D’Alessandro, A., Francese, G., Toppino, L., y Rotino, G. L. (2012). Chemical and bioactive quality traits during fruit ripening in eggplant ( $S$. melongena L.) and allied species. Journal of Agricultural and Food Chemistry, 60(47), 11821-11831.

Mewis I., Schreiner M., Nguyen CN., Krumbein A., Ulrichs C., Lohse M., y Zrenner R. (2012). UVB irradiation changes specifically the secondary metabolite profile in broccoli sprouts: induced signaling overlaps with defense response to biotic stressors. Plant Cell Physiology, 53, 15461560 .

Meyer, A. J. (2008). The integration of glutathione homeostasis and redox signaling. Journal of Plant Physiology, 165(13), 1390-1403.

Mi, L., Wang, X., Govind, S., Hood, B. L., Veenstra, T. D., Conrads, T. P., Saha DT, Goldman R, y Chung FL. (2007). The role of protein binding in induction of apoptosis by phenethyl isothiocyanate and sulforaphane in human non-small lung cancer cells. Cancer Research, 67(13), 6409-6416.

Miceli, A., Sabatino, L., Moncada, A., Vetrano, F., y D’Anna, F. (2014). Nursery and field evaluation of eggplant grafted onto unrooted cuttings of Solanum torvum Sw. Scientia Horticulturae, 178, 203-210.

Mittler, R. (2002). Oxidative stress, antioxidants and stress tolerance. Trends in Plant Science, 7(9), 405-410.

Mohammed, M, y Brecht, J. (2003). Immature fruit vegetables. Postharvest physiology and pathology of vegetables. 2nd edition. Bartz, J., Brecht, J. (eds). Marcel Dekker, New York. pp. 671-690.

Mohammed, M., y Brecht, J. K. (2002). Immature fruit vegetables. In Postharvest Physiology and Pathology of Vegetables (pp. 670-689). CRC Press.

Molinar, R., Trejo, E., y Cantwell, M. (1996). The development of chilling injury in three types of eggplants. Research Summary.

Møller, I. M. (2001). Plant mitochondria and oxidative stress: electron transport, NADPH turnover, and metabolism of reactive oxygen species. Annual Review of Plant Biology, 52(1), 561-591.

Moncada, A., Miceli, A., Vetrano, F., Mineo, V., Planeta, D., y D’Anna, F. (2013). Effect of grafting on yield and quality of eggplant (Solanum melongena L.). Scientia Horticulturae, 149, 108-114. 
Mudau, A. R., Soundy, P., Araya, H. T., y Mudau, F. N. (2018). Influence of Modified Atmosphere Packaging on Postharvest Quality of Baby Spinach (Spinacia oleracea L.) Leaves. HortScience, 53(2), 224-230.

Nicoletto, C., Santagata, S., Pino, S., y Sambo, P. (2016). Antioxidant characterization of different italian broccoli landraces. Horticultura Brasileira, 34(1), 74-79.

Niggeweg, R., Michael, A. J., y Martin, C. (2004). Engineering plants with increased levels of the antioxidant chlorogenic acid. Nature Biotechnology, 22(6), 746.

Nigro, F., Ippolito, A., Lattanzio, V., Di Venere, D., y Salerno, M. (2000). Effect of ultraviolet-C light on postharvest decay of strawberry. Journal of Plant Pathology, 29-37.

Nothmann, J. (1986). Eggplant. In: Handbook of Fruit Set and Development, Monselise, S. (ed.). CRC Press, Boca Raton, FL. pp.145-152.

Nothmann, J., y Koller, D. (1975). Effects of low-temperature stress on fertility and fruiting of eggplant (Solanum melongena) in a subtropical climate. Experimental Agriculture, 11(1), 33-38.

Nunn, M. D., Giraud, D. W., Parkhurst, A. M., Hamouz, F. L., y Driskell, J. A. (2006). Effects of cooking methods on sensory qualities and carotenoid retention in selected vegetables. Journal of Food Quality, 29, 445-457.

Obied, H. K., Allen, M. S., Bedgood, D. R., Prenzler, P. D., Robards, K., y Stockmann, R. (2005). Bioactivity and analysis of biophenols recovered from olive mill waste. Journal of Agricultural and Food Chemistry, 53(4), 823-837.

Oda, M. (1995). New grafting methods for fruit-bearing vegetables in Japan. Japan Agricultural Research Quarterly, 28, 177-184.

Oda, M. (1999). Grafting of vegetables to improve greenhouse production. En: http://www.fftc.agnet.org/library.php?func=viewyid=20110803135029Visitado. Octubre2018.

Okimura, M., Matsuo, S., Arai, K., y Okitsu, S. (1986). Influence of soil temperature on the growth of fruit vegetable grafted on different stocks. Bulletin of the Vegetable and Ornamental Crops Research Station. Japan, 9, 43-58.

Okmen, B., Sigva, H. O., Mutlu, S., Doganlar, S., Yemenicioglu, A., y Frary, A. (2009). Total antioxidant activity and total phenolic contents in different Turkish eggplant (Solanum melongena L.) cultivars. International Journal of Food Properties, 12(3), 616-624.

Onopiuk, A., Półtorak, A., Moczkowska, M., Szpicer, A., y Wierzbicka, A. (2017). The impact of ozone on health- promoting, microbiological, and colour properties of Rubus ideaus raspberries. CyTA-Journal of Food, 15(4), 563-573.

Pal, R. S., Hedau, N. K., Kant, L., y Pattanayak, A. (2018). Research Article Functional quality and antioxidant properties of tomato genotypes for breeding better quality varieties. Electronic Journal of Plant Breeding, 9(1), 1-8.

Pan, J., Vicente, A. R., Martínez, G. A., Chaves, A. R., y Civello, P. M. (2004). Combined use of UV- C irradiation and heat treatment to improve postharvest life of strawberry fruit. Journal of the Science of Food and Agriculture, 84(14), 1831-1838.

Park, Y. S., Jung, S. T., Kang, S. G., Heo, B. G., Arancibia-Avila, P., Toledo, F., y Gorinstein, S. (2008). Antioxidants and proteins in ethylene-treated kiwifruits. Food Chemistry, 107(2), 640648.

Paull, R. E., y Chen, N. J. (2000). Heat treatment and fruit ripening. Postharvest Biology and Technology, 21(1), 21-37.

Paulsen, E., Barrios, S., Baenas, N., Moreno, D. A., Heinzen, H., y Lema, P. (2018). Effect of temperature on glucosinolate content and shelf life of ready-to-eat broccoli florets packaged in passive modified atmosphere. Postharvest Biology and Technology, 138, 125-133. 
Penella, C., González Nebauer, S., López Galarza, S. V., San Bautista Primo, A., Gorbe, E., y Calatayud, A. (2013). Evaluation for salt stress tolerance of pepper genotypes to be used as rootstocks. Journal of Food Agriculture and Environment, 11(3), 1101-1107.

Penella, C., Landi, M., Guidi, L., Nebauer, S. G., Pellegrini, E., San Bautista, A., y Calatayud, A. (2016). Salt-tolerant rootstock increases yield of pepper under salinity through maintenance of photosynthetic performance and sinks strength. Journal of Plant Physiology, 193, 1-11.

Perez-Gilabert, M., y García Carmona, F. (2000). Characterization of catecholase and cresolase activities of eggplant polyphenol oxidase. Journal of Agricultural and Food Chemistry, 48(3), 695-700.

Petran, A., y Hoover, E. (2014). Solanum torvum as a compatible rootstock in interspecific tomato grafting. Journal of Horticulture, 103(1).

Petropoulos, S., Fernandes, Â, Barros, L., y Ferreira, I. C. (2018). Chemical composition, nutritional value and antioxidant properties of Mediterranean okra genotypes in relation to harvest stage. Food Chemistry, 242, 466-474.

Plazas, M., Andújar, I., Vilanova, S., Hurtado, M., Gramazio, P., Herraiz, F. J., y Prohens, J. (2013b). Breeding for chlorogenic acid content in eggplant: interest and prospects. Notulae Botanicae Horti Agrobotanici Cluj-Napoca, 41(1), 26-35.

Plazas, M., López-Gresa, M. P., Vilanova, S., Torres, C., Hurtado, M., Gramazio, P., y Prohens, J. (2013). Diversity and relationships in key traits for functional and apparent quality in a collection of eggplant: Fruit phenolics content, antioxidant activity, polyphenol oxidase activity, and browning. Journal of Agricultural and Food Chemistry, 61(37), 8871-8879.

Pombo MA., Martínez GA., y Civello PM. (2011). Cloning of FaPAL6 gene from strawberry fruit and characterization of its expression and enzymatic activity in two cultivars with different anthocyanin accumulation. Plant Science, 181,111-118.

Potters, G., De Gara, L., Asard, H., y Horemans, N. (2002). Ascorbate and glutathione: guardians of the cell cycle, partners in crime? Plant Physiology and Biochemistry, 40(6-8), 537-548.

Prohens, J., Blanca, J., y Nuez, F. (2005). Morphological and molecular variation in a collection of eggplant from a secondary center of diversity: implications for conservation and breeding. Journal of the American Society for the Horticultural Sciences, 130, 54-63.

Prohens, J., Rodríguez-Burruezo, A., Raigón, M. D., y Nuez, F. (2007). Total phenolic concentration and browning susceptibility in a collection of different varietal types and hybrids of eggplant: Implications for breeding for higher nutritional quality and reduced browning. Journal of the American Society for Horticultural Science, 132(5), 638-646.

Prohens, J., Whitaker, B. D., Plazas, M., Vilanova, S., Hurtado, M., Blasco, M., y Stommel, J. R. (2013). Genetic diversity in morphological characters and phenolic acids content resulting from an interspecific cross between eggplant, Solanum melongena, and its wild ancestor (S. incanum). Annals of Applied Biology, 162(2), 242-257.

Purvis, A. C. (1997). Role of the alternative oxidase in limiting superoxide production by plant mitochondria. Physiologia Plantarum, 100(1), 165-170.

Purvis, A. C. (2002). Diphenylamine reduces chilling injury of green bell pepper fruit. Postharvest Biology and Technology, 25(1), 41-48.

Raigón, M. D., Rodríguez-Burruezo, A., y Prohens, J. (2010). Effects of organic and conventional cultivation methods on composition of eggplant fruits. Journal of Agricultural and Food Chemistry, 58(11), 6833-6840.

Ramírez- Acosta, S., Arias- Borrego, A., Gómez- Ariza, J. L., y García- Barrera, T. (2018). Metabolomic study of bioactive compounds in strawberries preserved under controlled atmosphere based on GC- MS and DI- ESI- QqQ- TOF- MS. Phytochemical Analysis, 30(2), 198-207. 
Ramprasath, V. R., y Jones, P. J. H. (2010). Anti-atherogenic effects of resveratrol. European Journal of Clinical Nutrition, 64(7), 660.

Reinbothe C, Springer A, Samol I, y Reinbothe S, (2009). Plant oxylipins: role of jasmonic acid during programmed cell death, defence and leaf senescence, The FEBS Journal, 276, 4666-4681.

Renard, C. M., Dupont, N., y Guillermin, P. (2007). Concentrations and characteristics of procyanidins and other phenolics in apples during fruit growth. Phytochemistry, 68(8), 1128 1138.

Rhee, J. Y., Lee, S. H., Singh, A. P., Chung, G. C., y Ahn, S. J. (2007). Detoxification of hydrogen peroxide maintains the water transport activity in figleaf gourd (Cucurbita ficifolia) root system exposed to low temperature. Physiologia Plantarum, 130(2), 177-184.

Ribeiro, C., y Alvarenga, B. (2012). Prospects of UV radiation for application in postharvest technology. Emirates Journal of Food and Agriculture, 586-597.

Ricco, R. A., Vai, V. M., Sena, G. A., Wagner, M. L., y Gurni, A. A. (2003). Taninos condensados de Ephedra ochreata Miers (Ephedraceae). Acta Farmacéutica Bonaerense, 22.

Rice-Evans, C., Miller, N., y Paganga, G. (1997). Antioxidant properties of phenolic compounds. Trends Plant Science. 2(4), 152-159.

Rivero, R. M., Ruiz, J. M., Sánchez, E., \& Romero, L. (2003). Does grafting provide tomato plants an advantage against $\mathrm{H} 2 \mathrm{O} 2$ production under conditions of thermal shock?. Physiologia Plantarum, 117(1), 44-50.

Rivero, R. M., Ruiz, J. M., y Romero, L. (2003). Role of grafting in horticultural plants under stress conditions. Journal of Food Agriculture and Environment, 1, 70-74.

Roca, M., y Mínguez-Mosquera, M. I. (2003). Involvement of chlorophyllase in chlorophyll metabolism in olive varieties with high and low chlorophyll content. Physiologia Plantarum, 117(4), 459-466.

Rodoni, L. M., Hasperué, J. H., Ortiz, C. M., Lemoine, M. L., Concellón, A., y Vicente, A. R. (2016). Combined use of mild heat treatment and refrigeration to extend the postharvest life of organic pepper sticks, as affected by fruit maturity stage. Postharvest Biology and Technology, 117, 168176.

Rodoni, L., Casadei, N., Concellón, A., Chaves Alicia, A. R., y Vicente, A. R. (2009). Effect of shortterm ozone treatments on tomato (Solanum lycopersicum L.) fruit quality and cell wall degradation. Journal of Agricultural and Food Chemistry, 58(1), 594-599.

Rodríguez- Aguilera R, y Oliveira J.C. (2009). Review of Design Engineering Methods and Applications of Active and Modified Atmosphere Packaging Systems. Food Engineering Reviews, 1, 66-83.

Ruiz, J. M., Belakbir, A., López-Cantarero, I., y Romero, L. (1997). Leaf-macronutrient content and yield in grafted melon plants. A model to evaluate the influence of rootstock genotype. Scientia Horticulturae, 71(3-4), 227-234.

Rybarczyk-Plonska A., Hagen SF., y Borge GIA. (2016). Glucosinolates in broccoli (Brassica oleracea L. var. italica) as affected by postharvest temperature and radiation treatments. Postharvest Biology and Technology, 116, 16-25.

Sabatino, L., Iapichino, G., D’Anna, F., Palazzolo, E., Mennella, G., y Rotino, G. L. (2018). Hybrids and allied species as potential rootstocks for eggplant: Effect of grafting on vigour, yield and overall fruit quality traits. Scientia Horticulturae, 228, 81-90.

Sabatino, L., Iapichino, G., Maggio, A., D’anna, E., Bruno, M., y D’Anna, F. (2016). Grafting affects yield and phenolic profile of Solanum melongena L. landraces. Journal of Integrative Agriculture, 15(5), 1017-1024. 
Saldilova, E., Stintzing, F. C., y Carle, R. (2006). Anthocyanins, colour and antioxidant properties of eggplant (Solanum melongena L.) and violet pepper (Capsicum annuum L.) peel extracts. Zeitschrift für Naturforschung C, 61(7-8), 527-535.

Saltveit, M. E. (2003). Is it possible to find an optimal controlled atmosphere? Postharvest Biology and Technology, 27(1), 3-13.

Sams, C. E. (1999). Preharvest factors affecting postharvest texture. Postharvest Biology and Technology, 15(3), 249-254.

Samuel, A. (2004). Plants: diet and health. Nutrition Bulletin, 29(2), 156-159.

Sanchez-Ballesta, M. T., Zacarias, L., Granell, A., y Lafuente, M. T. (2000). Accumulation of PAL transcript and PAL activity as affected by heat-conditioning and low-temperature storage and its relation to chilling sensitivity in mandarin fruits. Journal of Agricultural and Food Chemistry, 48(7), 2726-2731.

Sánchez-Rodríguez, E., Ruiz, J. M., Ferreres, F., y Moreno, D. A. (2012). Phenolic profiles of cherry tomatoes as influenced by hydric stress and rootstock technique. Food Chemistry, 134(2), 775782.

Sapitnitskaya, M., Maul, P., McCollum, G. T., Guy, C. L., Weiss, B., Samach, A., y Porat, R. (2006). Postharvest heat and conditioning treatments activate different molecular responses and reduce chilling injuries in grapefruit. Journal of Experimental Botany, 57(12), 2943-2953.

Sato, Y., Itagaki, S., Kurokawa, T., Ogura, J., Kobayashi, M., Hirano, T., y Iseki, K. (2011). In vitro and in vivo antioxidant properties of chlorogenic acid and caffeic acid. International Journal of Pharmaceutics, 403(1-2), 136-138.

Sayyari, M., Castillo, S., Valero, D., Díaz-Mula, H. M., y Serrano, M. (2011). Acetyl salicylic acid alleviates chilling injury and maintains nutritive and bioactive compounds and antioxidant activity during postharvest storage of pomegranates. Postharvest Biology and Technology, 60(2), 136-142.

SB, I. A., LM, L. L., AL, A. A. S., y Rubio-Pino, J. L. (2013). Effect of maturity and harvest season on antioxidant activity, phenolic compounds and ascorbic acid of Morinda citrifolia L. (noni) grown in Mexico (with track change). African Journal of Biotechnology, 12(29), 4623-4629.

Scalzo, J., Politi, A., Pellegrini, N., Mezzetti, B., y Battino, M. (2005). Plant genotype affects total antioxidant capacity and phenolic contents in fruit. Nutrition, 21(2), 207-213.

Schreiner M., Krumbeina A., Mewis I, Ulrichs C. y Huyskens-Keil S. (2009). Short-term andmoderate UV-B radiation effects on secondary plant metabolism in different organs of nasturtium (Tropaeolum majus L.). Innovative Food Science and Emerging Technologies, 10, 9396.

Schwarz, D., Öztekin, G. B., Tüzel, Y., Brückner, B., y Krumbein, A. (2013). Rootstocks can enhance tomato growth and quality characteristics at low potassium supply. Scientia Horticulturae, 149, 70-79.

Schwarz, D., Rouphael, Y., Colla, G., Venema, J. H. (2010). Grafting as a tool to improve tolerance of vegetables to abiotic stresses: thermal stress, water stress and organic pollutants. Scientia Horticulturae, 127(2), 162-171.

Sękara, A., Cebula, S., y Kunicki, E. (2007). Cultivated eggplants-origin, breeding objectives and genetic resources, a review. Folia Horticulturae, 19(1), 97-114.

Sen, A., Chatterjee, R., Bhaisare, P., y Subba, S. (2018). Grafting as an Alternate Tool for Biotic and Abiotic Tolerance with Improved Growth and Production of Solanaceous Vegetables: Challenges and Scopes in India. International Journal of Current Microbiology and Applied Sciences, 7(1), 121-135. 
Serrano, M., y Valero, D. (2018). Application of Polyamines to Maintain Functional Properties in Stored Fruits. In Polyamines (pp. 449-458). Humana Press, New York, NY.

Sevillano, L., Sanchez-Ballesta, M.T., Romojaro, F., Flores, F.B. (2009). Physiologicalhormonal and molecular mechanisms regulating chilling injury in horticulturalspecies. Postharvest technologies applied to reduce its impact. Journal of the Science of Food and Agriculture, 89, 555-573.

Sharom, M., Willemot, C., Thompson, J.E. (1994). Chilling injury induces lipid phasechanges in membranes of tomato fruit. Plant Physiology, 105, 305-308.

Sheng, L., Zhou, X., Liu, Z. Y., Wang, J. W., Zhou, Q., Wang, L., ... y Ji, S. J. (2016). Changed activities of enzymes crucial to membrane lipid metabolism accompany pericarp browning in 'Nanguo'pears during refrigeration and subsequent shelf life at room temperature. Postharvest Biology and Technology, 117, 1-8.

Shi, J., Zuo, J., Zhou, F., Gao, L., Wang, Q., y Jiang, A. (2018). Low-temperature conditioning enhances chilling tolerance and reduces damage in cold-stored eggplant (Solanum melongena L.) fruit. Postharvest Biology and Technology, 141, 33-38.

Shioi, Y., Tomita, N., Tsuchiya, T. y Takamiya, K., (1996). Conversion of chlorophyllide to pheophorbide by Mg-dechelating substance in extracts of Chenopodium album. Plant Physiolology. Biochemistry, 34, 41-47.

Siller-Cepeda, J. (2004). Postharvest eggplant. Postharvest physiology and technology laboratory, CIAD. México. USDA Handbook. http://www.agrifoodgateway.com/es/articles/postharvest-eggplant.

Simonne, A. H., Simonne, E. H., Eitenmiller, R. R., Mills, H. A., y Green, N. R. (1997). Ascorbic acid and provitamin a contents in unusually colored bell peppers (Capsicum annuum L.). Journal of Food Composition and Analysis, 10(4), 299-311.

Singleton VL., Orthofer R. y Lamuela-Raventos R.M. (1999). Analysis of total phenols and other oxidation substrates and antioxidants by means of Folin-Ciocalteu reagent. Methods in Enzymology, 299, 152-178.

Sivakumar, D., Van Deventer, F., Terry, L. A., Polenta, G. A., y Korsten, L. (2012). Combination of 1- methylcyclopropene treatment and controlled atmosphere storage retains overall fruit quality and bioactive compounds in mango. Journal of the Science of Food and Agriculture, 92(4), 821830 .

Skrede, G. (1996). Fruits. In Freezing Effects on Food Quality; Jeremiah, L. E., Ed.; Dekker: New York.

Skrzyński, J., y Gąstoł, M. (2007). The Effect of Rootstocks on the Fruit Characteristic Attributes of 'Jonica'Apples. Vegetable Crops Research Bulletin, 66, 171-176.

Smolikova, G., Dolgikh, E., Vikhnina, M., Frolov, A. y Medvedev, S. (2017). Genetic and Hormonal Regulation of Chlorophyll Degradation during Maturation of Seeds with Green Embryos. International Journal of Molecular Sciences, 18, 1993.

Soheila, A. H. (2000). Plant responses to ultraviolet-B (UV-B: 280-320 nm) stress: What are the key regulators? Plant Growth Regulation, 32(1), 27-39.

Somkuwar, R.G., Satisha, J., Ramteke, S.D. and Sharma, J. (2008). Effect of rootstocks and preharvest treatments on storage life of Thompson seedless grapes. Acta Horticulturae, 785, 441446.

Stanger, M. C., Steffens, C. A., Soethe, C., Moreira, M. A., do Amarante, C. V. T., Both, V., y Brackmann, A. (2018). Phenolic compounds content and antioxidant activity of 'Galaxy'apples stored in dynamic controlled atmosphere and ultralow oxygen conditions. Postharvest Biology and Technology, 144, 70-76. 
Stegemann, S., y Bock, R. (2009). Exchange of genetic material between cells in plant tissue grafts. Science, 324(5927), 649-651.

Stommel, J. R., Whitaker, B. D., Haynes, K. G., y Prohens, J. (2015). Genotype $\times$ environment interactions in eggplant for fruit phenolic acid content. Euphytica, 205(3), 823-836.

Stoppani M I y Francescangeli N. (2000). El brócoli y su potencial: hortaliza top del tercer milenio. INTA EEA San Pedro. www.inta.gov.ar/sanpedro/info/doc/hor/nf_011.htm??

Suárez-Hernández, A.M., Grimaldo-Juárez, O., García-López, A.M., González-Mendoza, D., Huitrón-Ramírez, M.V. (2017). Influence of rootstock on postharvest watermelon quality. Chapingo Serie Horticultura, 23(1).

Sun, Y., Qian, M., Wu, R., Niu, Q., Teng, Y., y Zhang, D. (2014). Postharvest pigmentation in red Chinese sand pears (Pyrus pyrifolia Nakai) in response to optimum light and temperature. Postharvest Biology and Technology, 91, 64-71.

Tachibana, S. (1982). Comparison of effects of root temperature on the growth and mineral nutrition of cucumber cultivars and figleaf gourd. Journal of the Japanese Society for Horticultural Science, 51(3), 299-308.

Taiz, L y Zeiger, E. (2006). Secondary metabolites and plant defense. Plant Physiology. Fourth Edition. Sinauer Associates, Inc. Capítulo, 13, 125.

Taiz, L.; Zeiger, E. (1998). Plant Physiology, segunda edición. Sinauer. EEUU. 792 pág.

Tang, L., Okazawa, A., Fukusaki, E., y Kobayashi, A. (2000). Removal of magnesium by Mgdechelatase is a major step in the chlorophyll-degrading pathway in Ginkgo biloba in the process of autumnal tints. Zeitschrift für Naturforschung C, 55(11-12), 923-926.

Thompson, A. K. (2010). Modified atmosphere packaging. Controlled atmosphere storage of fruits and vegetables, (Ed. 2), 81-115.

Thompson, J. E., Froese, C. D., Madey, E., Smith, M. D., y Hong, Y. (1998). Lipid metabolism during plant senescence. Progress in Lipid Research, 37(2), 119-141.

Tian M S, Talebul I, Stevenson D G e Irving DE. (1997). Color, ethylene production, respiration, and compositional changes in broccoli dipped in hot water, Journal of the American Society for the Horticultural Sciences, 122, 112-116.

Tian Q., Rosselot R., Schwartz SJ. (2005). Quantitative determination of intact glucosinolates in broccoli, broccoli sprouts, Brussels sprouts, and cauliflower by high-performance liquid chromatography-electrospray ionization-tandem mass spectrometry. Analytical Biochemistry 343, 93-99.

Tiecher, A.; Arante de Paula, L.; Chaves, F.C. y Rombaldi, C.V. (2013) UV-C effect on ethylene, polyamines and the regulation of tomto fruit ripening. Postharvest Biology and Technology, 86, 230-239.

Toivonen, P. (2011). Postharvest Physiology of Vegetables. En: Handbook of Vegetables and Vegetable Processing, Sinha, N. (ed.), Wiley-Blackwell, 199-215.

Tomala, K., Andziak, J., Jeziorek, K., Dziuban, R. (2008). Influence of rootstock on the quality of 'jonagold' apples at harvest and after storage. Journal of Fruit and Ornamental Plant Research, $16,31-38$.

Topcu, Y., Dogan, A., Kasimoglu, Z., Sahin-Nadeem, H., Polat, E., y Erkan, M. (2015). The effects of UV radiation during the vegetative period on antioxidant compounds and postharvest quality of broccoli (Brassica oleracea L.). Plant Physiology and Biochemistry, 93, 56-65.

Traka, M., Spinks, C., Doleman, J., Melchini, A., Ball, R., Mills, R. y Mithen, RF. (2010). The dietary isothiocyanate sulforaphane modulates gene expression and alternative gene splicing in a PTEN null preclinical murine model of prostate cancer. Molecular Cancer, 9(1), 189. 
Trinchera, A., Pandozy, G., Rinaldi, S., Crinò, P., Temperini, O., y Rea, E. (2013). Graft union formation in artichoke grafting onto wild and cultivated cardoon: An anatomical study. Journal of Plant Physiology, 170(18), 1569-1578.

Tripodi, P., Cardi, T., Bianchi, G., Migliori, C. A., Schiavi, M., Rotino, G. L., y Scalzo, R. L. (2018). Genetic and environmental factors underlying variation in yield performance and bioactive compound content of hot pepper varieties (Capsicum annuum) cultivated in two contrasting Italian locations. European Food Research and Technology, 1-13.

Usall, J., Ippolito, A., Sisquella, M., y Neri, F. (2016). Physical treatments to control postharvest diseases of fresh fruits and vegetables. Postharvest Biology and Technology, 122, 30-40.

USDA. (2014). United States Department of Agriculture. National Nutrient Database for Standard Reference. Acceso 2014. En: http://ndb.nal.usda.gov/ndb/search/list.

Uzun, S. (2007). Effect of light and temperature on the phenology and maturation of the fruit of eggplant (Solanum melongena) grown in greenhouses. New Zealand Journal of Crop and Horticultural Science, 35(1), 51-59.

Valenzuela, J.L., Manzano, S., Palma, F., Carvajal, F., Garrido, D., Jamilena, M. (2017). Oxidative Stress Associated with Chilling Injury in Immature Fruit: Postharvest Technological and Biotechnological Solutions. Int J Mol Sci. 18(7), 1467.

Valerga, L., Darré, M., Zaro, M. J., Arambarri, A., Vicente, A. R., Lemoine, M. L., y Concellón, A. (2018). Micro-structural and quality changes in growing dark-purple eggplant (Solanum melongena L.) as affected by the harvest season. Scientia Horticulturae, 244, 22-30.

Valero, D., Serrano, M. (2010) Postharvest biology and technology for preserving fruit quality. CRC Press. Cap. 3. https://doi.org/10.1201/9781439802670.

Vallejo, F., Tomás-Barberán, F.A., García-Viguera, C., (2003). Phenolic compound contents in edible parts of broccoli inflorescences after domestic cooking. Journal of the Science of Food and Agriculture, 83, 1511-1516.

Varela, R., y Massa, I. (1983). Concentracion de clorofila a feopigmentos y materia en suspension en Laguna de Raya, Isla de Margarita, Venezuela, periodo abril-junio 1981. Memoria Sociedad de Ciencias Naturales La Salle (Venezuela), 43(119), 39-65.

Vargas-Arcila, M., Cartagena-Valenzuela, J. R., Franco, G., Correa-Londoño, G. A., QuinteroVásquez, L. M., y Gaviria-Montoya, C. A. (2017). Changes in the physico-chemical properties of four lettuce (Lactuca sativa L.) varieties during storage. Corpoica Ciencia y Tecnología Agropecuaria, 18(2), 257-273.

Variyar P.S., Banerjee A., Akkarakaran J., y Suprasanna P. (2014). Chapter 12: Role of glucosinolates in plant stress tolerance, In P. Ahmad and S. Rassol (Eds.) Emerging Technologies and Management of Crop Stress Tolerance San Diego: Academic Press, pp: 271-291.

Venditti, T., y D'hallewin, G. (2014). Use of ultraviolet radiation to increase the health-promoting properties of fruits and vegetables. Stewart Postharvest Rev, 10, 1-3.

Vendrell M., y Mc Glasson W.B, (1971). Inhibition of Ethylene Production in Banana Fruit Tissue by Ethylene Treatment. Australian Journal of Biological Sciences, 24, 885-896.

Venema, J. H., Linger, P., Van Heusden, A. W., Van Hasselt, P. R., y Brüggemann, W. (2005). The inheritance of chilling tolerance in tomato (Lycopersicon spp.). Plant Biology, 7(02), 118-130.

Vermerris, W y Nicholson, R. (2006). Phenolic compound biochemistry. Springer pp 151-196.

Vicente A.R., Martínez G.A., Chaves A.R., y Civello P.M. (2002). Quality of heat treated strawberry fruit during refrigerated storage. Postharvest Biology and Technology, 25, 59-71.

Vicente, A. R., Manganaris, G. A., Sozzi, G. O., y Crisosto, C. H. (2009). Nutritional quality of fruits and vegetables. Postharvest handling: A systems approach, 57-106. 
Vicente, A. R., Saladie, M., Rose, J. K., y Labavitch, J. M. (2007). The linkage between cell wall metabolism and fruit softening: looking to the future. Journal of the Science of Food and Agriculture, 87(8), 1435-1448.

Vicente, AR., Lurie, S. (2014). Editorial: Physical methods for preventing postharvest deterioration. Stewart Postharvest Reviews, 10, 2.

Vig, A. P., Rampal, G., Thind, T. S., y Arora, S. (2009). Bio-protective effects of glucosinolates-A review. LWT-Food Science and Technology, 42(10), 1561-1572.

Vrcek, I. V., Samobor, V., Bojic, M., Saric, M. M., Vukobratovic, M., Erhatic, R., y Matotan, Z. (2011). The effect of grafting on the antioxidant properties of tomato (Solanum lycopersicum L.). Spanish Journal of Agricultural Research, (3), 844-851.

Vršič, S., Pulko, B., y Kocsis, L. (2015). Factors influencing grafting success and compatibility of grape rootstocks. Scientia Horticulturae, 181, 168-173.

Wang, S. Y., y Stretch, A. W. (2001). Antioxidant capacity in cranberry is influenced by cultivar and storage temperature. Journal of Agricultural and Food Chemistry, 49(2), 969-974.Wang, C. Y. (1993). Approaches to reduce chilling injury of fruits and vegetables. Horticultural Reviews, 15, 63-95.

Wang, C. Y. (1994). Chilling injury of tropical horticultural commodities. HortScience, 29(9), 986988.

Wang, C. Y., Kramer, G. F., Whitaker, B. D., y Lusby, W. R. (1992). Temperature preconditioning increases tolerance to chilling injury and alters lipid composition in zucchini squash. Journal of Plant Physiology, 140(2), 229-235.

Wang, H., Qian, Z., Ma, S., Zhou, Y., Patrick, J. W., Duan, X., y Qu, H. (2013). Energy status of ripening and postharvest senescent fruit of litchi (Litchi chinensis Sonn.). BMC Plant Biology, 13(1), 55.

Wang, J., Zhou, X., Zhou, Q., Cheng, S., Wei, B., y Ji, S. (2017). Low temperature conditioning alleviates peel browning by modulating energy and lipid metabolisms of 'Nanguo'pears during shelf life after cold storage. Postharvest Biology and Technology, 131, 10-15.

Wang, S., Cheng, J., Zhao, J., y Yang, R. (2007). Effect of rootstocks on the tolerance to high temperature of eggplants under solar greenhouse during summer season. Acta Horticulturae, 761, 357-360.

Wang, Y., Xu, W. J., y Yan, X. F. (2011). Glucosinolate content and related gene expression in response to enhanced UV-B radiation in Arabidopsis. African Journal of Biotechnology, 10(34), 6481-6491.

Wannabussapawich, B., y Seraypheap, K. (2018). Effects of putrescine treatment on the quality attributes and antioxidant activities of 'Nam Dok Mai No. 4'mango fruit during storage. Scientia Horticulturae, 233, 22-28.

Watkins C.B. (2006). Research review paper: The use of 1- methylcyclopropene (1- MCP) on fruits and vegetables. Biotechnology Advances, 24, 389-409.

Watkins, C. B., Nock, J. F., y Whitaker, B. D. (2000). Responses of early, mid and late season apple cultivars to postharvest application of 1-methylcyclopropene (1-MCP) under air and controlled atmosphere storage conditions. Postharvest Biology and technology, 19(1), 17-32.

Winardiantika, V., Lee, Y. H., Park, N. I., y Yeoung, Y. R. (2015). Effects of cultivar and harvest time on the contents of antioxidant phytochemicals in strawberry fruits. Horticulture, Environment, and Biotechnology, 56(6), 732-739.

Woolf, A. B., Cox, K. A., White, A., y Ferguson, I. B. (2003). Low temperature conditioning treatments reduce external chilling injury of 'Hass' avocados. Postharvest Biology and Technology, 28(1), 113-122. 
Wu, X., Beecher, G. R., Holden, J. M., Haytowitz, D. B., Gebhardt, S. E., y Prior, R. L. (2004). Lipophilic and hydrophilic antioxidant capacities of common foods in the United States. Journal of Agricultural and Food Chemistry, 52(12), 4026-4037.

Wu, X., y Prior, R. L. (2005). Identification and characterization of anthocyanins by highperformance liquid chromatography-electrospray ionization-tandem mass spectrometry in common foods in the United States: Vegetables, nuts, and grains. Journal of Agricultural and Food Chemistry, 53(8), 3101-3113.

Yamauchi, N. (2015). Postharvest chlorophyll degradation and oxidative stress. In Abiotic Stress Biology in Horticultural Plants (pp. 101-113). Springer, Tokyo.

Yamauchi, N., Funamoto, Y., y Shigyo, M. (2004). Peroxidase-mediated chlorophyll degradation in horticultural crops. Phytochemistry reviews, 3(1-2), 221-228.

Yamauchi, N., y A. E. Watada. (1998). Chlorophyll and xanthophyll changes in broccoli florets stored under elevated $\mathrm{CO} 2$ or ethylene-containing atmosphere. Scientia Horticulturae, 33,114117.

Yang, C. M., Chang, K. W., Yin, M. H., y Huang, H. M. (1998). Methods for the determination of the chlorophylls and their derivatives. Taiwania, 43(2), 116-122.

Yang, Q., Zhang, Z., Rao, J., Wang, Y., Sun, Z., Ma, Q., y Dong, X. (2013). Low-temperature conditioning induces chilling tolerance in 'hayward' kiwifruit by enhancing antioxidant enzyme activity and regulating endogenous hormones levels. Journal Sciences of Food Agricultural, 93 (15), 3691-3699.

Zaro M. J., Vicente A. R., Ortiz C. M., Chaves A. R., y Concellón A. (2015). Eggplant. En: Handbook of Vegetable Preservation and Processing. Second Edition. Ed.: Y. H. Hui y E. Özgül Evranuz. CRC Press. Taylor and Francis UCA. 800 pp. Págs. 479-493. Boca Raton, Florida, USA.

Zaro, M. J. (2014). Análisis de factores que afectan la acumulación, distribución y estabilidad de antioxidantes de naturaleza fenólica en berenjena (Solanum melongena L.) (Doctoral dissertation, Facultad de Ciencias Exactas).

Zaro, M. J., Chaves, A. R., Vicente, A. R., y Concellón, A. (2014). Distribution, stability and fate of phenolic compounds in white and purple eggplants (Solanum melongena L.). Postharvest Biology and Technology, 92, 70-78.

Zaro, M. J., Keunchkarian, S., Chaves, A. R., Vicente, A. R., y Concellón, A. (2014). Changes in bioactive compounds and response to postharvest storage conditions in purple eggplants as affected by fruit developmental stage. Postharvest Biology and Technology, 96, 110-117.

Zaro, M. J., Ortiz, L. C., Keunchkarian, S., Chaves, A. R., Vicente, A. R., y Concellón, A. (2015a). Chlorogenic acid retention in white and purple eggplant after processing and cooking. LWT-Food Science and Technology, 64(2), 802-808.

Zhang, B., Deng, Z., Tang, Y., Chen, P., Liu, R., Ramdath, D. D.y Tsao, R. (2014). Fatty acid, carotenoid and tocopherol compositions of 20 Canadian lentil cultivars and synergistic contribution to antioxidant activities. Food Chemistry, 161, 296-304.

Zhang, X., Sheng, J., Li, F., Meng, D., y Shen, L. (2012). Methyl jasmonate alters arginine catabolism and improves postharvest chilling tolerance in cherry tomato fruit. Postharvest Biology and Technology, 64(1), 160-167.

Zhang, X., Wang, W., Wang, M., Zhang, H.Y., Liu, J.H. (2016). The miR396b of Poncirus trifoliata functions in cold tolerance by regulating ACC oxidase gene expression and modulating ethylenepolyamine homeostasis. Plant and Cell Physiology, 57, 1865-1878.

Zhang, X.N., Li, X. and Liu, J.H. (2014) Identification of conserved and novel cold-responsive microRNAs in trifoliate orange (Poncirus trifoliata (L.) Raf.) using high-throughput sequencing. Plant Molecular Biology Reports, 32, 328-341. 
Zhang, Z., Zhu, Q., Hu, M., Gao, Z., An, F., Li, M., y Jiang, Y. (2017). Low-temperature conditioning induces chilling tolerance in stored mango fruit. Food Chemistry, 219, 76-84.

Zhao X., Guo Y., Huber D.J., Lee J., (2011). Grafting effects on postharvest ripening and quality of 1-methylcyclopropene-treated muskmelon fruit. Scientia Horticulturae 130, 581-587.

Zhao, Y. Y., Chen, J. J., Jin, P., Yuan, R. X., Li, H. H., y Zheng, Y. H. (2012). Effects of low temperature conditioning on chilling injury and energy status in cold-stored peach fruit. Food Science, 33(4), 276-281.

Zhao, Y., Li, Y., y Yin, J. (2019). Effects of hot air treatment in combination with Pichia guilliermondii on postharvest preservation of peach fruit. Journal of the Science of Food and Agriculture, 99(2), 647-655.

Zhou, X., Dong, L., Li, R., Zhou, Q., Wang, J. W., y Ji, S. J. (2015). Low temperature conditioning prevents loss of aroma-related esters from 'Nanguo' pears during ripening at room temperature. Postharvest Biology and Technology, 100, 23-32.

Zhou, Y., Huang, L., Zhang, Y., Shi, K., Yu, J., y Nogués, S. (2007). Chill-induced decrease in capacity of RuBP carboxylation and associated $\mathrm{H} 2 \mathrm{O} 2$ accumulation in cucumber leaves are alleviated by grafting onto figleaf gourd. Annals of Botany, 100(4), 839-848.

Zhou, Y.H., Yu, J.Q., Huang, L.F., Nogues, S., (2004). The relationship between $\mathrm{CO}_{2}$ assimilation, photosynthetic electron transport and water-water cycle in chillexposed cucumber leaves under low light and subsequent recovery. Plant Cell Environ, 27, 1503-1514.

Zhou, Y.H., Yu, J.Q., Mao, W.H., Huang, L.F., Song, X.S., Nogues, S., (2006). Genotypic variation of rubisco expression, photosynthetic electron flow and antioxidant metabolism in the chloroplasts of chill-exposed cucumber plants. Plant Cell Physiology. 47, 192-199.

Zimmermann, P y Zentgraf, U. (2005). The correlation between oxidative stress and leaf senescence during plant development. Cellular and Molecular Biology Letters, 10(3), 515. 